\title{
Something old, something new
}

Citation for published version (APA):

Engels, E. B. (2016). Something old, something new: vectorcardiographic loop size and response to cardiac resynchronization therapy. [Doctoral Thesis, Maastricht University]. Maastricht University. https://doi.org/10.26481/dis.20161019ee

Document status and date:

Published: 01/01/2016

DOI:

10.26481/dis.20161019ee

Document Version:

Publisher's PDF, also known as Version of record

\section{Please check the document version of this publication:}

- A submitted manuscript is the version of the article upon submission and before peer-review. There can be important differences between the submitted version and the official published version of record.

People interested in the research are advised to contact the author for the final version of the publication, or visit the DOI to the publisher's website.

- The final author version and the galley proof are versions of the publication after peer review.

- The final published version features the final layout of the paper including the volume, issue and page numbers.

Link to publication

\footnotetext{
General rights rights.

- You may freely distribute the URL identifying the publication in the public portal. please follow below link for the End User Agreement:

www.umlib.nl/taverne-license

Take down policy

If you believe that this document breaches copyright please contact us at:

repository@maastrichtuniversity.nl

providing details and we will investigate your claim.
}

Copyright and moral rights for the publications made accessible in the public portal are retained by the authors and/or other copyright owners and it is a condition of accessing publications that users recognise and abide by the legal requirements associated with these

- Users may download and print one copy of any publication from the public portal for the purpose of private study or research.

- You may not further distribute the material or use it for any profit-making activity or commercial gain

If the publication is distributed under the terms of Article $25 \mathrm{fa}$ of the Dutch Copyright Act, indicated by the "Taverne" license above, 


\section{Something old, something new}

Vectorcardiographic loop size and response to cardiac resynchronization therapy

Elien Engels 
ISBN 978-94-6233-413-7

Copyright (c) 2016 by E.B. Engels

All rights reserved. No part of this publication may be reproduced, stored in a retrieval system, or transmitted in any form or by any means, electronic, mechanical, photocopying, recording, or otherwise, without the prior written permission of the author.

Cover design by B. Spronck

Printed by Gildeprint, The Netherlands 


\section{Something old, something new}

Vectorcardiographic loop size and response to cardiac resynchronization therapy

\section{PROEFSCHRIFT}

ter verkrijging van de graad van doctor aan de Universiteit Maastricht, op gezag van de Rector Magnificus, Prof. dr. Rianne M. Letschert, volgens het besluit van het College van Decanen, in het openbaar te verdedigen op woensdag 19 oktober 2016 om 14:00 uur

door

\section{Elien Berti Engels}

geboren op 4 augustus 1989

te Helmond, Nederland 


\section{Promotor}

Prof. dr. F.W. Prinzen

\section{Copromotor}

Dr. K. Vernooy

\section{Beoordelingscommissie}

Prof. dr. U. Schotten (voorzitter)

Prof. dr. A. Auricchio (Fondazione Cardiocentro Ticino, Lugano, Switzerland)

Prof. dr. H.J.G.M. Crijns

Prof. dr. T. Delhaas

Dr. M. Meine (Universitair medisch centrum Utrecht)

Parts of the research described is this thesis were performed within the framework of CTMM, the Center for Translational Molecular Medicine, project

COHFAR (Congestive Heart Failure and Arrhythmia; grant 01C-203).

Financial support by the Dutch Heart Foundation for the publication of this thesis is gratefully acknowledged.

Financial support for the publication of this thesis as provided by Maastricht University, Stichting Hartsvrienden RESCAR, St. Jude Medical, and BIOTRONIK is gratefully acknowledged. 


\section{Contents}

1 General introduction

2 Why QRS duration should be replaced by better measures of electrical activation to improve patient selection for cardiac resynchronization therapy

3 The synthesized vectorcardiogram resembles the measured vectorcardiogram in patients with dyssynchronous heart failure

4 Electrical remodeling in patients with iatrogenic left bundle branch block

5 T-wave area predicts response to cardiac resynchronization therapy in patients with left bundle branch block

6 T-wave area as biomarker of clinical response to cardiac resynchronization therapy

7 Prediction of optimal cardiac resynchronization by device-based vectorcardiography in dyssynchronous canine hearts

8 Tailoring device settings in cardiac resynchronization therapy by vectorcardiography using the implanted pacing electrodes.

9 General discussion

Summary

Samenvatting

Valorization

Dankwoord

About the author 


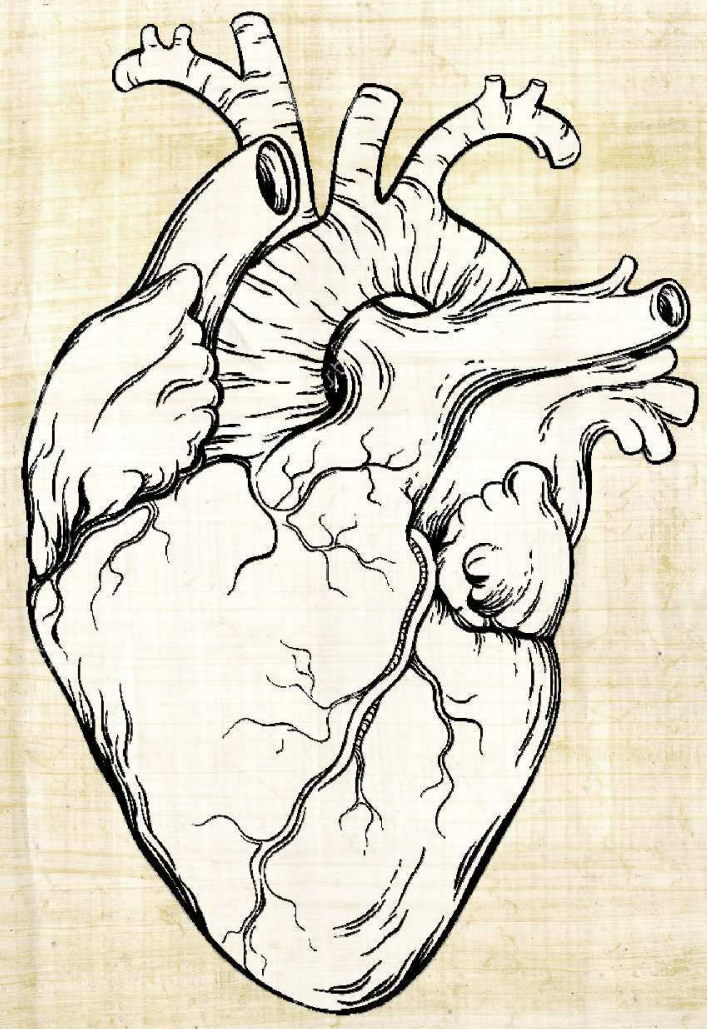




\section{Chapter}

\section{General introduction}




\subsection{Introduction}

I $\mathrm{N}$ a normal healthy heart, the electrical activation starts in the sinoatrial (SA) node after which the electrical activation spreads throughout the right and left atria. The electrical activation then reaches the atrioventricular (AV) node through which the activation is slowed down, to allow optimal ventricular filling. Hereafter, the right and left ventricle are quickly activated by the specialized His-Purkinje fibers, resulting in a synchronous contraction of the ventricles needed for an optimal pump function. ${ }^{1}$

\subsection{Heart failure with dyssynchrony}

In certain conditions there is abnormal ventricular impulse conduction, such as during left bundle branch block (LBBB), resulting in asynchronous ventricular activation and contraction. With $\mathrm{LBBB}$, the left ventricle $(\mathrm{LV})$ is activated through the slowly conducting ventricular myocardium rather than through the rapidly conducting His-Purkinje system. In LBBB, the electrical activation starts in the septum and right ventricle (RV) and proceeds through the slowly conducting septum to activate the LV. ${ }^{2,3}$ The prevalence of LBBB ranges from $\sim 1 \%$ in a general hospital population ${ }^{4}$ to as high as $23.8 \%$ in a heart failure (HF) population ${ }^{5}$. LBBB leads to a reduction in contractility and relaxation ${ }^{6,7}$ as well as to adverse remodelling ${ }^{8}$, resulting in LV dysfunction, emerging $\mathrm{HF}^{9}$ and eventually cardiac death ${ }^{10,11}$.

Several experimental and clinical studies show that the heart adapts to the presence of ventricular dyssynchrony in a very complicated manner that is yet incompletely understood. The changes induced by altered electrical activation alter blood flow and myocardial strain throughout the heart, triggering myocardial remodeling. This myocardial remodeling in the long run results in progressive LV dilation, decreasing ejection fraction, and asymmetrical hypertrophy. ${ }^{12}$ Beside these structural changes there are also electrical changes that emerge during the repolarization phase. This remodeling of repolarization occurs via changes in the expression and function of multiple ion channels and gap junctions, such as calcium channels responsible for the contraction and relaxation, and potassium channels responsible for repolarization. ${ }^{13}$

The electrical remodeling also leads to changes in the electrocardiogram (ECG). Studies, in which a temporary period of altered electrical activation was induced by RV pacing, showed that after this period the T-wave remained in the direction of the paced R-wave when returning to the normal activation, a phenomenon called cardiac memory. ${ }^{14,15}$ Changes in the ECG have also been demonstrated between acute and chronic RV pacing. These changes manifest as a reduction in T-vector amplitude of the paced beats with increased duration of pacing. ${ }^{14}$ It is however unknown whether this phenomenon is also present in patients with LBBB. We hypothesize that the presence of LBBB also induces electrical remodeling that leads to 
changes during the repolarization phase as reflected by the T-wave on the ECG.

\subsection{Cardiac resynchronization therapy}

In the past decade, cardiac resynchronization therapy (CRT) has become an established treatment for patients with dyssynchrony-induced HF accompanied by a reduced LV ejection fraction (LVEF). CRT has been shown to be more effective than optimal pharmacological therapy alone. ${ }^{16}$ As its name suggests, CRT aims to resynchronize the right and left ventricular contraction by either letting the wave fronts of a paced LV collide with the intrinsic activation of the RV or by pacing both ventricles simultaneously. CRT is known to improve cardiac pump function and quality of life and reduce HF symptoms, hospitalization, and mortality. ${ }^{17}$ However, dependent on the definition of 'CRT-response' $30-50 \%$ of the patients are nonresponders. ${ }^{18}$ The main factors leading to non-response are non-optimal patient selection, suboptimal CRT device settings, and LV lead location. ${ }^{19}$ In this thesis, improvements in the first two factors are investigated.

\subsection{Improving patient selection for CRT}

The success of CRT starts with proper patient selection. When patients are not likely to benefit from therapy, implantation of an expensive CRT device with corresponding risks for complications during and after this invasive procedure should be avoided. On the other hand, patients likely to benefit should not be withheld from a therapy that can potentially improve their quality of life and reduce mortality. Therefore, reliable prediction of those patients who will and those who will not benefit from CRT is very important. Current guidelines on CRT state that patients should have HF, as evidenced by a reduced LVEF and a NYHA functional class of II-IV. In addition, there should be evidence of electrical ventricular dyssynchrony, indicated by prolonged QRS duration and/or LBBB QRS morphology. ${ }^{20,21}$ Patients with LBBB QRS morphology benefit most from CRT, but a problem is that the definition of complete LBBB from the 12-lead ECG is not uniform. ${ }^{22,23}$ In this thesis we investigate the possibilities to use vectorcardiography to improve and simplify patient selection for CRT. Vectorcardiography is a technique that records the magnitude and direction of the electrical forces over time. Connecting the heads of the hereby-formed vectors results in a 3D representation of the activation pattern of the heart, the vectorcardiogram (VCG) (Fig. 1.1). The VCG might be a valuable tool to optimize patient selection even further.

Until now the overwhelming majority of research in the area of CRT deals with studying the abnormalities in sequence of depolarization. In section 1.2 we hypothesized that the presence of LBBB induces electrical remodeling that leads to changes in the repolarization. If this is indeed the case, it may be worthwhile to also study the importance of repolarization- 


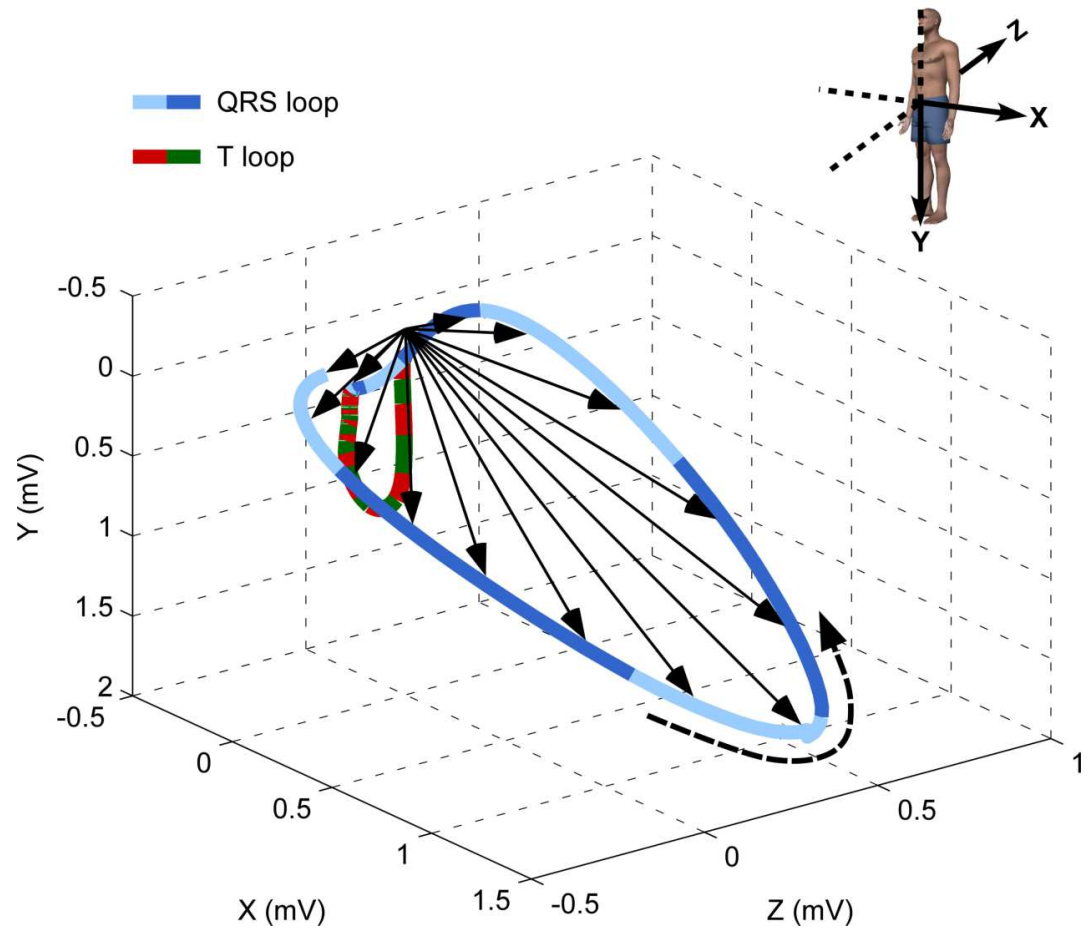

Figure 1.1: Representation of the 3D vectorcardiogram construction. The vectors change rapidly in direction and length (indicated by the solid black arrows). The QRS loop is indicated in blue and the T loop in red and green. Every color alteration represents $10 \mathrm{~ms}$. The dashed black arrow indicates the direction of the QRS loop.

based VCG metrics for the selection of CRT candidates. Therefore, in this thesis, we will compare the effectiveness of different QRS variables (depolarization) and T-wave variables (repolarization) as predictors of CRT response.

\subsection{Optimizing CRT device settings}

Once the CRT device is implanted, one can program its settings non-invasively and possibly adapt them to optimize application of CRT in the individual patient. These settings are the atrioventricular (AV) interval, the interval between atrial and ventricular activation, and the interventricular (VV) interval, the interval between RV and LV stimulation. The AV-interval is responsible for ventricular filling and timing of contraction as well as for the extent of fusion of the pacing generated activation wave front with the intrinsic activation. The VVinterval is responsible for improved resynchronization between the right and left ventricle to improve systolic performance of the two ventricles. Currently, CRT devices are commonly 
programmed using e.g., echocardiography or hemodynamic measurements. However, echocardiography is observer-dependent and time consuming ${ }^{24}$, and hemodynamic measurements are invasive which limits their use in routine clinical practice ${ }^{25,26}$. Furthermore, all optimization methods have demonstrated that optimized intervals result in acute improvements in LV diastolic and systolic function, but no study has been able to show that this optimization translates into improvements in clinical outcomes. ${ }^{27}$ The lack of hard clinical evidence and the serious disadvantages of currently available optimization methods explains that in the majority of patients the CRT devices are left at their default 'out-of-the-box' settings.

In order to avoid the time consuming optimization, several algorithms have been developed: the smartDelay ${ }^{28}$, QuickOpt ${ }^{29}$, and ADAPTIVECRT ${ }^{\mathrm{TM}}$ (trademark of Medtronic, Inc. $)^{30}$. All algorithms use a combination of ECG and electrogram (EGM) signals and are embedded in CRT devices to perform automated optimization of the device settings.

Another disadvantage of the conventional optimization procedures is that they are performed during rest, in supine position and only once. However, it is conceivable that the optimal settings may change with patient activity and/or due to changes in the disease state of the patient. Therefore, ideally one would like to be able to optimize the intervals individually and continuously. Of the previously mentioned automated algorithms, only ADAPTIVECRT ${ }^{\mathrm{TM} 30}$ provides an almost continuous optimization.

Until now none of the automatic AV-and VV-interval optimization algorithms has shown superiority to echocardiographic optimization methods. However, these new methods are less time consuming and easy to use. ${ }^{28,30-36}$ A drawback of all currently available algorithms is that they are based on the average population and not on the individual itself. The baseline activation or atrial pacing is used to calculate the optimal AV- or VV-interval using a certain equation; they thus do not use LV- or biventricular (BiV)-paced settings to immediately find the optimal settings. This might introduce a bias for patients that do not qualify as the 'average' patient.

Recently, van Deursen et al. showed that the VCG could also be used to optimize the $\mathrm{AV}$ - and VV-interval in both animals ${ }^{37}$ and patients ${ }^{38}$. In this thesis, we hypothesized that a similar VCG could be calculated from the electrodes on the implanted LV and RV leads that are not being used for pacing: the EGM-based VCG (EGM-VCG). This EGM-VCG could then be used to individually and continuously optimize the CRT device settings.

\subsection{Aims of the thesis}

The ultimate goal of this thesis is to improve the response to CRT using vectorcardiographic analysis. To this end the following general aims are formulated:

1. Compare measured VCGs with VCGs calculated from a 12-lead ECG in CRT candidates. 
2. Create a better understanding of how the heart adapts electrically to the presence of LBBB.

3. Improve patient selection for CRT.

4. Explore the feasibility of using a EGM-based VCG (derived from the pacing electrodes) to optimize CRT device settings continuously and individually.

\subsection{Overview of the thesis}

The strengths and weaknesses of ECG markers currently being used in guidelines for CRT patient selection, e.g. QRS duration and morphology, is reviewed in chapter 2. Furthermore, the current knowledge on the underlying electrical substrate and the mechanism of action of CRT will be discussed.

In chapter 3 a comparison is made between the measured Frank-VCG ${ }^{39}$ and the synthesized Kors- $\mathrm{VCG}^{40}$ from a 12-lead ECG in patients with HF and conduction abnormalities who are candidate for CRT. Multiple vectorcardiographic variables related to either the depolarization or repolarization phase of a heartbeat will be evaluated.

The way the heart adapts to the sudden presence of LBBB is investigated in chapter 4. Normally LBBB starts silently, making this investigation difficult. However, in patients receiving a new aortic valve through a transcatheter aortic valve implantation (TAVI) procedure, $\sim 33 \%$ develops LBBB as a result of this procedure. These patients are followed for $\sim 6$ months, making it possible to investigate the electrical changes of the heart from the first moment of LBBB presence.

The aim of reducing CRT non-response by improving patient selection using the VCG is addressed in chapter 5 and 6 . In chapter 5, this assessment is based on echocardiographic outcome parameters, while in chapter 6 long-term clinical outcome parameters are used. A comparison is made between the uses of QRS- and T-wave derived variables as predictors for CRT response.

The ability to optimize CRT device settings using the EGM-VCG is investigated in an animal model (chapter 7) and in humans (chapter 8).

This thesis ends with a general discussion (chapter 9) in which the findings of the abovementioned studies are linked and discussed in a broader scientific and clinical perspective. 


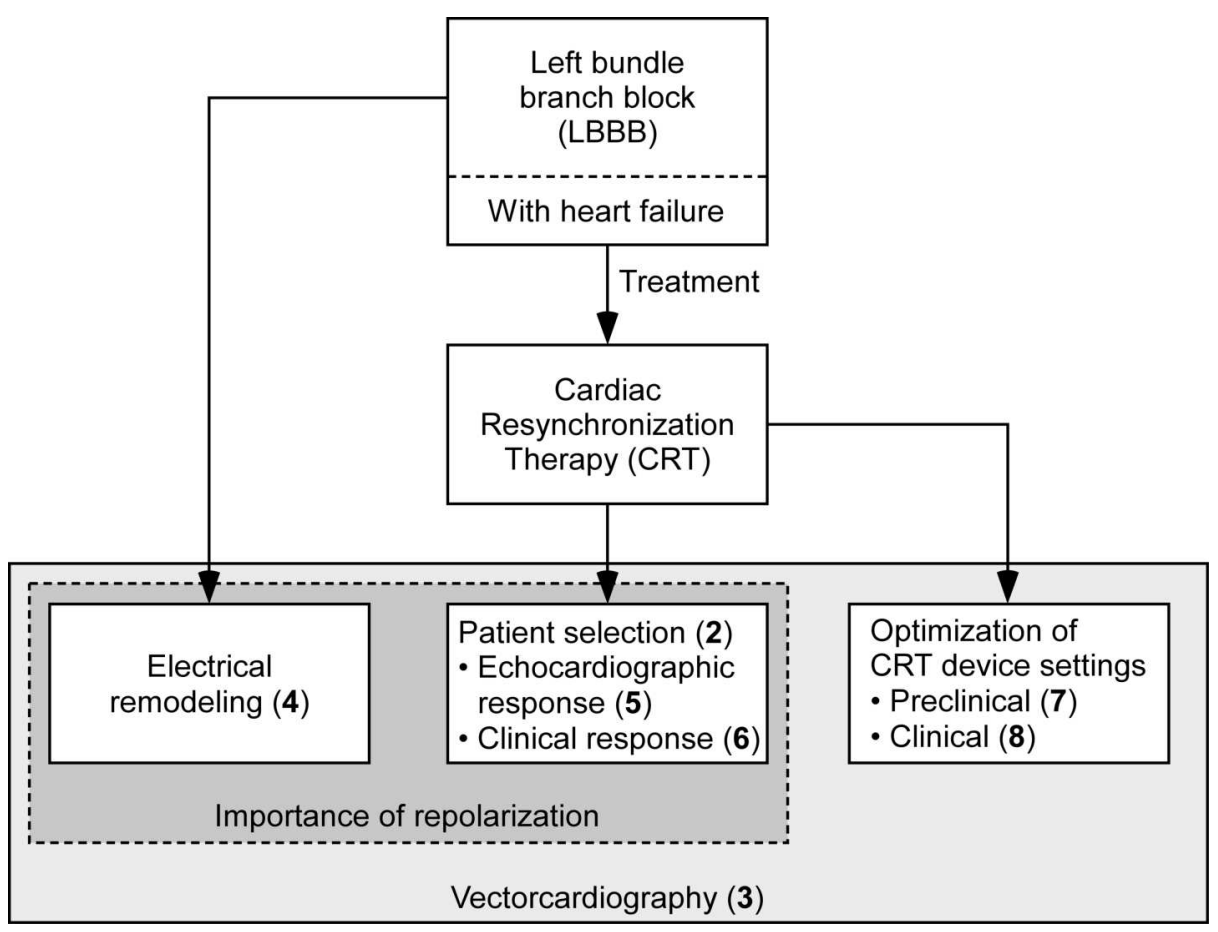

Figure 1.2: Overview of this thesis 


\section{References}

1. MO Sweeney and FW Prinzen. Ventricular pump function and pacing: physiological and clinical integration. Circ Arrhythm Electrophysiol (2008) 1:127-139.

2. DG Strauss, RH Selvester, JAC Lima, H Arheden, JM Miller, G Gerstenblith, E Marbán, RG Weiss, GF Tomaselli, GS Wagner, and KC Wu. ECG quantification of myocardial scar in cardiomyopathy patients with or without conduction defects: correlation with cardiac magnetic resonance and arrhythmogenesis. Circ Arrhythm Electrophysiol (2008) 1:327-336.

3. JA Vassallo, DM Cassidy, FE Marchlinski, AE Buxton, HL Waxman, JU Doherty, and ME Josephson. Endocardial activation of left bundle branch block. Circulation (1984) 69:914-923.

4. DM Boyle and SS Fenton. Left bundle branch block. Ulster Med J (1966) 35:93-99.

5. NM Hawkins, D Wang, JJV McMurray, MA Pfeffer, K Swedberg, CB Granger, S Yusuf, SJ Pocock, J Ostergren, EL Michelson, FG Dunn, and CHARM Investigators and Committees. Prevalence and prognostic impact of bundle branch block in patients with heart failure: evidence from the CHARM programme. Eur J Heart Fail (2007) 9:510-517.

6. XAAM Verbeek, K Vernooy, M Peschar, RNM Cornelussen, and FW Prinzen. Intraventricular resynchronization for optimal left ventricular function during pacing in experimental left bundle branch block. J Am Coll Cardiol (2003) 42:558-567.

7. M Nahlawi, M Waligora, SM Spies, RO Bonow, AH Kadish, and JJ Goldberger. Left ventricular function during and after right ventricular pacing. J Am Coll Cardiol (2004) 44:1883-1888.

8. F Zannad, E Huvelle, K Dickstein, DJ van Veldhuisen, C Stellbrink, L Køber, S Cazeau, P Ritter, AP Maggioni, R Ferrari, and P Lechat. Left bundle branch block as a risk factor for progression to heart failure. Eur J Heart Fail (2007) 9:7-14.

9. JF Schneider, H Thomas Jr, BE Kreger, PM McNamara, and WB Kannel. Newly acquired left bundle-branch block: the Framingham study. Ann Intern Med (1979) 90:303-310.

10. GJ Fahy, SL Pinski, DP Miller, N McCabe, C Pye, MJ Walsh, and K Robinson. Natural history of isolated bundle branch block. Am J Cardiol (1996) 77:1185-1190.

11. JF Schneider, H Thomas Jr, P Sorlie, BE Kreger, PM McNamara, and WB Kannel. 
Comparative features of newly acquired left and right bundle branch block in the general population: the Framingham study. Am J Cardiol (1981) 47:931-940.

12. K Vernooy, XAAM Verbeek, M Peschar, HJGM Crijns, T Arts, RNM Cornelussen, and FW Prinzen. Left bundle branch block induces ventricular remodelling and functional septal hypoperfusion. Eur Heart J (2005) 26:91-98.

13. MJ Cutler, D Jeyaraj, and DS Rosenbaum. Cardiac electrical remodeling in health and disease. Trends Pharmacol Sci (2011) 32:174-180.

14. A Shvilkin, B Bojovic, B Vajdic, I Gussak, P Zimetbaum, and ME Josephson. Vectorcardiographic determinants of cardiac memory during normal ventricular activation and continuous ventricular pacing. Heart Rhythm (2009) 6:943-948.

15. L Wecke, A Rubulis, G Lundahl, MR Rosen, and L Bergfeldt. Right ventricular pacinginduced electrophysiological remodeling in the human heart and its relationship to cardiac memory. Heart Rhythm (2007) 4:1477-1486.

16. MR Bristow, LA Saxon, J Boehmer, S Krueger, DA Kass, T De Marco, P Carson, L DiCarlo, D DeMets, BG White, DW DeVries, AM Feldman, and Comparison of Medical Therapy, Pacing, and Defibrillation in Heart Failure (COMPANION) Investigators. Cardiac-resynchronization therapy with or without an implantable defibrillator in advanced chronic heart failure. N Engl J Med (2004) 350:2140-2150.

17. WT Abraham, WG Fisher, AL Smith, DB Delurgio, AR Leon, E Loh, DZ Kocovic, M Packer, AL Clavell, DL Hayes, et al. Cardiac resynchronization in chronic heart failure. N Engl J Med (2002) 346:1845-1853.

18. European Heart Rhythm Association, European Society of Cardiology, Heart Rhythm Society, Heart Failure Society of America, American Society of Echocardiography, American Heart Association, European Association of Echocardiography, Heart Failure Association, JC Daubert, L Saxon, et al. 2012 EHRA/HRS expert consensus statement on cardiac resynchronization therapy in heart failure: implant and follow-up recommendations and management. Heart Rhythm (2012) 9:1524-1576.

19. W Mullens, RA Grimm, T Verga, T Dresing, RC Starling, BL Wilkoff, and WHW Tang. Insights from a cardiac resynchronization optimization clinic as part of a heart failure disease management program. J Am Coll Cardiol (2009) 53:765-773.

20. AE Epstein, JP DiMarco, KA Ellenbogen, NAM Estes 3rd, RA Freedman, LS Gettes, AM Gillinov, G Gregoratos, SC Hammill, DL Hayes, et al. 2012 ACCF/AHA/HRS focused update incorporated into the ACCF/AHA/HRS 2008 guidelines for devicebased therapy of cardiac rhythm abnormalities: a report of the American College of Cardiology Foundation/American Heart Association Task Force on Practice Guidelines and the Heart Rhythm Society. Circulation (2013) 127:e283-e352.

21. M Brignole, A Auricchio, G Baron-Esquivias, P Bordachar, G Boriani, OA Breithardt, J Cleland, JC Deharo, V Delgado, PM Elliott, et al. 2013 ESC Guidelines on cardiac 
pacing and cardiac resynchronization therapy: the Task Force on cardiac pacing and resynchronization therapy of the European Society of Cardiology (ESC). Developed in collaboration with the European Heart Rhythm Association (EHRA). Eur Heart J (2013) 34:2281-2329.

22. MR Gold, C Thébault, C Linde, WT Abraham, B Gerritse, S Ghio, M St John Sutton, and JC Daubert. Effect of QRS duration and morphology on cardiac resynchronization therapy outcomes in mild heart failure: results from the Resynchronization Reverses Remodeling in Systolic Left Ventricular Dysfunction (REVERSE) study. Circulation (2012) 126:822-829.

23. W Zareba, H Klein, I Cygankiewicz, WJ Hall, S McNitt, M Brown, D Cannom, JP Daubert, M Eldar, MR Gold, et al. Effectiveness of Cardiac Resynchronization Therapy by QRS Morphology in the Multicenter Automatic Defibrillator Implantation Trial-Cardiac Resynchronization Therapy (MADIT-CRT). Circulation (2011) 123:1061-1072.

24. CE Raphael, A Kyriacou, S Jones, P Pabari, G Cole, R Baruah, AD Hughes, and DP Francis. Multinational evaluation of the interpretability of the iterative method of optimisation of AV delay for CRT. Int J Cardiol (2013) 168:407-413.

25. A Auricchio, C Stellbrink, M Block, S Sack, J Vogt, P Bakker, H Klein, A Kramer, J Ding, R Salo, B Tockman, T Pochet, and J Spinelli. Effect of pacing chamber and atrioventricular delay on acute systolic function of paced patients with congestive heart failure. The Pacing Therapies for Congestive Heart Failure Study Group. The Guidant Congestive Heart Failure Research Group. Circulation (1999) 99:2993-3001.

26. N Derval, P Steendijk, LJ Gula, A Deplagne, J Laborderie, F Sacher, S Knecht, M Wright, I Nault, S Ploux, et al. Optimizing hemodynamics in heart failure patients by systematic screening of left ventricular pacing sites: the lateral left ventricular wall and the coronary sinus are rarely the best sites. J Am Coll Cardiol (2010) 55:566-575.

27. WW Brabham and MR Gold. The role of AV and VV optimization for CRT. Journal of Arrhythmia (2013) 29:153-161.

28. MR Gold, I Niazi, M Giudici, RB Leman, JL Sturdivant, MH Kim, Y Yu, J Ding, and AD Waggoner. A prospective comparison of AV delay programming methods for hemodynamic optimization during cardiac resynchronization therapy. J Cardiovasc Electrophysiol (2007) 18:490-496.

29. JH Baker 2nd, J McKenzie 3rd, S Beau, GS Greer, J Porterfield, M Fedor, S Greenberg, EG Daoud, R Corbisiero, JR Bailey, and L Porterfield. Acute evaluation of programmer-guided AV/PV and VV delay optimization comparing an IEGM method and echocardiogram for cardiac resynchronization therapy in heart failure patients and dual-chamber ICD implants. J Cardiovasc Electrophysiol (2007) 18:185-191.

30. H Krum, B Lemke, D Birnie, KLF Lee, K Aonuma, RC Starling, M Gasparini, J 
Gorcsan, T Rogers, A Sambelashvili, A Kalmes, and D Martin. A novel algorithm for individualized cardiac resynchronization therapy: rationale and design of the adaptive cardiac resynchronization therapy trial. Am Heart J (2012) 163:747-752.e1.

31. P Ritter, PPHM Delnoy, L Padeletti, M Lunati, H Naegele, A Borri-Brunetto, and J Silvestre. A randomized pilot study of optimization of cardiac resynchronization therapy in sinus rhythm patients using a peak endocardial acceleration sensor vs. standard methods. Europace (2012) 14:1324-1333.

32. KA Ellenbogen, MR Gold, TE Meyer, I Fernndez Lozano, S Mittal, AD Waggoner, B Lemke, JP Singh, FG Spinale, JE Van Eyk, J Whitehill, S Weiner, M Bedi, J Rapkin, and KM Stein. Primary results from the SmartDelay determined AV optimization: a comparison to other AV delay methods used in cardiac resynchronization therapy (SMART-AV) trial: a randomized trial comparing empirical, echocardiography-guided, and algorithmic atrioventricular delay programming in cardiac resynchronization therapy. Circulation (2010) 122:2660-2668.

33. MC Porciani, CM Rao, M Mochi, F Cappelli, G Bongiorno, AP Perini, A Lilli, G Ricciardi, L Hashtroudi, P Silvestri, SS Barold, and L Padeletti. A real-time threedimensional echocardiographic validation of an intracardiac electrogram-based method for optimizing cardiac resynchronization therapy. Pacing Clin Electrophysiol (2008) 31:56-63.

34. D Wang, H Yu, T Yun, H Zang, G Yang, S Wang, Z Wang, Q Jing, and Y Han. Longterm clinical effects of programmer-guided atrioventricular and interventricular delay optimization: Intracardiac electrography versus echocardiography for cardiac resynchronization therapy in patients with heart failure. J Int Med Res (2013) 41:115-122.

35. M Packer. Proposal for a new clinical end point to evaluate the efficacy of drugs and devices in the treatment of chronic heart failure. J Card Fail (2001) 7:176-182.

36. DO Martin, B Lemke, D Birnie, H Krum, KLF Lee, K Aonuma, M Gasparini, RC Starling, G Milasinovic, T Rogers, A Sambelashvili, J Gorcsan 3rd, M Houmsse, and Adaptive CRT Study Investigators. Investigation of a novel algorithm for synchronized left-ventricular pacing and ambulatory optimization of cardiac resynchronization therapy: results of the adaptive CRT trial. Heart Rhythm (2012) 9:1807-1814.

37. CJM van Deursen, M Strik, LM Rademakers, A van Hunnik, M Kuiper, L Wecke, HJGM Crijns, K Vernooy, and FW Prinzen. Vectorcardiography as a tool for easy optimization of cardiac resynchronization therapy in canine left bundle branch block hearts. Circ Arrhythm Electrophysiol (2012) 5:544-552.

38. CJM van Deursen, L Wecke, WM van Everdingen, M Ståhlberg, MHG Janssen, F Braunschweig, L Bergfeldt, HJGM Crijns, K Vernooy, and FW Prinzen. Vectorcardiography for optimization of stimulation intervals in cardiac resynchronization therapy. J Cardiovasc Transl Res (2015) 8:128-137. 
39. E Frank. An accurate, clinically practical system for spatial vectorcardiography. Circulation (1956) 13:737-749.

40. JA Kors, G van Herpen, AC Sittig, and JH van Bemmel. Reconstruction of the Frank vectorcardiogram from standard electrocardiographic leads: diagnostic comparison of different methods. Eur Heart J (1990) 11:1083-1092. 



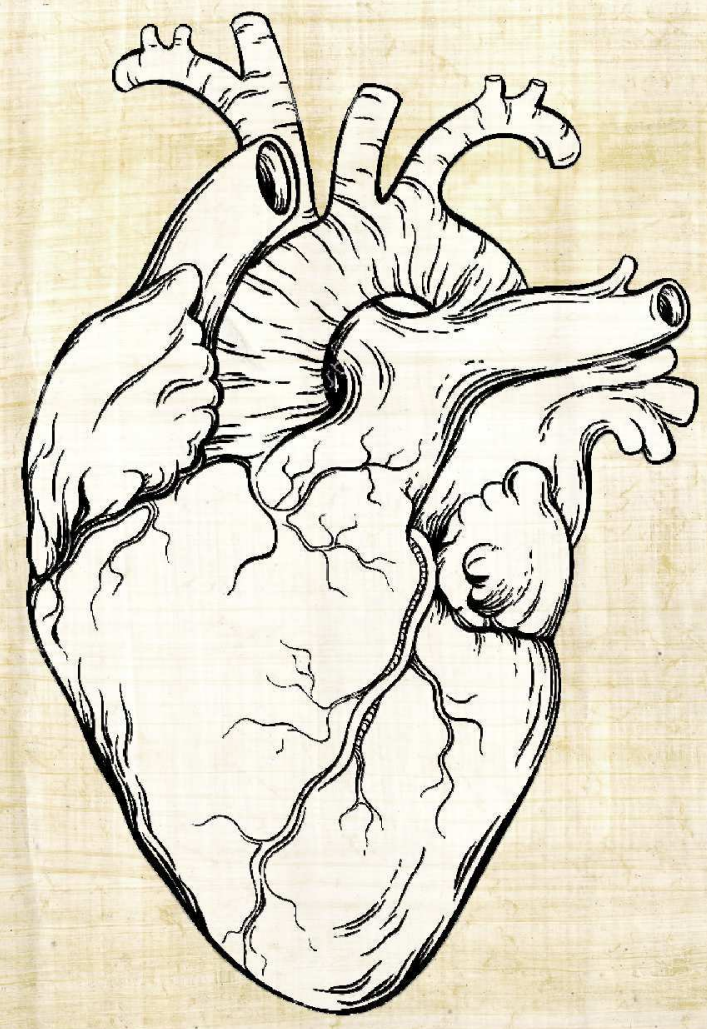




\section{Chapter}

\section{Why QRS duration should be replaced by better measures of electrical activation to improve patient selection for cardiac resynchronization therapy}

The content of this chapter is based on:

Elien B. Engels, ${ }^{1, *}$ Masih Mafi-Rad, ${ }^{2, *}$ Antonius M.W. van Stipdonk, ${ }^{2}$

Kevin Vernooy, ${ }^{2}$ and Frits W. Prinzen ${ }^{1}$ (2016).

Why QRS duration should be replaced by better measures of electrical activation to improve patient selection for cardiac resynchronization therapy. J Cardiovasc Transl Res 9(4):257-265.

* Authors contributed equally.

${ }^{1}$ Department of Physiology, CARIM School for Cardiovascular Diseases, Maastricht University, Maastricht, the Netherlands.

${ }^{2}$ Department of Cardiology, Maastricht University Medical Center, Maastricht, the Netherlands. 


\section{Abstract}

Cardiac resynchronization therapy (CRT) is a well-known treatment modality for patients with a reduced left ventricular ejection fraction accompanied by a ventricular conduction delay. However, a large proportion of patients does not benefit from this therapy. Better patient selection may importantly reduce the number of non-responders. Here we review the strengths and weaknesses of the electrocardiogram (ECG) markers currently being used in guidelines for patient selection, e.g. QRS duration and morphology. We shed light on the current knowledge on the underlying electrical substrate and the mechanism of action of CRT. Finally, we discuss potentially better ECG-based biomarkers for CRT candidate selection, of which the vectorcardiogram may have high potential. 


\subsection{Introduction}

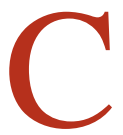

ARDIAC resynchronization therapy (CRT) is an effective therapy for patients with a decreased left ventricular ejection fraction (LVEF) in combination with a ventricular conduction delay, especially due to left bundle branch block (LBBB). CRT creates a more coordinated and efficient contraction of the heart, improves LV systolic function and quality of life, and reduces heart failure (HF) symptoms, hospitalizations and mortality. ${ }^{1,2}$

Nevertheless, there is still an incomplete understanding of the mechanism of the therapy and unsatisfying selection of patients. On the one hand, a significant portion (30-50\%) of patients that are implanted according to current guidelines ${ }^{3,4}$ benefit little from this therapy whereas $\sim 20 \%$ of patients show complete normalization of LVEF. ${ }^{5}$ Possible explanations for this huge range of benefit are variation in substrate that is amenable to resynchronization, inadequate device settings, suboptimal medical treatment, arrhythmias, and variable lead position. ${ }^{6}$

The most important selection criteria in current CRT implantation guidelines are derived from the ECG: QRS duration and morphology. ${ }^{3,7}$ Here we review the strengths and weaknesses of these ECG markers in the light of the current knowledge on the underlying electrical substrate and the mechanism of action of CRT and discuss potentially better ECG-based biomarkers for selection of CRT candidates.

\subsection{The role of the 12-lead ECG in the selection of CRT candidates}

The clinical application of CRT began in 1994 when the first cases of atrio-biventricular pacemaker implantations in patients with severe congestive HF were described. ${ }^{8,9}$ The surface ECG of these patients often showed a prolonged PR-interval and a widened QRS complex due to ventricular conduction disturbances.

The first randomized crossover trial investigating the clinical efficacy of CRT was the MUSTIC study. ${ }^{10}$ This trial in patients with chronic severe HF (NYHA III), reduced LVEF $(<35 \%)$ and a broad QRS complex (> $150 \mathrm{~ms})$, showed that biventricular (BiV) pacing improved the 6-min walking distance, peak oxygen uptake, quality of life score, and NYHA class. The MIRACLE study confirmed these results in patients with a QRS duration $\geq 130 \mathrm{~ms}^{2,11}$ This study also showed a clear reduction in LV volumes, reduced HF hospitalization, and better survival. Similar results were shown by the COMPANION ${ }^{12}$ and the CARE-HF ${ }^{1}$ trials, which included patients with QRS duration $\geq 120 \mathrm{~ms}$ and NYHA class III-IV.

These favorable and consistent results led to the recommendation of CRT in patients in NYHA class III-IV despite optimal medical treatment, with a reduced LVEF $(<35 \%)$, in 
sinus rhythm, and a wide QRS complex ( $\geq 120 \mathrm{~ms}) .{ }^{13}$

Subsequent trials investigated the effect of CRT in less symptomatic patients (the REVERSE $^{14}$, MADIT-CRT ${ }^{15}$ and RAFT trials ${ }^{16}$ ). Again, LV function improved and both all-cause mortality and non-fatal HF events improved. However, subgroup analyses of these three trials demonstrated that these effects were predominantly confined to patients with a QRS duration $\geq 150 \mathrm{~ms}$ (Fig. 2.1). ${ }^{17}$ This evidence resulted in the addition of a class I indication to CRT for patients presenting with NYHA class II, a reduced LVEF, and a QRS duration $>150 \mathrm{~ms}$, in the 2010 guidelines. ${ }^{18}$

\begin{tabular}{|c|c|c|}
\hline Trial (QRS group) & Primary Outcome & HR for Primary Outcome $(95 \% \mathrm{Cl})$ \\
\hline COMPANION (< $148 \mathrm{~ms})$ & & $0.93(0.69,1.24)$ \\
\hline COMPANION (148 to $168 \mathrm{~ms}$ ) & Death or Hospitalization & $0.78(0.58,1.03)$ \\
\hline COMPANION ( > $168 \mathrm{~ms}$ ) & & $0.66(0.47,0.92)$ \\
\hline CARE HF (<160 ms) & Death or CV & $0.74(0.54,1.02)$ \\
\hline CARE HF ( $\geq 160 \mathrm{~ms})$ & Hospitalization & $0.60(0.46,0.79)$ \\
\hline REVERSE (< $152 \mathrm{~ms})$ & HF Clinical Composite & $1.05(0.58,1.89)$ \\
\hline REVERSE ( $\geq 152 \mathrm{~ms}$ ) & Score Worsened & $0.42(0.22,0.81)$ \\
\hline MADIT-CRT (< $150 \mathrm{~ms})$ & Death or HF Fvent & $1.04(0.73,1.46)$ \\
\hline MADIT-CRT ( $\geq 150 \mathrm{~ms}$ ) & & $0.50(0.32,0.73)$ \\
\hline RAFT (< 150ms) & $\begin{array}{l}\text { Death or HF } \\
\text { Hospitalization }\end{array}$ & $0.99(0.77,1.27)$ \\
\hline RAFT ( $\geq 150 \mathrm{~ms})$ & & $0.59(0.48,0.73)$ \\
\hline & CRT Better & Control Better \\
\hline
\end{tabular}

Figure 2.1: Effect of CRT on composite clinical events in patients with moderately prolonged (QRS duration of $120-150 \mathrm{~ms}$ ) and severely prolonged QRS duration (> $150 \mathrm{~ms}$ ) (reprinted from Bryant et al. ${ }^{17}$ ).

Even though most studies show an increased response rate after CRT in patients with a severely prolonged QRS duration, these studies used the fairly crude division of the cohorts in patients with a QRS duration < and > $150 \mathrm{~ms}$. However, the best cut-off value for QRS duration is unclear.

More recently, attention has shifted from QRS duration to QRS morphology. Small singlecenter studies $^{19,20}$ and sub-analyses of the MADIT-CRT ${ }^{21}$, REVERSE $^{22}$, and RAFT ${ }^{16}$ study showed that patients with a LBBB morphology benefit most from CRT. In contrast, patients with right bundle branch block (RBBB) or intra-ventricular conduction delays (IVCD) had no benefit or even a worse outcome from CRT (Fig. 2.2). These observations led to the 
adaptation of the guidelines in 2012/2013, including LBBB as the primary ECG criterion and QRS duration > $150 \mathrm{~ms}$ only if a non-LBBB morphology is present. ${ }^{3,4}$
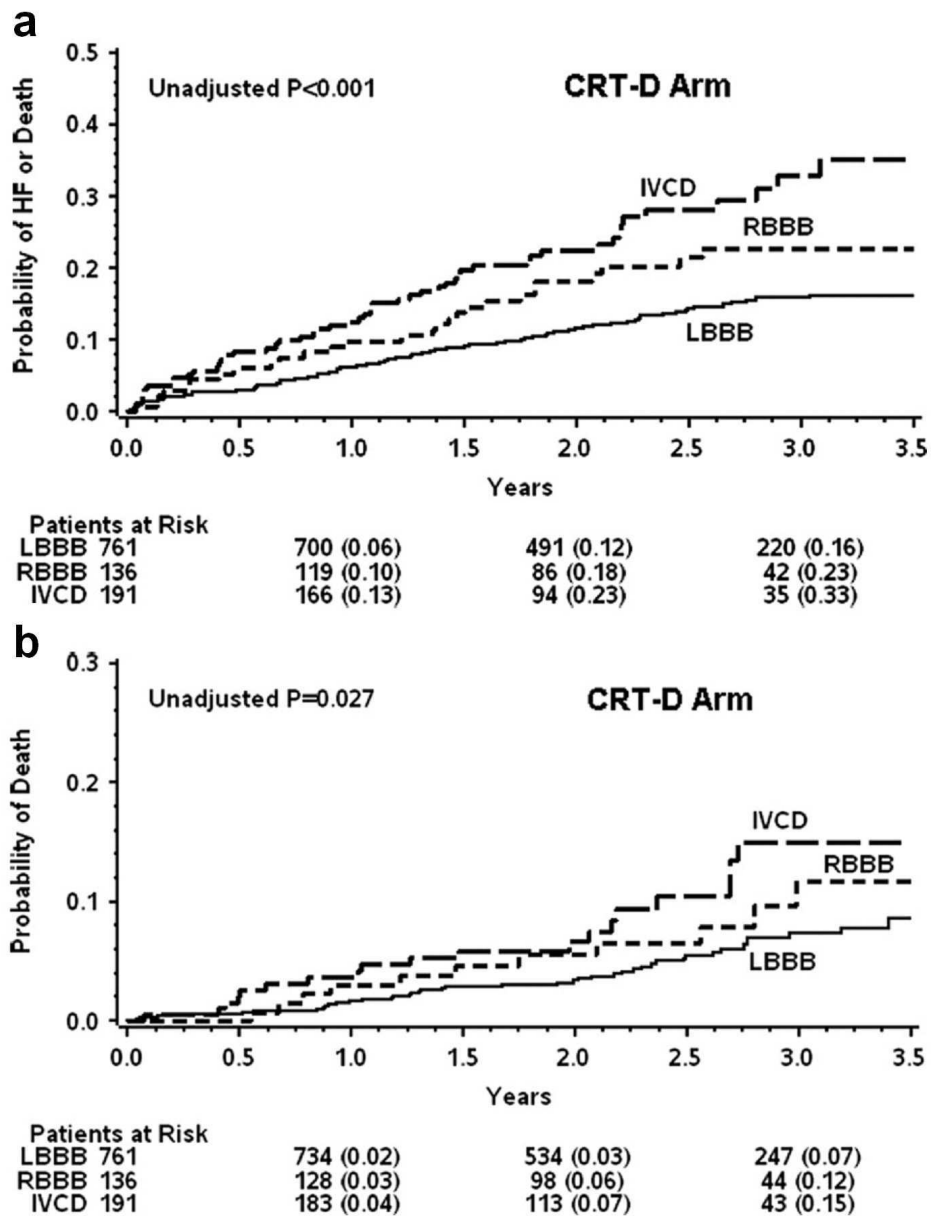

Figure 2.2: Cumulative probability of HF event or death (top) and of death alone (bottom) according to QRS morphology in the CRT with defibrillator (CRT-D) arm of the MADIT-CRT (adjusted from Tian et al. ${ }^{20}$ ).

Interesting and important however, is that the definition of complete LBBB from the 12lead ECG varies between European and American guidelines and between large clinical trials $^{21,22}$ or studies ${ }^{23}$ that investigated LBBB as a predictor of CRT effectiveness. The refinement of LBBB morphology with the presence of notching or slurring appears to significantly improve the prediction of CRT response and clinical outcome, at least in small single center studies. $^{20,24}$

While QRS morphology is now one of the primary indicators for CRT, a recent meta- 
analysis, combining data from CARE-HF, MIRACLE, MIRACLE ICD, REVERSE, and RAFT showed that QRS duration is a more powerful predictor of CRT outcomes (mortality and morbidity) than QRS morphology. ${ }^{25}$ This conclusion is in contrast to several reports derived from some of the individual trials and to a meta-analysis of the MADIT-CRT, RAFT, and REVERSE study (Fig. 2.1). ${ }^{26}$ One possible explanation for this discrepancy is the use of 'liberal' LBBB criteria. In that case, it is likely that QRS duration provides additional information. Indeed, when using 'liberal' LBBB criteria the non-LBBB patients tended to have a lower QRS duration than the LBBB patients ${ }^{21}$, but this difference could not be observed when stricter LBBB criteria were used. ${ }^{20}$ Furthermore, in the studies where strict LBBB criteria as defined by Strauss et al. ${ }^{23}$ were used, QRS duration was not a predictor of response while LBBB was. ${ }^{20,27}$

In conclusion, currently it is not clear whether QRS duration or morphology should be preferred as primary marker for selection of CRT patients. QRS duration may not be specific, but LBBB criteria may be too complex and/or dependent. In order to come to a possible solution, it may be worthwhile to go back to the basic physiology of dyssynchronous HF and the mechanisms of CRT.

\subsection{Electrophysiological evaluation of the electrical substrate for CRT}

Delayed electrical activation of the LV is considered the underlying substrate of LV dysfunction in patients with systolic dysfunction and a conduction delay, mainly due to LBBB. ${ }^{28}$ CRT aims to correct the underlying electrical substrate by paced pre-excitation of late depolarized and contracting LV regions, thereby restoring synchronous ventricular electrical activation and contraction. ${ }^{28}$ Experimental studies have confirmed that in hearts with delayed $\mathrm{LV}$ activation due to $\mathrm{LBBB}, \mathrm{LV}$-only or BiV pacing creates a more synchronous contraction pattern, which is accompanied by marked hemodynamic improvement. ${ }^{28,29}$ The clinical importance of LV activation delay has become evident in studies showing that a greater delay in time from onset of the QRS complex to the local intrinsic activation at the LV stimulation site (Q-LV) is associated with a greater likelihood of benefit from CRT. Singh et al. ${ }^{30}$ measured Q-LV intra-procedurally as a percentage of the baseline QRS interval in 71 patients undergoing CRT device implantation. A longer Q-LV was related to superior acute LV hemodynamic improvement, whereas a reduced Q-LV $(<50 \%$ of QRS duration) was related to a worse clinical outcome. ${ }^{30}$ A secondary analysis of the prospective multi-center SMART-AV trial showed that patients with a Q-LV > 95 ms show significantly improved odds of reverse remodeling and quality of life response. ${ }^{31}$ Conversely, experimental studies and computer simulations have shown that pacing induced pre-excitation in a heart without a significant electrical delay (narrow QRS complex) widens the QRS complex and consequently worsens 
LV pump function. ${ }^{32-34}$ The clinical significance of these findings has become evident in the results of the recent EchoCRT trial. ${ }^{35}$ This was a randomized trial that evaluated the effect of CRT in patients with a narrow QRS complex $(<130 \mathrm{~ms})$ and evidence of mechanical dyssynchrony. The trial was prematurely stopped because the CRT group did not derive any detectable clinical benefit and even showed a significant increase in mortality compared to the control group. ${ }^{35}$

All the aforementioned data support the notion that an electrical substrate, consisting of a sufficient amount of LV activation delay, needs to be present for CRT to be efficient. LBBB is considered the hallmark conduction disturbance that is associated with delayed LV activation. In canine hearts where proximal ablation of the left bundle branch was performed, electrical mapping showed that earliest electrical activation occurs inside the right ventricle and that the electrical wave front then slowly propagates through the interventricular septum towards the lateral wall of the LV. ${ }^{36}$ Induction of LBBB in healthy canine hearts leads to electrical and mechanical dyssynchrony that in turn causes loss of LV pump function and ventricular remodeling. ${ }^{37}$ In these hearts, CRT largely reverses functional and structural abnormalities. ${ }^{28}$ The key clinical investigation to detect and evaluate the extent of LV activation delay remains the surface ECG. However, identifying true LBBB on the ECG is not as straightforward as one might presume. As discussed earlier, numerous dissimilarities in ECG criteria for the diagnosis of LBBB between different definitions complicate a uniform diagnosis.

The most accurate way to evaluate the cardiac electrical activation sequence in patients is by invasive mapping using conventional point-by-point technique or three-dimensional electro-anatomical reconstruction contact (CARTO, NOGA) or non-contact (EnSite) mapping. Studies that performed endocardial mapping in patients with HF and LBBB according to conventional ECG criteria have shown that the sequence of LV endocardial activation in these patients is heterogeneous. ${ }^{38-41}$ The activation wave front originating from the right ventricle was shown to cause LV endocardial breakthrough in different septal regions. ${ }^{39,40}$ In some patients, breakthrough occurred in the vicinity of the conduction system in the midseptal region, which suggests activation by slow conduction through the left bundle branch, in others, LV endocardial activation occurred as a result of right-to-left transseptal spread of activation. ${ }^{40}$ A characteristic finding in true LBBB patients also seems to be a long ( $>40 \mathrm{~ms}$ ) transseptal conduction time. ${ }^{42}$

Endocardial non-contact mapping has also identified two different patterns of electrical wave front propagation in the LV of these patients. The first entity, observed in approximately two thirds of patients, is characterized by a U-shaped pattern of activation that turns around the LV apex and inferior wall in order to activate the lateral wall ${ }^{39,41,43}$, which is similar to the activation pattern that has been observed during endocardial non-contact mapping in canine hearts where proximal ablation of the left bundle branch has been performed. ${ }^{44}$ The second entity is characterized by homogeneous propagation of electrical activation throughout the 
left ventricle. ${ }^{41,43}$ The varying conduction patterns observed in these mapping studies could be explained by variations in left bundle branch anatomy ${ }^{45}$ and the location of the block, but also by the fact that cellular uncoupling as a consequence of LV hypertrophy or fibrosis can give rise to a wide QRS complex with morphological features that meet conventional ECG criteria for LBBB. ${ }^{46,47}$

In contrast to $\mathrm{LBBB}, \mathrm{RBBB}$ is typically associated with delayed RV activation, but not delayed LV activation. However, in some RBBB patients, the QRS morphology differs significantly from the characteristic RBBB pattern. These patients show a specific electrocardiographic pattern previously defined as RBBB masking $\mathrm{LBBB}^{48,49}$, which is characterized by precordial lead findings consistent with RBBB and limb lead findings consistent with LBBB. Extensive measurements of both RV and LV endocardial electrical activation in heart failure patients with RBBB using CARTO 3D contact mapping showed that patients with RBBB masking LBBB, have LV activation delay similar to that found in LBBB. ${ }^{50}$

Although the aforementioned mapping techniques provide accurate characterization of cardiac electrical activation, the application of these techniques in clinical practice is timeconsuming, cumbersome, and not without risk. Measuring the Q-LV as described above provides a relatively simple manner of assessing the extent of LV activation delay. However, this technique provides limited information on LV electrical activation because usually measurements are only performed at the anatomically targeted region. A technique that provides a middle ground between complete mapping and single Q-LV measurement is intra-procedural coronary venous electro-anatomic mapping. In a recent study, we assessed the LV electrical activation in a cohort of 51 CRT candidates using this technique. ${ }^{51}$ A guidewire that allows for unipolar sensing and pacing was inserted into the coronary sinus and connected to an EnSite NavX system. The wire was then manipulated to various coronary sinus branches creating an anatomic map along with determining the electrical activation time associated with each anatomic region. Significant LV activation delay ( $>75 \%$ of QRS duration) was found in 38 of 51 patients. QRS duration was shown to perform poorly in identifying delayed LV activation (area under the curve $=0.49$ ). Twenty-nine of the 51 patients had LBBB according to specific ECG criteria which included broad, notched or slurred R waves in leads I, aVL, $\mathrm{V}_{5}$ and $\mathrm{V}_{6}$, an occasional RS pattern in leads $\mathrm{V}_{5}$ and $\mathrm{V}_{6}$ attributed to displaced transition of the QRS complex, and absent $q$ waves in lead $I, V_{5}$ and $V_{6}$ (in the absence of a large anteriorapical infarction). As described earlier, this refined LBBB definition, which includes the presence of QRS notching and slurring, has previously been shown to significantly improve the predictive value of LBBB QRS morphology for CRT response. ${ }^{52}$ Of the remaining 22 patients, 7 met ECG criteria for RBBB and 15 met neither criteria for LBBB nor RBBB and were classified as IVCD. QRS duration did not differ between different QRS morphologies. However, LV activation time was significantly larger in LBBB patients as compared to RBBB and IVCD patients. Significant LV activation delay was found in all patients diagnosed with 
LBBB according to specific ECG criteria, but also in 8 of 15 patients with IVCD and even in 1 of 7 patients with RBBB (examples shown in Fig. 2.3). The findings of this mapping study indicate that: (1) a prolonged QRS duration by itself is not a reliable marker of delayed LV activation. Thus, patient selection based on QRS duration alone will most likely include a substantial number of patients without the appropriate electrical substrate to benefit from CRT, and (2) the refined LBBB definition, which includes QRS notching and slurring, is highly specific for delayed LV activation, but lacks sufficient sensitivity. As a consequence, a substantial number of patients that have delayed LV activation are not identified as such, and in these patients, CRT may be withheld erroneously.

\section{ECG Electro-anatomic map Coronary venogram}

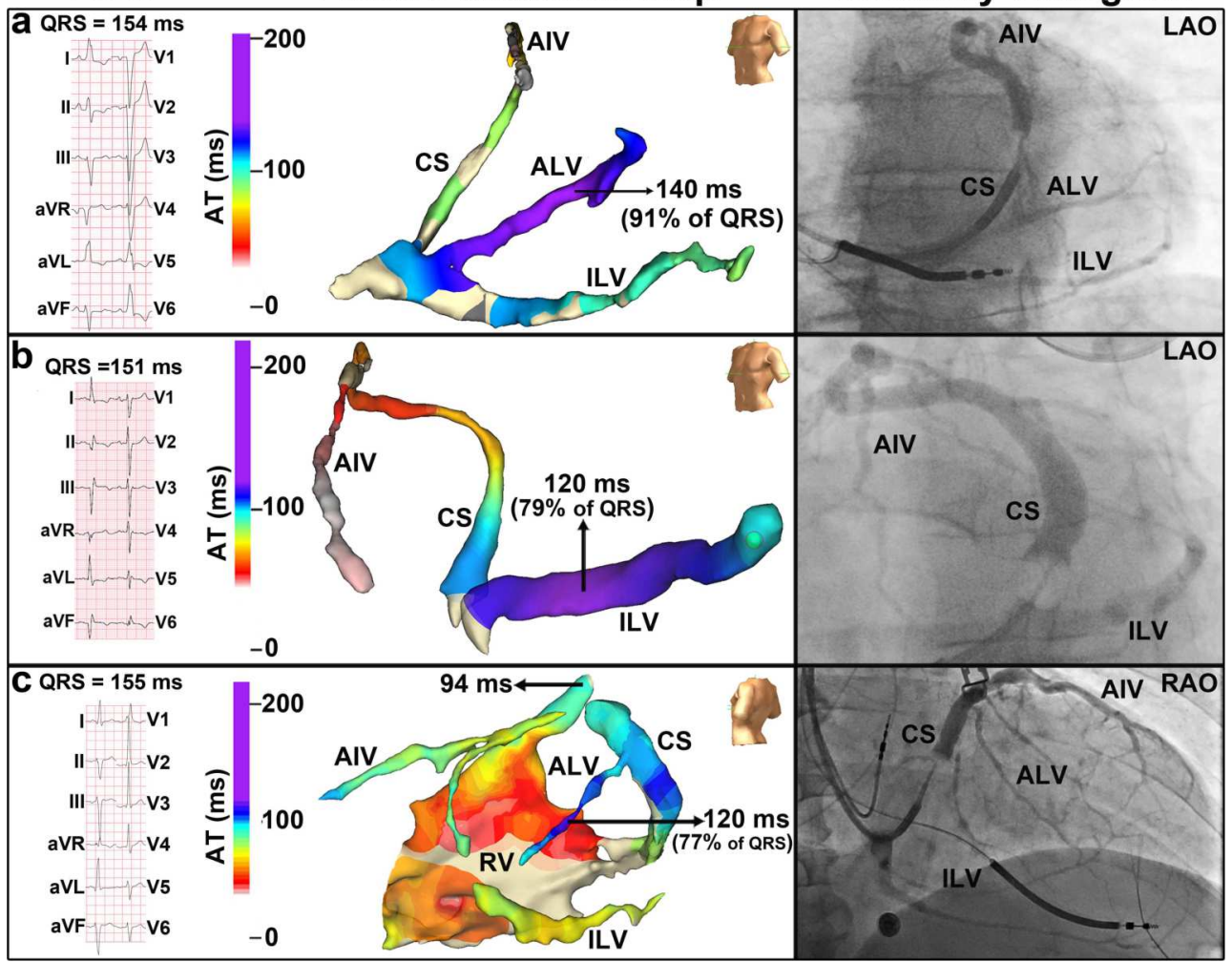

Figure 2.3: Coronary venous electro-anatomic map of a LBBB patient demonstrating delayed activation of the LV anterolateral wall (A), an IVCD patient demonstrating delayed activation of the LV inferolateral wall (B), and a RBBB patient with a potential left anterior hemiblock demonstrating delayed activation of the LV anterolateral wall $(\mathbf{C})$. AIV $=$ anterior interventricular vein, $\mathrm{ALV}=$ anterolateral vein, ILV = inferolateral vein, $\mathrm{CS}=$ coronary sinus, $\mathrm{AT}=$ electrical activation time, $\mathrm{AP}=$ antero-posterior, $\mathrm{L} / \mathrm{RAO}=$ left/right anterior oblique, $\mathrm{RV}=$ right ventricle (Adapted from Mafi Rad et al. ${ }^{51}$ ). 
Instead, the above described technique of coronary venous electro-anatomic mapping can be used at the time of CRT implantation for a more precise characterization of the electrical substrate at only minor prolongation of procedure time $(\sim 20 \mathrm{~min}) .{ }^{51,53}$ However, ideally the decision whether or not to implant a CRT device is made in advance. In this respect, electrocardiographic imaging (ECGi) provides an entirely non-invasive alternative. ${ }^{54}$ ECGi provides high-resolution non-invasive electrical mapping of the epicardial electrical activation. The technique acquires electrical data from more than 200 body surface electrodes using a multielectrode vest. Epicardial anatomy and body-surface electrode positions are registered simultaneously by a thoracic computed tomography scan. The body-surface electrical data and the anatomical data are then processed with algorithms to construct epicardial depolarization and repolarization patterns, using a single heartbeat. ${ }^{54}$ In this way, detailed information on LV electrical activation can be readily obtained prior to CRT implantation, which may be used to guide the decision on whether or not to implant a CRT device. However, the requirement for a multi-electrode vest in combination with a computed tomography scan may preclude widespread application of this technique in clinical practice.

\subsection{Better electrocardiographic identification of the electrical substrate: new ECG parameters}

The demand for easy and widely applicable non-invasive techniques that can be used to accurately characterize the electrical substrate in CRT candidates has renewed the interest in finding additional/alternative electrocardiographic markers of dyssynchrony. Sweeney et al. ${ }^{19}$ carefully analyzed standard 12-lead ECGs of 202 CRT candidates with LBBB according to specific ECG criteria that included QRS notching/slurring and identified new measurements that predict volumetric CRT response. ${ }^{19}$ The time difference between the first notch after $40 \mathrm{~ms}$ of QRS onset and the end of the QRS on the baseline ECG was indicated as the LV activation time ( LVAT $_{\text {max }}$, Fig. 2.4). A longer LVAT $\max$ was shown to be predictive of CRT response $(\mathrm{OR}[\mathrm{CI}]=1.30$ [1.11 - 1.52] for each $10 \mathrm{~ms}$ increase up to $125 \mathrm{~ms})$. In addition, the Selvester QRS score for LBBB was used to quantify LV scar extent. A higher Selvester score was negatively associated with reverse remodeling $(\mathrm{OR}[\mathrm{CI}]=0.49[0.27-0.88]$ for each 1-point increase from 0 to 4; $0.92[0.83-1.01]$ for each 1-point increase $>4) .{ }^{19}$

Recently, the value of the vectorcardiogram (VCG) for characterizing the electrical substrate and predicting CRT response has been explored. VCG is a technique that records the magnitude and direction of the electrical forces that are generated by the heart over time, resulting in a resultant electrical force depicted by a vector for each time-point. Connecting the arrow heads of all vectors, a vector loop is constructed. The VCG thus contains 3D information of the electrical forces within the heart, which might provide more valuable information than the 1D-ECG. It was hypothesized that large electrical dyssynchrony, amenable to CRT, 


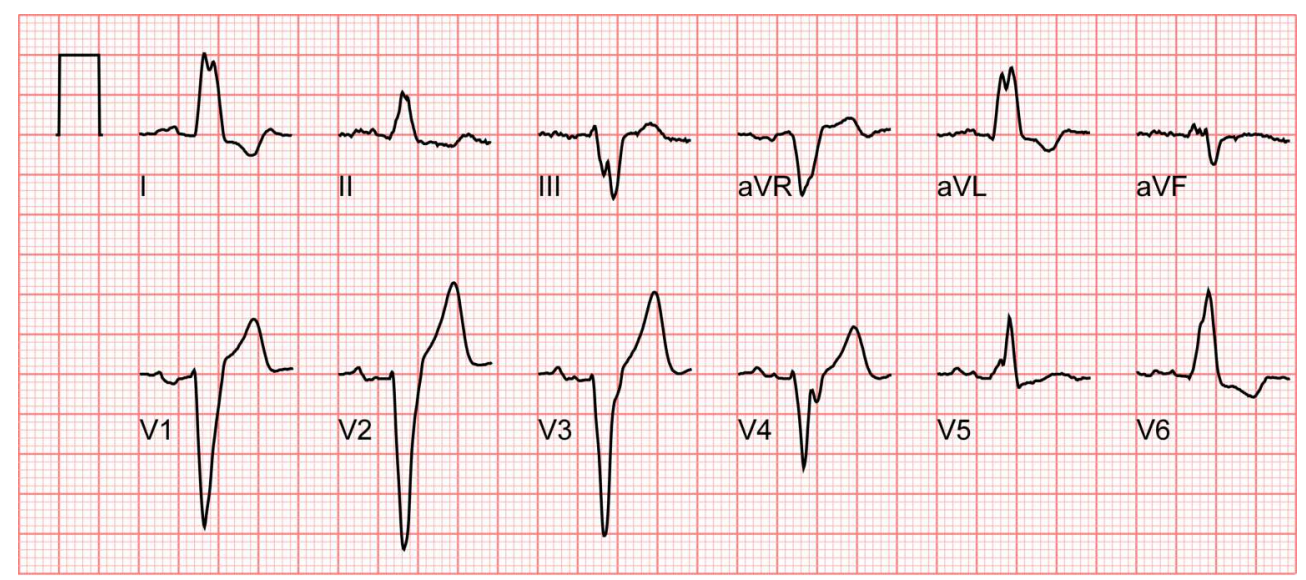

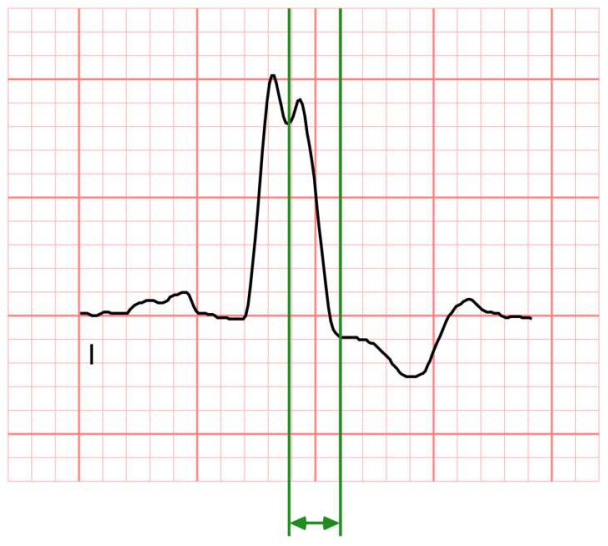

LVAT

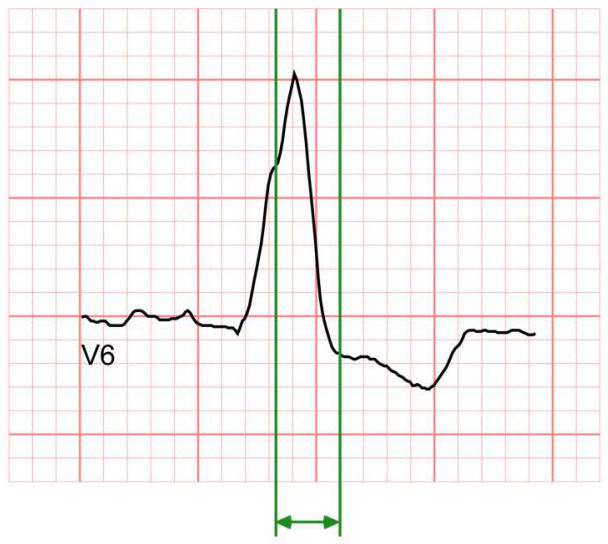

LVAT

Figure 2.4: Example of a left ventricular activation time (LVAT) measurement. LVAT $_{\max }$ is measured as the time difference between the first notch after $40 \mathrm{~ms}$ of QRS onset and the end of the QRS

would lead to large unopposed electrical forces during ventricular depolarization and that the size of these forces may be well represented by the $\mathrm{QRS}_{\text {area }}$, the area of the QRS complex in the three principle directions. van Deursen et al. ${ }^{24}$ assessed the area of the QRS complex $\left(\mathrm{QRS}_{\text {area }}\right)$ on the VCG in 81 consecutive CRT candidates and showed that a large $\mathrm{QRS}_{\text {area }}$ was associated with high odds of long-term volumetric CRT response. Moreover, $\mathrm{QRS}_{\text {area }}$ predicted CRT response better than QRS duration and then conventionally defined LBBB and as least as good as the most refined LBBB definition. ${ }^{24}$

The notion that $\mathrm{QRS}_{\text {area }}$ represents the extent of unopposed electrical forces is supported by the observation that $\mathrm{QRS}_{\text {area }}$ is larger in patients with $\mathrm{LBBB}$ as compared to patients with IVCD and that $\mathrm{QRS}_{\text {area }}$ is lower in ischemic than in non-ischemic patients. ${ }^{24}$ Further support 
comes from observations in the above mentioned study on coronary venous mapping. In this study, VCGs were constructed from pre-procedural standard 12-lead ECGs for all patients using the Kors algorithm. A large $\mathrm{QRS}_{\text {area }}(>69 \mu \mathrm{Vs}$ ) on the VCG was shown to be highly predictive of delayed LV lateral wall activation as determined by coronary venous mapping (Fig. 2.5). ${ }^{51}$ On the other hand, $\mathrm{QRS}_{\text {area }}$ has been shown to be smaller in patients with heart failure of ischemic etiology, which may be explained by the presence of non-conductive fibrotic tissue. ${ }^{24}$ Taken together, these observations suggest that $\mathrm{QRS}_{\text {area }}$ is not only useful to determine the extent of electrical dyssynchrony, but that it may also reflect the presence of determinants known to reduce the chance of CRT benefit, such as an ischemic etiology of heart failure. However, more research is required to better understand all determinants of $\mathrm{QRS}_{\text {area }}$.

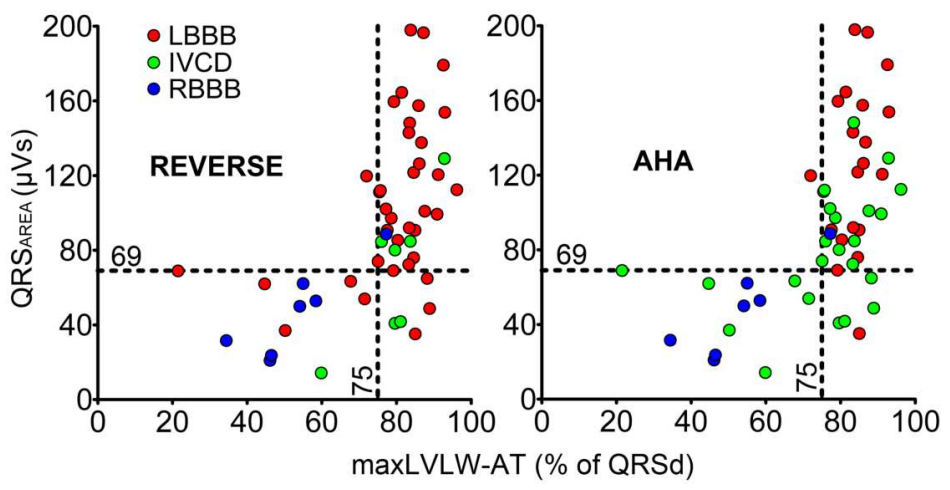

Figure 2.5: $\mathrm{QRS}_{\text {area }}$ plotted as a function of maximal LV lateral wall activation time (maxLVLW-AT) expressed as \% of QRS duration (QRSd) for all patients (each dot represents a patient, $\mathrm{n}=51$ ) with LBBB diagnosed according to the definition provided by the REVERSE trial (left) and the American Heart Association (AHA) definition (right). This figure demonstrates the excellent diagnostic performance of $\mathrm{QRS}_{\text {area }}>69 \mu \mathrm{Vs}$ for delayed LV lateral wall activation (defined as a maxLVLW-AT exceeding $75 \%$ of QRS duration), independent of the QRS morphology on the surface ECG, and illustrates the difference in QRS morphology classification caused by disparity in LBBB definitions (Adapted from Mafi Rad et al. $\left.{ }^{51}\right)$.

Interestingly, two studies showed that VCG-derived measures of repolarization predict CRT response even better than $\mathrm{QRS}_{\text {area. }}$. Engels et al. ${ }^{55}$ assessed the $\mathrm{T}_{\text {area }}$ from VCGs of 244 CRT recipients (VCG examples shown in Fig. 2.6C and D). The VCG-derived $\mathrm{T}_{\text {area }}$ was shown to predict echocardiographic CRT response better than $\mathrm{QRS}_{\text {area }}{ }^{55} \mathrm{In}$ a larger cohort consisting of 335 CRT recipients in which the primary endpoint was the composite of heart failure hospitalization, heart transplantation, left ventricular assist device implantation or death during a 3-year follow-up period, the predictive power of $\mathrm{T}_{\text {area }}$ for CRT response 
was found to be primarily evident in the group of patients with LBBB (Fig. 2.6E and F) ${ }^{56}$ A large $T_{\text {area }}$ in LBBB patients was associated with less HF hospitalizations and a higher chance of survival. ${ }^{56}$ The size of the $\mathrm{T}_{\text {area }}$ is a reflection of the extent of unopposed electrical forces during the repolarization phase. The $\mathrm{T}_{\text {area }}$ is partially determined by the size of the $\mathrm{QRS}_{\text {area }}{ }^{55}$, but other factors such as changes in $\mathrm{K}^{+}$and $\mathrm{Ca}^{2+}$ ion channel expression might also play a role. In this study a larger $\mathrm{T}_{\text {area }}$ was primarily caused by a larger amplitude and not so much by a longer JT-interval. Further research is needed to investigate which other factors are exactly reflected in the $\mathrm{T}_{\text {area }}$.

A limitation of all these studies regarding the $\mathrm{QRS}_{\text {area }}$ is that relatively small sample sizes were used. Furthermore, the studies related to the prediction of CRT response using the $\mathrm{QRS}_{\text {area }}$ were all retrospective. Therefore, these results need to be validated in a larger prospective study.

The great practical benefit of $\mathrm{QRS}_{\text {area }}$ and $\mathrm{T}_{\text {area }}$ is that these parameters are measured in an objective manner and quantified as continuous variables, as opposed to LBBB which is a dichotomous measurement that is subject to the use of different definitions and subjective interpretations of QRS notching/slurring. Another practical feature of $\mathrm{QRS}_{\text {area }}$ and $\mathrm{T}_{\text {area }}$ is that they can easily be derived from the standard 12-lead ECG. Most commercially available ECG machines have algorithms to construct VCGs from standard 12-lead ECGs using the inverse Dower or Kors' regression transformation. ${ }^{57,58}$ These VCGs provide a good resemblance of the gold standard Frank-VCG and have recently also been validated for use in patients with dyssynchronous heart failure. ${ }^{59}$ The non-invasive and simple nature of VCG analysis combined with the excellent predictive power of $\mathrm{QRS}_{\text {area }}$ and $\mathrm{T}_{\text {area }}$ for CRT response indicates that these parameters can be easily applied in clinical practice to identify appropriate candidates for CRT, thereby potentially improving response to this therapy.

\subsection{Conclusions}

Based on the evidence obtained from electro-anatomic mapping that $\mathrm{QRS}_{\text {area }}$ reflects LV activation delay, the primary electrical substrate for CRT, and on the better prediction of CRT response by $\mathrm{QRS}_{\text {area }}$ as compared to QRS duration, we propose to include $\mathrm{QRS}_{\text {area }}$ in the guidelines as a selection criterion for CRT implantation. The possibly even better prediction of CRT response by using the T-wave rather than the QRS complex requires further investigation. 
A
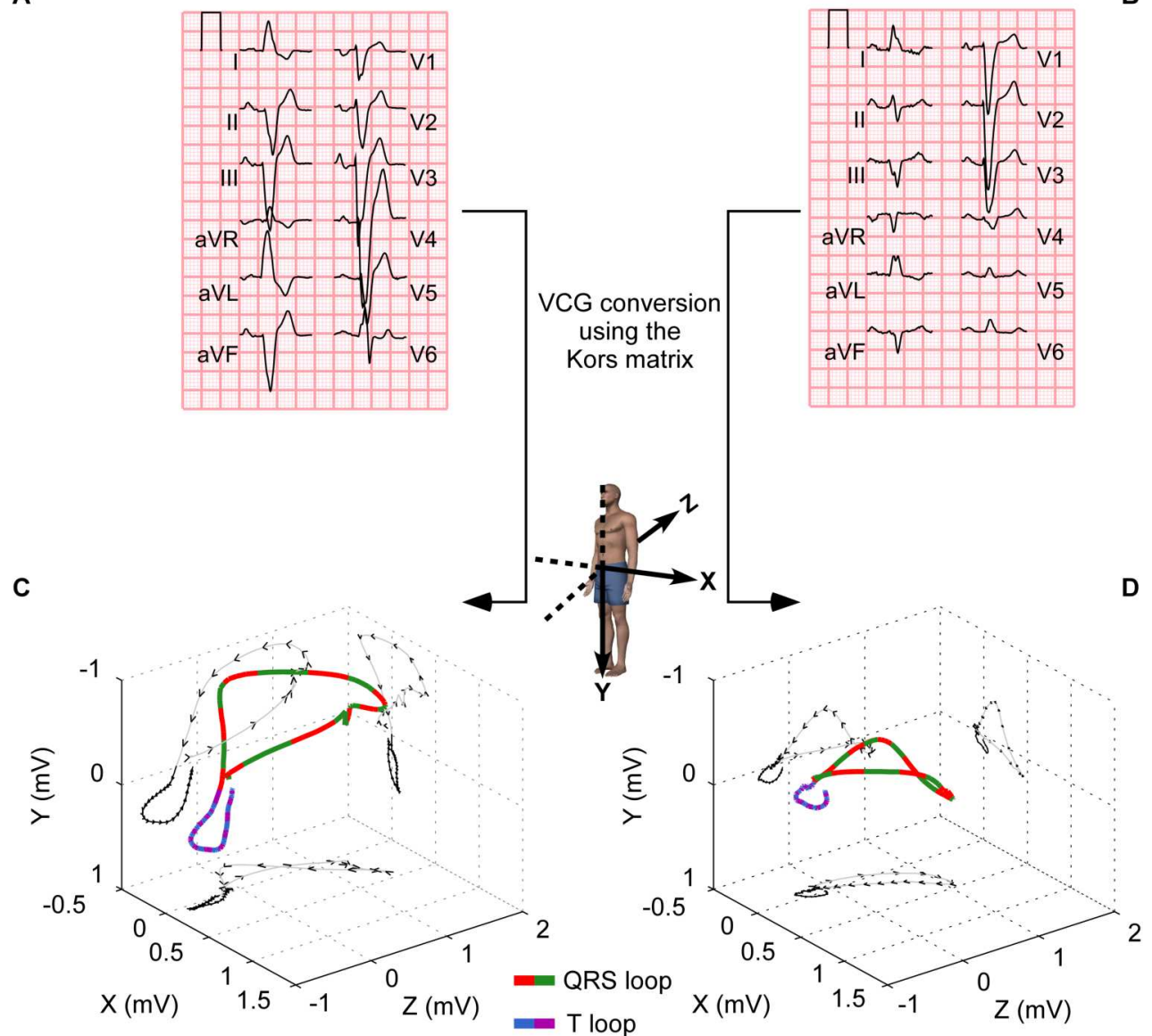

E

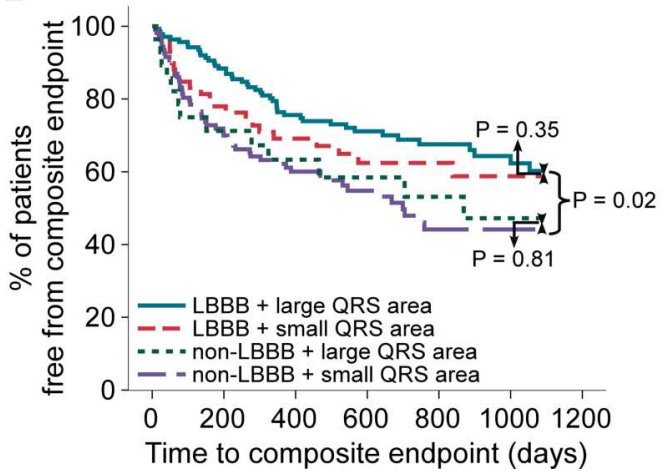

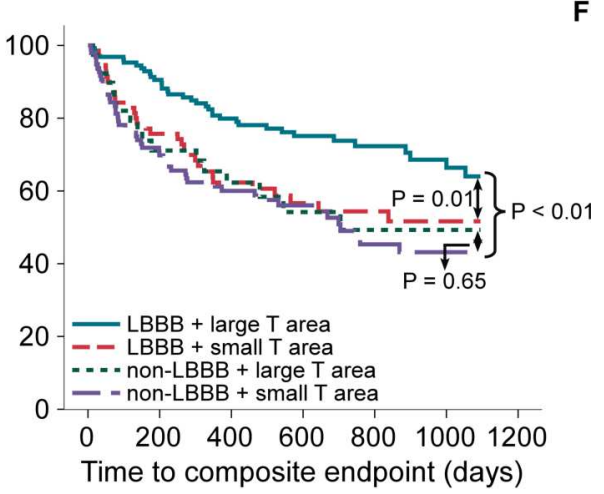

Figure 2.6: Typical example of VCGs constructed from standard 12-lead ECGs for a patient with a large (A and $\mathbf{C}$ ) and a patient with a small $(\mathbf{B}$ and $\mathbf{D}) \mathrm{T}_{\text {area }}$, despite being both classified as having LBBB. Panels $\mathbf{E}$ and $\mathbf{F}$ show Kaplan-Meier estimates of the probability free from the composite endpoint HTLD (HF hospitalization, heart transplantation, LVAD implantation, death) after 3 years of CRT. Large QRS or T area are values $\geq$ median value and small QRS or $\mathrm{T}$ area are values $<$ median value (adapted from Engels et al. ${ }^{55}$ and Végh et al. ${ }^{56}$ ). 


\section{References}

1. JGF Cleland, JC Daubert, E Erdmann, N Freemantle, D Gras, L Kappenberger, L Tavazzi, and Cardiac Resynchronization-Heart Failure (CARE-HF) Study Investigators. The effect of cardiac resynchronization on morbidity and mortality in heart failure. N Engl J Med (2005) 352:1539-1549.

2. WT Abraham, WG Fisher, AL Smith, DB Delurgio, AR Leon, E Loh, DZ Kocovic, M Packer, AL Clavell, DL Hayes, et al. Cardiac resynchronization in chronic heart failure. N Engl J Med (2002) 346:1845-1853.

3. M Brignole, A Auricchio, G Baron-Esquivias, P Bordachar, G Boriani, OA Breithardt, J Cleland, JC Deharo, V Delgado, PM Elliott, et al. 2013 ESC Guidelines on cardiac pacing and cardiac resynchronization therapy: the Task Force on cardiac pacing and resynchronization therapy of the European Society of Cardiology (ESC). Developed in collaboration with the European Heart Rhythm Association (EHRA). Eur Heart J (2013) 34:2281-2329.

4. CM Tracy, AE Epstein, D Darbar, JP Dimarco, SB Dunbar, NAM Estes 3rd, TB Ferguson Jr, SC Hammill, PE Karasik, MS Link, et al. 2012 ACCF/AHA/HRS Focused Update of the 2008 Guidelines for Device-Based Therapy of Cardiac Rhythm Abnormalities: a report of the American College of Cardiology Foundation/American Heart Association Task Force on Practice Guidelines. Heart Rhythm (2012) 9:1737-1753.

5. European Heart Rhythm Association, European Society of Cardiology, Heart Rhythm Society, Heart Failure Society of America, American Society of Echocardiography, American Heart Association, European Association of Echocardiography, Heart Failure Association, JC Daubert, L Saxon, et al. 2012 EHRA/HRS expert consensus statement on cardiac resynchronization therapy in heart failure: implant and follow-up recommendations and management. Heart Rhythm (2012) 9:1524-1576.

6. W Mullens, RA Grimm, T Verga, T Dresing, RC Starling, BL Wilkoff, and WHW Tang. Insights from a cardiac resynchronization optimization clinic as part of a heart failure disease management program. J Am Coll Cardiol (2009) 53:765-773.

7. SG Priori, C Blomström-Lundqvist, A Mazzanti, N Blom, M Borggrefe, J Camm, PM Elliott, D Fitzsimons, R Hatala, G Hindricks, et al. 2015 ESC Guidelines for the management of patients with ventricular arrhythmias and the prevention of sudden cardiac death: The Task Force for the Management of Patients with Ventricular Arrhythmias 
and the Prevention of Sudden Cardiac Death of the European Society of Cardiology (ESC)Endorsed by: Association for European Paediatric and Congenital Cardiology (AEPC). Eur Heart J (2015) 36:2793-2867.

8. S Cazeau, P Ritter, S Bakdach, A Lazarus, M Limousin, L Henao, O Mundler, JC Daubert, and J Mugica. Four chamber pacing in dilated cardiomyopathy. Pacing Clin Electrophysiol (1994) 17:1974-1979.

9. PF Bakker, HW Meijburg, JW de Vries, MM Mower, AC Thomas, ML Hull, EO Robles De Medina, and JJ Bredée. Biventricular pacing in end-stage heart failure improves functional capacity and left ventricular function. J Interv Card Electrophysiol (2000) 4:395-404.

10. C Linde, C Leclercq, S Rex, S Garrigue, T Lavergne, S Cazeau, W McKenna, M Fitzgerald, JC Deharo, C Alonso, S Walker, F Braunschweig, C Bailleul, and JC Daubert. Long-term benefits of biventricular pacing in congestive heart failure: results from the MUltisite STimulation in cardiomyopathy (MUSTIC) study. J Am Coll Cardiol (2002) 40:111-118.

11. MGSJ Sutton, T Plappert, KE Hilpisch, WT Abraham, DL Hayes, and E Chinchoy. Sustained reverse left ventricular structural remodeling with cardiac resynchronization at one year is a function of etiology: quantitative Doppler echocardiographic evidence from the Multicenter InSync Randomized Clinical Evaluation (MIRACLE). Circulation (2006) 113:266-272.

12. MR Bristow, LA Saxon, J Boehmer, S Krueger, DA Kass, T De Marco, P Carson, L DiCarlo, D DeMets, BG White, DW DeVries, AM Feldman, and Comparison of Medical Therapy, Pacing, and Defibrillation in Heart Failure (COMPANION) Investigators. Cardiac-resynchronization therapy with or without an implantable defibrillator in advanced chronic heart failure. N Engl J Med (2004) 350:2140-2150.

13. PE Vardas, A Auricchio, JJ Blanc, JC Daubert, H Drexler, H Ector, M Gasparini, C Linde, FB Morgado, A Oto, R Sutton, M Trusz-Gluza, European Society of Cardiology, and European Heart Rhythm Association. Guidelines for cardiac pacing and cardiac resynchronization therapy. The Task Force for Cardiac Pacing and Cardiac Resynchronization Therapy of the European Society of Cardiology. Developed in collaboration with the European Heart Rhythm Association. Europace (2007) 9:959-998.

14. C Linde, WT Abraham, MR Gold, M St. John Sutton, S Ghio, C Daubert, and REVERSE (REsynchronization reVErses Remodeling in Systolic left vEntricular dysfunction) Study Group. Randomized Trial of Cardiac Resynchronization in Mildly Symptomatic Heart Failure Patients and in Asymptomatic Patients With Left Ventricular Dysfunction and Previous Heart Failure Symptoms. Journal of the American College of Cardiology (2008) 52:1834-1843. 
15. AJ Moss, WJ Hall, DS Cannom, H Klein, MW Brown, JP Daubert, NAM Estes 3rd, E Foster, H Greenberg, SL Higgins, MA Pfeffer, SD Solomon, D Wilber, W Zareba, and MADIT-CRT Trial Investigators. Cardiac-resynchronization therapy for the prevention of heart-failure events. N Engl J Med (2009) 361:1329-1338.

16. ASL Tang, GA Wells, M Talajic, MO Arnold, R Sheldon, S Connolly, SH Hohnloser, G Nichol, DH Birnie, JL Sapp, R Yee, JS Healey, JL Rouleau, and Resynchronization-Defibrillation for Ambulatory Heart Failure Trial Investigators. Cardiac-resynchronization therapy for mild-to-moderate heart failure. $N \mathrm{Engl} \mathrm{J} \mathrm{Med}$ (2010) 363:2385-2395.

17. AR Bryant, SB Wilton, MP Lai, and DV Exner. Association between QRS duration and outcome with cardiac resynchronization therapy: a systematic review and metaanalysis. J Electrocardiol (2013) 46:147-155.

18. K Dickstein, PE Vardas, A Auricchio, JC Daubert, C Linde, J McMurray, P Ponikowski, SG Priori, R Sutton, DJ van Veldhuisen, and ESC Committee for Practice Guidelines. 2010 Focused Update of ESC Guidelines on device therapy in heart failure: an update of the 2008 ESC Guidelines for the diagnosis and treatment of acute and chronic heart failure and the 2007 ESC Guidelines for cardiac and resynchronization therapy. Developed with the special contribution of the Heart Failure Association and the European Heart Rhythm Association. Europace (2010) 12:1526-1536.

19. MO Sweeney, RJ van Bommel, MJ Schalij, CJW Borleffs, AS Hellkamp, and JJ Bax. Analysis of ventricular activation using surface electrocardiography to predict left ventricular reverse volumetric remodeling during cardiac resynchronization therapy. Circulation (2010) 121:626-634.

20. Y Tian, P Zhang, X Li, Y Gao, T Zhu, L Wang, D Li, J Wang, C Yuan, and J Guo. True complete left bundle branch block morphology strongly predicts good response to cardiac resynchronization therapy. Europace (2013) 15:1499-1506.

21. W Zareba, H Klein, I Cygankiewicz, WJ Hall, S McNitt, M Brown, D Cannom, JP Daubert, M Eldar, MR Gold, et al. Effectiveness of Cardiac Resynchronization Therapy by QRS Morphology in the Multicenter Automatic Defibrillator Implantation Trial-Cardiac Resynchronization Therapy (MADIT-CRT). Circulation (2011) 123:1061-1072.

22. MR Gold, C Thébault, C Linde, WT Abraham, B Gerritse, S Ghio, M St John Sutton, and JC Daubert. Effect of QRS duration and morphology on cardiac resynchronization therapy outcomes in mild heart failure: results from the Resynchronization Reverses Remodeling in Systolic Left Ventricular Dysfunction (REVERSE) study. Circulation (2012) 126:822-829. 
23. DG Strauss, RH Selvester, and GS Wagner. Defining left bundle branch block in the era of cardiac resynchronization therapy. Am J Cardiol (2011) 107:927-934.

24. CJM van Deursen, K Vernooy, E Dudink, L Bergfeldt, HJGM Crijns, FW Prinzen, and L Wecke. Vectorcardiographic QRS area as a novel predictor of response to cardiac resynchronization therapy. J Electrocardiol (2015) 48:45-52.

25. JG Cleland, WT Abraham, C Linde, MR Gold, JB Young, J Claude Daubert, L Sherfesee, GA Wells, and ASL Tang. An individual patient meta-analysis of five randomized trials assessing the effects of cardiac resynchronization therapy on morbidity and mortality in patients with symptomatic heart failure. Eur Heart J (2013) 34:3547-3556.

26. R Zusterzeel, KA Selzman, WE Sanders, DA Caños, KM O'Callaghan, JL Carpenter, IL Piña, and DG Strauss. Cardiac resynchronization therapy in women: US Food and Drug Administration meta-analysis of patient-level data. JAMA Intern Med (2014) 174:1340-1348.

27. G Mascioli, L Padeletti, B Sassone, M Zecchin, E Lucca, S Sacchi, G Boggian, AL Tondo, C Belvito, N Bakhtadze, A Borrelli, and G Sinagra. Electrocardiographic criteria of true left bundle branch block: a simple sign to predict a better clinical and instrumental response to CRT. Pacing Clin Electrophysiol (2012) 35:927-934.

28. K Vernooy, RNM Cornelussen, XAAM Verbeek, WYR Vanagt, A van Hunnik, M Kuiper, T Arts, HJGM Crijns, and FW Prinzen. Cardiac resynchronization therapy cures dyssynchronopathy in canine left bundle-branch block hearts. Eur Heart J (2007) 28:2148-2155.

29. L Liu, B Tockman, S Girouard, J Pastore, G Walcott, B KenKnight, and J Spinelli. Left ventricular resynchronization therapy in a canine model of left bundle branch block. Am J Physiol Heart Circ Physiol (2002) 282:H2238-H2244.

30. JP Singh, D Fan, EK Heist, CR Alabiad, C Taub, V Reddy, M Mansour, MH Picard, JN Ruskin, and T Mela. Left ventricular lead electrical delay predicts response to cardiac resynchronization therapy. Heart Rhythm (2006) 3:1285-1292.

31. MR Gold, U Birgersdotter-Green, JP Singh, KA Ellenbogen, Y Yu, TE Meyer, M Seth, and PJ Tchou. The relationship between ventricular electrical delay and left ventricular remodelling with cardiac resynchronization therapy. Eur Heart J (2011) 32:2516-2524.

32. MF van Oosterhout, FW Prinzen, T Arts, JJ Schreuder, WY Vanagt, JP Cleutjens, and RS Reneman. Asynchronous electrical activation induces asymmetrical hypertrophy of the left ventricular wall. Circulation (1998) 98:588-595.

33. BT Wyman, WC Hunter, FW Prinzen, OP Faris, and ER McVeigh. Effects of singleand biventricular pacing on temporal and spatial dynamics of ventricular contraction. Am J Physiol Heart Circ Physiol (2002) 282:H372-H379. 
34. J Lumens, T Delhaas, B Kirn, and T Arts. Three-wall segment (TriSeg) model describing mechanics and hemodynamics of ventricular interaction. Ann Biomed Eng (2009) 37:2234-2255.

35. F Ruschitzka, WT Abraham, JP Singh, JJ Bax, JS Borer, J Brugada, K Dickstein, I Ford, J Gorcsan 3rd, D Gras, H Krum, P Sogaard, J Holzmeister, and Echo-CRT Study Group. Cardiac-resynchronization therapy in heart failure with a narrow QRS complex. N Engl J Med (2013) 369:1395-1405.

36. M Strik, LB van Middendorp, and K Vernooy. Animal models of dyssynchrony. $J$ Cardiovasc Transl Res (2012) 5:135-145.

37. K Vernooy, XAAM Verbeek, M Peschar, HJGM Crijns, T Arts, RNM Cornelussen, and FW Prinzen. Left bundle branch block induces ventricular remodelling and functional septal hypoperfusion. Eur Heart J (2005) 26:91-98.

38. JA Vassallo, DM Cassidy, FE Marchlinski, AE Buxton, HL Waxman, JU Doherty, and ME Josephson. Endocardial activation of left bundle branch block. Circulation (1984) 69:914-923.

39. A Auricchio, C Fantoni, F Regoli, C Carbucicchio, A Goette, C Geller, M Kloss, and $\mathrm{H}$ Klein. Characterization of left ventricular activation in patients with heart failure and left bundle-branch block. Circulation (2004) 109:1133-1139.

40. LM Rodriguez, C Timmermans, A Nabar, G Beatty, and HJJ Wellens. Variable patterns of septal activation in patients with left bundle branch block and heart failure. $J$ Cardiovasc Electrophysiol (2003) 14:135-141.

41. JWH Fung, CM Yu, G Yip, Y Zhang, H Chan, CC Kum, and JE Sanderson. Variable left ventricular activation pattern in patients with heart failure and left bundle branch block. Heart (2004) 90:17-19.

42. FW Prinzen and A Auricchio. Is echocardiographic assessment of dyssynchrony useful to select candidates for cardiac resynchronization therapy? Echocardiography is not useful before cardiac resynchronization therapy if QRS duration is available. Circ Cardiovasc Imaging (2008) 1:70-77.

43. JWH Fung, JYS Chan, GWK Yip, HCK Chan, WWL Chan, Q Zhang, and CM Yu. Effect of left ventricular endocardial activation pattern on echocardiographic and clinical response to cardiac resynchronization therapy. Heart (2007) 93:432-437.

44. M Strik, S Ploux, K Vernooy, and FW Prinzen. Cardiac resynchronization therapy: refocus on the electrical substrate. Circ J (2011) 75:1297-1304.

45. JC Demoulin and HE Kulbertus. Histopathological examination of concept of left hemiblock. Br Heart J (1972) 34:807-814.

46. L Bacharova, A Mateasik, R Krause, FW Prinzen, A Auricchio, and M Potse. The effect of reduced intercellular coupling on electrocardiographic signs of left ventricular hypertrophy. J Electrocardiol (2011) 44:571-576. 
47. L Bacharova, V Szathmary, and A Mateasik. Electrocardiographic patterns of left bundle-branch block caused by intraventricular conduction impairment in working myocardium: a model study. J Electrocardiol (2011) 44:768-778.

48. PN Unger, ME Lesser, VH Kugel, and M Lev. The concept of masquerading bundle-branch block; an electrocardiographic-pathologic correlation. Circulation (1958) 17:397-409.

49. JL Richman and L Wolff. Left bundle branch block masquerading as right bundle branch block. Am Heart J (1954) 47:383-393.

50. C Fantoni, M Kawabata, R Massaro, F Regoli, S Raffa, V Arora, JA Salerno-Uriarte, HU Klein, and A Auricchio. Right and left ventricular activation sequence in patients with heart failure and right bundle branch block: a detailed analysis using threedimensional non-fluoroscopic electroanatomic mapping system. J Cardiovasc Electrophysiol (2005) 16:112-9, 112-9.

51. M Mafi Rad, GWM Wijntjens, EB Engels, Y Blaauw, JGLM Luermans, L Pison, HJ Crijns, FW Prinzen, and K Vernooy. Vectorcardiographic QRS area identifies delayed left ventricular lateral wall activation determined by electroanatomic mapping in candidates for cardiac resynchronization therapy. Heart Rhythm (2016) 13:217-225.

52. CJM van Deursen, Y Blaauw, MI Witjens, L Debie, L Wecke, HJGM Crijns, FW Prinzen, and K Vernooy. The value of the 12-lead ECG for evaluation and optimization of cardiac resynchronization therapy in daily clinical practice. J Electrocardiol (2014) 47:202-211.

53. AMW van Stipdonk, MM Rad, JGLM Luermans, HJ Crijns, FW Prinzen, and K Vernooy. Identifying delayed left ventricular lateral wall activation in patients with non-specific intraventricular conduction delay using coronary venous electroanatomical mapping. Neth Heart J (2016) 24:58-65.

54. C Ramanathan, RN Ghanem, P Jia, K Ryu, and Y Rudy. Noninvasive electrocardiographic imaging for cardiac electrophysiology and arrhythmia. Nat Med (2004) 10:422-428.

55. EB Engels, EM Végh, CJM Van Deursen, K Vernooy, JP Singh, and FW Prinzen. Twave area predicts response to cardiac resynchronization therapy in patients with left bundle branch block. J Cardiovasc Electrophysiol (2015) 26:176-183.

56. EM Végh, EB Engels, CJM van Deursen, B Merkely, K Vernooy, JP Singh, and FW Prinzen. T-wave area as biomarker of clinical response to cardiac resynchronization therapy. Europace (2016) 18:1077-1085.

57. JA Kors, G van Herpen, AC Sittig, and JH van Bemmel. Reconstruction of the Frank vectorcardiogram from standard electrocardiographic leads: diagnostic comparison of different methods. Eur Heart J (1990) 11:1083-1092. 
58. L Edenbrandt and O Pahlm. Vectorcardiogram synthesized from a 12-lead ECG: superiority of the inverse Dower matrix. J Electrocardiol (1988) 21:361-367.

59. EB Engels, S Alshehri, CJM van Deursen, L Wecke, L Bergfeldt, K Vernooy, and FW Prinzen. The synthesized vectorcardiogram resembles the measured vectorcardiogram in patients with dyssynchronous heart failure. J Electrocardiol (2015) 48:586-592. 


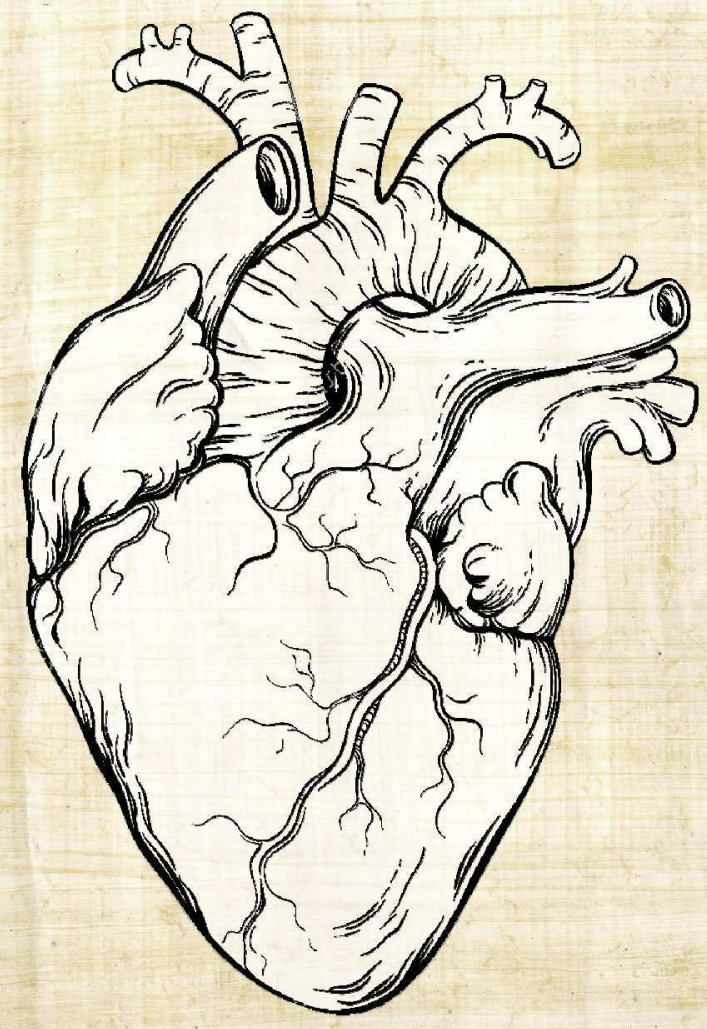




\section{Chapter}

\section{The synthesized vectorcardiogram resembles the measured vectorcardiogram in patients with dyssynchronous heart failure}

The content of this chapter is based on:

Elien B. Engels, ${ }^{1}$ Salih Alshehri, ${ }^{1}$ Caroline J.M. van Deursen, ${ }^{1}$ Liliana Wecke, ${ }^{2}$ Lennart Bergfeldt, ${ }^{2}$ Kevin Vernooy, ${ }^{3}$ and Frits W. Prinzen ${ }^{1}$ (2015).

The synthesized vectorcardiogram resembles the measured vectorcardiogram in patients with dyssynchronous heart failure. J Electrocardiol 48(4):586-592.

\footnotetext{
${ }^{1}$ Department of Physiology, CARIM School for Cardiovascular Diseases, Maastricht University, Maastricht, the Netherlands.

${ }^{2}$ Department of Cardiology, Karolinska Institutet, Karolinska University Hospital, Stockholm, Sweden.

${ }^{3}$ Department of Cardiology, Maastricht University Medical Center, Maastricht, the Netherlands.
} 


\section{Abstract}

Introduction: The use of vectorcardiography (VCG) has regained interest, however, original Frank-VCG equipment is rare. This study compares the measured VCGs with those synthesized from the 12-lead electrocardiogram (ECG) in patients with heart failure and conduction abnormalities, who are candidate for cardiac resynchronization therapy (CRT).

Methods and Results: In 92 CRT candidates, Frank-VCG and 12-lead ECG were recorded before CRT implantation. The ECG was converted to a VCG using the Kors method (KorsVCG) and the two methods were compared using correlation and Bland-Altman analyses. Variables calculated from the Frank- and Kors-VCG showed correlation coefficients between 0.77 and 0.90 . There was a significant but small underestimation by the Kors-VCG method, relative bias ranging from $-1.9 \pm 4.6 \%$ (QRS-T angle) to $-9.4 \pm 20.8 \%$ ( $\mathrm{T}_{\text {area }}$ ).

Conclusions: The present study shows that it is justified to use Kors-VCG calculations for VCG analysis, which enables retrospective VCG analysis of previously recorded ECGs in studies related to CRT. 


\subsection{Introduction}

W

IтH the use of vectorcardiography (VCG), the size and direction of the electrical forces generated by the heart are recorded and displayed in three dimensions. The VCG consists of three orthonormal leads X, Y, and Z, containing phase information between these leads. This technique was first described 101 years ago by Williams. ${ }^{1}$ The VCG technique was almost abandoned and the 12-lead electrocardiogram (ECG) became the clinical standard, because of the need for special VCG recording equipment, the lack of a standard VCG-lead system $^{2-4}$, the impracticality of a back electrode in many of these systems, and the complexity to interpret the different loop morphologies for diagnosis. ${ }^{5,6}$ The interest in the diagnostic value of the VCG has, however, never completely subsided and with today's computer technology the vector loops can be synthesized from the 12-lead ECG resulting in a revival of the VCG.

Several systems of three orthonormal leads have been described for recording the VCG, though the most commonly used one is the 8-electrode system according to Frank. ${ }^{4}$ Due to limited availability of Frank-VCG recording systems, the VCG is commonly synthesized from the 12-lead ECG. This is achieved by multiplying 8 independent ECG leads (two limb leads and all six precordial leads) by a matrix. Recent studies demonstrated that the Korsderived VCG results in the best approximation of the Frank-VCG. ${ }^{5,7-9}$

The matrix proposed by Kors et al. ${ }^{8}$ is based on a learning set from the Common Standards for Electrocardiography (CSE) multilead library, including both patients and healthy individuals, and was generated by multiple linear regression. ${ }^{8}$ Although the Kors-VCG nicely resembles the Frank-VCG in previous studies ${ }^{5,7-9}$, a comparison has never been made for patients with heart failure and a left ventricular (LV) conduction delay, mostly due to left bundle branch block (LBBB). These patients are commonly treated with cardiac resynchronization therapy (CRT). CRT has been shown to improve cardiac pump function, heart failure symptoms, quality of life, and survival. ${ }^{10}$ Although the effects of CRT in large clinical trials are impressive on a group level, the benefits in individuals vary considerably; the non-response rate to this therapy is still $30-50 \% .{ }^{11}$ To reduce the risk of complications and the unnecessary use of expensive products, patient selection should be improved. Recent studies have shown that the VCG could play an important role in the selection of patients for CRT ${ }^{12,13}$ or in the optimization of the CRT settings ${ }^{14}$. Therefore, the current study aims to compare the FrankVCG and the Kors-VCG in patients with heart failure and LV conduction delay focussing on vectorcardiographic variables relevant to resynchronization of the ventricles. 


\subsection{Methods}

\subsubsection{Patient population}

The patient population used in this study has been described previously. ${ }^{13}$ It consisted of 138 consecutive patients with heart failure, who were scheduled for implantation of a CRT device at the Maastricht University Hospital between September 2010 and June 2012. Excluded were patients with an intrinsic QRS duration $<120 \mathrm{~ms}(\mathrm{n}=13)$ or previous RV pacing during either the VCG $(n=22)$ or ECG recording $(n=2)$. Another 9 patients were excluded due to technical disturbances, multiple ectopic beats or missing ECGs. This resulted in a final population of 92 patients. The project was approved by the ethics committee of Maastricht University Hospital and was conducted in accordance with the Declaration of Helsinki. All participants gave written informed consent prior to investigation.

\subsubsection{Study design}

One day before CRT implantation, a VCG and 12-lead ECG were recorded. In some cases $(\mathrm{n}=25)$ the 12-lead ECG was not recorded at the same date, but near this date (with a median of 12 days, ranging between 1 and 57 days). Both VCG and ECG were recorded at rest and in supine position.

The VCGs were recorded as described earlier ${ }^{13}$, using 8-electrodes according to the Frank orthogonal lead system at a sampling frequency of $500 \mathrm{~Hz}$ for 5 minutes after which the complexes were averaged over a period of one minute (Coronet II System, Ortivus AB, Danderyd, Sweden).

The ECGs were recorded at a frequency of $250 \mathrm{~Hz}$ and stored digitally as PDF files in the MUSE Cardiology Information system (GE Medical System). The digital data of the 12lead ECGs were extracted from the PDF files using Inkscape version 2 (Boston, MA, USA) as described previously. ${ }^{12}$ A VCG was then synthesized by multiplying the voltages in the digital ECG leads by the Kors matrix. ${ }^{7}$

\subsubsection{VCG analysis}

Both the Frank-VCG and the Kors-VCG were analyzed offline using customized software described previously. ${ }^{12,15}$ This software calculates the different VCG variables described here. The QRS duration and QT interval were defined as the duration between the beginning of the QRS complex and the end of the QRS complex or T-wave, respectively. Subsequently, the maximal QRS vector and $\mathrm{T}$ vector were found by the maximal distance between the origin of the 3D loop and a point on the QRS- and T-vector loop, respectively. The size and direction of these maximal vectors were expressed by the vector amplitude, azimuth (angle in the transversal plane with backward vector directions being negative) and elevation (angle 
in the craniocaudal direction with downward vector directions being $<90^{\circ}$ ), as described by Wecke et al. ${ }^{16}$. Furthermore, the areas of the QRS- and T-loops were computed by numerical integration as the area between the curve and the baseline in the $\mathrm{X}, \mathrm{Y}$, and $\mathrm{Z}$ direction between the beginning and ending of the QRS complex or T-wave, respectively, and calculated as $\mathrm{QRS}_{\text {area }}=\sqrt{\mathrm{QRS}_{\text {area }, \mathrm{x}}^{2}+\mathrm{QRS}_{\text {area }, \mathrm{y}}^{2}+\mathrm{QRS}_{\text {area }, \mathrm{z}}^{2}}$ or $\mathrm{T}_{\text {area }}=\sqrt{\mathrm{T}_{\text {area } \mathrm{x}}^{2}+\mathrm{T}_{\text {area }, \mathrm{y}}^{2}+\mathrm{T}_{\text {area }, \mathrm{z}}^{2}} \cdot 7$ The QRS-T angle was derived from the two vectors of the QRS- and T-integrals.

\subsubsection{Statistical Analysis}

The statistical analysis was performed using IBM SPSS statistics software version 21 (SPSS Inc, Chicago, Illinois). Continuous and discrete variables are presented as mean \pm standard deviation (SD) and counts (percentages), respectively. To compare the recorded Frank-VCG outcomes with the Kors-VCG outcomes, a paired t-test was performed and the Pearson correlation coefficient was calculated. Furthermore, a Bland-Altman analysis was used to show the differences between the two VCG methods. The mean difference between the measured and calculated values is defined as bias and the 95\% upper and lower limits of agreement (LoA) were defined as bias $\pm 1.96 \cdot \mathrm{SD}$ (of the difference). In addition, the bias and limits of agreement relative to the Frank-VCG measurements were calculated.

\subsection{Results}

\subsubsection{Patient characteristics}

The baseline characteristics of the 92 patients are shown in Table 3.1. Most patients were male, had NYHA class II or III and LBBB according to the Strauss ${ }^{17}$ criteria. In addition, half of the patients had ischemic heart failure etiology and a quarter had atrial fibrillation (AF). Furthermore, the patients had a reduced left ventricular ejection fraction (LVEF). These characteristics are typical for patients receiving CRT. ${ }^{18}$

\subsubsection{Frank-VCG versus Kors-VCG}

Examples of the Frank-VCG and Kors-VCG are presented in Fig. 3.1. They are also indicated by red squares in the Bland-Altman plots of Fig. 3.3. Patient 1 showed large resemblances between the two methods, with very similar shape of the loops as well as amplitudes and directions of the maximal vectors. In patient 2 the shape of the loops were slightly different, especially in the transversal plane where the Frank-VCG QRS loop had a figure-of-eight shape while the Kors-VCG QRS loop was open. Furthermore, large differences were observed in the amplitudes of the VCG loops, the amplitudes being considerably larger in the Frank-VCG. Moreover, the direction of the maximal QRS-vector in the frontal plane was 


\section{Patient 1}

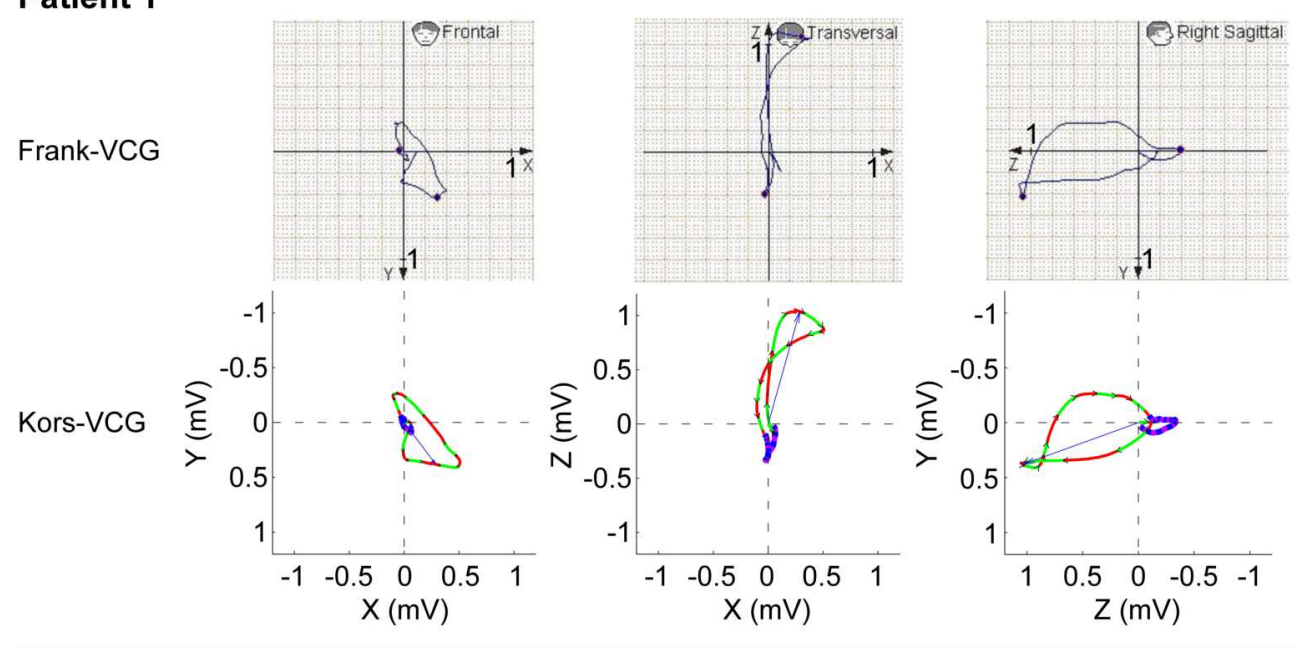

\section{Patient 2}

Frank-VCG
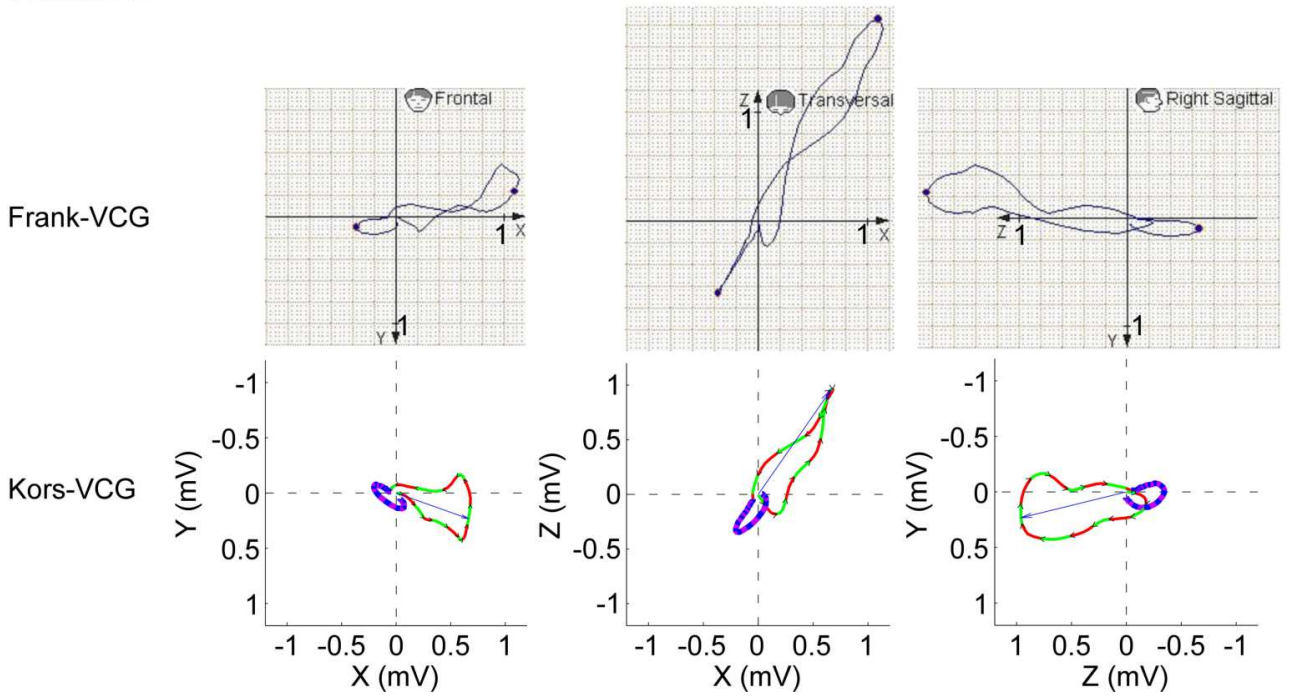

Figure 3.1: Two examples of VCGs: a recorded Frank-VCG and a Kors-VCG. Patient 1 showed comparable results between the Kors-VCG and Frank-VCG while Patient 2 showed large differences between the calculated and measured VCGs. 
Table 3.1: Baseline characteristics of the 92 included patients.

\begin{tabular}{lc}
\hline Patient characteristics & $\mathrm{n}=92$ \\
\hline Age (years) & $67 \pm 9$ \\
Female (n, \%) & $33(36)$ \\
Heart rate (bpm) & $69 \pm 12$ \\
BMI (kg/m²) & $27 \pm 5$ \\
Ischemic HF etiology (n, \%) & $50(54)$ \\
Atrial Fibrillation (n, \%) & $23(25)$ \\
Diabetes mellitus (n, \%) & $30(33)$ \\
NYHA class & \\
I (n, \%) & $9(10)$ \\
II (n, \%) & $40(43)$ \\
III (n, \%) & $33(36)$ \\
IV (n, \%) & $1(1)$ \\
Unknown (n, \%) & $9(10)$ \\
LBBB (n, \%) & $73(79)$ \\
LVEF (\%) & $26 \pm 7$ \\
LVEDV (ml) & $195 \pm 58$ \\
QRS duration (ms) & $168 \pm 17$ \\
QT interval (ms) & $458 \pm 39$ \\
$\beta$-blocker (n, \%) & $83(90)$ \\
ACE-inhibitor/ARB (n, \%) & $81(88)$ \\
Loop diuretics (n, \%) & $62(67)$ \\
Ald-antagonist (n, \%) & $29(32)$ \\
\hline O
\end{tabular}

Variables are shown as counts (percentage) $\overline{\text { or mean } \pm \text { standard deviation when appropriate. }}$

BMI: body mass index, HF: heart failure, NYHA: New York heart association, LBBB: left bundle branch block, LVEF: left ventricular ejection fraction, LVEDV: left ventricular end diastolic volume, ACE: angiotensin-converting enzyme, ARB: angiotensin II type 1 receptor blocker, Ald-antagonist: aldosterone antagonist.

slightly below the y-axis in the Kors-VCG while it was slightly above the y-axis in the FrankVCG. The same can be observed in the right sagittal plane. As shown in Fig. 3.3, this patient showed the largest difference in VCG variables between the two methods.

All individual values of various variables, extracted from the Kors-VCG and the FrankVCG, were plotted against each other (Fig. 3.2). Fig. 3.2A shows the results for the QRS amplitude, of which the points align well around the line of identity, resulting in a high correlation between the Frank-VCG and Kors-VCG values. The absolute T amplitude values were lower than the QRS amplitude, leading to a wider distribution of the points around the line of identity and to a somewhat lower correlation coefficient (Fig. 3.2B). Angle variables such as the QRS azimuth (Fig. 3.2C) and the QRS-T angle (Fig. 3.2D) also showed good correlations between the Kors-VCG and Frank-VCG.

Fig. 3.3 shows the scatter plots and Bland-Altman plots for the $\mathrm{QRS}_{\text {area }}$ (left) and $\mathrm{T}_{\text {area }}$ (right). Again, the points in the scatter plot are nicely distributed along the line of identity. This observation is substantiated by a random distribution of the points around the zero bias line in the Bland-Altman plot. For the $\mathrm{QRS}_{\text {area }}$ the bias was $-3.4 \pm 20.2 \mu \mathrm{Vs}$, while it was slightly larger $(-10.3 \pm 17.1 \mu \mathrm{Vs})$ for the $\mathrm{T}_{\text {area }}$. The latter indicates a small underestimation by the Kors-VCG method compared to the Frank-VCG values. 
A

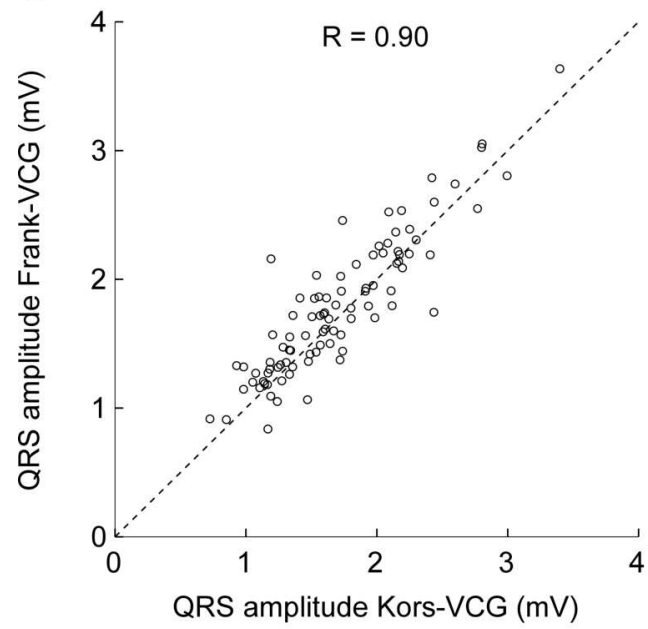

B

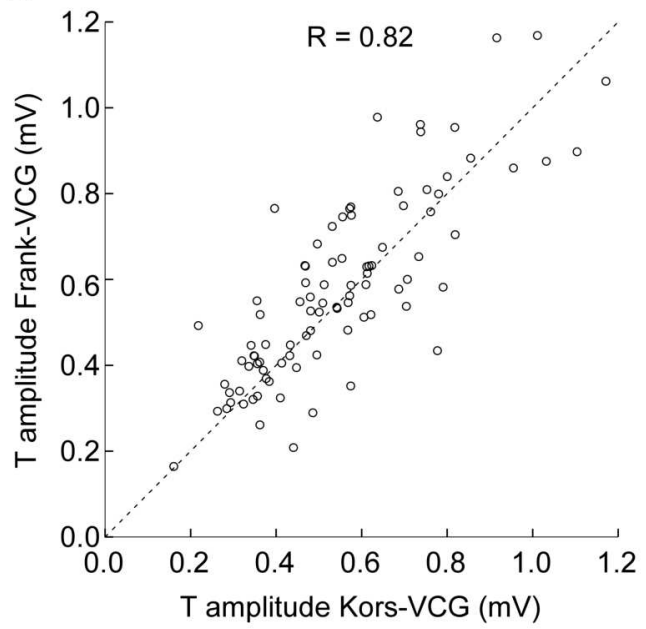

C

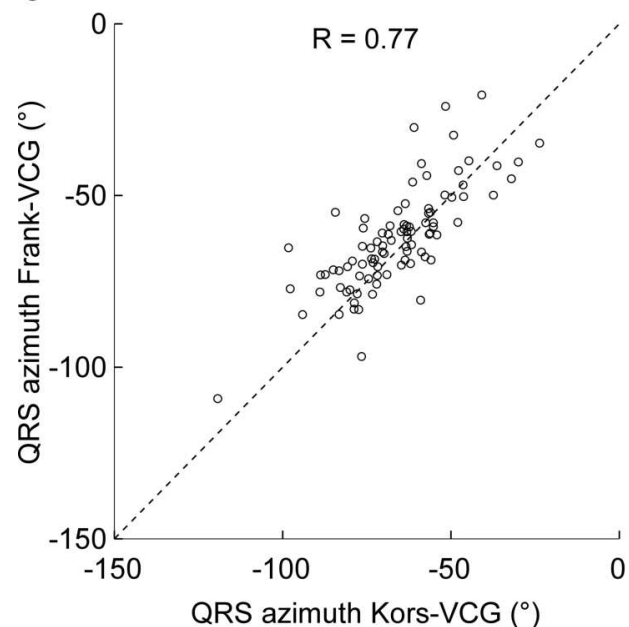

D

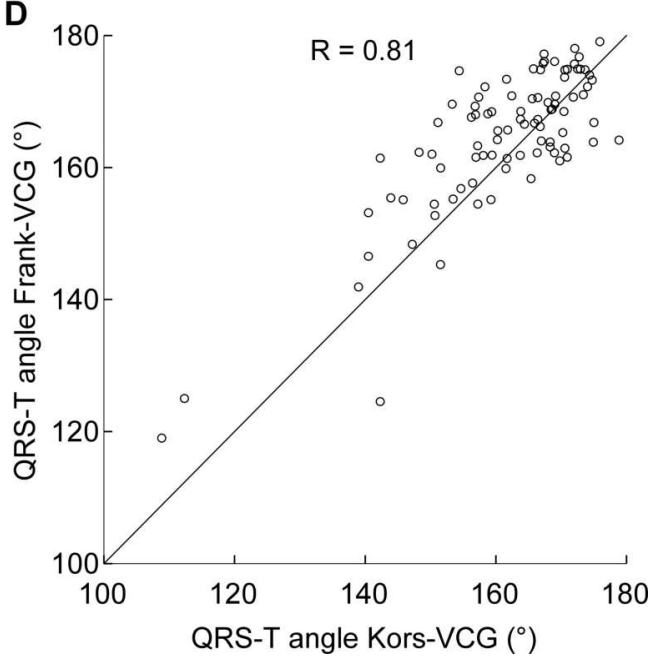

Figure 3.2: Scatter plots of different VCG variables as derived from either the Kors-VCG (x-axis) or the Frank-VCG (y-axis). The dotted line represents the line of identity. Figure (A) displays the QRS amplitude, (B) T amplitude, (C) QRS azimuth, and (D) QRS-T angle.

Table 3.2 shows the various indices calculated from the Frank- and Kors-VCG analysis and results from the Bland-Altman analysis. The values of most indices differed significantly between the two VCG methods when using paired t-test analysis, but absolute differences were small. The largest difference was seen for the $\mathrm{T}_{\text {area }}$, where the Kors method showed an underestimation of the $\mathrm{T}_{\text {area }}$ with a large variability, as evidenced by the $95 \% \mathrm{LoA}(-44 \mu \mathrm{Vs}$ to $23 \mu \mathrm{Vs})$ and relative LoA ( $-51 \%$ to $26 \%)$. This resulted in a relative bias of $(-9.4 \pm 20.8 \%)$. Most other VCG-variables showed relative biases below $10 \%$, the smallest one being for the 

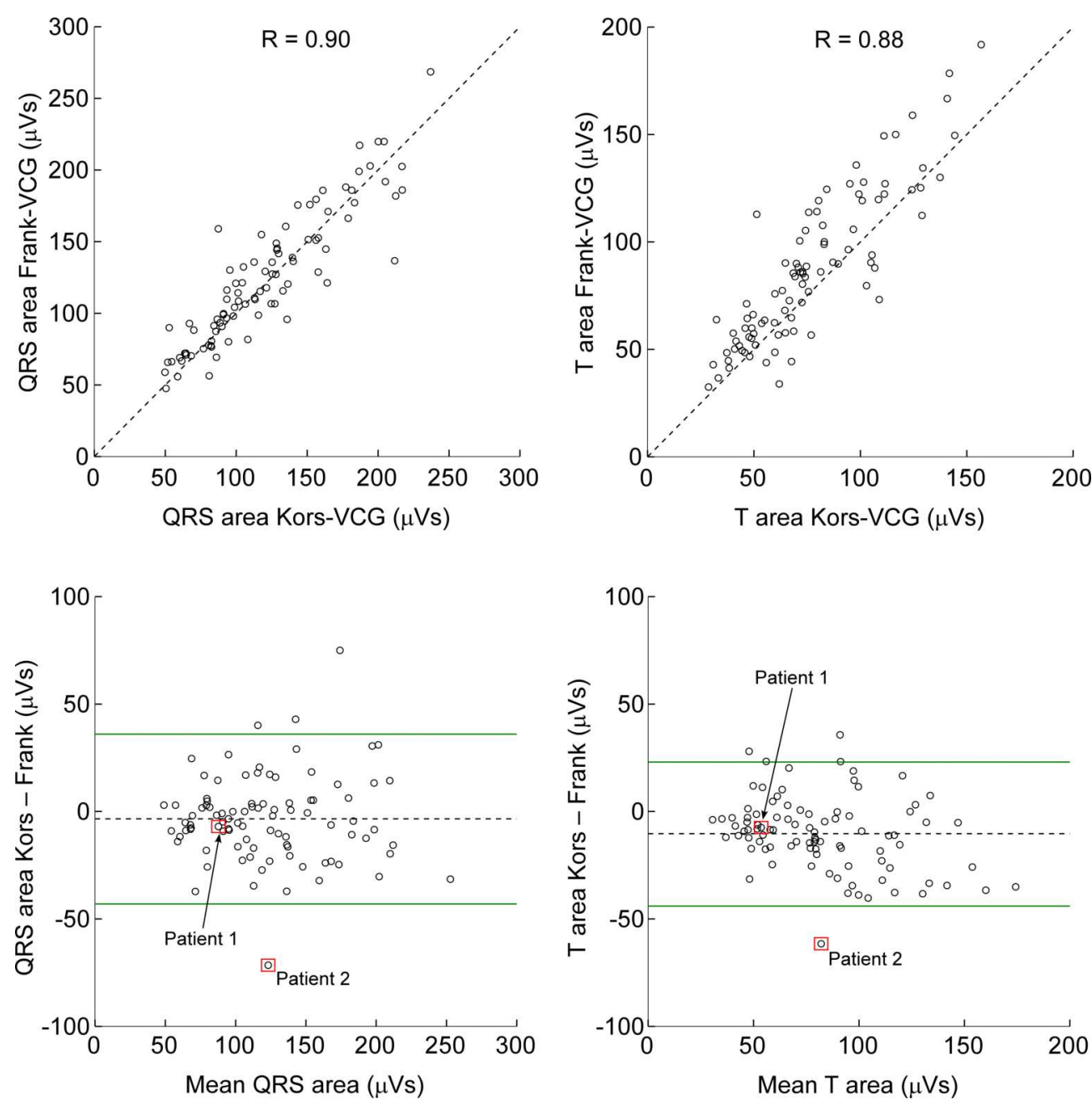

Figure 3.3: The two figures on top show the correlation between the Kors-VCG and Frank-VCG for either the $\mathrm{QRS}_{\text {area }}$ (left) or the $\mathrm{T}_{\text {area }}$ (right). The corresponding Bland-Altman figures are shown at the bottom. The red squares indicate the patients that are shown in Fig. 3.1.

QRS-T angle (-1.9 $\pm 4.6 \%)$. Finally, correlation coefficients of all different variables between the Frank-VCG and the Kors-VCG ranged from 0.77 to 0.90 , and were all significant with a $\mathrm{P}<0.01$. 
Table 3.2: Mean values from Frank- and Kors-VCG analysis for different variables are shown. In addition, the bias, relative bias, $95 \%$ limits of agreement, relative limits of agreement, and the Pearson correlation coefficient $(\mathrm{R})$ are given. The relative parameters are compared to the Frank-VCG.

\begin{tabular}{|c|c|c|c|c|c|c|c|}
\hline VCG variable & $\begin{array}{c}\text { Frank- } \\
\text { VCG }\end{array}$ & $\begin{array}{l}\text { Kors- } \\
\text { VCG }\end{array}$ & Bias & $\begin{array}{l}\text { Relative } \\
\text { bias }(\%)\end{array}$ & $95 \%$ LoA & $\begin{array}{l}\text { Relative } \\
\text { LoA }(\%)\end{array}$ & $\mathrm{R}$ \\
\hline QRS amplitude (mV) & $1.8 \pm 0.5$ & $1.7 \pm 0.5^{\dagger}$ & $-0.1 \pm 0.2$ & $-3.4 \pm 14.1$ & -0.5 to 0.3 & -28 to 17 & 0.90 \\
\hline QRS elevation $\left(^{\circ}\right)$ & $88 \pm 18$ & $80 \pm 16^{\dagger}$ & $-7.8 \pm 8.6$ & $-8.2 \pm 9.2$ & -25 to 9 & -28 to 10 & 0.88 \\
\hline QRS azimuth $\left({ }^{\circ}\right)$ & $-63 \pm 15$ & $-66 \pm 16^{\dagger}$ & $-3.5 \pm 10.3$ & $8.0 \pm 24.3$ & -24 to 17 & -27 to 38 & 0.77 \\
\hline $\mathrm{QRS}_{\text {area }}(\mu \mathrm{Vs})$ & $124 \pm 46$ & $121 \pm 46$ & $-3.4 \pm 20.2$ & $-2.0 \pm 16.6$ & -43 to 36 & -35 to 29 & 0.90 \\
\hline $\mathrm{T}$ amplitude $(\mathrm{mV})$ & $0.6 \pm 0.2$ & $0.5 \pm 0.2^{\star}$ & $-0.03 \pm 0.13$ & $-1.8 \pm 25.0$ & -0.3 to 0.2 & -50 to 33 & 0.82 \\
\hline $\mathrm{T}$ elevation $\left({ }^{\circ}\right)$ & $88 \pm 14$ & $93 \pm 15^{\dagger}$ & $5.1 \pm 9.1$ & $6.6 \pm 15.6$ & -13 to 23 & -15 to 26 & 0.81 \\
\hline T azimuth $\left({ }^{\circ}\right)$ & $112 \pm 15$ & $106 \pm 18^{\dagger}$ & $-6.3 \pm 10.6$ & $-5.7 \pm 9.6$ & -27 to 14 & -24 to 13 & 0.81 \\
\hline $\mathrm{T}_{\text {area }}(\mu \mathrm{Vs})$ & $87 \pm 35$ & $77 \pm 30^{\dagger}$ & $-10.3 \pm 17.1$ & $-9.4 \pm 20.8$ & -44 to 23 & -51 to 26 & 0.88 \\
\hline QRS-T angle $\left({ }^{\circ}\right)$ & $165 \pm 11$ & $161 \pm 12^{\dagger}$ & $-3.1 \pm 7.2$ & $-1.9 \pm 4.6$ & -17 to 11 & -10 to 7 & 0.81 \\
\hline
\end{tabular}

LoA: Limits of agreement.

${ }^{\star} \mathrm{P}$-value $<0.05$ compared to Frank-VCG using the paired t-test.

${ }^{\dagger} \mathrm{P}$-value $<0.01$ compared to Frank-VCG using the paired t-test.

\subsection{Discussion}

This study shows a good resemblance between the recorded Frank-VCG and the Kors-VCG in patients with left ventricular conduction abnormalities. Also variables calculated from the Frank-VCG and the Kors-VCG method showed good correspondence.

\subsubsection{Good resemblance between Kors-VCG and Frank-VCG}

This report illustrates many similarities between the Kors-VCG and the recorded Frank-VCG in patients with ventricular conduction abnormalities who are candidate for CRT. These findings are in line with an earlier comparison between these two methods in healthy individuals and in patients with narrow QRS complex ${ }^{8}$, as well as studies comparing only the QRS-T angle computed using these two methods in different patient populations. ${ }^{5,7,9}$ In these articles, the recorded Frank-VCG is compared to both the Kors method and the inverse Dower method $^{19}$, resulting in the superiority of the Kors method. Although not shown here, for the current patient population the Kors method also performed better than the inverse Dower. Comparing the Frank-VCG with the inverse Dower VCG resulted in correlation coefficients ranging from 0.52 to 0.84 , while these ranged from 0.77 to 0.90 for the Kors method.

Although statistically significant, absolute differences between the Frank-VCG and KorsVCG derived variables were small and when calculating the bias using the Bland-Altman analysis, no relative bias was larger than $10 \%$. The differences in values between the two methods were small enough that they would not influence diagnosis or therapy predictions. For instance, a QRS elevation and azimuth found to be $88^{\circ}$ and $-63^{\circ}$, respectively, in the 
Frank-VCG and $80^{\circ}$ and $-66^{\circ}$ in the Kors-VCG is in both cases pointing left posteriorly and slightly downward. Also, in previous studies we showed that the $\mathrm{QRS}_{\text {area }}{ }^{13}$ and the $\mathrm{T}_{\text {area }}{ }^{12}$ are predictors for CRT response. For example, patients with a $\mathrm{QRS}_{\text {area }}$ larger than $98 \mu \mathrm{Vs}$ have better odds for CRT response. ${ }^{13}$ Adjusting this cut-off value for the bias found for the KorsVCG in the present study and applying it to the subset of patients with a known response status according to their echocardiogram $(n=68)$, there would be 2 extra false positive cases and 5 extra false negative cases compared to Frank-VCG predictions (Fig. 3.4). Two of these false negative cases were borderline predicted as non-responders according to the Kors-VCG, while 2 others were borderline predicted as responders according to the Frank-VCG. This indicates that in $90 \%$ of the patients the small differences between the two methods would not lead to clinically different predictions.

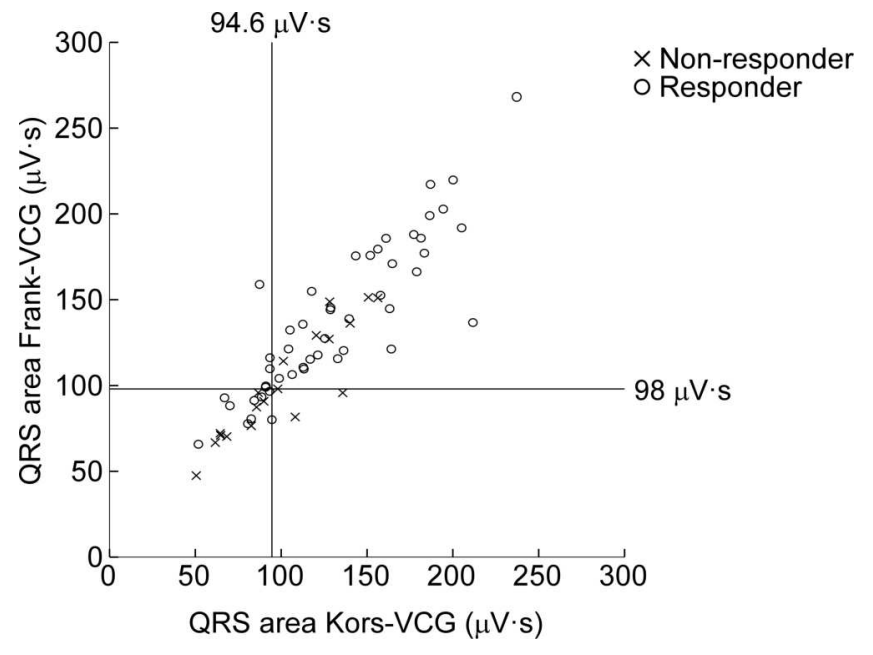

Figure 3.4: Similar figure as the top left figure in Fig. 3.3, but including only patients with available echocardiographic data. Indicated are the optimal Frank-VCG derived $\mathrm{QRS}_{\text {area }}$ threshold to distinguish CRT responders from non-responders found by van Deursen et al. ${ }^{13}$ (98 $\mu \mathrm{Vs}$ ) as well as the bias-corrected Kors-VCG threshold (94.6 $\mu \mathrm{Vs})$. The CRT responders are indicated by circles and the non-responders by crosses.

There are several explanations for the small differences between the Frank-VCG and the Kors-VCG, made up by bias or variability, in the variables obtained by both methods. A first source of variability may have been introduced by the fact that for some patients $(n=25)$ the 12-lead ECG and VCG were recorded on different days. This may have led to differences due to a different physiological state of the patient as well as differences in placement of part of the ECG vs. VCG electrodes. Five of the Frank electrodes need to be positioned at the level of the fifth intercostal space ${ }^{4}$, the same position holds for the electrodes used to measure lead $\mathrm{V}_{4}$ and $\mathrm{V}_{6}$. Differences in electrode position might result in different amplitudes as well as 
directions of the loops. ${ }^{20,21}$ Secondly, the Frank-VCGs were averaged over 1 minute, while the 12-lead ECG only contains 10 seconds of a recording. This allows less averaging for the Kors-method, leading to a lower signal-to-noise ratio.

\subsubsection{Potential Clinical Implications}

The concordance between the Frank-VCG and Kors-VCG in patients with LV conduction delay supports the use of the Kors-VCG method. This method avoids the need for special equipment to record the VCG, while the extra information from the VCG is still obtained. Using this method, every 12-lead ECG recording that measured the eight independent leads simultaneously or that includes a running lead during a stable RR interval (multiplexed ECG) could be used to synthesize a VCG. It should be noted that there are some limitations to the use of a multiplexed ECG. First, the calculation of an averaged heartbeat is often hampered by the fact that only 1 or 2 complete heartbeats are present per lead, this might lead to a lower signal-to-noise ratio. Furthermore, because of the limited amount of heartbeats per lead, the computation of a VCG is impossible if too much premature ventricular contractions or other artifacts are present. Therefore, it would be preferable to save the digital recording of the 12-lead ECG or to save a PDF with a parallel display of the eight independent leads I, II, and $\mathrm{V}_{1}-\mathrm{V}_{6}$. Use of the synthesized VCG might result in a better diagnosis or treatment plan for the patient. Moreover, VCGs can be reconstructed from already existing ECGs, using the method to extract the digital signal out of PDF-files generated by the ECG recording systems.

\subsection{Conclusions}

In patients with heart failure and LV conduction delay who are candidate for CRT, the FrankVCG and the Kors-VCG show a good resemblance. Furthermore, the Kors-VCG method avoids the need for special recording equipment, while the extra information from the VCG is still obtained. The Kors-VCG enables retrospective as well as prospective VCG analysis of routinely recorded 12-lead ECGs in studies related to CRT.

\subsection{Funding}

This research was performed within the framework of CTMM (Center for Translational Molecular Medicine; www.ctmm.nl), Project COHFAR (Congestive Heart Failure and Arrhythmia; Grant 01C-203), and supported by the Dutch Heart Foundation. 


\section{References}

1. HB Willams. On the cause of the phase difference frequently observed between homonymous peaks of the electrocardiogram. Am. J. Physiol. (1914) 35:292-300.

2. HC Burger, A van Brummelen, and van Herpen. Heartvector and leads. Am Heart J (1961) 61:317-323.

3. OH Schmitt and E Simonson. The present status of vectorcardiography. AMA Arch Intern Med (1955) 96:574-590.

4. E Frank. An accurate, clinically practical system for spatial vectorcardiography. Circulation (1956) 13:737-749.

5. S Man, AM Algra, CA Schreurs, CJW Borleffs, RWC Scherptong, L van Erven, EE van der Wall, SC Cannegieter, MJ Schalij, and CA Swenne. Influence of the vectorcardiogram synthesis matrix on the power of the electrocardiogram-derived spatial QRS-T angle to predict arrhythmias in patients with ischemic heart disease and systolic left ventricular dysfunction. J Electrocardiol (2011) 44:410-415.

6. L Edenbrandt, A Houston, and PW Macfarlane. Vectorcardiograms synthesized from 12-lead ECGs: a new method applied in 1792 healthy children. Pediatr Cardiol (1994) 15:21-26.

7. DL Cortez and TT Schlegel. When deriving the spatial QRS-T angle from the 12-lead electrocardiogram, which transform is more Frank: regression or inverse Dower? $J$ Electrocardiol (2010) 43:302-309.

8. JA Kors, G van Herpen, AC Sittig, and JH van Bemmel. Reconstruction of the Frank vectorcardiogram from standard electrocardiographic leads: diagnostic comparison of different methods. Eur Heart J (1990) 11:1083-1092.

9. CA Schreurs, AM Algra, SC Man, SC Cannegieter, EE van der Wall, MJ Schalij, JA Kors, and CA Swenne. The spatial QRS-T angle in the Frank vectorcardiogram: accuracy of estimates derived from the 12-lead electrocardiogram. J Electrocardiol (2010) 43:294-301.

10. WT Abraham, WG Fisher, AL Smith, DB Delurgio, AR Leon, E Loh, DZ Kocovic, M Packer, AL Clavell, DL Hayes, et al. Cardiac resynchronization in chronic heart failure. N Engl J Med (2002) 346:1845-1853.

11. European Heart Rhythm Association, European Society of Cardiology, Heart Rhythm Society, Heart Failure Society of America, American Society of Echocardiography, 
American Heart Association, European Association of Echocardiography, Heart Failure Association, JC Daubert, L Saxon, et al. 2012 EHRA/HRS expert consensus statement on cardiac resynchronization therapy in heart failure: implant and follow-up recommendations and management. Heart Rhythm (2012) 9:1524-1576.

12. EB Engels, EM Végh, CJM Van Deursen, K Vernooy, JP Singh, and FW Prinzen. Twave area predicts response to cardiac resynchronization therapy in patients with left bundle branch block. J Cardiovasc Electrophysiol (2015) 26:176-183.

13. CJM van Deursen, K Vernooy, E Dudink, L Bergfeldt, HJGM Crijns, FW Prinzen, and L Wecke. Vectorcardiographic QRS area as a novel predictor of response to cardiac resynchronization therapy. J Electrocardiol (2015) 48:45-52.

14. CJM van Deursen, M Strik, LM Rademakers, A van Hunnik, M Kuiper, L Wecke, HJGM Crijns, K Vernooy, and FW Prinzen. Vectorcardiography as a tool for easy optimization of cardiac resynchronization therapy in canine left bundle branch block hearts. Circ Arrhythm Electrophysiol (2012) 5:544-552.

15. L Wecke, A Rubulis, G Lundahl, MR Rosen, and L Bergfeldt. Right ventricular pacinginduced electrophysiological remodeling in the human heart and its relationship to cardiac memory. Heart Rhythm (2007) 4:1477-1486.

16. L Wecke, F Gadler, C Linde, G Lundahl, MR Rosen, and L Bergfeldt. Temporal characteristics of cardiac memory in humans: vectorcardiographic quantification in a model of cardiac pacing. Heart Rhythm (2005) 2:28-34.

17. DG Strauss, RH Selvester, and GS Wagner. Defining left bundle branch block in the era of cardiac resynchronization therapy. Am J Cardiol (2011) 107:927-934.

18. GL Botto, CD Dicandia, M Mantica, C La Rosa, A D’Onofrio, MG Bongiorni, G Molon, R Verlato, GQ Villani, A Scaccia, G Raciti, and E Occhetta. Clinical characteristics, mortality, cardiac hospitalization, and ventricular arrhythmias in patients undergoing CRT-D implantation: results of the ACTION-HF study. J Cardiovasc Electrophysiol (2013) 24:173-181.

19. L Edenbrandt and O Pahlm. Vectorcardiogram synthesized from a 12-lead ECG: superiority of the inverse Dower matrix. J Electrocardiol (1988) 21:361-367.

20. M Kania, H Rix, M Fereniec, H Zavala-Fernandez, D Janusek, T Mroczka, G Stix, and $\mathrm{R}$ Maniewski. The effect of precordial lead displacement on ECG morphology. Med Biol Eng Comput (2014) 52:109-119.

21. RR Bond, DD Finlay, CD Nugent, C Breen, D Guldenring, and MJ Daly. The effects of electrode misplacement on clinicians' interpretation of the standard 12-lead electrocardiogram. Eur J Intern Med (2012) 23:610-615. 



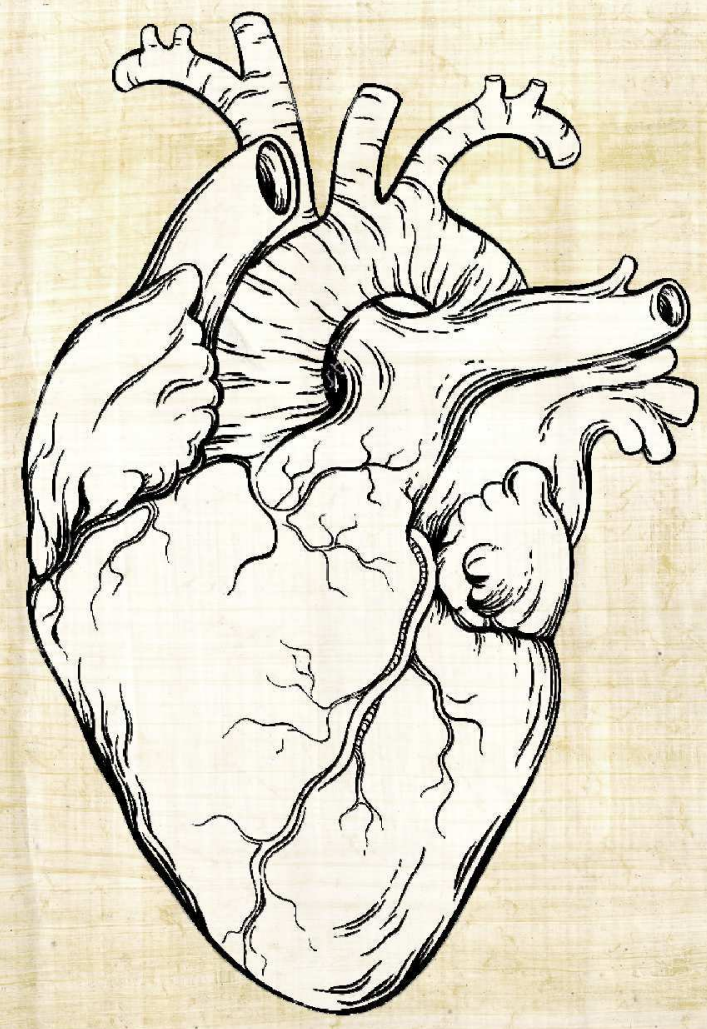




\section{Chapter}

\section{Electrical remodeling in patients with iatrogenic left bundle branch block}

The content of this chapter is based on:

Elien B. Engels, ${ }^{1}$ Thomas T. Poels, ${ }^{2}$ Patrick Houthuizén, ${ }^{3}$ Peter P.T. de Jaegere, ${ }^{4}$ Jos G. Maessen, ${ }^{2}$ Kevin Vernooy, ${ }^{5}$ and Frits W. Prinzen ${ }^{1}$ (2016).

Electrical remodeling in patients with iatrogenic left bundle branch block. Revision under review for Europace.

\footnotetext{
${ }^{1}$ Department of Physiology, CARIM School for Cardiovascular Diseases, Maastricht University, Maastricht, the Netherlands.

${ }^{2}$ Department of Cardiothoracic Surgery, Maastricht University Medical Center, Maastricht, the Netherlands.

${ }^{3}$ Department of Cardiothoracic Surgery, Catharina Hospital, Eindhoven, the Netherlands.

${ }^{4}$ Department of Cardiology, Erasmus Medical Center, Rotterdam, the Netherlands.

${ }^{5}$ Department of Cardiology, Maastricht University Medical Center, Maastricht, the Netherlands.
} 


\section{Abstract}

Introduction: Left bundle branch block (LBBB) is induced in approximately one third of all transcatheter aortic valve implantation (TAVI) procedures. We investigated electrophysiological remodeling in patients with TAVI-induced LBBB.

Methods and Results: This retrospective study comprises 107 patients with initially narrow QRS complex of whom 40 did not and 67 did develop persistent LBBB after TAVI. 12-lead electrocardiograms (ECGs) taken before TAVI, within 24 hours ('acute'), and 1-12 months after TAVI ('chronic') were used to reconstruct vectorcardiograms. From these vectorcardiograms, $\mathrm{QRS}_{\text {area }}$ and $\mathrm{T}_{\text {area }}$ were calculated as comprehensive indices of depolarization and repolarization abnormalities, respectively. TAVI-induced LBBB resulted in significant acute depolarization and repolarization changes while further repolarization changes were observed with longer lasting LBBB. The amount of long-term repolarization changes (remodeling) was highly variable between patients. The change in $\mathrm{T}_{\text {area }}$ between acute and chronic LBBB ranged from $+57 \%$ to $-77 \%$. After dividing the LBBB cohort into tertiles based on the change in $\mathrm{T}_{\text {area }}$, only baseline $\mathrm{QRS}_{\text {area }}$ was larger in the tertile with no significant change in $\mathrm{T}_{\text {area }}$. During longer lasting LBBB the spatial ventricular gradient (SVG) changed orientation towards the direction of the QRS-vector, indicating that later-activated regions developed shorter action potential duration.

Conclusions: This study in patients with TAVI-induced LBBB shows that repolarization changes develop within months after onset of LBBB, and that these changes are highly variable between individual patients. 


\subsection{Introduction}

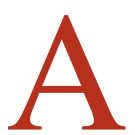

PPROXIMATELY $25 \%$ of patients with heart failure (HF) are diagnosed with left bundle branch block (LBBB). ${ }^{1}$ LBBB is associated with an increased risk of cardiovascu-

lar morbidity and mortality and it may thus be a marker for progressive, degenerative cardiac disease. ${ }^{2}$ Furthermore, animal experiments have shown that induction of LBBB induces a rapid reduction of cardiac pump function and cardiac remodeling on the long run. ${ }^{3}$ Experimental dyssynchronous heart failure, induced by a combination of LBBB and rapid pacing, causes extensive molecular and cellular remodeling in dyssynchronous heart failure, including up- and down regulation of various ion channels and even loss of sarcoplasmic reticulum. ${ }^{4,5}$ However, it is still not well known in which way the human heart adapts to the presence of $\mathrm{LBBB}$, partly because LBBB usually develops silently, so that the duration of LBBB in a patient is usually not known.

Besides LBBB, also right ventricular pacing creates dyssynchrony. Since the onset of pacing is known, some information about the natural history of dyssynchrony has been derived from pacemaker studies. ${ }^{6,7}$ In patients, electrical remodeling was characterized by a reduction of the T-wave amplitude, the main reduction occurring within several weeks of pacing (cardiac memory).

New insight in the natural history of LBBB may be achieved by investigating patients that develop LBBB during a transcatheter aortic valve implantation (TAVI) procedure. TAVI is a relatively new, less invasive treatment for severe, symptomatic aortic stenosis in patients who do not qualify for open chest surgery. In such procedures approximately one third of all patients develops LBBB. ${ }^{8}$

The aim of the present study was to investigate electrical remodeling in patients with LBBB. To this purpose we analyzed the 12-lead electrocardiogram (ECG) and vectorcardiogram (VCG) in patients with TAVI-induced LBBB. The advantage of the VCG is that it contains three-dimensional information of the electrical forces within the heart in one image and might provide more valuable information than the multiple one-dimensional images of a 12-lead ECG. We compared repolarization variables found immediately after TAVI ('acute LBBB') with the same variables during longer lasting LBBB.

\subsection{Methods}

\subsubsection{Study population}

The index patient population consisted of 998 patients who underwent TAVI in the Catharina Hospital Eindhoven, Erasmus Medical Center Rotterdam or Maastricht University Medical Center between January 2006 and April 2014 (Fig. 4.1). From all patients, electrocardiographic measurements were available at baseline, within 24 hours after TAVI (further referred 
to as 'acute'), and one to twelve months after TAVI ('chronic'). Patients were included in the current study if the baseline QRS duration was smaller than $120 \mathrm{~ms}$ and the ECGs recorded at the different time points were stored as PDF-files in order to enable VCG conversion (see below). Exclusion criteria were pre- or postoperative ventricular pacing, the presence of postoperative QRS widening other than LBBB, and/or transient LBBB that was only present postoperative and not at 12 months follow-up. A total of 293 patients were eligible for analysis (Fig. 4.1).

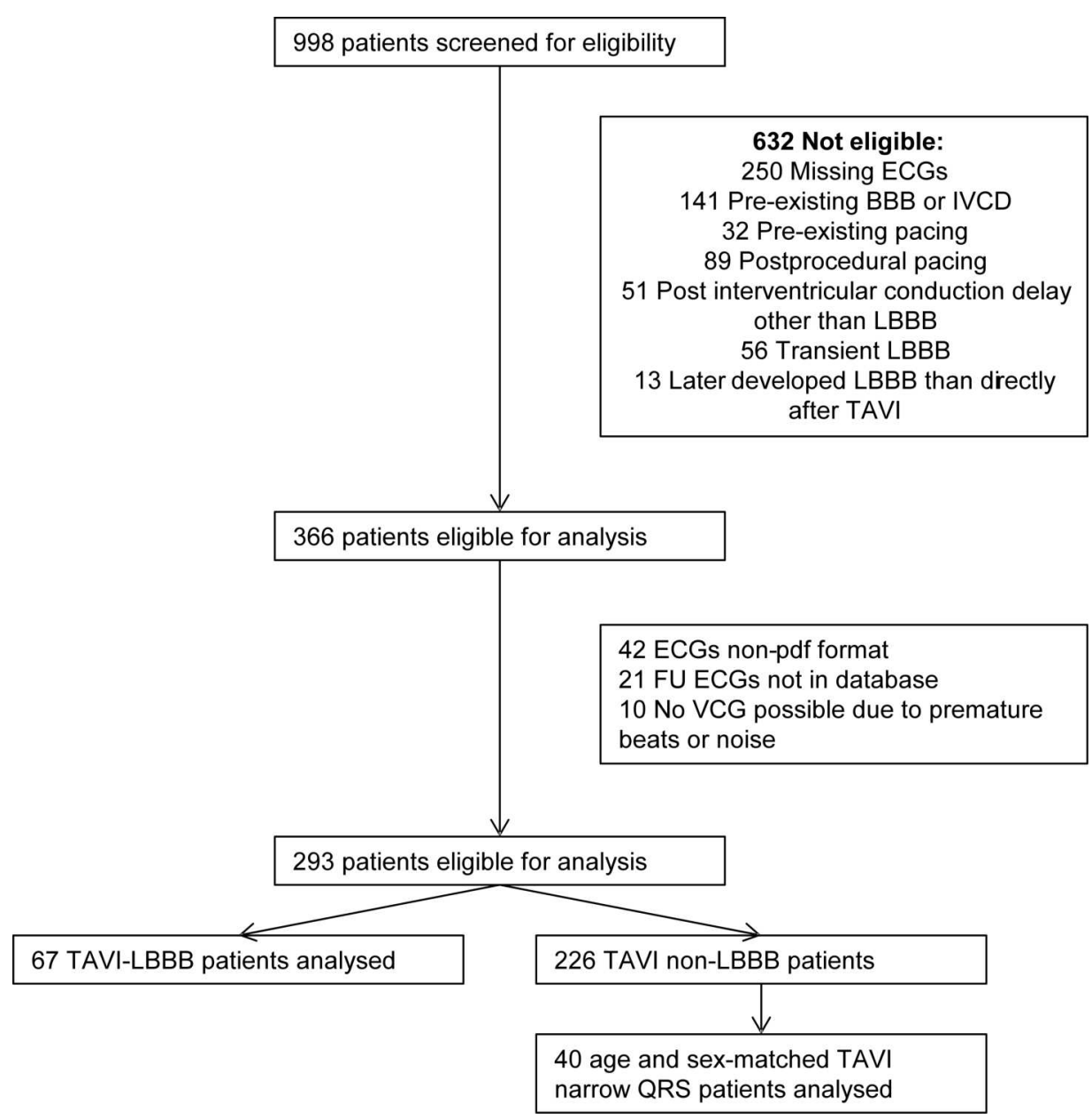

Figure 4.1: Study population selection. LBBB indicated left bundle branch block.

The study population consisted of 67 patients who developed LBBB directly after TAVI (acute LBBB) and had persistent LBBB for at least 12 months after the procedure (chronic LBBB). Out of 226 patients who did not develop LBBB upon TAVI, a group of 40 age and 
sex-matched patients were selected in order to investigate the changes in the electrocardiographic properties due to the TAVI procedure in the absence of LBBB (narrow QRS group). This project was conducted in accordance with the principles of the Declaration of Helsinki.

\subsubsection{ECG and VCG}

The PDF files of all ECGs were semi-automatically analyzed using a custom-made computer program written in MATLAB R2010b (MathWorks, Natick, MA) and were synthesized to VCGs using the Kors method. ${ }^{9}$ Multiple variables were extracted from both the ECG and VCG analysis as described in detail before. ${ }^{10}$ Briefly, QRS duration and QTc interval were defined as the duration between the beginning of the QRS complex and the end of the QRS complex or T-wave, respectively. The maximal QRS- and T-vector were defined as the maximal distance from the origin to any point on the 3-dimensional VCG loop. The maximal vector can be described by its amplitude, azimuth (orientation in the transverse plane), and elevation (orientation in the frontal plane). The QRS/T-amplitude ratio represents the ratio between QRS and T amplitude while the QRS-T angle is the 3D angle between the maximal QRS- and T-vector. The $\mathrm{QRS}_{\text {area }}$ and $\mathrm{T}_{\text {area }}$ are the 'three-dimensional' areas between the curve and the baseline over time for the parts of interest in lead $\mathrm{X}, \mathrm{Y}$, and $\mathrm{Z}$ and are calculated using the

formulas $\mathrm{QRS}_{\text {area }}=\sqrt{\mathrm{QRS}_{\text {area } \mathrm{x}}^{2}+\mathrm{QRS}_{\text {area } \mathrm{y}}^{2}+\mathrm{QRS}_{\text {area } \mathrm{Z}}^{2}}$ or $\mathrm{T}_{\text {area }}=\sqrt{\mathrm{T}_{\text {area } \mathrm{x}}^{2}+\mathrm{T}_{\text {area }, \mathrm{y}}^{2}+\mathrm{T}_{\text {area }, \mathrm{z}}^{2}}$. The vectors composed of the area in the different directions $\mathrm{X}, \mathrm{Y}$, and $\mathrm{Z}$ are called the QRSor T-integral. The vectorial sum of the QRS- and T-integral is represented by the spatial ventricular gradient $(\mathrm{SVG}) .{ }^{11}$

\subsubsection{Statistical analysis}

The statistical analysis was performed using IBM SPSS statistics software version 22 (SPSS Inc, Chicago, IL). Continuous variables are presented as mean \pm standard deviation (SD), and discrete variables as counts (percentage). The comparison between discrete variables was performed using the $\chi^{2}$-test. The Friedman test was used to test whether there were differences in VCG variables at the different time points: 1) baseline (before TAVI), 2) within 24 hours after TAVI, and 3) 1-12 months after TAVI. When the Friedman test showed significant differences, the Wilcoxon signed-rank test with a Bonferroni adjustment was performed to see which time points were different. Possible differences between different patient groups were tested using the Kruskal-Wallis and Wilcoxon rank-sum test with Bonferroni correction consecutively. A two-sided P-value $<0.05$ was considered statistically significant. 


\subsection{Results}

\subsubsection{Patient characteristics}

Baseline characteristics of patients who developed LBBB $(n=67)$ and the group of 40 age and sex-matched patients who did not are summarized in Table 4.1. Almost all patients were septua- and octogenarians with an even gender distribution. Most patients were in NYHA class III and approximately $20 \%$ had a prior myocardial infarction. The QRS duration at baseline as extracted from the VCG was around $110 \mathrm{~ms}$ for both the LBBB group and the narrow QRS group.

Table 4.1: Baseline characteristics of the included LBBB and narrow QRS patients.

\begin{tabular}{lccc}
\hline & $\begin{array}{c}\text { Study population } \\
\mathrm{n}=107\end{array}$ & $\begin{array}{c}\text { Entire LBBB } \\
\mathrm{n}=67\end{array}$ & $\begin{array}{c}\text { Narrow QRS } \\
\mathrm{n}=40\end{array}$ \\
\hline $\begin{array}{l}\text { Demographics } \\
\text { Age (years) }\end{array}$ & $79 \pm 7$ & $79 \pm 6$ & $80 \pm 8$ \\
$\quad$ Male gender (n, \%) & $49(46)$ & $32(48)$ & $17(43)$ \\
Clinical & & & \\
$\quad$ Previous myocardial infarction (n, \%) & $23(22)$ & $14(21)$ & $9(23)$ \\
Diabetes Mellitus (n, \%) & $24(22)$ & $17(25)$ & $7(18)$ \\
CVA (n, \%) & $19(18)$ & $13(19)$ & $6(15)$ \\
CABG (n, \%) & $29(27)$ & $17(25)$ & $12(30)$ \\
NYHA class I/II/III/IV (\%) & $3 / 17 / 68 / 12$ & $3 / 15 / 70 / 12$ & $3 / 20 / 65 / 13$ \\
Electrocardiography & & & \\
QRS duration (ms) & $110 \pm 15$ & $110 \pm 15$ & $110 \pm 13$ \\
QRS axis $\left({ }^{\circ}\right)$ & $19 \pm 30$ & $20 \pm 29$ & $17 \pm 32$ \\
\hline
\end{tabular}

Variables are shown as counts (percentage) or mean \pm standard deviation when appropriate. CVA = cerebrovascular accident; $\mathrm{CABG}=$ coronary artery bypass graft; NYHA $=$ New York Heart Association.

\subsubsection{ECG and VCG changes in narrow QRS patients}

VCG variables of the narrow QRS group did not significantly change between baseline and directly after TAVI (Table 4.2). The depolarization variables showed some minor changes between briefly and 1-12 months after TAVI. QRS-vector amplitude and QRS-area decreased significantly (-12\% and $-16 \%$, respectively) over time while QRS duration did not change significantly. Furthermore, the elevation of the T-vector decreased significantly (Table 4.2).

\subsubsection{ECG and VCG changes in TAVI-induced LBBB patients}

An example of ECG and VCG changes in one patient with TAVI-induced LBBB is shown in Fig. 4.2. From the 12-lead ECG the widening of the QRS complex within 24 hours after TAVI can be observed. Also, the orientation of the maximal QRS-vector changed from pointing to the left before TAVI to pointing posteriorly directly after TAVI, which is expressed by a more 
Table 4.2: Changes in electrocardiographic variables over time in the narrow QRS group. Data are as calculated from the VCG.

\begin{tabular}{|c|c|c|c|c|}
\hline Variable & Baseline & $\begin{array}{l}<24 \text { hours } \\
\text { after TAVI }\end{array}$ & $\begin{array}{c}1-12 \text { months } \\
\text { after TAVI }\end{array}$ & $\begin{array}{l}\text { Friedman } \\
\text { test P-value }\end{array}$ \\
\hline Heart rate (bpm) & $72 \pm 10$ & $76 \pm 14$ & $74 \pm 11$ & 0.30 \\
\hline QRS duration (ms) & $110 \pm 13$ & $107 \pm 13$ & $107 \pm 17$ & 0.08 \\
\hline QTc interval (ms) & $442 \pm 39$ & $461 \pm 57$ & $437 \pm 36^{\dagger}$ & $<0.01$ \\
\hline JTc interval (ms) & $322 \pm 34$ & $341 \pm 57$ & $319 \pm 31^{\dagger}$ & 0.01 \\
\hline QRS-vector amplitude (mV) & $1.9 \pm 0.7$ & $1.8 \pm 0.6$ & $1.5 \pm 0.5^{\star \dagger}$ & $<0.01$ \\
\hline QRS azimuth $\left({ }^{\circ}\right)$ & $-23 \pm 25$ & $-24 \pm 29$ & $-25 \pm 32$ & 0.18 \\
\hline QRS elevation $\left({ }^{\circ}\right)$ & $71 \pm 16$ & $62 \pm 18$ & $69 \pm 23$ & 0.11 \\
\hline $\mathrm{QRS}_{\text {area }}(\mu \mathrm{Vs})$ & $59 \pm 26$ & $57 \pm 25$ & $47 \pm 23^{\star \dagger}$ & $<0.01$ \\
\hline T-vector amplitude (mV) & $0.4 \pm 0.3$ & $0.3 \pm 0.2$ & $0.3 \pm 0.2$ & 0.80 \\
\hline T azimuth $\left({ }^{\circ}\right)$ & $74 \pm 77$ & $47 \pm 103$ & $62 \pm 43$ & 0.34 \\
\hline T elevation $\left({ }^{\circ}\right)$ & $81 \pm 26$ & $85 \pm 31$ & $69 \pm 24^{\dagger}$ & 0.01 \\
\hline $\mathrm{T}_{\text {area }}(\mu \mathrm{Vs})$ & $62 \pm 53$ & $52 \pm 28$ & $44 \pm 22$ & 0.39 \\
\hline QRS/T-amplitude ratio (-) & $6.2 \pm 2.9$ & $5.9 \pm 2.5$ & $5.4 \pm 3.7$ & 0.04 \\
\hline QRS-T angle $\left({ }^{\circ}\right)$ & $104 \pm 52$ & $111 \pm 41$ & $84 \pm 42$ & 0.06 \\
\hline $\mathrm{QRS} / \mathrm{T}$ area ratio (-) & $1.3 \pm 0.9$ & $1.4 \pm 0.9$ & $1.4 \pm 1.0$ & 0.27 \\
\hline SVG amplitude $(\mu \mathrm{Vs})$ & $75 \pm 63$ & $54 \pm 25$ & $62 \pm 29$ & 0.31 \\
\hline SVG azimuth $\left({ }^{\circ}\right)$ & $4 \pm 60$ & $1 \pm 62$ & $12 \pm 37$ & 0.27 \\
\hline SVG elevation $\left(^{\circ}\right)$ & $70 \pm 29$ & $64 \pm 28$ & $62 \pm 15$ & 0.43 \\
\hline
\end{tabular}

Variables are shown as mean \pm standard deviation. SVG $=$ spatial ventricular gradient.

${ }^{\star} \mathrm{P}$ value $<0.05$ compared to baseline, calculated using the Wilcoxon signed rank test.

${ }^{\dagger} \mathrm{P}$ value $<0.05$ compared to $<24$ hours after TAVI, calculated using the Wilcoxon signed rank test.

negative QRS azimuth. In addition, both the ECG and VCG show an increased T-wave size during acute LBBB (Fig. 4.2). Between acute and chronic LBBB minor changes in the QRS complex and QRS loop were observed and also the direction of the T-vector did not change. In contrast, the size of the T-wave loop and the $\mathrm{T}_{\text {area }}$, decreased over time (Fig. 4.2).

For the entire cohort of LBBB patients, development of LBBB during TAVI caused significant increases in QRS duration and QTc interval (Table 4.3) as well as more than doubling of $\mathrm{T}_{\text {area }}, \mathrm{T}_{\text {area }}$ and the T-vector amplitude. LBBB significantly decreased the QRS azimuth by about $40^{\circ}$ while it did not change the direction of the T-wave. As a consequence, the QRS-T angle increased from $100^{\circ}$ to $155^{\circ}$ (Table 4.3), consistent with the characteristic discordant T-wave in LBBB. However, the SVG did not change significantly in either size or direction in the acute stage.

Between acute and chronic LBBB, no significant changes were observed in depolarization variables such as QRS duration, QRS-vector amplitude, QRS-vector direction, or $\mathrm{QRS}_{\text {area }}$ (Table 4.3). In contrast, all repolarization variables, such as the QTc interval, T-vector amplitude, and $\mathrm{T}_{\text {area }}$, decreased significantly. Accordingly, the QRS/T amplitude ratio increased significantly during longer lasting LBBB. These repolarization changes were not associated with any significant change in direction of the T-vector (azimuth and elevation) and QRS-T angle. However, the azimuth of the SVG decreased significantly to negative values, becoming 


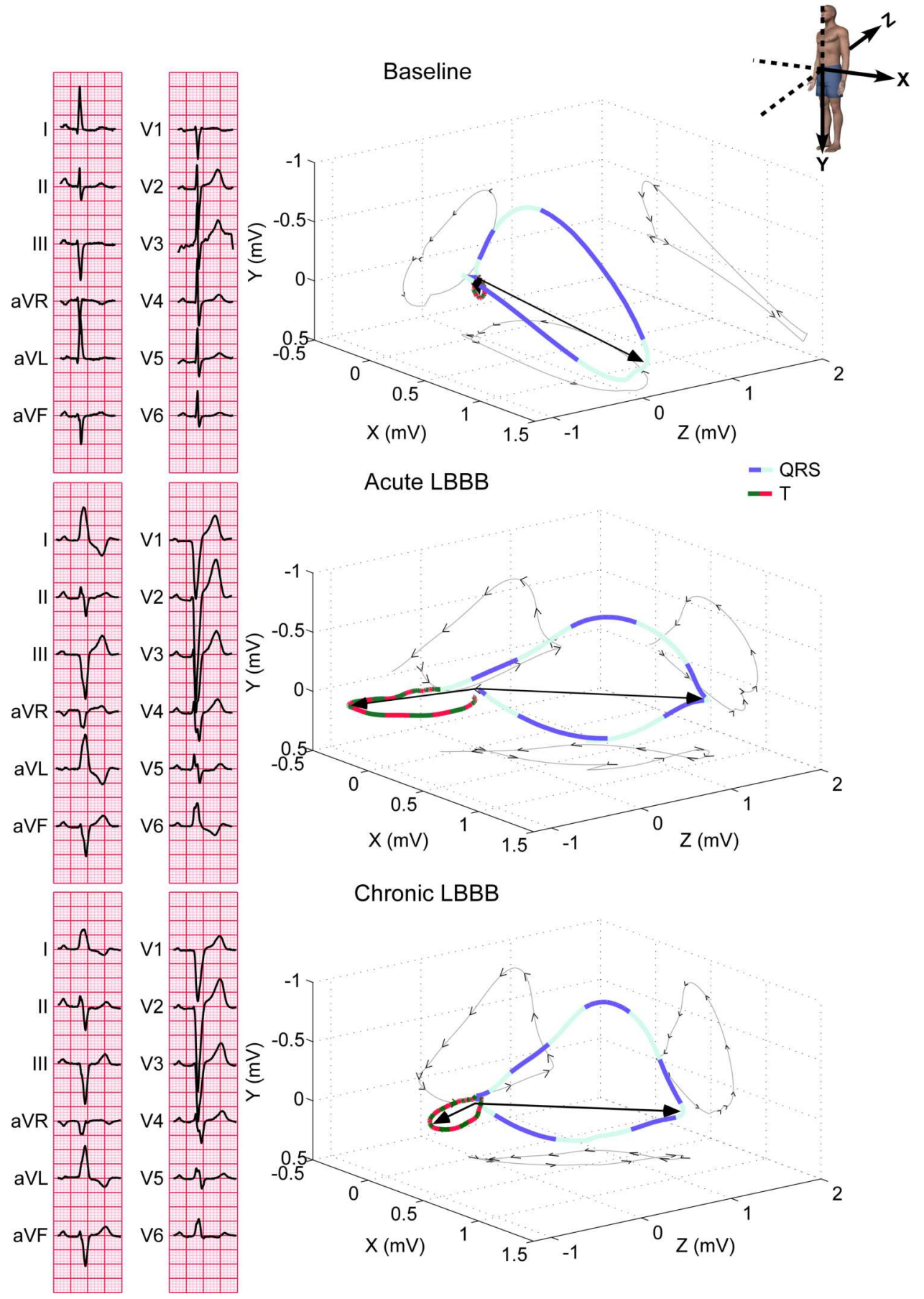

Figure 4.2: Typical example of one patient undergoing TAVI and developing LBBB. From top to bottom the 12-lead ECG (left) and 3D VCG (right) at baseline, within 24 hours after TAVI and 12 months after TAVI are shown. The black arrows in the 3D-VCG image indicate the maximal QRS- and T-vector. 
Table 4.3: Changes in electrocardiographic variables over time in the LBBB group. The first columns shows the results of the electrocardiographic measurements performed before TAVI, the second column within 24 hours after TAVI, the third column represents the results between one and twelve months after TAVI, and the last column represents the P-value of the Friedman test. Data are as calculated from the VCG.

\begin{tabular}{|c|c|c|c|c|}
\hline Variable & Baseline & $\begin{array}{l}<24 \text { hours } \\
\text { after TAVI }\end{array}$ & $\begin{array}{c}1-12 \text { months } \\
\text { after TAVI }\end{array}$ & $\begin{array}{l}\text { Friedman } \\
\text { test P-value }\end{array}$ \\
\hline Heart rate (bpm) & $71 \pm 11$ & $77 \pm 14^{\star}$ & $78 \pm 17^{\star}$ & 0.02 \\
\hline QRS duration (ms) & $109 \pm 15$ & $159 \pm 22^{\star}$ & $159 \pm 20^{\star}$ & $<0.01$ \\
\hline QTc interval (ms) & $448 \pm 48$ & $520 \pm 56^{\star}$ & $488 \pm 51^{\star \dagger}$ & $<0.01$ \\
\hline JTc interval (ms) & $329 \pm 38$ & $341 \pm 40$ & $307 \pm 39^{\star \dagger}$ & $<0.01$ \\
\hline QRS-vector amplitude (mV) & $1.7 \pm 0.5$ & $1.7 \pm 0.5$ & $1.7 \pm 0.4$ & 0.53 \\
\hline QRS azimuth $\left({ }^{\circ}\right)$ & $-26 \pm 28$ & $-70 \pm 15^{\star}$ & $-67 \pm 18^{\star}$ & $<0.01$ \\
\hline QRS elevation $\left({ }^{\circ}\right)$ & $71 \pm 18$ & $80 \pm 16^{\star}$ & $80 \pm 16^{\star}$ & 0.01 \\
\hline $\mathrm{QRS}_{\text {area }}(\mu \mathrm{Vs})$ & $54 \pm 21$ & $114 \pm 37^{\star}$ & $113 \pm 35^{\star}$ & $<0.01$ \\
\hline T-vector amplitude $(\mathrm{mV})$ & $0.4 \pm 0.2$ & $0.8 \pm 0.2^{\star}$ & $0.6 \pm 0.2^{\star \dagger}$ & $<0.01$ \\
\hline T azimuth $\left(^{\circ}\right)$ & $81 \pm 63$ & $99 \pm 22$ & $100 \pm 19$ & 0.40 \\
\hline T elevation $\left(^{\circ}\right)$ & $80 \pm 26$ & $85 \pm 19$ & $85 \pm 17$ & 0.19 \\
\hline $\mathrm{T}_{\text {area }}(\mu \mathrm{Vs})$ & $56 \pm 40$ & $124 \pm 43^{\star}$ & $84 \pm 34^{\star \dagger}$ & $<0.01$ \\
\hline QRS/T-amplitude ratio (-) & $5.3 \pm 2.3$ & $2.3 \pm 0.5^{\star}$ & $3.1 \pm 1.1^{\star \dagger}$ & $<0.01$ \\
\hline QRS-T angle $\left({ }^{\circ}\right)$ & $108 \pm 43$ & $156 \pm 14^{\star}$ & $156 \pm 14^{\star}$ & $<0.01$ \\
\hline QRS/T area ratio (-) & $1.2 \pm 0.6$ & $1.0 \pm 0.3^{\star}$ & $1.5 \pm 0.5^{\dagger}$ & $<0.01$ \\
\hline SVG amplitude ( $\mu \mathrm{Vs})$ & $62 \pm 40$ & $64 \pm 35$ & $59 \pm 26$ & 0.04 \\
\hline SVG azimuth $\left({ }^{\circ}\right)$ & $6 \pm 63$ & $8 \pm 65$ & $-29 \pm 38^{\star \dagger}$ & $<0.01$ \\
\hline SVG elevation $\left({ }^{\circ}\right)$ & $68 \pm 32$ & $62 \pm 25$ & $69 \pm 23$ & 0.15 \\
\hline
\end{tabular}

Variables are shown as mean \pm standard deviation. $\mathrm{SVG}=$ spatial ventricular gradient.

${ }^{\star} \mathrm{P}$ value $<0.05$ compared to baseline, calculated using the Wilcoxon signed rank test.

${ }^{\dagger} \mathrm{P}$ value $<0.05$ compared to acute LBBB, calculated using the Wilcoxon signed rank test.

directed more towards the QRS azimuth.

\subsubsection{Individual repolarization changes}

While the LBBB cohort showed a significant decrease in repolarization variables with longer lasting $\mathrm{LBBB}$, especially expressed by a clear reduction in the $\mathrm{T}_{\text {area }}$, these changes were highly variable between individual LBBB patients (Fig. 4.3). The size of these changes was not dependent of the time-point at which the chronic LBBB VCG was measured (Fig. 4.3, right panel). In order to further explore the variability in T-wave remodeling, the LBBB cohort was divided in tertiles, based on the relative changes in $\mathrm{T}_{\text {area }}$. Naturally, Tertile 1 showed no significant change in $\mathrm{T}_{\text {area }}(\mathrm{red}, \mathrm{n}=22$ ). In contrast, tertile 2 (black, $\mathrm{n}=23$ ) and tertile 3 (blue, $\mathrm{n}=22$ ) showed an averaged reduction of $32 \%$ and $58 \%$ reduction in $\mathrm{T}_{\text {area }}$, respectively. The only observed difference between the three groups at baseline, specifically between tertile 1 and 3, was a significantly smaller QRS $_{\text {area }}$ in tertile 3 (Fig. 4.4). None of the other VCG variables or variables mentioned in Table 4.1 showed a significant difference between tertiles. During acute LBBB, the only differences observed between tertile 1 and 3 were 
$\mathrm{T}_{\text {area }}$ and T/QRS area ratio (Fig. 4.4). From acute to chronic LBBB, the T-vector amplitude, $\mathrm{T}_{\text {area }}$, and $\mathrm{T} / \mathrm{QRS}$ area ratio remained unchanged in tertile 1 , while these variables decreased significantly in the other two groups. It should be noted that at baseline the T-wave was concordant to the QRS complex, but that the T-wave became discordant once LBBB developed. Despite decreasing T-wave size, the T-wave remained discordant (see also Fig. 4.2), even in subgroups 2 and 3. The JTc interval was not significantly different between tertiles at any time-point and shortened for all subgroups during chronic LBBB compared to acute LBBB. Finally, the SVG azimuth showed a large $\left(\sim 80^{\circ}\right)$ change in tertile 3 but no change in tertile 1 .
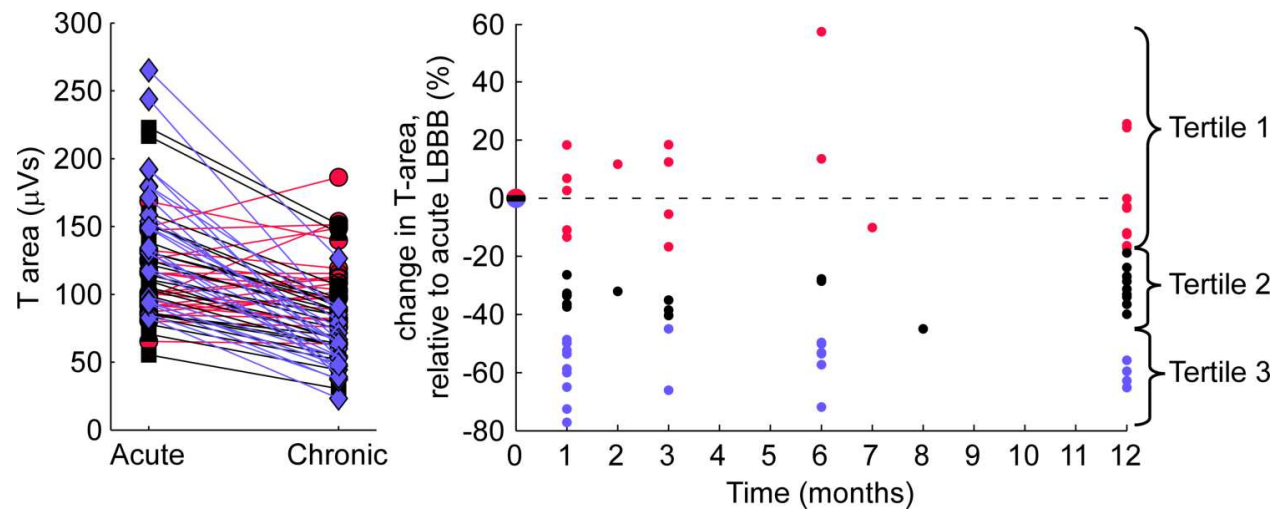

Figure 4.3: Absolute values of $\mathrm{T}_{\text {area }}$ (left) and relative changes over time (right panel), in which the patients were divided into tertiles. In red the patients in tertile 1 are indicated, black represents the patients in tertile 2 , and blue the patients in tertile 3 .

\subsection{Discussion}

The present study demonstrates that within one month after onset of TAVI-induced LBBB, electrical remodeling develops, that is mainly expressed as reduction in repolarization variables (like JTc interval, T-wave amplitude, and $\mathrm{T}_{\text {area }}$ ). The redirection of the SVG indicates an adaptation in repolarization sequence opposite to the sequence of activation. This remodeling is highly variable between patients, despite similar baseline characteristics.

\subsubsection{Electrical remodeling in LBBB patients}

A reduction of T-wave amplitudes in longer lasting LBBB has been reported earlier by Shvilkin et al. ${ }^{12}$. These investigators retrospectively compared ECGs from patients with LBBB lasting $<24$ hours versus $>24$ hours. The same investigators also reported a similar 

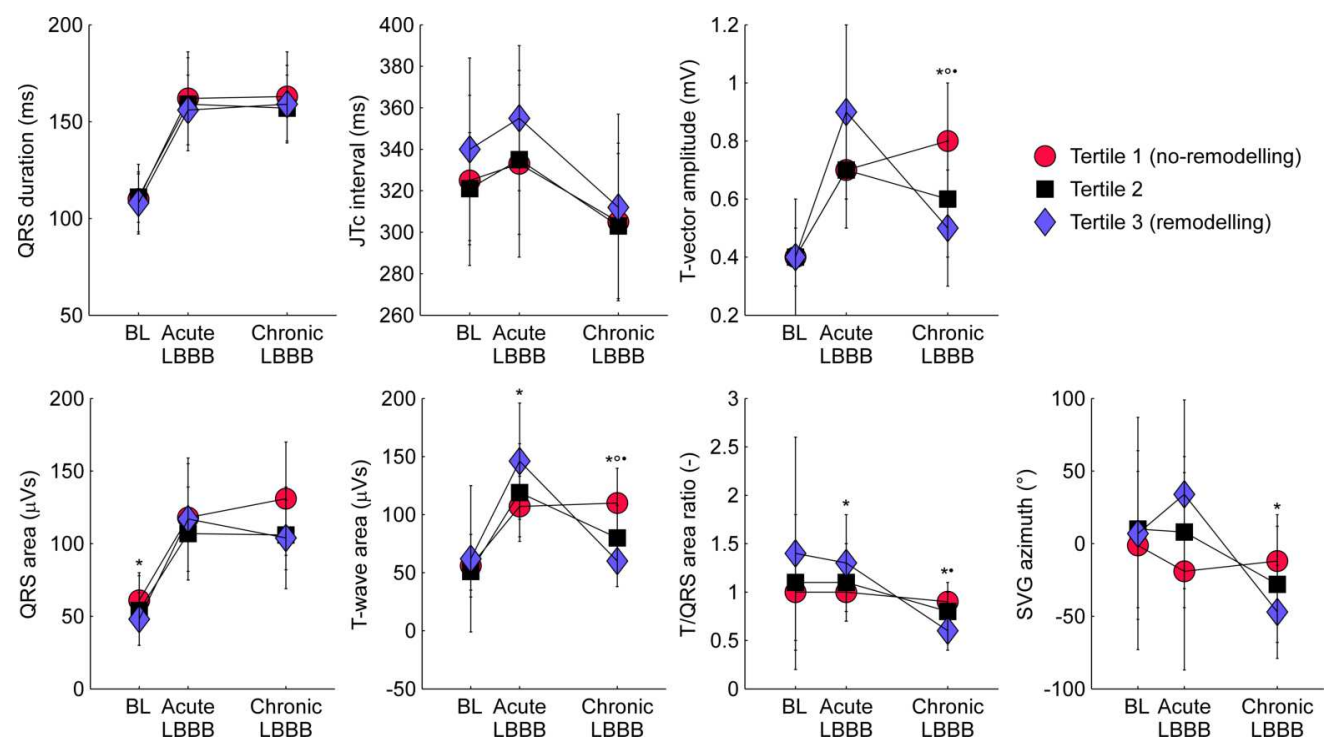

Figure 4.4: A selection of electrocardiographic findings of the LBBB group after the division according to their $\mathrm{T}_{\text {area }}$ decrease. The circle indicates the group with the lowest $\mathrm{T}_{\text {area }}$ decrease, the square the middle group, and the diamond the largest decrease in $\mathrm{T}_{\text {area }}{ }^{\star} \mathrm{P}<0.05$ between tertile 1 and $3,{ }^{\circ} \mathrm{P}<0.05$ between tertile 1 and 2 , and ${ }^{\circ} \mathrm{P}<0.05$ between tertile 2 and 3 all using the Wilcoxon rank sum test.

reduction in T-wave amplitude over time during longer lasting right ventricular pacing in patients with a 1:1 AV conduction. ${ }^{7}$ Importantly, these patients differed from the present population in that they were younger, had no aortic valve disease, and (presumably) less severe heart failure. Therefore, a reduction in repolarization variables during longer lasting dyssynchrony of any cause (LBBB, RV pacing) appears to be a common behavior. That LBBB can induce electrophysiological changes is known from studies in the canine model of LBBB and/or tachypacing induced heart failure. Worsening of pump function and extensive molecular and cellular changes, including changes in ion channels and calcium handling proteins, have been reported in these models. ${ }^{3,5}$

The idea that the observed reductions in T-wave area and amplitude are solely due to repolarization changes and not due to depolarization changes is supported by the observed changes in SVG. The SVG assesses the 'primary factors' determining the T-wave, i.e. heterogeneity of action potential morphology irrespective of activation sequence factors that contribute to the T-wave ('secondary factors'). ${ }^{11}$ Indeed, there is no change in SVG amplitude or angles between baseline and acute LBBB despite huge changes in QRS and T-wave morphology. However, between acute and chronic LBBB the observed changes in T-wave are likely due to changes in the heterogeneity of the action potential morphology since the 
azimuth of the SVG changed. This indicates that the observed electrical remodeling may be attributed to changes in the heterogeneity and/or shape of ventricular action potentials. The most pronounced change in SVG concerns a shift in SVG azimuth towards negative values, implying a rotation in direction towards the direction of the QRS vector. Because repolarization is an electrophysiological process that is opposite to depolarization, the redirection of the T-wave towards the QRS complex (less discordant) indicates that the sequence of repolarization changes in a direction that is opposite to the sequence of depolarization. This is consistent with the observation in rabbit hearts that the sequence of repolarization adapts slowly after onset of ventricular pacing. ${ }^{13}$

An intriguing observation in this study is that although all patients developed a similar, iatrogenic, proximal LBBB, the change in $\mathrm{T}_{\text {area }}$ ranged between $+57 \%$ to $-77 \%$ compared to acute LBBB. In addition, the subgroup of patients showing the smallest amount of $\mathrm{T}_{\text {area }}$ reduction (tertile 1) does not show any change in the azimuth of the SVG, while changes are observed in the other two patient groups. This indicates that electrical remodeling is occurring in the tertile 2 and 3 group, but not in the tertile 1 group. The only difference between the two extreme groups (tertile 1 and tertile 3 ) that could be observed at baseline was that the $\mathrm{QRS}_{\text {area }}$ was significantly larger for patients showing almost no signs of electrical remodeling. Larger QRS amplitudes observed on the ECG may be associated with a higher degree of left ventricular hypertrophy $(\mathrm{LVH})^{14}$ or a larger end systolic volume ${ }^{15}$. Both conditions could indicate a worse left ventricular function. This would suggest that more diseased hearts are less capable of electrical remodeling, an idea that requires further investigation.

\subsubsection{Possible explanation}

A possible mechanism for the observed electrical remodeling might be mechano-electrical (MEC) coupling. This hypothesis was previously tested in a computer model. ${ }^{16}$ In this model study it was assumed that the myocardium strives to maintain local myocardial mechanical work constant, despite the abnormal electrical activation. Because in LBBB the early septal activation lowers contractility in the septum, the MEC simulation imposes an increase in L-type calcium channel conductance during longer lasting LBBB in an attempt to increase contractility. This remodeling of the calcium channel also leads to an increase in action potential duration in the early-activated septum and therefore a smaller dispersion of ventricular repolarization. Applying the simulation predictions to the present clinical observations, more pronounced 'remodeling' would imply a stronger MEC. The latter was also observed in isolated rabbit hearts. ${ }^{17}$ In this study the investigators applied local stretch to the left ventricle of $\sim 15 \%$, while the heart was continuously paced from the paced right atrium at a constant cycle length. It was observed that 5 minutes of applied local stretch led to changes in T-wave morphology and longer stretch led to more electrical remodeling. 


\subsubsection{Electrical remodeling due to unloading versus LBBB}

In TAVI-induced LBBB patients two events occur at (almost) the same time: development of LBBB and removal of the stenosis of the aortic valve. Accordingly, some of the changes over time in LBBB could also have occurred as a consequence of the mechanical unloading. However, comparable mechanical unloading without conduction abnormalities, as occurring in the narrow $\mathrm{QRS}$ patients, led to a significant reduction in $\mathrm{QRS}_{\text {area }}$ but no significant reduction in the $\mathrm{T}_{\text {area }}$. The LBBB patients showed opposite changes, characterized by a significant reduction in the $\mathrm{T}_{\text {area }}$. Therefore, the changes observed after the TAVI procedure in the LBBB group were predominantly a result of LBBB and not of the TAVI procedure. In fact, some of the changes due to TAVI alone are overruled by the changes due to LBBB.

\subsubsection{Potential relevance}

In this study a large range of $\mathrm{T}_{\text {area }}$ change between acute and chronic LBBB was observed. The tertile showing the largest decrease, the electrical remodeling group, did not show a significantly larger decrease in JTc interval compared to patients in the non-remodeling group. In most studies looking at electrical remodeling, only the JTc or QTc intervals are reported, whereas T-wave amplitude or area might also be important variables to quantify the amount of electrical remodeling. However, the functional significance and the mechanism of electrical remodeling are still unknown. It is suggested in some studies that a longer JTc interval is accompanied by a higher risk of ventricular tachyarrhythmia's like Torsade de Pointes, but the JTc interval between the different groups were similar during all time-points. Furthermore, the mechanism and function of cardiac memory (observed after a short duration of dyssynchrony) is also unknown. The model as described above is hypothesis generating, more research is necessary to find the exact mechanism.

\subsubsection{Limitations}

This was a retrospective observational study with imperfections in data collection and missing data. Only $26 \%$ of the original TAVI patient population was eligible for analysis. A large portion of patients were excluded due to missing ECGs, either entirely or at follow-up $(31 \%)$. Other reasons were related to pre-existing dyssynchrony, the type of dyssynchrony or transient or later developed LBBB (30\%). However, baseline characteristics of our study population were similar to that of the entire study population by Houthuizen et al. ${ }^{18}$. Unfortunately, echocardiographic measurements were collected inconsistently in these patients. As a consequence, adding these data to this study would have led to an even smaller study population. A larger, multicenter prospective study including systematic echocardiographic measurements and clinical outcome measures is required to confirm our results and to achieve a better understanding of the relation between structural, electrical and mechanical changes 
in the heart. Such a study will also allow performing a multivariate analysis to adjust for covariates such as age, gender, comorbidities, and echo parameters.

VCGs were reconstructed from the 12-lead ECG using the Kors method rather than direct recording of the Frank-VCG ${ }^{19}$. This was dictated by the available 12-lead ECG data. However, the Kors method shows a good resemblance to the true 3-dimensional Frank-VCG., ${ }^{9,20}$

For the chronic measurements, ECG recordings were used that were acquired between one month and one year after TAVI ( $6 \pm 5$ months). This wide range was accepted because repolarization changes associated with primary electrical remodeling only occur within the first week after initiation of an altered electrical activation. ${ }^{6}$ Furthermore, no significant changes were observed between ECGs measured during one to twelve months after the onset of TAVIinduced LBBB (Fig. 4.3).

\subsection{Conclusions}

This study in patients with TAVI-induced LBBB shows that on a population level LBBB induces electrical remodeling. However, there is a large difference in change in $\mathrm{T}_{\text {area }}$ on a patient level. The amount of electrical remodeling might be associated with the functional status of a patient.

\subsection{Funding}

This work was supported within the framework of Center for Translational Molecular Medicine (www.ctmm.nl), Project COHFAR (Congestive Heart Failure and Arrhythmia) [Grant number 01C-203], and supported by the Dutch Heart Foundation. 


\section{References}

1. S Baldasseroni, C Opasich, M Gorini, D Lucci, N Marchionni, M Marini, C Campana, G Perini, A Deorsola, G Masotti, L Tavazzi, AP Maggioni, and Italian Network on Congestive Heart Failure Investigators. Left bundle-branch block is associated with increased 1-year sudden and total mortality rate in 5517 outpatients with congestive heart failure: a report from the Italian network on congestive heart failure. Am Heart J (2002) 143:398-405.

2. F Zannad, E Huvelle, K Dickstein, DJ van Veldhuisen, C Stellbrink, L Køber, S Cazeau, P Ritter, AP Maggioni, R Ferrari, and P Lechat. Left bundle branch block as a risk factor for progression to heart failure. Eur J Heart Fail (2007) 9:7-14.

3. K Vernooy, XAAM Verbeek, M Peschar, HJGM Crijns, T Arts, RNM Cornelussen, and FW Prinzen. Left bundle branch block induces ventricular remodelling and functional septal hypoperfusion. Eur Heart J (2005) 26:91-98.

4. GF Tomaselli and E Marbán. Electrophysiological remodeling in hypertrophy and heart failure. Cardiovasc Res (1999) 42:270-283.

5. T Aiba, GG Hesketh, AS Barth, T Liu, S Daya, K Chakir, VL Dimaano, TP Abraham, B O'Rourke, FG Akar, DA Kass, and GF Tomaselli. Electrophysiological consequences of dyssynchronous heart failure and its restoration by resynchronization therapy. Circulation (2009) 119:1220-1230.

6. L Wecke, A Rubulis, G Lundahl, MR Rosen, and L Bergfeldt. Right ventricular pacinginduced electrophysiological remodeling in the human heart and its relationship to cardiac memory. Heart Rhythm (2007) 4:1477-1486.

7. A Shvilkin, B Bojovic, B Vajdic, I Gussak, P Zimetbaum, and ME Josephson. Vectorcardiographic determinants of cardiac memory during normal ventricular activation and continuous ventricular pacing. Heart Rhythm (2009) 6:943-948.

8. P Houthuizen, LAFM Van Garsse, TT Poels, P de Jaegere, RMA van der Boon, BM Swinkels, JM Ten Berg, F van der Kley, MJ Schalij, J Baan Jr, et al. Left bundlebranch block induced by transcatheter aortic valve implantation increases risk of death. Circulation (2012) 126:720-728.

9. JA Kors, G van Herpen, AC Sittig, and JH van Bemmel. Reconstruction of the Frank vectorcardiogram from standard electrocardiographic leads: diagnostic comparison of different methods. Eur Heart J (1990) 11:1083-1092. 
10. EB Engels, EM Végh, CJM Van Deursen, K Vernooy, JP Singh, and FW Prinzen. Twave area predicts response to cardiac resynchronization therapy in patients with left bundle branch block. J Cardiovasc Electrophysiol (2015) 26:176-183.

11. HHM Draisma, MJ Schalij, EE van der Wall, and CA Swenne. Elucidation of the spatial ventricular gradient and its link with dispersion of repolarization. Heart Rhythm (2006) 3:1092-1099.

12. A Shvilkin, B Bojovic, B Vajdic, I Gussak, KK Ho, P Zimetbaum, and ME Josephson. Vectorcardiographic and electrocardiographic criteria to distinguish new and old left bundle branch block. Heart Rhythm (2010) 7:1085-1092.

13. A Costard-Jäckle, B Goetsch, M Antz, and MR Franz. Slow and long-lasting modulation of myocardial repolarization produced by ectopic activation in isolated rabbit hearts. Evidence for cardiac "memory". Circulation (1989) 80:1412-1420.

14. PY Courand, P Lantelme, and P Gosse. Electrocardiographic detection of left ventricular hypertrophy: Time to forget the Sokolow-Lyon index? Arch Cardiovasc Dis (2015) 108:277-280.

15. EG Caiani, A Auricchio, M Potse, R Krause, A Pellegrini, RM Lang, and P Vaïda. Evaluation of the relation between changes in R-wave amplitude and LV mass and dimensions in a model of 'Reversed Hypertrophy'. In: Computing in Cardiology 2013. 2013, pp. 867-870.

16. NHL Kuijpers, E Hermeling, J Lumens, HMM ten Eikelder, T Delhaas, and FW Prinzen. Mechano-electrical coupling as framework for understanding functional remodeling during LBBB and CRT. Am J Physiol Heart Circ Physiol (2014) 306:H1644H1659.

17. EA Sosunov, EP Anyukhovsky, and MR Rosen. Altered ventricular stretch contributes to initiation of cardiac memory. Heart Rhythm (2008) 5:106-113.

18. P Houthuizen, RMA van der Boon, M Urena, N Van Mieghem, GBR Brueren, TT Poels, LAFM Van Garsse, J Rodés-Cabau, FW Prinzen, and P de Jaegere. Occurrence, fate and consequences of ventricular conduction abnormalities after transcatheter aortic valve implantation. EuroIntervention (2014) 9:1142-1150.

19. E Frank. An accurate, clinically practical system for spatial vectorcardiography. Circulation (1956) 13:737-749.

20. EB Engels, S Alshehri, CJM van Deursen, L Wecke, L Bergfeldt, K Vernooy, and FW Prinzen. The synthesized vectorcardiogram resembles the measured vectorcardiogram in patients with dyssynchronous heart failure. J Electrocardiol (2015) 48:586-592. 



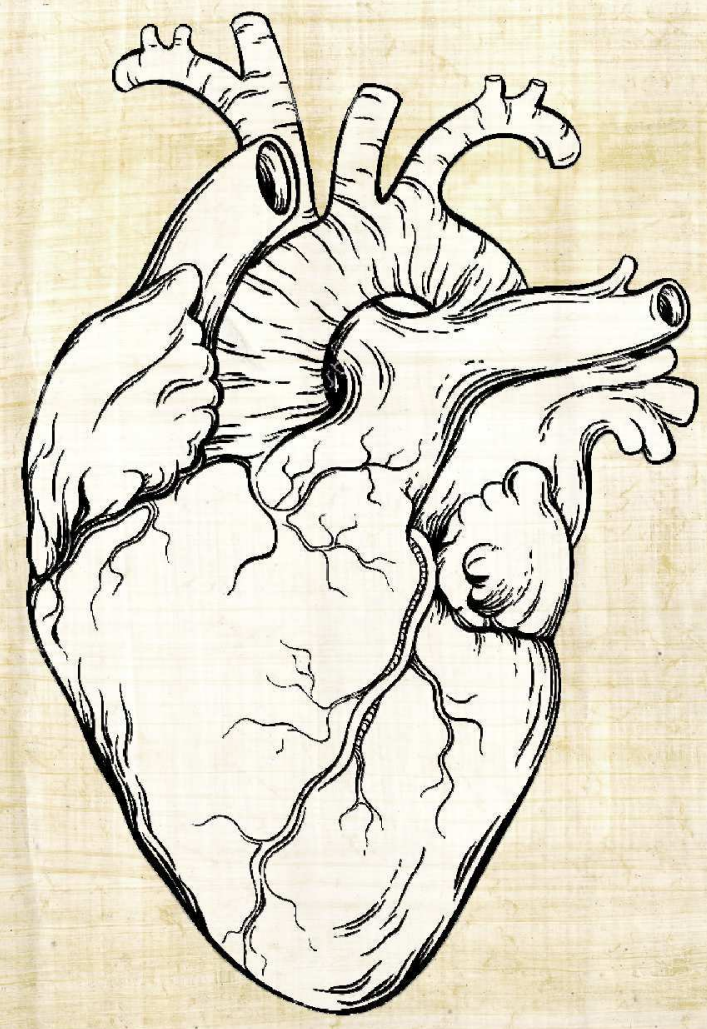




\section{Chapter}

\section{T-wave area predicts response to cardiac resynchronization therapy in patients with left bundle branch block}

The content of this chapter is based on:

Elien B. Engels, ${ }^{1, *}$ Eszter M. Végh, ${ }^{2,3, *}$ Caroline J.M.'van Deursen, ${ }^{1}$

Kevin Vernooy, ${ }^{4}$ Jagmeet P. Singh, ${ }^{2}$ and Frits W. Prinzen ${ }^{1}$ (2015).

T-wave area predicts response to cardiac resynchronization therapy in patients with left bundle branch block. J Cardiovasc Electrophysiol 26(2):176-183.

* Authors contributed equally.

${ }^{1}$ Department of Physiology, CARIM School for Cardiovascular Diseases, Maastricht University, Maastricht, the Netherlands.

${ }^{2}$ Cardiac Arrhythmia Service, Massachusetts General Hospital, Harvard Medical School, Boston, MA, USA.

${ }^{3}$ Semmelweis University Heart and Vascular Center, Budapest, Hungary.

${ }^{4}$ Department of Cardiology, Maastricht University Medical Center, Maastricht, the Netherlands. 


\section{Abstract}

Introduction: Chronic heart failure patients with a left ventricular (LV) conduction delay, mostly due to left bundle branch block (LBBB), generally derive benefit from cardiac resynchronization therapy (CRT). However, 30-50\% of patients do not show a clear response to CRT. We investigated whether T-wave analysis of the ECG can improve patient selection.

Methods and Results: The study population comprised 244 CRT recipients with baseline 12-lead electrocardiogram recordings. Echocardiographic response after 6-months CRT was defined as a $\geq 5 \%$ increase in LV ejection fraction (LVEF). Vectorcardiograms (VCGs) were constructed from the measured 12-lead ECGs using an adapted Kors algorithm on digitized ECGs. Logistic regression models indicated repolarization variables as good predictors of CRT response. The VCG-derived $\mathrm{T}_{\text {area }}$ predicted CRT response (odds ratio [OR] per $10 \mu \mathrm{Vs}$ increase $1.172[\mathrm{P}<0.001])$, even better than $\mathrm{QRS}_{\text {area }}(\mathrm{OR}=1.116[\mathrm{P}=0.001]) . \mathrm{T}_{\text {area }}$ had especially predictive value in the $\mathrm{LBBB}$ patient group $(\mathrm{OR}=2.77$ in LBBB vs. 1.09 in non-LBBB). This predictive value persisted after adjustment of multiple covariates, such as gender, ischemia, age, hypertension, coronary artery bypass graft, and the usage of diuretics and beta-blockers. In LBBB patients the increase in LVEF was $6.1 \pm 9.7 \%$ and $11.3 \pm 9.1 \%$ in patients with $\mathrm{T}_{\text {area }}$ below and above the median value, respectively $(\mathrm{P}<0.01)$.

Conclusions: In patients with LBBB morphology of the QRS complex, a larger baseline $\mathrm{T}_{\text {area }}$ is an important independent predictor of LVEF increase following CRT. 


\subsection{Introduction}

HRONIC heart failure (HF) patients with a left ventricular (LV) conduction delay, mostly due to left bundle branch block (LBBB), and decreased left ventricular ejection fraction $(\mathrm{LVEF}<35 \%)$ generally derive benefit from cardiac resynchronization therapy (CRT). CRT has been shown to improve cardiac pump function, HF symptoms, quality of life, hospitalization and survival. ${ }^{1}$ However, $20-30 \%$ of individual patients do not show clinical response after CRT and up to $50 \%$ show no evidence of cardiac reverse remodeling. ${ }^{2}$ It is therefore important to improve patient selection, to reduce the unnecessary use of expensive devices and prevent complications related to the implantation procedure itself.

CRT is indicated for patients with HF and a wide QRS complex. A QRS duration $\geq 150 \mathrm{~ms}$ is a strong predictor of CRT response, while values between 120 and 150 ms require further evidence. ${ }^{3,4}$ More recently, LBBB morphology of the QRS complex has been shown to be a good predictor of CRT response. ${ }^{5-9}$

The QRS complex reflects the sequence of electrical activation, that is: depolarization, throughout the ventricular wall. While this activation sequence is clearly central to electrical dyssynchrony, it ignores the importance of the equally vital repolarization phase of the myocardium. We hypothesized that the T-wave may provide additional information, since it is reflective of the plateau and repolarization phases of the myocardial action potential. These phases are determined by the activity of many ion channels, including those that regulate intracellular calcium concentrations, that mediate contraction and relaxation.

In order to explore the predictive value of the T-wave, we retrospectively investigated the electrocardiograms from a large cohort of CRT patients. For more comprehensive analysis of the T-wave, ECG signals were converted into vectorcardiograms (VCG). The advantage of the VCG is that it contains three-dimensional information of the electrical forces within the heart and might provide more valuable information than the one-dimensional ECG. This study compares the different depolarization and repolarization parameters to the established ECG predictor of QRS duration. We also investigated the potential predictive values of these repolarization parameters within different QRS morphologies.

\subsection{Methods}

\subsubsection{Study population}

Between 2004 and 2010, 569 consecutive patients who met established indications (New York Heart Association class III/IV symptoms, LVEF<35\% and QRS duration>120 milliseconds), underwent CRT implantation at the Massachusetts General Hospital (MGH). Patients had a followup visit at 1-, 3-, and 6-month at the MGH Multidisciplinary Clinic. The project was approved by the MGH Institutional Review Board and Ethics Committee and was conducted 
in accordance with the Declaration of Helsinki.

Patients with a preimplantation ECG available in digital archives, either in sinus rhythm or atrial fibrillation, were enrolled in this retrospective analysis. ECGs with $<3$ normal beats (e.g., due to premature ventricular complexes [PVCs]), remarkable interfering noise, or ventricular pacing were excluded from the analysis.

\subsubsection{Echocardiography}

Transthoracic echocardiography was performed at baseline and at 6 months clinical follow-up. The images were taken by Philips iE33 (Eindhoven, The Netherlands), SONOS 5500/7500 (Andover, MA, USA) and General ElectricVivid 7 (GE, Milwaukee, WI,USA) ultrasound machines. CRT response was defined as absolute increase in LVEF of $\geq 5 \%$ after 6 months of CRT, determined using the biplane method of discs (modified Simpson's method).

\subsubsection{ECG analysis}

Before CRT implantation, supine 12-lead ECGs were recorded digitally by a MAC 5500 ECG Machine (GE Healthcare, Waukesha, WI, USA) at a paper speed of $25 \mathrm{~mm} / \mathrm{s}$ and a frequency of $250 \mathrm{~Hz}$. All ECGs were stored digitally as PDF files in the MUSE Cardiology Information system (GE Medical System). ECGs recorded up to 1 month before CRT implantation were included into the analysis. The vector graphics of these PDF files were obtained by converting the files to an .svg file using Inkscape version 2 (Boston, MA, USA). The calibration pulses, as indicated in Fig. 5.1, were used to scale the signals to real time and amplitude.

The digital ECG signals were semiautomatically analyzed using a custom-made computer program written in MATLAB R2010b (MathWorks, Natick, MA, USA). After band-pass filtering between $0.5-40 \mathrm{~Hz}$ and baseline wander removal, the beginning and end of the QRS complex could be detected using the curve length transformation (cLT). ${ }^{10}$ The beginning of the QRS complex corresponded to the last found minimum value and the end of the QRS complex was the first point with maximal cLT value. Additionally, the end of the T-wave was identified as the intersection between baseline and the tangent of the slope of the T-wave.

The QRS axis was calculated using lead I and II, where angles between $-30^{\circ}$ and $-90^{\circ}$ were defined as left axis deviation (LAD). Furthermore, patients were classified as LBBB or non-LBBB according to the MADIT-CRT criteria. ${ }^{5}$

\subsubsection{VCG analysis}

From the digital 12-lead ECG signals, a VCG was synthesized using the Kors method. ${ }^{11}$ The matrix proposed by Kors et al. ${ }^{12}$ is based on a learning set from the Common Standards for 
Electrocardiography multilead library and was generated by multiple linear regressions. The populations included both healthy subjects and patients. ${ }^{11}$ The Kors method assumes all 8 independent leads measured simultaneously. However, in our case there were 4 groups of 3 leads (1: I, II, III; 2: aVR, aVL, aVF; 3: $\mathrm{V}_{1}, \mathrm{~V}_{2}, \mathrm{~V}_{3} ; 4: \mathrm{V}_{4}, \mathrm{~V}_{5}, \mathrm{~V}_{6}$ ) and 1 running lead simultaneously measured, as shown in Fig. 5.1. This running lead was needed to select the same beginning and end of an R-R interval in each lead. After selecting 1 beat for each lead, the VCG was synthesized.

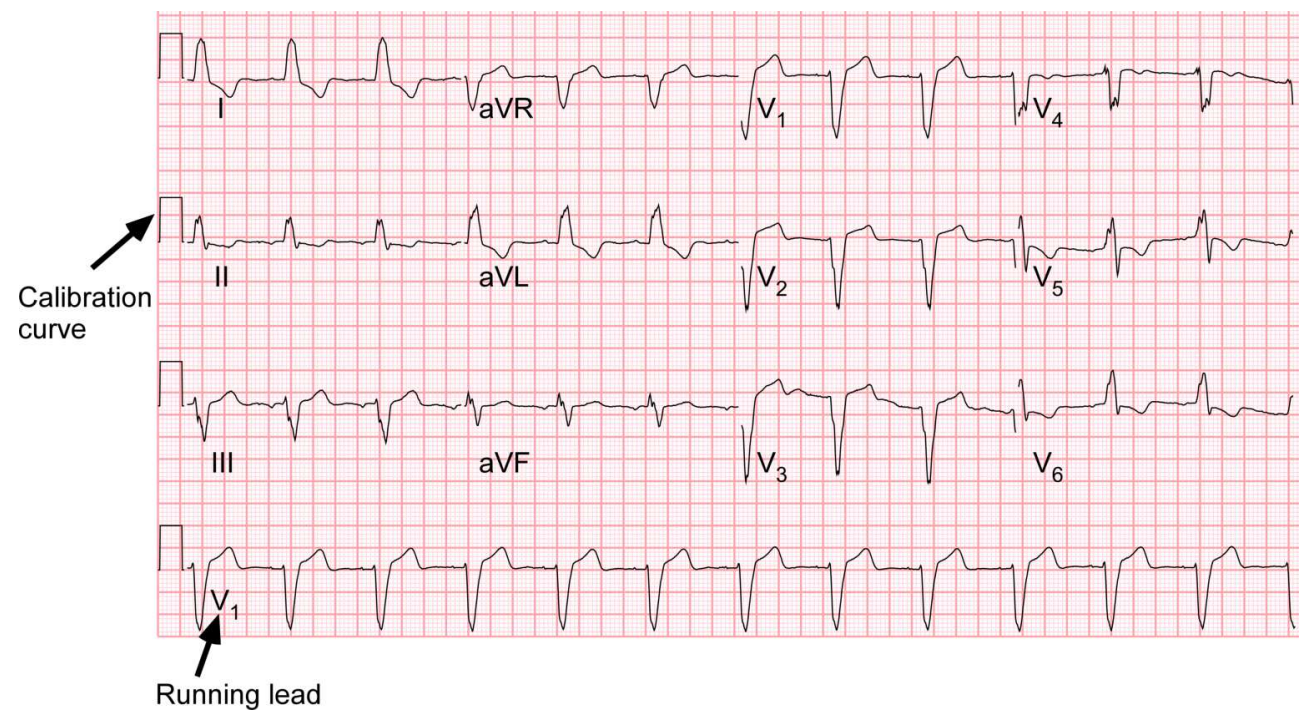

Figure 5.1: Typical example of the layout of a measured 12-lead ECG, showing calibration pulses and lead $\mathrm{V}_{1}$ as running lead.

For each patient, the QRS loop and T loop were identified using the same method as described for the ECG analysis. ${ }^{10}$ The QRS duration and QT interval were defined as the time between the beginning of the QRS complex and the end of the QRS complex or the T-wave, respectively. The QT interval was corrected for heart rate changes using Bazett's method (QTc interval). Subsequently, the maximum QRS and T-vector were defined (maximal distance from the origin to a point on the loop), and its amplitude and location in space were calculated. The vector angles were expressed as azimuth and elevation. Azimuth is the angle in the transverse plane $\left(0^{\circ} \mathrm{left},+90^{\circ}\right.$ front, $-90^{\circ}$ back, $180^{\circ}$ right $)$. The elevation angle is the angle in the frontal plane defined from $0^{\circ}$ (downwards) to $180^{\circ}$ (upwards). The angle between the maximal QRS- and T-vector was defined as the QRS/T angle.

The VCG gave us the opportunity to also analyze the area of the loops. The $\mathrm{QRS}_{\text {area }}$ is the '3-D' area between the curve and the baseline from QRS beginning to end in leads X, Y, and $\mathrm{Z}: \mathrm{QRS}_{\text {area }}=\sqrt{\mathrm{QRS}_{\text {area } \mathrm{x}}^{2}+\mathrm{QRS}_{\text {area } \mathrm{y}}^{2}+\mathrm{QRS}_{\text {area }, \mathrm{z}}^{2}}$. The $\mathrm{T}_{\text {area }}$ was calculated similarly, using 
the part from the end of the QRS complex to the end of the T-wave. The sum QRST area was the sum of the absolute values of the $\mathrm{QRS}_{\text {area }}$ and $\mathrm{T}_{\text {area }}$ (Fig. 5.2). The ratio between $\mathrm{QRS}$ and $\mathrm{T}$ areas was defined as the $\mathrm{QRS} / \mathrm{T}$ area ratio.

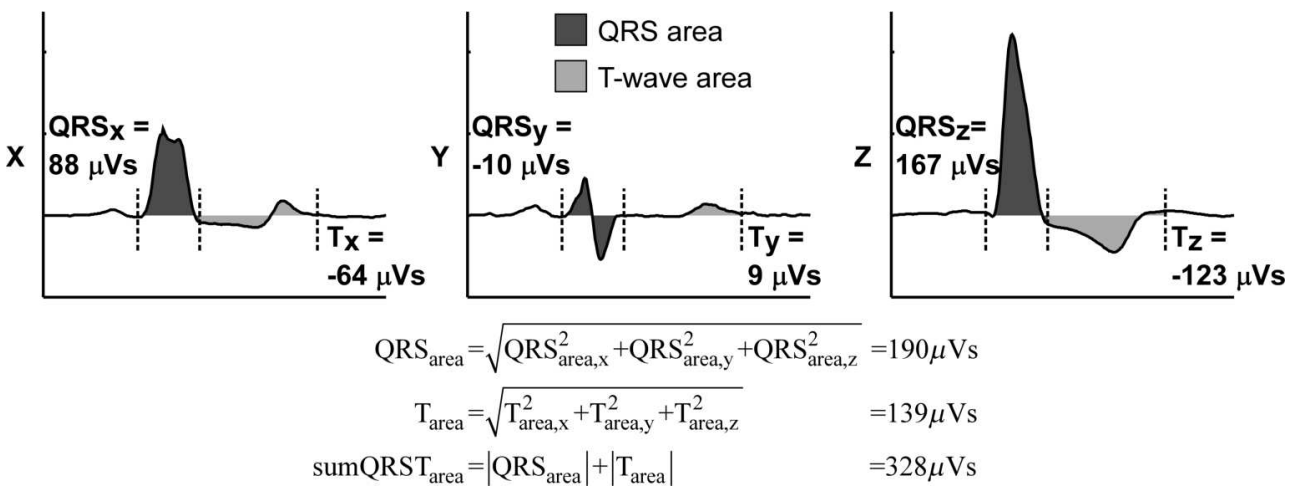

Figure 5.2: Calculation of the 3-D QRS and $T_{\text {area }}$ using the integral between the signal and the baseline from beginning to end of the QRS complex or from the end of the QRS complex to end of the T-wave, respectively. From the QRS and $\mathrm{T}_{\text {area }}$, the sum QRST area was calculated.

\subsubsection{Statistical analysis}

The statistical analysis was performed using IBM SPSS statistics software version 21 (SPSS Inc., Chicago, IL, USA). Continuous and discrete variables are presented as mean \pm standard deviation (SD) and counts (percentages), respectively. Linear correlations were evaluated by Pearson's correlation or Kendall's tau coefficient when appropriate. Comparison between different patient groups was performed using either 1-way ANOVA (continuous variables) or the $\chi^{2}$-test (discrete variables). Follow-up paired comparisons were made using the Tukey test. The classification performance of electrical parameters in identifying CRT response was evaluated by odds ratios (OR) calculated using logistic regression models. The likelihood ratio test was used for comparison of the goodness-of-fit of hierarchical models. A 2-sided P-value $<0.05$ was considered statistically significant.

\subsection{Results}

\subsubsection{Patient characteristics}

During the study period, a total of 569 patients underwent CRT implantation. Eighty patients were excluded because of missing ECGs, 91 because of missing baseline or follow-up echocardiograms, 116 due to pre-existent pacing, and 38 because of frequent PVCs or unac- 
ceptable noise. Consequently, a total of 244 patients remained for analysis. Table 5.1 presents the baseline characteristics, indicating that the included patient group was similar to the entire cohort. The 244 patients represent a typical CRT population with a mean age of 67 years and a baseline LVEF of 24\%.Most patients were male, about half of the patients had ischemic cardiomyopathy, and most had NYHA class III or IV symptoms (Table 5.1).

Table 5.1: Baseline patient characteristics of the included $(n=244)$ and entire cohort $(n=596)$ as well as the ECG and VCG analysis results of only the included cohort

\begin{tabular}{|c|c|c|}
\hline Variable & $\begin{array}{l}\text { Included } \\
\mathrm{n}=244\end{array}$ & $\begin{array}{c}\text { Entire Cohort } \\
\mathrm{n}=596\end{array}$ \\
\hline \multicolumn{3}{|l|}{ Baseline Characteristics } \\
\hline Age (years) & $66.9 \pm 12.8$ & $68.6 \pm 12.4$ \\
\hline Female (n, \%) & $51(20.9)$ & $116(20.4)$ \\
\hline Baseline LVEF (\%) & $24.3 \pm 7.0$ & $24.2 \pm 7.2$ \\
\hline \multicolumn{3}{|l|}{ NYHA class } \\
\hline II $(\mathrm{n}, \%)$ & $8(3.3)$ & $24(4.2)$ \\
\hline III (n, \%) & $190(77.9)$ & $378(66.4)$ \\
\hline IV $(\mathrm{n}, \%)$ & $22(9.0)$ & $49(8.6)$ \\
\hline Unknown (n, \%) & $24(9.8)$ & $118(20.7)$ \\
\hline Ischemic HF etiology (n, \%) & $136(55.7)$ & 337 (59.3) \\
\hline $\operatorname{LBBB}(\mathrm{n}, \%)$ & $154(63.1)$ & $258(48.5)$ \\
\hline Chronic AF (n, \%) & $53(21.7)$ & $168(29.5)$ \\
\hline \multicolumn{3}{|l|}{ ECG measurements } \\
\hline Heart rate (bpm) & $75 \pm 15$ & \\
\hline QRS axis $\left({ }^{\circ}\right)$ & $-15 \pm 61$ & \\
\hline \multicolumn{3}{|l|}{ VCG measurements } \\
\hline QRS duration (milliseconds) & $175 \pm 33$ & \\
\hline QT interval (milliseconds) & $472 \pm 88$ & \\
\hline QTc interval (milliseconds) & $520 \pm 77$ & \\
\hline $\mathrm{QRS}_{\text {area }}(\mu \mathrm{Vs})$ & $90 \pm 47$ & \\
\hline QRS-vector azimuth $\left({ }^{\circ}\right)$ & $-65 \pm 53$ & \\
\hline QRS-vector elevation $\left({ }^{\circ}\right)$ & $90 \pm 24$ & \\
\hline T-vector amplitude (mV) & $0.5 \pm 0.2$ & \\
\hline $\mathrm{T}_{\text {area }}(\mu \mathrm{Vs})$ & $84 \pm 45$ & \\
\hline T-vector azimuth $\left({ }^{\circ}\right)$ & $78 \pm 63$ & \\
\hline T-vector elevation $\left({ }^{\circ}\right)$ & $87 \pm 26$ & \\
\hline QRS/T angle $\left({ }^{\circ}\right)$ & $156 \pm 29$ & \\
\hline Sum QRST area $(\mu \mathrm{Vs})$ & $174 \pm 83$ & \\
\hline
\end{tabular}

Variables are shown as counts (percentage) or mean \pm standard deviation when appropriate. LVEF $=$ left ventricular ejection fraction; NYHA = New York Heart Association; HF = heart failure; LBBB = left bundle branch block; AF = atrial fibrillation.

\subsubsection{ECG and VCG analysis}

The patients had a prolonged QRS duration. The average QRS axis was in the normal axis range $\left(-30^{\circ}\right.$ to $\left.-90^{\circ}\right)$ but the SD was large, indicating a large variation between patients. The QRS-vector amplitude was 3 times larger than the T-vector amplitude, but the areas of the QRS and T loop were similar, because the T-wave lasted longer. In general, the QRS-vector pointed to the left and the back while the $\mathrm{T}$ vector was pointing to the left and the front, 
indicating a large angle between the 2 vectors (Table 5.1). Typical examples of 12-lead ECGs and corresponding 3-D vector loops for 2 patients, diagnosed with LBBB with a large or small $\mathrm{T}_{\text {area }}$, are shown in Fig. 5.3A, Fig. 5.3B, respectively.

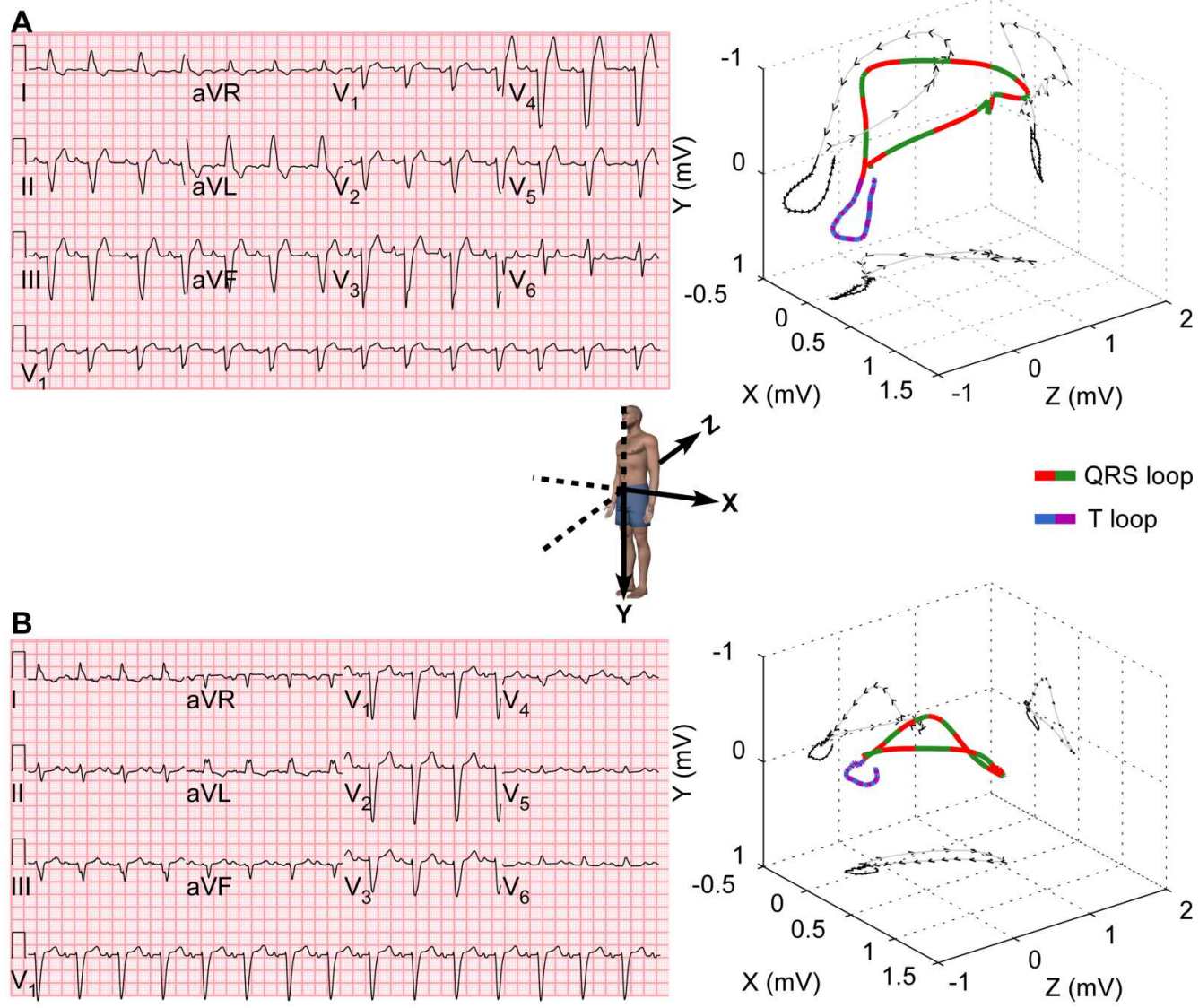

Figure 5.3: Typical examples of 12-lead ECGs and corresponding 3-D vector loops for a patient with a large (A) and a small (B) $\mathrm{T}_{\text {area }}$, despite being both classified as having LBBB.

\subsubsection{Echocardiographic response predicted by ECG and VCG variables}

Logistic regression models indicated VCG-derived repolarization variables as good predictors of CRT response (Table 5.2). An increase in T-vector amplitude or $\mathrm{T}_{\text {area }}$ was associated with a greater probability of $\geq 5 \%$ or $\geq 10 \%$ points increase in LVEF. Prediction of LVEF increase by the T-vector amplitude and $\mathrm{T}_{\text {area }}$ was even stronger than by the QRS-vector amplitude or $\mathrm{QRS}_{\text {area }}$ (Table 5.2). Adding $\mathrm{QRS}_{\text {area }}$ to a model including only the $\mathrm{T}_{\text {area }}$ did not 
improve the goodness-of-fit significantly ( $\mathrm{P}=0.40)$, while adding $\mathrm{T}_{\text {area }}$ to a model consisting of $\mathrm{QRS}_{\text {area }}$ alone, the goodness-of-fit improved significantly $(\mathrm{P}<0.01)$. The sum QRST area had a predictive power comparable to that of the $\mathrm{T}_{\text {area }}$ alone. A larger angle between the $\mathrm{QRS}$ and $\mathrm{T}$ vector ( $\mathrm{QRS} / \mathrm{T}$ angle) was associated with a non-significantly $(\mathrm{P}=0.06)$ higher probability of echo response. Patients without LAD of the QRS-vector did not show a better CRT response $(\mathrm{OR}=1.15$ [0.69-1.91]; $\mathrm{P}=0.59)$.

Table 5.2: Linear Regression Model for Prediction of $\geq 5 \%$ or $\geq 10 \%$ Absolute Increase in LVEF

\begin{tabular}{lcrcrc}
\hline Variable & $\begin{array}{c}\text { OR }(95 \% \mathrm{CI}) \text { for } \\
\Delta \mathrm{LVEF} \geq 5 \%\end{array}$ & P-Value & $\begin{array}{c}\text { OR }(95 \% \mathrm{CI}) \text { for } \\
\Delta \mathrm{LVEF} \geq 10 \%\end{array}$ & P-Value & Increase \\
\hline QRS duration $(\mathrm{ms})$ & $0.994(0.919-1.077)$ & 0.890 & $0.983(0.907-1.066)$ & 0.679 & $10 \mathrm{~ms}$ \\
QRS amplitude $(\mathrm{mV})$ & $1.071(1.017-1.129)$ & 0.009 & $1.068(1.015-1.124)$ & 0.011 & $0.1 \mathrm{mV}$ \\
$\mathrm{T}$ amplitude $(\mathrm{mV})$ & $1.256(1.115-1.413)$ & $<0.001$ & $1.231(1.101-1.377)$ & $<0.001$ & $0.1 \mathrm{mV}$ \\
$\mathrm{QRS} \mathrm{T}$ angle $\left({ }^{\circ}\right)$ & $1.094(0.990-1.195)$ & 0.067 & $1.105(0.990-1.231)$ & 0.063 & $10^{\circ}$ \\
$\mathrm{QRS}_{\text {area }}(\mu \mathrm{Vs})$ & $1.116(1.051-1.195)$ & 0.001 & $1.094(1.030-1.149)$ & 0.003 & $10 \mu \mathrm{Vs}$ \\
$\mathrm{T}_{\text {area }}(\mu \mathrm{Vs})$ & $1.172(1.083-1.255)$ & $<0.001$ & $1.127(1.062-1.207)$ & $<0.001$ & $10 \mu \mathrm{Vs}$ \\
$\mathrm{QRS}_{\mathrm{T}} \mathrm{T}$ area $(\mu \mathrm{Vs})$ & $1.175(1.090-1.266)$ & $<0.001$ & $1.131(1.057-1.210)$ & $<0.001$ & $20 \mu \mathrm{Vs}$
\end{tabular}

Presented are median values and $95 \%$ confidence intervals (CI). The Increase column indicates the step size of the variables used to calculate the odds ratios (OR). Corresponding $\mathrm{P}$ values were calculated using the Wald-test. LVEF $=$ left ventricular ejection fraction; $\mathrm{OR}=$ odds ratio.

\subsubsection{Tarea as an additional predictor of echocardiographic response}

In order to better understand the good prediction of CRT response by the $T_{\text {area }}$, this variable was further evaluated in its relation to QRS duration, $\mathrm{QRS}_{\text {area }}$, as well as presence of LBBB and ischemic etiology. $\mathrm{T}_{\text {area }}$ was poorly related to both the $\mathrm{QRS}$ duration $(\mathrm{R}=0.34)$ and LBBB $(\mathrm{R}=0.36)$. Nevertheless, patients diagnosed with LBBB had a significantly larger $\mathrm{T}_{\text {area }}$ than patients without LBBB $(97.8 \pm 45.4$ vs. $60.6 \pm 33.6$; $\mathrm{P}<0.001)$. Similarly, $\mathrm{T}_{\text {area }}$ was smaller in patients with ischemic etiology compared to non-ischemic etiology $(88.6 \pm 44.9$ vs. $105.5 \pm 47.3 ; \mathrm{P}=0.01)$. $\mathrm{T}_{\text {area }}$ correlated better with $\mathrm{QRS}_{\text {area }}$, although the correlation coefficient of 0.63 indicated that more factors than $\mathrm{QRS}_{\text {area }}$ alone determine $\mathrm{T}_{\text {area }}$ (Table 5.3 and Fig. 5.4). The OR of the QRS/T area ratio for predicting CRT response was $0.753(\mathrm{P}=0.13)$, indicating that a large $\mathrm{T}_{\text {area }}$ relative to the $\mathrm{QRS}_{\text {area }}$ tends to increase the odds of becoming a CRT responder.

As expected, non-LBBB patients were more commonly non-responders than responders. Non-LBBB patients also had fairly small $\mathrm{T}_{\text {area }}$ and $\mathrm{QRS}_{\text {area }}$ (Fig. 5.4A). In the LBBB group most patients were responders and $\mathrm{T}_{\text {area }}$ and $\mathrm{QRS}_{\text {area }}$ were larger than in the non-LBBB group (Fig. 5.4B). 
A

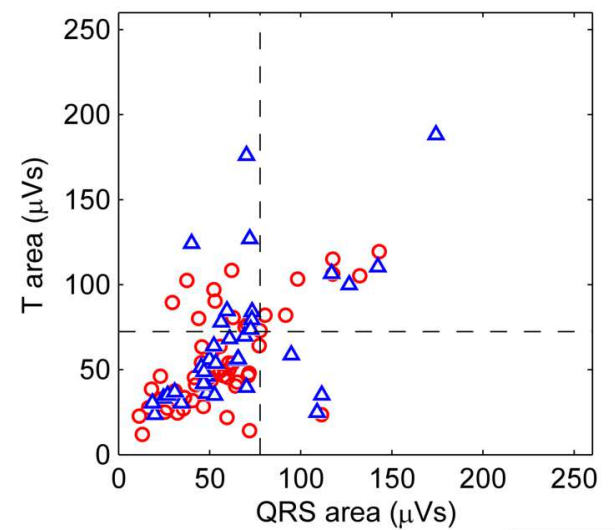

B

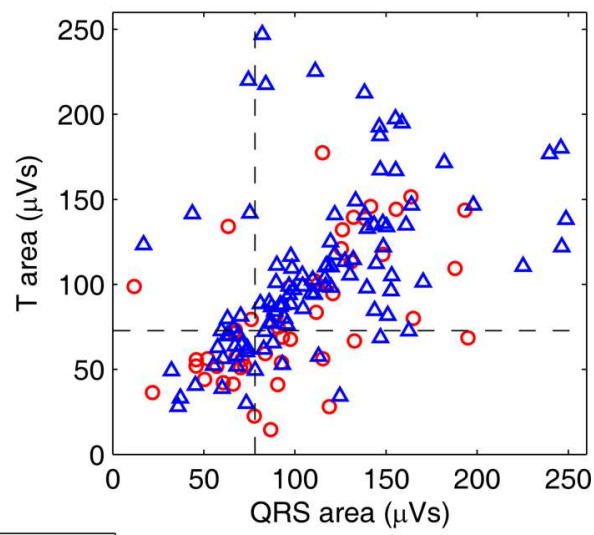

$\circ \Delta \mathrm{LVEF}<5 \%$
$\Delta \Delta \mathrm{LVEF} \geq 5 \%$

Figure 5.4: Scatter plot of the relation between $\mathrm{QRS}_{\text {area }}$ and $\mathrm{T}_{\text {area }}$ within non-LBBB (A) and LBBB patients $(\mathbf{B})$. The responders are indicated by blue triangles, non-responders by red circles.

Table 5.3: Baseline and outcome patient characteristics after dividing patients according to their QRS morphology and $\mathrm{T}_{\text {area }}$

\begin{tabular}{lcccc}
\hline & \multicolumn{2}{c}{ LBBB } & \multicolumn{2}{c}{ Non-LBBB } \\
& $\begin{array}{c}\mathrm{T}_{\text {area }} \\
<\text { Median } \\
(\mathrm{n}=51)\end{array}$ & $\begin{array}{c}\mathrm{T}_{\text {area }} \\
(\mathrm{n}=103)\end{array}$ & $\begin{array}{c}\mathrm{T}_{\text {area }} \\
<\text { Median } \\
(\mathrm{n}=61)\end{array}$ & $\begin{array}{c}\mathrm{T}_{\text {area }} \\
(\mathrm{n}=29)\end{array}$ \\
& $66.1 \pm 10.6$ & $68.1 \pm 12.0$ & $66.9 \pm 13.5$ & $64.3 \pm 16.8$ \\
\hline Age (years) & $8(15.7)$ & $32(31.1)^{\star}$ & $8(13.1)$ & $3(10.3)$ \\
Female (n, \%) & $33(64.7)$ & $50(48.5)$ & $37(60.7)$ & $16(55.2)$ \\
Ischemic HF etiology (n, \%) & $36(70.6)$ & $83(80.6)$ & $45(73.8)$ & $17(58.6)$ \\
Hypertension (n, \%) & $22(43.1)$ & $34(33.0)$ & $24(39.3)$ & $12(41.4)$ \\
CABG (n, \%) & $173 \pm 30$ & $183 \pm 31$ & $162 \pm 32$ & $174 \pm 39$ \\
QRS duration (ms) & $524 \pm 92$ & $533 \pm 75$ & $495 \pm 61$ & $518 \pm 78$ \\
QTc interval (ms) & $78.0 \pm 32.7$ & $122.1 \pm 44.0^{\dagger}$ & $50.1 \pm 22.5$ & $83.4 \pm 36.3^{\dagger}$ \\
QRS area $(\mu$ Vs) & $53.0 \pm 14.1$ & $120.0 \pm 38.6^{\dagger}$ & $41.7 \pm 13.7$ & $100.5 \pm 27.5^{\dagger}$ \\
$\mathrm{T}_{\text {area }}(\mu$ Vs) & $3.0 \pm 0.4$ & $3.1 \pm 0.4$ & $3.0 \pm 0.3$ & $3.2 \pm 0.4$ \\
NYHA class baseline (-) & $2.3 \pm 0.8$ & $2.0 \pm 0.8$ & $2.4 \pm 0.9$ & $2.3 \pm 0.4$ \\
NYHA class follow-up (-) & $-0.8 \pm 0.8$ & $-1.0 \pm 0.8$ & $-0.7 \pm 0.8$ & $-0.9 \pm 0.7$ \\
$\Delta$ NYHA class $(-)$ & $25.1 \pm 7.1$ & $24.5 \pm 6.6$ & $24.3 \pm 7.5$ & $22.4 \pm 7.2^{\star}$ \\
LVEF baseline (\%) & $31.2 \pm 11.1$ & $35.8 \pm 10.9^{\star}$ & $28.6 \pm 10.8$ & $28.9 \pm 13.4$ \\
LVEF follow-up (\%) & $6.1 \pm 9.7$ & $11.3 \pm 9.1^{\star}$ & $4.3 \pm 10.0$ & $6.5 \pm 14.3$ \\
$\Delta \mathrm{LVEF}(\%)$ & $27(52.9)$ & $78(75.7)^{\dagger}$ & $24(39.3)$ & $12(41.4)$ \\
$\Delta \mathrm{LVEF} \geq 5 \%(\mathrm{n}, \%)$ & $19(37.3)$ & $58(56.3)^{\star}$ & $14(23.0)$ & $10(34.5)$ \\
$\Delta \mathrm{LVEF} \geq 10 \%(\mathrm{n}, \%)$ & &
\end{tabular}

Continuous variables are presented as mean \pm standard deviation (SD), discrete variables as counts (percentages). $\mathrm{HF}=$ heart failure; $\mathrm{CABG}=$ coronary artery bypass graft; $\mathrm{NYHA}=\mathrm{New}$ York Heart Association; $\mathrm{LVEF}=$ left ventricular ejection fraction. ${ }^{\star} \mathrm{P}$ value $<0.05$ compared to the $\mathrm{T}_{\text {area }}<$ median group with the same $\mathrm{LBBB}$ conditions.

${ }^{\dagger} \mathrm{P}$ value $<0.01$ compared to the $\mathrm{T}_{\text {area }}<$ median group with the same LBBB conditions. 
In order to investigate whether $\mathrm{T}_{\text {area }}$ had a predictive value complementary to $\mathrm{LBBB}$, the LBBB and non-LBBB patient groups were subdivided in subgroups with a baseline $\mathrm{T}_{\text {area }}<$ or $\geq$ the median. Between these 4 subgroups, the only patient characteristic showing differences were a higher percentage of females $(\mathrm{P}=0.04)$ and a lower percentage of patients with ischemic HF etiology $(\mathrm{P}=0.06)$ in the LBBB-high T-wave subgroup (Table 5.3). In this subgroup also, the decrease in NYHA class (1.0 vs. $0.7-0.9)$ was slightly larger and the increase in LVEF was significantly larger than in the other 3 subgroups (11.3\% vs. $4.3-6.5 \%$; $\mathrm{P}<0.01)$. This larger increase in LVEF also translated into a significantly higher percentage of echocardiographic responders (75 vs. 39 - 53\%; Fig. 5.5). Table 5.3 and Fig. 5.5 also indicate that $\mathrm{T}_{\text {area }}$ had no predictive value in the non-LBBB subgroup. While Fig. 5.5 shows the ORs before adjustments to covariates, values of ORs remained similar after adjustment of multiple covariates, such as gender, ischemia, age, hypertension, coronary artery bypass graft, and the usage of diuretics and $\beta$-blockers (adjusted OR within LBBB patients was 2.50 [1.16-5.39]; $\mathrm{P}=0.02)$.

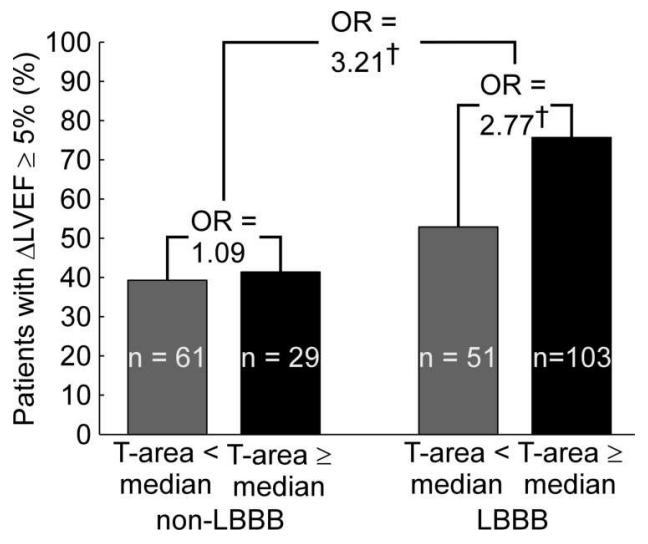

Figure 5.5: The percentage of echocardiographic responders in LBBB and non-LBBB QRS morphology, subdivided into cohorts with $\mathrm{T}_{\text {area }}<$ or $\geq$ the median value. The number of patients within 1 group is indicated in the bars. The ORs between the 2 QRS morphologies and between small and large $\mathrm{T}_{\text {areas }}$ are indicated. ${ }^{\dagger}$ indicates $\mathrm{P}<0.01$.

The use of QRS $_{\text {area }}$ or sum QRST area instead of $\mathrm{T}_{\text {area }}$ did not provide a higher distinctive power in both the LBBB (OR $=1.76$ [N.S.] and $\mathrm{OR}=2.40[\mathrm{P}=0.02]$, respectively) and non-LBBB patient groups ( $\mathrm{OR}=1.39$ [N.S.] and $\mathrm{OR}=1.50$ [N.S.], respectively).

\subsection{Discussion}

This study demonstrates that the T-wave contains information that improves the prediction for echocardiographic CRT response at 6 months. VCG-derived $\mathrm{T}_{\text {area }}$ predicts CRT response 
even better than any QRS-complex related parameter. This better outcome prediction especially applies to patients diagnosed with LBBB.

\subsubsection{Tarea as an additional predictor of CRT response}

This report clearly illustrates the added value of the VCG derived T-wave in predicting CRT response in $\mathrm{LBBB}$ patients. The data indicate that the chance of echocardiographic CRT response in patients with $\mathrm{LBBB}$ and a large $\mathrm{T}_{\text {area }}$ is $75 \%$, as opposed to $53 \%$ in $\mathrm{LBBB}$ patients with small $\mathrm{T}_{\text {area }}$ and $40 \%$ in non-LBBB patients. Considering the fact that large studies show an average echocardiographic response rate of $\sim 50 \% \%^{2}$, the combination of LBBB and T-wave criteria strongly improves patient selection for CRT. The sum QRST area showed similar prognostic value within $\mathrm{LBBB}$ patients (unadjusted $\mathrm{OR}=2.40$ vs. 2.77 for $\mathrm{T}_{\text {area }}$ alone) but this parameter was probably mainly determined by the $\mathrm{T}_{\text {area }}$ itself. The lack of additional predictive value of $\mathrm{T}_{\text {area }}$ in the non-LBBB group might be due to the fact that the LBBB sequence of electrical activation is the dominant electrical substrate for CRT. ${ }^{5}$

There may be several reasons why $\mathrm{T}_{\text {area }}$ improves predicted CRT response. First of all, there is, to some extent, a positive relation between $\mathrm{T}_{\text {area }}$ and $\mathrm{QRS}$ duration. It is well known that QRS duration is an independent predictor of CRT response, especially when differentiating between QRS duration values below and over 150 milliseconds. ${ }^{3,4}$ Moreover, the T-wave amplitude is known to be smaller in patients with large $\mathrm{BMI}^{13}$, possibly simply related to the larger distance of the surface to the heart. Large BMI is known, for not well-understood reasons, to reduce CRT response. ${ }^{14}$ Notably, in this study the ORs were not adjusted for BMI.

In contrast to Brenyo et al. ${ }^{15}$ we did not find a significant effect of the QRS axis deviation on the benefit of CRT in this study. A possible explanation for these discrepant findings might be that the patients in this study had severe HF (mostly NYHA class III-IV) while the MADIT-CRT study consisted of patients with NYHA class I-II. Another explanation may be that the MADIT-CRT study consisted of a larger number of patients.

Even though different heart conditions might also reduce $\mathrm{QRS}_{\text {area }}$, in this study the QRS/T area ratio showed a tendency to predict CRT response, pointing toward specific repolarization related factors. One possible explanation might be hypertrophy. In patients with narrow QRS complex hypertrophy is known to lead to smaller T waves: T-wave flattening, also referred to as 'strain-pattern' of the T-wave. ${ }^{16}$ It is incompletely understood whether similar conditions also reduce the T-wave in patients with wide QRS complex. Finally, it is known that HF in general and dyssynchronous $\mathrm{HF}$ in particular leads to extensive changes in expression of many ion channels, such as $\mathrm{K}^{+}$and $\mathrm{Ca}^{2+}$ channels. ${ }^{17}$ In short, the predictive power of the $\mathrm{T}$-wave reflective of electrical recovery suggests that this component of the action potential may give additional information of the responsiveness of the myocardial substrate.

Regardless of the exact mechanism, this study shows that several categories of patients, which are known to respond well to CRT, are overrepresented in the higher $\mathrm{T}_{\text {area }}$ category, 
namely patients who are females and/or have non-ischemic etiology of HF. Several studies indicate that women respond better to CRT. ${ }^{18,19}$ Although they tend to have less ischemic etiology of HF and more LBBB, the reason for this sex-related beneficial effect is unclear. Additionally, the MIRACLE study ${ }^{20}$ showed that ischemic cardiomyopathy patients show a smaller volumetric response than patients with non-ischemic cardiomyopathy. During ischemia, degeneration or cellular coupling can occur $^{21}$ resulting in nonconducting fibrotic tissue leading to a smaller amount of tissue that can be resynchronized by CRT. Indeed, as shown by a computer modeling study ${ }^{22}$, uncoupling leads to a reduction in T-wave amplitude, which would also reduce the $\mathrm{T}_{\text {area }}$.

\subsubsection{Potential clinical implications}

The VCG, as analyzed in this study, can be constructed from a regular 12-lead ECG. Subsequently, the $\mathrm{T}_{\text {area }}$ can be automatically calculated. Consequently, combined analysis of QRS morphology and $\mathrm{T}_{\text {area }}$ provides an easy and widely applicable approach to improve selection of CRT candidates. The advantage of this $\mathrm{T}_{\text {area }}$ is that it is both a 3-D measure and a continuous variable that provides additional objective evidence as a predictor of reverse remodeling. Therefore, the addition of $\mathrm{T}_{\text {area }}$ in patient selection for CRT is an easily available objective measure for better selection of patients with LBBB for CRT. Other studies showed the value of echocardiography ${ }^{23,24}$ and MRI in patient selection. ${ }^{25,26}$ It will be worthwhile to investigate whether our T-wave analysis can replace or add information to these approaches.

\subsubsection{Limitation}

This was a retrospective, single-center study with missing data as detailed in the methods section. Only $73 \%$ of patients had echocardiograms available before and after CRT implantation. A multicenter prospective study is required to confirm our results. Moreover, using an adapted version of the Kors method to calculate the VCG from the ECG is an estimation of the gold-standard Frank-VCG. However, previous studies have demonstrated that the Kors method shows the best resemblances to the Frank-VCG. ${ }^{12,27,28}$

\subsection{Conclusions}

In patients with LBBB morphology of the QRS complex, a larger baseline $\mathrm{T}_{\text {area }}$ is an important independent predictor of LVEF increase following CRT. Since this variable can be automatically calculated, it can easily be applied in the clinic, to further enhance our ability to predict response to CRT within LBBB patients. 


\section{References}

1. WT Abraham, WG Fisher, AL Smith, DB Delurgio, AR Leon, E Loh, DZ Kocovic, M Packer, AL Clavell, DL Hayes, et al. Cardiac resynchronization in chronic heart failure. N Engl J Med (2002) 346:1845-1853.

2. European Heart Rhythm Association, European Society of Cardiology, Heart Rhythm Society, Heart Failure Society of America, American Society of Echocardiography, American Heart Association, European Association of Echocardiography, Heart Failure Association, JC Daubert, L Saxon, et al. 2012 EHRA/HRS expert consensus statement on cardiac resynchronization therapy in heart failure: implant and follow-up recommendations and management. Heart Rhythm (2012) 9:1524-1576.

3. S Ploux, Z Whinnett, J Lumens, A Denis, A Zemmoura, M De Guillebon, K Ramoul, P Ritter, P Jaïs, J Clementy, M Haïssaguerre, and P Bordachar. Acute hemodynamic response to biventricular pacing in heart failure patients with narrow, moderately, and severely prolonged QRS duration. Heart Rhythm (2012) 9:1247-1250.

4. A Auricchio, C Stellbrink, C Butter, S Sack, J Vogt, AR Misier, D Böcker, M Block, JH Kirkels, A Kramer, E Huvelle, Pacing Therapies in Congestive Heart Failure II, Study Group, and Guidant Heart Failure Research Group. Clinical efficacy of cardiac resynchronization therapy using left ventricular pacing in heart failure patients stratified by severity of ventricular conduction delay. J Am Coll Cardiol (2003) 42:2109-2116.

5. W Zareba, H Klein, I Cygankiewicz, WJ Hall, S McNitt, M Brown, D Cannom, JP Daubert, M Eldar, MR Gold, et al. Effectiveness of Cardiac Resynchronization Therapy by QRS Morphology in the Multicenter Automatic Defibrillator Implantation Trial-Cardiac Resynchronization Therapy (MADIT-CRT). Circulation (2011) 123:1061-1072.

6. Y Seo, H Ito, S Nakatani, M Takami, S Naito, T Shiga, K Ando, Y Wakayama, K Aonuma, and J-CRT investigators. The role of echocardiography in predicting responders to cardiac resynchronization therapy. Circ J (2011) 75:1156-1163.

7. MO Sweeney, RJ van Bommel, MJ Schalij, CJW Borleffs, AS Hellkamp, and JJ Bax. Analysis of ventricular activation using surface electrocardiography to predict left ventricular reverse volumetric remodeling during cardiac resynchronization therapy. Circulation (2010) 121:626-634. 
8. K Vernooy, RNM Cornelussen, XAAM Verbeek, WYR Vanagt, A van Hunnik, M Kuiper, T Arts, HJGM Crijns, and FW Prinzen. Cardiac resynchronization therapy cures dyssynchronopathy in canine left bundle-branch block hearts. Eur Heart J (2007) 28:2148-2155.

9. Y Tian, P Zhang, X Li, Y Gao, T Zhu, L Wang, D Li, J Wang, C Yuan, and J Guo. True complete left bundle branch block morphology strongly predicts good response to cardiac resynchronization therapy. Europace (2013) 15:1499-1506.

10. W Zong, GB Moody, and D Jiang. A robust open-source algorithm to detect onset and duration of QRS complexes. In: Computers in Cardiology, 2003. 2003, pp. 737-740.

11. S Man, AM Algra, CA Schreurs, CJW Borleffs, RWC Scherptong, L van Erven, EE van der Wall, SC Cannegieter, MJ Schalij, and CA Swenne. Influence of the vectorcardiogram synthesis matrix on the power of the electrocardiogram-derived spatial QRS-T angle to predict arrhythmias in patients with ischemic heart disease and systolic left ventricular dysfunction. J Electrocardiol (2011) 44:410-415.

12. JA Kors, G van Herpen, AC Sittig, and JH van Bemmel. Reconstruction of the Frank vectorcardiogram from standard electrocardiographic leads: diagnostic comparison of different methods. Eur Heart J (1990) 11:1083-1092.

13. JM Nasir, BJ Rubal, SO Jones, and AD Shah. The effects of body mass index on surface electrocardiograms in young adults. J Electrocardiol (2012) 45:646-651.

14. JC Hsu, SD Solomon, M Bourgoun, S McNitt, I Goldenberg, H Klein, AJ Moss, E Foster, and MADIT-CRT Executive Committee. Predictors of super-response to cardiac resynchronization therapy and associated improvement in clinical outcome: the MADIT-CRT (multicenter automatic defibrillator implantation trial with cardiac resynchronization therapy) study. J Am Coll Cardiol (2012) 59:2366-2373.

15. A Brenyo, M Rao, A Barsheshet, D Cannom, A Quesada, S McNitt, DT Huang, AJ Moss, and W Zareba. QRS axis and the benefit of cardiac resynchronization therapy in patients with mildly symptomatic heart failure enrolled in MADIT-CRT. J Cardiovasc Electrophysiol (2013) 24:442-448.

16. D Levy, M Salomon, RB D’Agostino, AJ Belanger, and WB Kannel. Prognostic implications of baseline electrocardiographic features and their serial changes in subjects with left ventricular hypertrophy. Circulation (1994) 90:1786-1793.

17. T Aiba, GG Hesketh, AS Barth, T Liu, S Daya, K Chakir, VL Dimaano, TP Abraham, B O'Rourke, FG Akar, DA Kass, and GF Tomaselli. Electrophysiological consequences of dyssynchronous heart failure and its restoration by resynchronization therapy. Circulation (2009) 119:1220-1230.

18. A Arshad, AJ Moss, E Foster, L Padeletti, A Barsheshet, I Goldenberg, H Greenberg, WJ Hall, S McNitt, W Zareba, S Solomon, JS Steinberg, and MADIT-CRT Executive Committee. Cardiac resynchronization therapy is more effective in women than in 
men: the MADIT-CRT (Multicenter Automatic Defibrillator Implantation Trial with Cardiac Resynchronization Therapy) trial. J Am Coll Cardiol (2011) 57:813-820.

19. S Zabarovskaja, F Gadler, F Braunschweig, M Ståhlberg, J Hörnsten, C Linde, and LH Lund. Women have better long-term prognosis than men after cardiac resynchronization therapy. Europace (2012) 14:1148-1155.

20. MGSJ Sutton, T Plappert, KE Hilpisch, WT Abraham, DL Hayes, and E Chinchoy. Sustained reverse left ventricular structural remodeling with cardiac resynchronization at one year is a function of etiology: quantitative Doppler echocardiographic evidence from the Multicenter InSync Randomized Clinical Evaluation (MIRACLE). Circulation (2006) 113:266-272.

21. LR Dekker, H Rademaker, JT Vermeulen, T Opthof, R Coronel, JA Spaan, and MJ Janse. Cellular uncoupling during ischemia in hypertrophied and failing rabbit ventricular myocardium: effects of preconditioning. Circulation (1998) 97:1724-1730.

22. M Potse, D Krause, L Bacharova, R Krause, FW Prinzen, and A Auricchio. Similarities and differences between electrocardiogram signs of left bundle-branch block and leftventricular uncoupling. Europace (2012) 14 Suppl 5:v33-v39.

23. GE Leenders, MJ Cramer, MD Bogaard, M Meine, PA Doevendans, and BW De Boeck. Echocardiographic prediction of outcome after cardiac resynchronization therapy: conventional methods and recent developments. Heart Fail Rev (2011) 16:235250.

24. J Gorcsan 3rd. Role of echocardiography to determine candidacy for cardiac resynchronization therapy. Curr Opin Cardiol (2008) 23:16-22.

25. JA White, R Yee, X Yuan, A Krahn, A Skanes, M Parker, G Klein, and M Drangova. Delayed enhancement magnetic resonance imaging predicts response to cardiac resynchronization therapy in patients with intraventricular dyssynchrony. J Am Coll Cardiol (2006) 48:1953-1960.

26. H Cochet, A Denis, S Ploux, J Lumens, S Amraoui, N Derval, F Sacher, P Reant, S Lafitte, P Jais, F Laurent, P Ritter, M Montaudon, and P Bordachar. Pre- and intraprocedural predictors of reverse remodeling after cardiac resynchronization therapy: an MRI study. J Cardiovasc Electrophysiol (2013) 24:682-691.

27. DL Cortez and TT Schlegel. When deriving the spatial QRS-T angle from the 12-lead electrocardiogram, which transform is more Frank: regression or inverse Dower? $J$ Electrocardiol (2010) 43:302-309.

28. CA Schreurs, AM Algra, SC Man, SC Cannegieter, EE van der Wall, MJ Schalij, JA Kors, and CA Swenne. The spatial QRS-T angle in the Frank vectorcardiogram: accuracy of estimates derived from the 12-lead electrocardiogram. J Electrocardiol (2010) 43:294-301. 



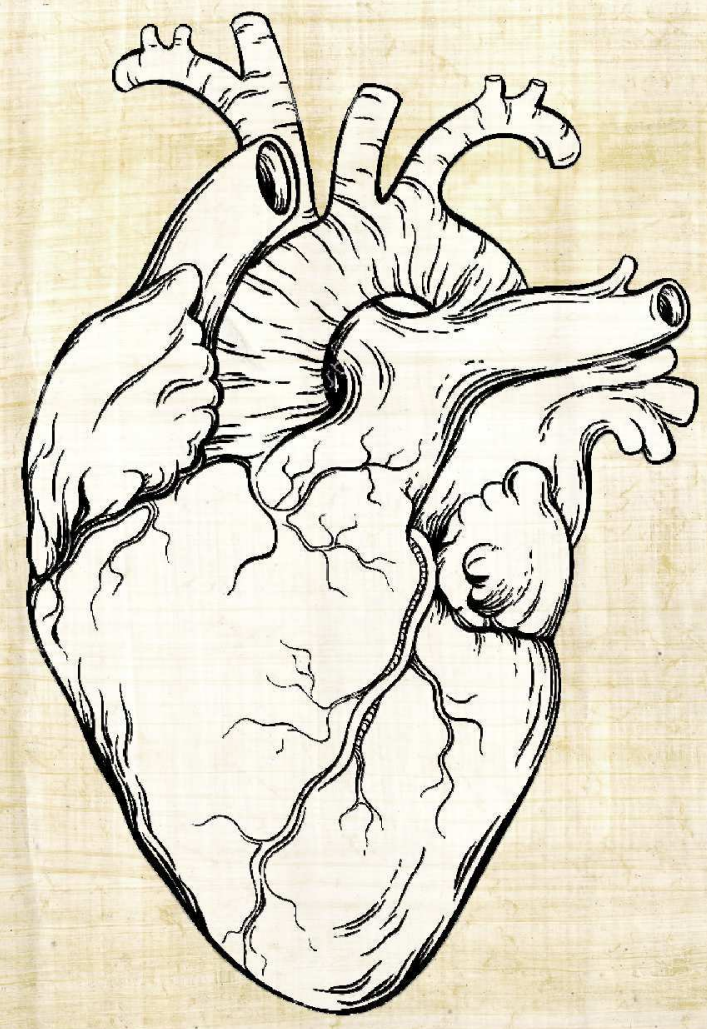




\title{
Chapter
}

\section{T-wave area as biomarker of clinical response to cardiac resynchronization}

\author{
therapy
}

The content of this chapter is based on:

Elien B. Engels, ${ }^{1, *}$ Eszter M. Végh, ${ }^{2,3, *}$ Caroline J.M. $v a n$ Deursen, ${ }^{1}$ Béla Merkely, ${ }^{3}$ Kevin Vernooy, ${ }^{4}$ Jagmeet P. Singh, ${ }^{2}$ and Frits W. Prinzen ${ }^{1}$ (2016).

T-wave area as biomarker of clinical response to cardiac resynchronization therapy. Europace 18(7):1077-1085.

\footnotetext{
* Authors contributed equally.

${ }^{1}$ Department of Physiology, CARIM School for Cardiovascular Diseases, Maastricht University, Maastricht, the Netherlands.

${ }^{2}$ Cardiac Arrhythmia Service, Massachusetts General Hospital, Harvard Medical School, Boston, MA, USA.

${ }^{3}$ Semmelweis University Heart and Vascular Center, Budapest, Hungary.

${ }^{4}$ Department of Cardiology, Maastricht University Medical Center, Maastricht, the Netherlands.
} 


\section{Abstract}

Introduction: There is increasing evidence that left bundle branch block (LBBB) morphology on the ECG is a positive predictor for response to cardiac resynchronization therapy (CRT). We previously demonstrated that the vectorcardiography(VCG)-derived $T_{\text {area }}$ predicts echocardiographic CRT response in LBBB patients. In the present study we investigate whether the $\mathrm{T}_{\text {area }}$ also predicts long-term clinical outcome to CRT.

Methods and Results: This is a retrospective study consisting of 335 CRT recipients. Primary endpoint was the composite of heart failure (HF) hospitalization, heart transplantation, left ventricular assist device implantation or death during a 3-year follow-up period. HF hospitalization or death alone were secondary endpoints. The patient subgroup with a large $\mathrm{T}_{\text {area }}$ and LBBB $36 \%$ reached the primary endpoint, which was considerably less $(\mathrm{P}<0.01)$ than for patients with $\mathrm{LBBB}$ and a small $\mathrm{T}_{\text {area }}$ or non-LBBB patients with a small or large $\mathrm{T}_{\text {area }}(48 \%, 57 \%$, and $51 \%$, respectively). Similar differences were observed for the secondary endpoints HF hospitalization $(31 \%$ vs. $51 \%, 51 \%$, and $38 \%$, respectively, $\mathrm{P}<0.01)$ and death $(19 \%$ vs. $42 \%, 34 \%$, and $42 \%$, respectively, $\mathrm{P}<0.01)$. In multivariate analysis a large $\mathrm{T}_{\text {area }}$ and $\mathrm{LBBB}$ were the only independent predictor of the combined endpoint beside high creatinine levels and use of diuretics.

Conclusions: $\mathrm{T}_{\text {area }}$ may be useful as an additional biomarker to stratify CRT candidates and improve selection of those most likely to benefit from CRT. A large $\mathrm{T}_{\text {area }}$ may derive its predictive value from reflecting good intrinsic myocardial properties and a substrate for CRT. 


\subsection{Introduction}

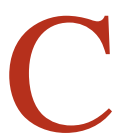

ARDIAC resynchronization therapy (CRT) has emerged as an effective therapy in patients with a decreased left ventricular ejection fraction (LVEF) combined with a left ventricular conduction delay, especially due to left bundle branch block (LBBB). It has been demonstrated that CRT improves both the morbidity and mortality. ${ }^{1}$ Nevertheless, there remain a considerable number of non-responders to CRT $(30-50 \%)^{2}$. One way to reduce this number is to improve the patient selection.

The current guidelines ${ }^{3}$ emphasize the importance of LBBB morphology of the QRS complex and the QRS duration. Both variables are a representation of the depolarization sequence during one heart cycle. However, T-wave variables that reflect the repolarization phase of the myocardial action potential, are not taken into account. In a previous study ${ }^{4}$, we demonstrated that the $\mathrm{T}_{\text {area }}$ as determined by vectorcardiography predicts the echocardiographic response to CRT in LBBB patients. Patients with both a LBBB morphology and a large $\mathrm{T}_{\text {area }}$ had a $75 \%$ chance of echocardiographic response (absolute increase in LVEF $\geq 5 \%$ after 6 months follow-up), as opposed to $53 \%$ in patients with LBBB and a small $\mathrm{T}_{\text {area }}$ and $40 \%$ in patients with non-LBBB morphology. ${ }^{4}$ The aim of the current study was to investigate whether the $\mathrm{T}_{\text {area }}$ in LBBB patients also predicts the long-term clinical outcome to CRT. In order to do so, we extended the patient group from the previous study with CRT patients with known clinical follow-up of at least 3 years.

The electrocardiograms (ECGs) and vectorcardiograms (VCGs) of all patients were retrospectively investigated to determine the potential predictive value of the $\mathrm{T}_{\text {area }}$ in combination with different QRS morphologies. This potential predictive value was also compared to other relevant electrocardiographic parameters.

\subsection{Methods}

\subsubsection{Study Population}

The current study population consisted of 569 patients who underwent CRT at the Massachusetts General Hospital (MGH). All patients had New York Heart Association class III/IV symptoms, LVEF $<35 \%$ and QRS duration $>120 \mathrm{~ms}$. In the present study patients with previous pacing $(\mathrm{n}=116)$, frequent premature ventricular contractions or unacceptable noise on the ECG $(n=38)$, or missing baseline ECGs $(n=80)$ were excluded, leading to a total of 335 patients included in the analysis. This study population is equal to the cohort described previously ${ }^{4}$, but it was extended with 91 CRT patients of whom we did have long-term clinical but not echocardiographic follow-up. Patients had follow-up visits in the MGH multidisciplinary clinic, where device control, heart failure (HF) specialist and echocardiography imaging were available. The project was approved by the MGH Institutional 
Review Board and Ethics Committee and was conducted in accordance with the Declaration of Helsinki.

\subsubsection{Study endpoints}

The patients were followed for an average of 2.4 years with the combined endpoint of HF hospitalization, heart transplantation, left ventricular assist device (LVAD) implantation, and all-cause death (HTLD) as primary endpoint. HF hospitalization was defined as necessity of in-patient admission due to acute cardiac decompensation, symptoms of shortness of breath, signs of congestion on the chest radiograph, peripheral oedema, or relieve of shortness of breath after intravenous medical therapy. Secondary endpoints included HF hospitalization or death alone. Clinical outcome data were gained with the review of hospital medical records and social security death index.

\subsubsection{ECG and VCG analysis}

All 12-lead ECGs measured up to 6 months prior to CRT implantation were recorded in supine position at a frequency of $250 \mathrm{~Hz}$. All ECGs were measured by MAC 5500 ECG Machine (GE Healthcare, Waukesha, WI, USA) and stored in the MUSE Cardiology Information system (GE Medical System). These digital PDF files contain vector graphics which were used to extract the original digital ECG, as previously described. ${ }^{4}$ The ECGs could be analyzed and VCGs could be constructed by the Kors method ${ }^{5}$ and analyzed using the methods described earlier in detail. ${ }^{4}$ Briefly, the digital ECGs were semi-automatically analyzed using a custom-made computer program written in MATLAB R2010b (MathWorks, Natick, MA). After band-pass filtering between 0.5 and $40 \mathrm{~Hz}$, the QRS complex was identified using the curve length transformation ${ }^{6}$ and the end of the T-wave as the intersection between the maximum T-wave slope after the final T-wave peak and the isoelectric line in the TP segment. The QRS axis was calculated using lead I and II. Patients were classified as LBBB or nonLBBB using the MADIT-CRT criteria (QRS duration $\geq 130 \mathrm{~ms}$; QS or $\mathrm{rS}$ in $\mathrm{V}_{1}$; notched or slurring $\mathrm{R}$ waves in leads $\mathrm{I}, \mathrm{aVL}, \mathrm{V}_{5}$, or $\mathrm{V}_{6}$; absent q waves in leads $\mathrm{V}_{5}$ and $\mathrm{V}_{6}$ ). ${ }^{7}$

The digital ECGs were subsequently converted to VCGs using the matrix multiplication provided by Kors et al. ${ }^{5}$ After defining the begin and end of the QRS complex and the end of the T-wave, QRS duration, QT interval, and QTc intervals could be measured. The maximum distance between the origin $(0,0,0)$ and a point on the three-dimensional QRS- or T-vector loop were represented by the variables QRS- and T-vector amplitude, respectively. The maximal vectors could also be described by their orientation using the azimuth (angle in the transversal plane with backward vector direction being negative) and elevation (angle in craniocaudal direction with upward vector directions being $>90^{\circ}$ ). ${ }^{8}$ The angle between the two maximal vectors was defined by the QRS/T angle. The area of the 
QRS- and T-loop were conducted from the VCG as the 'three-dimensional' areas between the curve and the baseline in the $\mathrm{X}, \mathrm{Y}$ and $\mathrm{Z}$ direction and calculated using the formulas $\mathrm{QRS}_{\text {area }}=\sqrt{\mathrm{QRS}_{\text {area } \mathrm{x}}^{2}+\mathrm{QRS}_{\text {area }, \mathrm{y}}^{2}+\mathrm{QRS}_{\text {area }, \mathrm{z}}^{2}}$ or $\mathrm{T}_{\text {area }}=\sqrt{\mathrm{T}_{\text {area }, \mathrm{x}}^{2}+\mathrm{T}_{\text {area } \mathrm{y}}^{2}+\mathrm{T}_{\text {area } \mathrm{z}}^{2}} \cdot 9$

\subsubsection{Statistical Analysis}

Continuous and discrete variables are presented as mean \pm standard deviation (SD) and counts (percentages), respectively. Linear correlations were evaluated by Pearson's correlation. Clinical characteristic variables between subgroups were compared with the one-way ANOVA test for continuous variables and follow-up paired comparisons were made using the Tukey test. The discrete variables were compared with the $\chi^{2}$-test. The Kaplan-Meier estimator of survival function was used to evaluate the associations between VCG-derived variables and reaching the primary or secondary endpoints. The log-rank test was used to determine probability values. The predictive performance of electrical parameters in predicting CRT response was evaluated by the Cox proportional hazard regression analyses and tested using the Wald-test. The Cox regression models were fitted for covariates $(\mathrm{P}<0.05)$, where a backward stepwise selection approach was used. For descriptive purposes, analysis of subsets was performed in patients with a baseline $\mathrm{T}_{\text {area }}<$ and $\geq$ the median with use of the Breslow-Day test for heterogeneity testing. A two-sided P-value $<0.05$ was considered statistically significant. The statistical analysis was performed using IBM SPSS statistics software version 21 (SPSS Inc, Chicago, Illinois).

\subsection{Results}

\subsubsection{Patient Characteristics}

The baseline characteristics of the 335 patients are listed in Table 6.1. The patients had a low LVEF and a prolonged QRS duration, consistent with the established indications for CRT. Most patients were male and in sinus rhythm. In addition, two-thirds of the patients had ischemic HF etiology and the same amount of patients had LBBB.

\subsubsection{The predictive ability of areas derived from the VCG}

The predictive power of LBBB and QRS duration is shown in Fig. 6.1A using Kaplan-Meier curves for the HTLD endpoint. There is no significant difference in the chance of reaching HTLD for patients with a QRS duration $\geq 150$ ms compared to patients with a QRS duration $<150 \mathrm{~ms}(\mathrm{P}=0.41)$. However, patients with a LBBB morphology performed significantly better than patients without LBBB $(\mathrm{P}<0.01)$. This distinction by LBBB was larger than that for QRS-area but similar to that for $\mathrm{T}_{\text {area }}$ and sum QRST area (Fig. 6.1B). 
Table 6.1: Baseline ECG and VCG analysis results of the entire cohort $(n=335)$ as well as the entire cohort divided by primary endpoint (HTLD) or survival status at the end of a 3-year followup

\begin{tabular}{|c|c|c|c|c|c|}
\hline Variable & $\begin{array}{l}\text { Entire cohort } \\
\qquad(\mathrm{n}=335)\end{array}$ & $\begin{array}{c}\text {-HTLD } \\
(\mathrm{n}=203)\end{array}$ & $\begin{array}{c}+ \text { HTLD } \\
(\mathrm{n}=132)\end{array}$ & $\begin{array}{l}\text { Survivors } \\
(\mathrm{n}=262)\end{array}$ & $\begin{array}{c}\text { Non-survivors } \\
\quad(\mathrm{n}=73)\end{array}$ \\
\hline \multicolumn{6}{|l|}{ Baseline characteristics } \\
\hline Age (years) & $67 \pm 13$ & $66 \pm 13$ & $69 \pm 12$ & $66 \pm 13$ & $71 \pm 11^{\S}$ \\
\hline Female $(\mathrm{n}, \%)$ & $70(21)$ & $50(25)$ & $20(15)^{\star}$ & $59(23)$ & $11(15)$ \\
\hline Baseline LVEF (\%) & $24 \pm 7$ & $24 \pm 7$ & $23 \pm 7$ & $24 \pm 7$ & $23 \pm 7$ \\
\hline \multicolumn{6}{|l|}{ NYHA class } \\
\hline II $(\mathrm{n}, \%)$ & $8(3)$ & $6(3)$ & $2(2)$ & $8(3)$ & $0(0)$ \\
\hline III $(\mathrm{n}, \%)$ & $236(70)$ & $148(73)$ & $88(67)$ & $190(73)$ & $46(63)$ \\
\hline IV (n, \%) & $31(9)$ & $16(8)$ & $15(11)$ & $22(8)$ & $9(12)$ \\
\hline Unknown (n, \%) & $60(18)$ & $33(7)$ & $27(20)$ & $42(16)$ & $18(25)$ \\
\hline Ischemic HF etiology(n, \%) & $192(57)$ & $105(52)$ & $87(66)^{\star}$ & $143(55)$ & $49(67)$ \\
\hline $\operatorname{LBBB}(\mathrm{n}, \%)$ & $199(59)$ & $132(65)$ & $67(51)^{\dagger}$ & $164(63)$ & $35(48)^{\ddagger}$ \\
\hline Chronic AF (n, \%) & $85(25)$ & $47(23)$ & $38(29)$ & $66(25)$ & $19(26)$ \\
\hline \multicolumn{6}{|l|}{ ECG measurements } \\
\hline Heart rate (bpm) & $75 \pm 15$ & $75 \pm 15$ & $76 \pm 14$ & $75 \pm 15$ & $75 \pm 14$ \\
\hline QRS axis $\left(^{\circ}\right)$ & $-20 \pm 58$ & $-17 \pm 57$ & $-24 \pm 59$ & $-22 \pm 56$ & $-11 \pm 64$ \\
\hline \multicolumn{6}{|l|}{ VCG measurements } \\
\hline QRS duration (ms) & $172 \pm 33$ & $172 \pm 32$ & $172 \pm 35$ & $173 \pm 34$ & $170 \pm 31$ \\
\hline QT interval (ms) & $467 \pm 86$ & $467 \pm 83$ & $466 \pm 90$ & $466 \pm 86$ & $469 \pm 85$ \\
\hline QTc interval (ms) & $516 \pm 77$ & $515 \pm 74$ & $517 \pm 82$ & $515 \pm 78$ & $518 \pm 75$ \\
\hline QRS amplitude (mV) & $1.5 \pm 0.5$ & $1.5 \pm 0.5$ & $1.4 \pm 0.5$ & $1.5 \pm 0.5$ & $1.4 \pm 0.5$ \\
\hline $\mathrm{QRS}_{\text {area }}(\mu \mathrm{Vs})$ & $88 \pm 46$ & $92 \pm 47$ & $82 \pm 45$ & $91 \pm 47$ & $78 \pm 40^{+}$ \\
\hline QRS azimuth $\left(^{\circ}\right)$ & $-62 \pm 57$ & $-69 \pm 47$ & $-49 \pm 70^{\dagger}$ & $-66 \pm 52$ & $-44 \pm 73^{+}$ \\
\hline QRS elevation $\left({ }^{\circ}\right)$ & $90 \pm 24$ & $89 \pm 24$ & $92 \pm 24$ & $90 \pm 23$ & $90 \pm 24$ \\
\hline $\mathrm{T}$ amplitude (mV) & $0.5 \pm 0.2$ & $0.5 \pm 0.3$ & $0.4 \pm 0.2^{\dagger}$ & $0.5 \pm 0.3$ & $0.4 \pm 0.2^{\S}$ \\
\hline $\mathrm{T}_{\text {area }}(\mu \mathrm{Vs})$ & $82 \pm 47$ & $88 \pm 47$ & $74 \pm 45^{\dagger}$ & $87 \pm 49$ & $66 \pm 35^{\S}$ \\
\hline T-vector azimuth $\left(^{\circ}\right)$ & $77 \pm 65$ & $77 \pm 62$ & $76 \pm 71$ & $77 \pm 64$ & $76 \pm 72$ \\
\hline T-vector elevation $\left({ }^{\circ}\right)$ & $85 \pm 26$ & $87 \pm 26$ & $83 \pm 26$ & $85 \pm 26$ & $85 \pm 27$ \\
\hline QRS/T angle $\left(^{\circ}\right)$ & $155 \pm 30$ & $156 \pm 30$ & $154 \pm 27^{\star}$ & $155 \pm 31$ & $156 \pm 21$ \\
\hline $\mathrm{QRS}+\mathrm{T}$ area $(\mu \mathrm{Vs})$ & $170 \pm 85$ & $179 \pm 84$ & $156 \pm 82^{\star}$ & $177 \pm 87$ & $144 \pm 68^{\S}$ \\
\hline
\end{tabular}

Variables are shown as counts (percentage) or mean \pm standard deviation when appropriate.

AF: atrial fibrillation, HF: heart failure, LBBB: left bundle branch block, LVEF: left ventricular ejection fraction, HTLD: composite endpoint of HF hospitalization, heart transplantation, left ventricular assist device, or death.

${ }^{\star} \mathrm{P}<0.05 ;{ }^{\dagger} \mathrm{P}<0.01$ compared to the patient-group whom did not reach HTLD.

${ }^{\ddagger} \mathrm{P}<0.05 ;{ }^{\S} \mathrm{P}<0.01$ compared to the survivor-group.

Patients with QRS-, T-, and sum QRST areas $\geq$ than their median values all reached the primary endpoint significantly less than patients with areas $<$ the median values. Moreover, patients reaching the primary endpoint had a significantly smaller $\mathrm{T}_{\text {area }}$ compared to patients not reaching the primary endpoint, while $\mathrm{QRS}_{\text {area }}$ was not significantly different between the two groups (Table 6.1).

Since LBBB morphology of the QRS complex is a well-known predictor for CRT response and because the percentage of patients with LBBB morphology was significantly higher in the patient group not reaching the primary endpoint (Table 6.1), the patient population was divided according to QRS morphology and subsequently subdivided into cohorts with $<$ or 

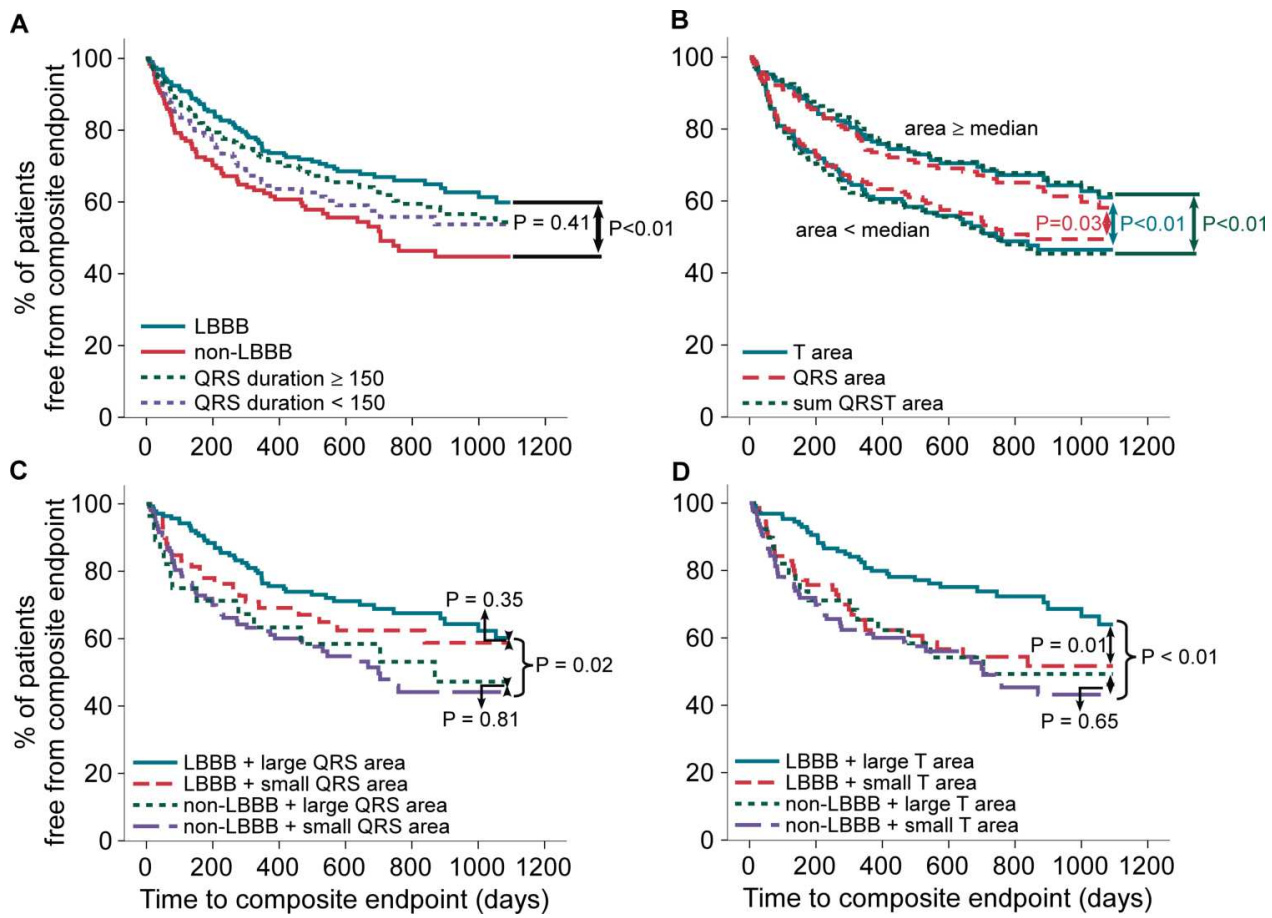

Figure 6.1: Kaplan-Meier estimates of the probability free of composite endpoint HTLD after 3 years. The results of current guideline variables LBBB and QRS duration are shown in (A) and the results of the new VCG variables $\mathrm{T}_{\text {area }}, \mathrm{QRS}_{\text {area }}$, and sum QRST area are shown in (B). The patients were then subdivided into four groups according to their QRS morphology and $\mathrm{QRS}_{\text {area }}(\mathbf{C})$ or $\mathrm{T}_{\text {area }}(\mathbf{D})$. Large $\mathrm{QRS}_{\text {area }}$ or $\mathrm{T}_{\text {area }}$ are values $\geq$ median value and small $\mathrm{QRS}_{\text {area }}$ or $\mathrm{T}_{\text {area }}$ are values $<$ median value.

$\geq$ median $\mathrm{QRS}_{\text {area }}$ or $\mathrm{T}_{\text {area }}$. Within non-LBBB and LBBB subgroups, $\mathrm{QRS}_{\text {area }}$ did not significantly influence the chance of reaching the HTLD endpoint at 3 year follow-up $(\mathrm{P}=0.81$ and $\mathrm{P}=0.35$, respectively; Fig. 6.1C). In contrast, the subgroup of patients with LBBB and a large $\mathrm{T}_{\text {area }}$ had a significantly lower incidence of reaching the HTLD endpoint (36\%) compared to the LBBB patients with a small $\mathrm{T}_{\text {area }}(48 \%, \mathrm{P}=0.01)$ as well as the non-LBBB patient groups $(\mathrm{P}<0.01)$ (Fig. 6.1D). $\mathrm{T}_{\text {area }}$ did not significantly affect HTLD in the non-LBBB patients $(57 \%$ for a small $\mathrm{T}_{\text {area }} \mathrm{vs} .51 \%$ for a larger $\mathrm{T}_{\text {area }}, \mathrm{P}=0.65$ ).

The cohort with $\mathrm{LBBB}$ and a large $\mathrm{T}_{\text {area }}$ trended to contain more females $(\mathrm{P}=0.09)$ and contained significantly less patients with ischemic HF etiology compared to the other subgroups (Table 6.2). Indeed, the highest percentage of patients with ischemic HF etiology was found in the patient group with $\mathrm{T}_{\text {areas }}$ in its first quartile (Fig. 6.2). In addition, 129 out of 168 patients $(77 \%)$ with a large $\mathrm{T}_{\text {area }}$ had a LBBB QRS morphology while LBBB was only present in 70 out of 167 patients $(42 \%)$ with a small $\mathrm{T}_{\text {area }}(\mathrm{P}<0.01$, Fig. 6.2). The QRS 
duration increases when the $\mathrm{T}_{\text {area }}$ increases, but the association between these two variables is not as high as the association between $\mathrm{T}_{\text {area }}$ and the number of LBBB patients.

Table 6.2: Baseline patient characteristics after dividing patients according to their QRS morphology and $\mathrm{T}_{\text {area }}$. The median cut-off value for the $\mathrm{T}_{\text {area }}$ was based on the entire cohort

\begin{tabular}{lcccc}
\hline & \multicolumn{2}{c}{ LBBB } & \multicolumn{2}{c}{ Non-LBBB } \\
& $\begin{array}{c}\text { T-area } \\
<\text { Median } \\
(\mathrm{n}=70)\end{array}$ & $\begin{array}{c}\geq \text { M-area } \\
(\mathrm{n}=129)\end{array}$ & $\begin{array}{c}\text { T-area } \\
<\text { Median } \\
(\mathrm{n}=97)\end{array}$ & $\begin{array}{c}\text { T-area } \\
(\mathrm{n}=39)\end{array}$ \\
\hline Age (years) & $67.3 \pm 10.4$ & $67.6 \pm 12.8$ & $67.1 \pm 13.3$ & $65.7 \pm 15.9$ \\
Female $(\mathrm{n}, \%)$ & $13(18.6)$ & $38(29.5)$ & $14(14.4)$ & $5(12.8)$ \\
Ischemic HF etiology $(\mathrm{n}, \%)$ & $45(64.3)$ & $63(48.8)^{\star}$ & $61(62.9)$ & $23(59.0)$ \\
Hypertension $(\mathrm{n}, \%)$ & $53(75.7)$ & $104(80.6)$ & $75(77.3)$ & $25(64.1)$ \\
CABG $(\mathrm{n}, \%)$ & $33(47.1)$ & $46(35.7)$ & $44(45.4)$ & $18(46.2)$ \\
Heart rate $(\mathrm{bpm})$ & $74 \pm 14$ & $75 \pm 15$ & $77 \pm 14$ & $74 \pm 15$ \\
QRS duration $(\mathrm{ms})$ & $170 \pm 29$ & $184 \pm 30^{\dagger}$ & $158 \pm 32$ & $173 \pm 39$ \\
QTc interval $(\mathrm{ms})$ & $514 \pm 87$ & $532 \pm 74$ & $492 \pm 64$ & $526 \pm 87$ \\
$\mathrm{QRS}_{\text {area }}(\mu \mathrm{Vs})$ & $77 \pm 34$ & $121 \pm 44^{\dagger}$ & $50 \pm 22$ & $88 \pm 36^{\dagger}$ \\
$\mathrm{T}_{\text {area }}(\mu \mathrm{Vs})$ & $52 \pm 15$ & $121 \pm 40^{\dagger}$ & $42 \pm 15$ & $108 \pm 42^{\dagger}$ \\
\hline
\end{tabular}

HF: Heart failure, CABG: Coronary artery bypass surgery.

${ }^{\star} \mathrm{P}<0.05$ compared with the T-area $<$ median group with the same LBBB conditions.

${ }^{\dagger} \mathrm{P}<0.01$ compared with the T-area $<$ median group with the same LBBB conditions.

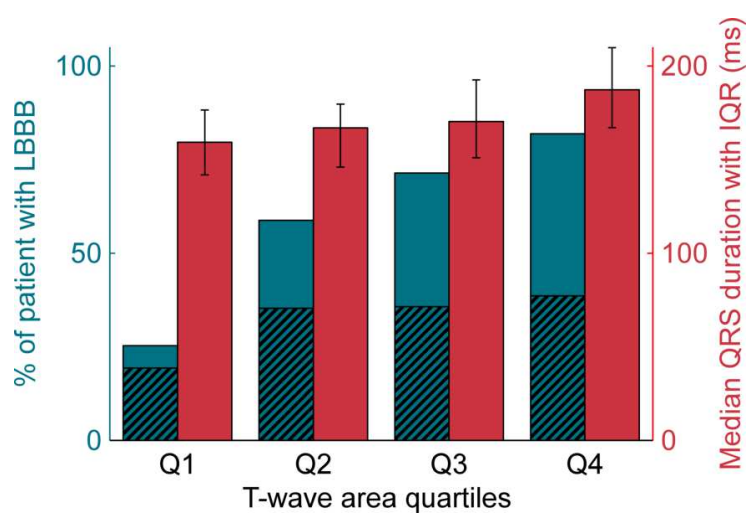

Figure 6.2: Histogram showing the associations between LBBB (Turquoise, left y-axis) or QRS duration (red, right $\mathrm{y}$-axis) with $\mathrm{T}_{\text {area }}$. The percentage of ischaemic patients was indicated by shading in the LBBB bars. $\mathrm{T}_{\text {area }}$ was divided into quartiles, indicated by Q1, Q2, Q3, and $\mathrm{Q} 4$ on the $\mathrm{x}$-axis.

In a univariate analysis of the total population ischemic $\mathrm{HF}$ etiology, $\mathrm{LBBB}, \mathrm{QRS}$ area, T amplitude, and $\mathrm{T}_{\text {area }}$ were some of the significant predictors for reaching HTLD (Table 6.3). Since $\mathrm{T}$ amplitude and $\mathrm{T}_{\text {area }}$ are mutually dependent $(\mathrm{R}=0.87)$, only $\mathrm{T}_{\text {area }}$ was included in the multivariate model. Multivariate analysis indicated that besides baseline creatinine levels and diuretics, only LBBB and $\mathrm{T}_{\text {area }}$ remained in the model. The multivariate model indicated 
that patients with a large $\mathrm{T}_{\text {area }}$ had a $37 \%$ lower risk of reaching HTLD compared to those with a small $\mathrm{T}_{\text {area }}$. Additionally, within LBBB patients the hazard ratio for HTLD between a $\mathrm{T}_{\text {area }} \geq$ or $<$ the median value was 0.54 , a ratio that remained significant after adjustment for significant covariates (hazard ratio $[\mathrm{HR}]=0.45, \mathrm{P}<0.01$; Table 6.3).

\subsubsection{Echocardiographic vs. clinical outcome}

The relation of reaching any adverse clinical outcome and echocardiography based on echocardiographic reverse remodeling was also examined. The mean increase in LVEF in patients reaching none of the combined endpoint HTLD was $10.4 \pm 10.6 \%$ while this improvement in LVEF was only $3.4 \pm 8.9 \%$ in patients who did reach the combined endpoint $(\mathrm{P}<0.01)$. Similarly, echo-responders ( $\triangle \mathrm{LVEF} \geq 5 \%$ after 6 months follow-up) reached HTLD less often than the echo-non-responders $\operatorname{did}(24 \%$ vs. $51 \%, \mathrm{P}<0.01)$.

\subsubsection{Tarea as additional predictor of mortality and heart failure hospitalization}

Cox-regression hazard model revealed the $\mathrm{T}_{\text {area }}$ also as a strong predictor of HF hospitalization and mortality, even after adjusting for significant covariates such as gender and medication. The chance of HF hospitalization was almost twice as high for patients with a small $\mathrm{T}_{\text {area }}(\mathrm{HR}=0.53,95 \%$ confidence interval $[\mathrm{CI}]: 0.35-0.83, \mathrm{P}<0.01)$. Indeed, the amount of HF hospitalizations after 3 years of CRT was highest in the non-LBBB group and LBBB subgroups with a small $\mathrm{T}_{\text {area }}$, whereas HF hospitalization was significantly lower in LBBB patients with a large $\mathrm{T}_{\text {area }}$ (Fig. 6.3A).

With regard to mortality, survivors had a higher prevalence of LBBB and large $\mathrm{T}_{\text {area }}$ (Table 6.1). Similarly, the chance of survival was approximately twice as large in the patient group with a large $\mathrm{T}_{\text {area }}$ compared to patients with a small $\mathrm{T}_{\text {area }}(\mathrm{HR}=0.57$, 95\% CI: $0.35-0.96, \mathrm{P}=0.03)$. This difference was even larger when only LBBB patients were analyzed, i.e. $\mathrm{LBBB}$ patients with a large $\mathrm{T}_{\text {area }}$ had on average a $\sim 3$ times lower chance of death compared to LBBB patients with a small $\mathrm{T}_{\text {area }}(\mathrm{HR}=0.34,95 \% \mathrm{CI}$ : $0.17-0.67, \mathrm{P}<0.01)$. Although descriptive subset analysis showed that the effect of $\mathrm{T}_{\text {area }}$ on mortality was constant throughout different subgroups, it was not present for patients without LBBB (Fig. 6.4). Analyzing all subgroups, the mortality risk was highest in patients with non-LBBB (42\%). For patients with LBBB, mortality was significantly and considerably lower in patients with a large $\mathrm{T}_{\text {area }}(19 \%)$ than in those with a small $\mathrm{T}_{\text {area }}(42 \%)$ (Fig. 6.3B). 


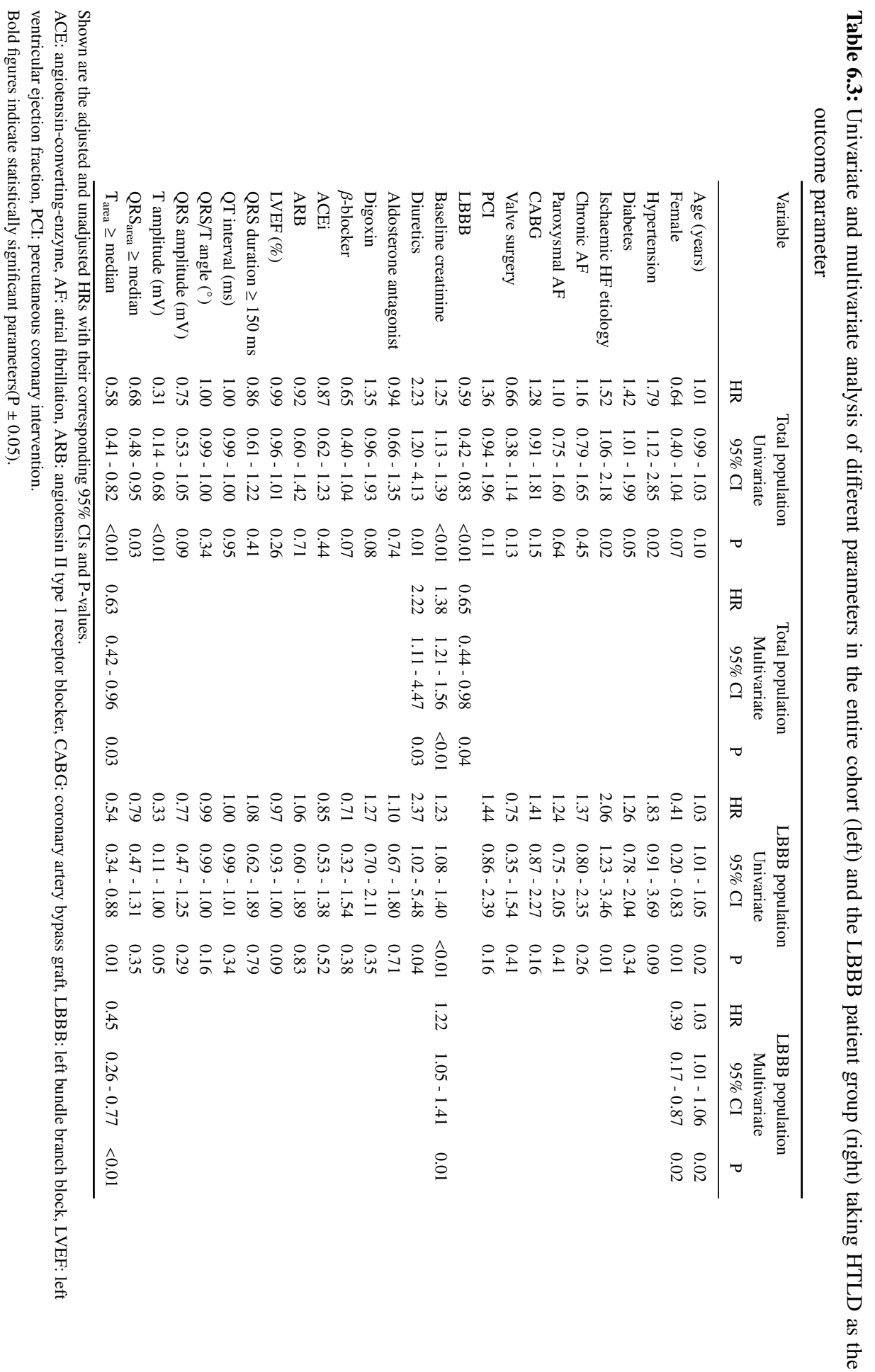



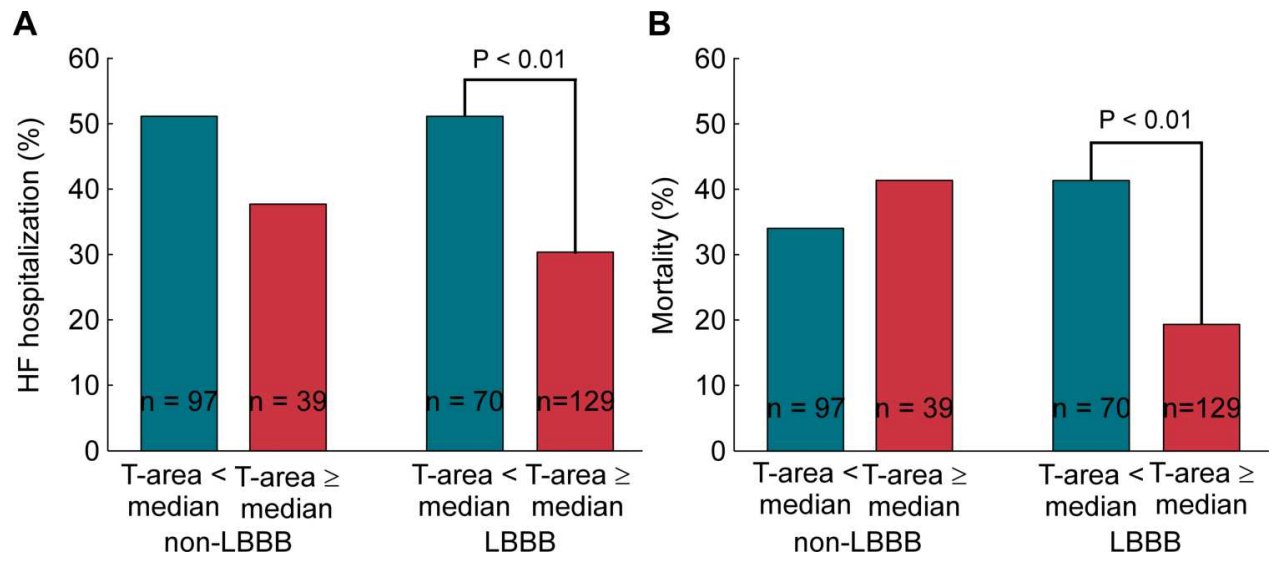

Figure 6.3: The percentage of patients reaching either HF hospitalization (A) or death (B) after dividing patients into those with LBBB or non-LBBB QRS morphology, and subdividing those with $\mathrm{T}_{\text {area }}<$ or $\geq$ the median value. The number of patients within one group is indicated in the bars.

\subsection{Discussion}

This study shows that in CRT patients with LBBB, a large baseline $\mathrm{T}_{\text {area }}$ is a strong predictor of a good clinical outcome (HF hospitalization, transplantation, LVAD, death) during 3-year follow-up. In combination with the data from a previous study, showing that a large $\mathrm{T}_{\text {area }}$ was predictive of a larger increase in LVEF in LBBB patients ${ }^{4}$, the present study implies that $T_{\text {area }}$ may be useful as an additional biomarker to stratify CRT candidates and improve selection of those most likely to benefit from CRT.

\subsection{1 $T_{\text {area, }}$ an additional predictor of long-term clinical response to CRT}

The present study corroborates findings from large randomized trials that LBBB is an important predictor of CRT response. However, interestingly, T-wave analysis appears to contribute to the prediction of CRT response on top of LBBB morphology. While LBBB patients with a large $\mathrm{QRS}_{\text {area }}$ tended to respond better to CRT than those with small $\mathrm{QRS}_{\text {areas }}$, this difference was more obvious in the $\mathrm{T}_{\text {area }}$. Patients with a large $\mathrm{T}_{\text {area }}$ and LBBB morphology had a lower chance of reaching one of the composite endpoints (HTLD) when receiving CRT compared with non-LBBB patients with small or large $\mathrm{T}_{\text {area }}$ and LBBB patients with a small $\mathrm{T}_{\text {area }}(36 \%$ as opposed to $57 \%, 51 \%$, and $48 \%$ respectively). Similar differences were seen for the secondary outcomes HF hospitalization (31\% vs. $51 \%$, 38\%, and $51 \%)$ and death (19\% vs. 34\%, $42 \%$, and $42 \%$ ) alone. 


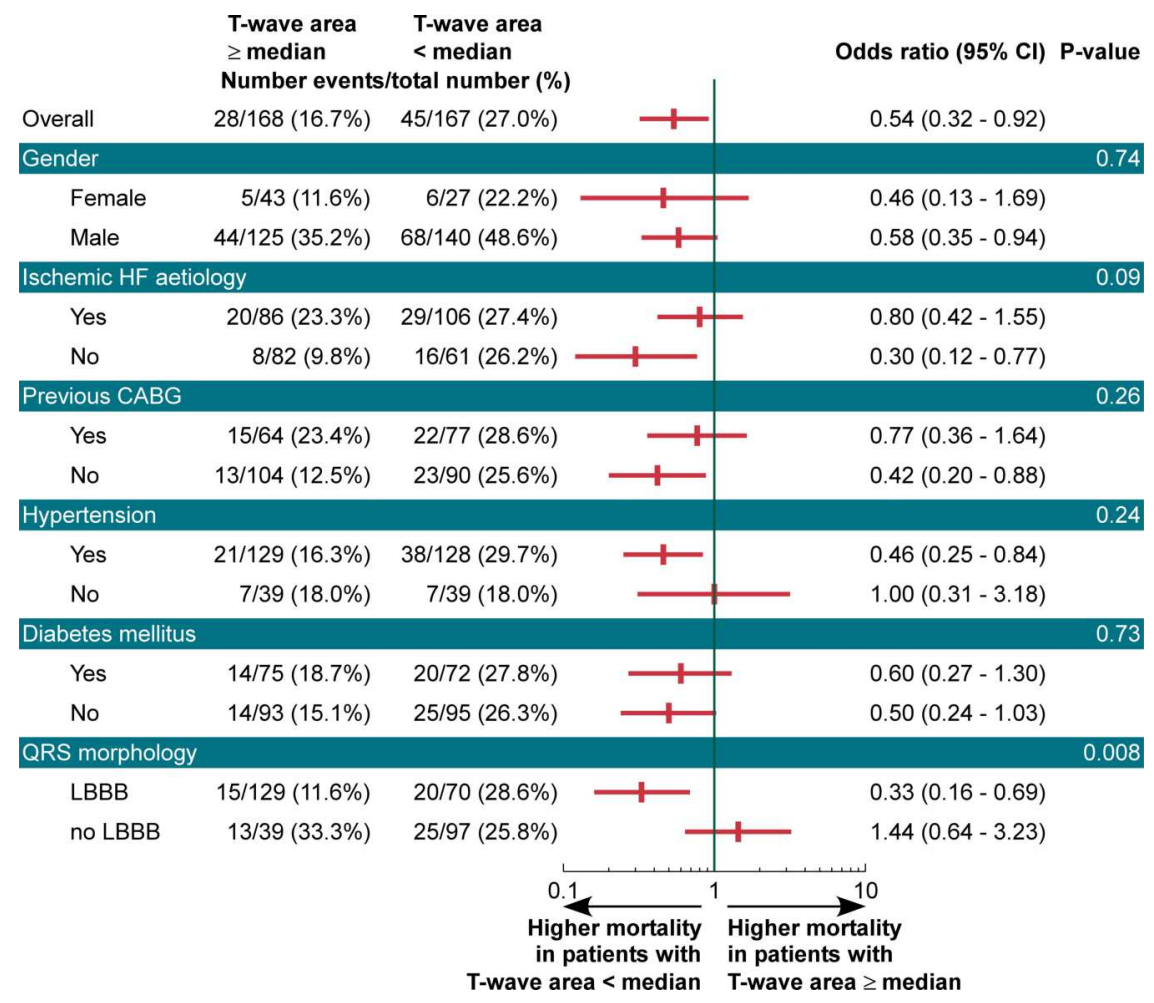

Figure 6.4: Subset analysis of all-cause mortality. Odds ratio and 95\% CI are plotted for the secondary endpoint of all-cause mortality at 3-year follow-up, comparing patients with a large and small $\mathrm{T}_{\text {area }}$. CABG: coronary artery bypass graft, HF: heart failure.

Because the present study was based on retrospective analysis and did not contain a control (non-paced) group, the better outcome in the LBBB-large- $\mathrm{T}_{\text {area }}$ patients may be explained by either a better baseline condition of these patients or a larger benefit of CRT. The latter idea is supported by the observation in our previous study that LBBB patients with large $\mathrm{T}_{\text {area }}$ showed a larger increase in LV ejection fraction. ${ }^{4}$ It seems plausible that this larger increase in cardiac function further translates into a better clinical outcome, as observed in the present study. Using the $\mathrm{T}_{\text {area }}$ in the LBBB patient could help predict whether CRT may be useful, especially in a subset of LBBB patients who have additional co-morbidities in whom the risk-benefit ratio may not be as clear as in other LBBB patients.

A large $\mathrm{T}_{\text {area }}$ (as well as $\mathrm{QRS}_{\text {area }}$ ) may also imply a better baseline condition, because it is known that electrical uncoupling ${ }^{10}$ or RV dilatation leads to lower ECG amplitudes. RV dilatation could lead to loss of myocardial tissue due to the replacement by fibrofatty tissue or could lead to a rotation of the heart affecting both QRS and T-wave amplitudes. However, in a previous study we showed that a large $\mathrm{QRS}_{\text {area }}$ is commonly accompanied by a large $\mathrm{T}_{\text {area }}$, 
but that there is also considerable variability. ${ }^{4}$ A possible explanation for this variability was given by Feldman et al. ${ }^{11}$ who showed that in acute measurements in patients the $\mathrm{T}_{\text {area }}$ and the ratio of $T: R$ wave amplitude increased with increasing cavity diameter while the $\mathrm{QRS}_{\text {area }}$ did not change. This, however, cannot be an explanation why patients with a relatively large $\mathrm{T}_{\text {area }}$ respond better to CRT since it is well known that too dilated ventricles respond less to CRT. ${ }^{12-14}$ This suggests that other factors, such as ionic channel properties present during the plateau and repolarization phases of a myocardial action potential, play a role in the variability between $\mathrm{QRS}$ - and $\mathrm{T}_{\text {area }}$. These ion channel properties may change due to heart failure and dyssynchrony. ${ }^{15}$ Additionally, the small $\mathrm{T}_{\text {areas }}$ might be related to hypertrophy. For patients with severe LV hypertrophy and narrow QRS complexes this phenomenon is also known as T-wave flattening. ${ }^{16}$ It is, however, not known whether T-wave flattening also applies to patients with a wide QRS complex. An important difference in this respect is that while narrow QRS complexes are commonly accompanied by concordant T-waves, this is rare in patients with wide QRS complex, and even rarer in case of LBBB.

Finally, females and patients without a history of ischemic cardiomyopathy were overrepresented in the patient group with a large $\mathrm{T}_{\text {area }}$ and LBBB morphology. Both patient characteristics are known to have a positive influence on the response to $\mathrm{CRT}^{17-19}$, for reasons incompletely understood.

Therefore, the $\mathrm{T}_{\text {area }}$ appears to be an objectively determined biomarker, expressed as a continuous variable, revealing various subgroups with known better outcome to CRT. Beside the possible practical use of this finding, these data also indicate that for better understanding of the mode of action of CRT, not only information on the sequence of ventricular depolarization is needed, but also that of processes determining later phases in the action potential.

\subsubsection{Potential Clinical Implications}

The present study demonstrates for the first time that, besides a LBBB morphology, the $T_{\text {area }}$ may be a valuable biomarker for the prediction of long-term clinical outcome after CRT. In this study the MADIT-CRT criteria with $\mathrm{R}$ wave notching or slurring in leads $\mathrm{I}$, aVL, $\mathrm{V}_{5}$, or $\mathrm{V}_{6}$ was used as LBBB criteria. Including this notching or slurring, the used criteria approaches the strict criteria developed by Strauss et al. ${ }^{20}$ more closely. In order to determine the $\mathrm{T}_{\text {area }}$, a VCG needs to be synthesized from the 12-lead ECG. If the VCG is not constructed by the ECG equipment, it can be easily calculated from every 12-lead ECG that is saved digitally or in pdf-format. ${ }^{5}$ After this conversion the analysis only requires a semi-automatic detection of the beginning and end of the T-wave. Therefore, assessment of the $\mathrm{T}_{\text {area }}$ in candidates for CRT device implantation is easy, non-invasive and can be implemented without significant investments. 


\subsubsection{Limitations}

The present study was a retrospective single center study in which $41 \%$ of the original cohort of consecutive patients had to be excluded because of missing or too low quality measurements. To confirm our results, a prospective multicenter study is required. Such multicenter study should also include systematic coverage of the cause of death, which was not included in the present study.

In the multivariate analysis the type of device, CRT-D vs. CRT-P, was not included because the data was not available in the database. However, it is expected that the vast majority were CRT-D devices and thus would not influence the result. Furthermore, factors related to LV lead position, such as Q-LV, were also not included because they were unknown and because focus of the current study was on pre-procedure predictors of response.

\subsection{Conclusions}

A vectorcardiographically derived $\mathrm{T}_{\text {area }}$ assessed before the start of CRT was able to strengthen the prediction of long-term clinical outcome in a CRT patient cohort, especially in patients with LBBB morphology on the ECG. The combined analysis of QRS morphology and T-wave provides an easy and widely applicable approach to improve selection of CRT candidates.

\subsection{Funding}

This work was supported within the framework of Center for Translational Molecular Medicine (www.ctmm.nl), Project COHFAR (Congestive Heart Failure and Arrhythmia) (Grant number 01C-203), and supported by the Dutch Heart Foundation. 


\section{References}

1. JGF Cleland, JC Daubert, E Erdmann, N Freemantle, D Gras, L Kappenberger, L Tavazzi, and Cardiac Resynchronization-Heart Failure (CARE-HF) Study Investigators. The effect of cardiac resynchronization on morbidity and mortality in heart failure. N Engl J Med (2005) 352:1539-1549.

2. European Heart Rhythm Association, European Society of Cardiology, Heart Rhythm Society, Heart Failure Society of America, American Society of Echocardiography, American Heart Association, European Association of Echocardiography, Heart Failure Association, JC Daubert, L Saxon, et al. 2012 EHRA/HRS expert consensus statement on cardiac resynchronization therapy in heart failure: implant and follow-up recommendations and management. Heart Rhythm (2012) 9:1524-1576.

3. M Brignole, A Auricchio, G Baron-Esquivias, P Bordachar, G Boriani, OA Breithardt, J Cleland, JC Deharo, V Delgado, PM Elliott, et al. 2013 ESC Guidelines on cardiac pacing and cardiac resynchronization therapy: the Task Force on cardiac pacing and resynchronization therapy of the European Society of Cardiology (ESC). Developed in collaboration with the European Heart Rhythm Association (EHRA). Eur Heart J (2013) 34:2281-2329.

4. EB Engels, EM Végh, CJM Van Deursen, K Vernooy, JP Singh, and FW Prinzen. Twave area predicts response to cardiac resynchronization therapy in patients with left bundle branch block. J Cardiovasc Electrophysiol (2015) 26:176-183.

5. JA Kors, G van Herpen, AC Sittig, and JH van Bemmel. Reconstruction of the Frank vectorcardiogram from standard electrocardiographic leads: diagnostic comparison of different methods. Eur Heart J (1990) 11:1083-1092.

6. W Zong, GB Moody, and D Jiang. A robust open-source algorithm to detect onset and duration of QRS complexes. In: Computers in Cardiology, 2003. 2003, pp. 737-740.

7. W Zareba, H Klein, I Cygankiewicz, WJ Hall, S McNitt, M Brown, D Cannom, JP Daubert, M Eldar, MR Gold, et al. Effectiveness of Cardiac Resynchronization Therapy by QRS Morphology in the Multicenter Automatic Defibrillator Implantation Trial-Cardiac Resynchronization Therapy (MADIT-CRT). Circulation (2011) 123:1061-1072.

8. L Wecke, F Gadler, C Linde, G Lundahl, MR Rosen, and L Bergfeldt. Temporal characteristics of cardiac memory in humans: vectorcardiographic quantification in a 
model of cardiac pacing. Heart Rhythm (2005) 2:28-34.

9. DL Cortez and TT Schlegel. When deriving the spatial QRS-T angle from the 12-lead electrocardiogram, which transform is more Frank: regression or inverse Dower? $J$ Electrocardiol (2010) 43:302-309.

10. M Potse, D Krause, L Bacharova, R Krause, FW Prinzen, and A Auricchio. Similarities and differences between electrocardiogram signs of left bundle-branch block and leftventricular uncoupling. Europace (2012) 14 Suppl 5:v33-v39.

11. T Feldman, RW Childers, KM Borow, RM Lang, and A Neumann. Change in ventricular cavity size: differential effects on QRS and T wave amplitude. Circulation (1985) 72:495-501.

12. M Gasparini and P Galimberti. Device therapy in heart failure: has CRT changed "the sickest benefit the most" to "the healthiest benefit the most?". J Am Coll Cardiol (2013) 61:945-947.

13. J Rickard, DM Brennan, DO Martin, E Hsich, WHW Tang, BD Lindsay, RC Starling, BL Wilkoff, and RA Grimm. The impact of left ventricular size on response to cardiac resynchronization therapy. Am Heart J (2011) 162:646-653.

14. E Díaz-Infante, L Mont, J Leal, I García-Bolao, I Fernández-Lozano, A HernándezMadrid, N Pérez-Castellano, M Sitges, R Pavón-Jiménez, J Barba, MA Cavero, JL Moya, L Pérez-Isla, J Brugada, and SCARS Investigators. Predictors of lack of response to resynchronization therapy. Am J Cardiol (2005) 95:1436-1440.

15. T Aiba, GG Hesketh, AS Barth, T Liu, S Daya, K Chakir, VL Dimaano, TP Abraham, B O'Rourke, FG Akar, DA Kass, and GF Tomaselli. Electrophysiological consequences of dyssynchronous heart failure and its restoration by resynchronization therapy. Circulation (2009) 119:1220-1230.

16. D Levy, M Salomon, RB D’Agostino, AJ Belanger, and WB Kannel. Prognostic implications of baseline electrocardiographic features and their serial changes in subjects with left ventricular hypertrophy. Circulation (1994) 90:1786-1793.

17. A Arshad, AJ Moss, E Foster, L Padeletti, A Barsheshet, I Goldenberg, H Greenberg, WJ Hall, S McNitt, W Zareba, S Solomon, JS Steinberg, and MADIT-CRT Executive Committee. Cardiac resynchronization therapy is more effective in women than in men: the MADIT-CRT (Multicenter Automatic Defibrillator Implantation Trial with Cardiac Resynchronization Therapy) trial. J Am Coll Cardiol (2011) 57:813-820.

18. S Zabarovskaja, F Gadler, F Braunschweig, M Ståhlberg, J Hörnsten, C Linde, and LH Lund. Women have better long-term prognosis than men after cardiac resynchronization therapy. Europace (2012) 14:1148-1155.

19. MGSJ Sutton, T Plappert, KE Hilpisch, WT Abraham, DL Hayes, and E Chinchoy. Sustained reverse left ventricular structural remodeling with cardiac resynchronization at one year is a function of etiology: quantitative Doppler echocardiographic evidence 
from the Multicenter InSync Randomized Clinical Evaluation (MIRACLE). Circulation (2006) 113:266-272.

20. DG Strauss, RH Selvester, and GS Wagner. Defining left bundle branch block in the era of cardiac resynchronization therapy. Am J Cardiol (2011) 107:927-934. 


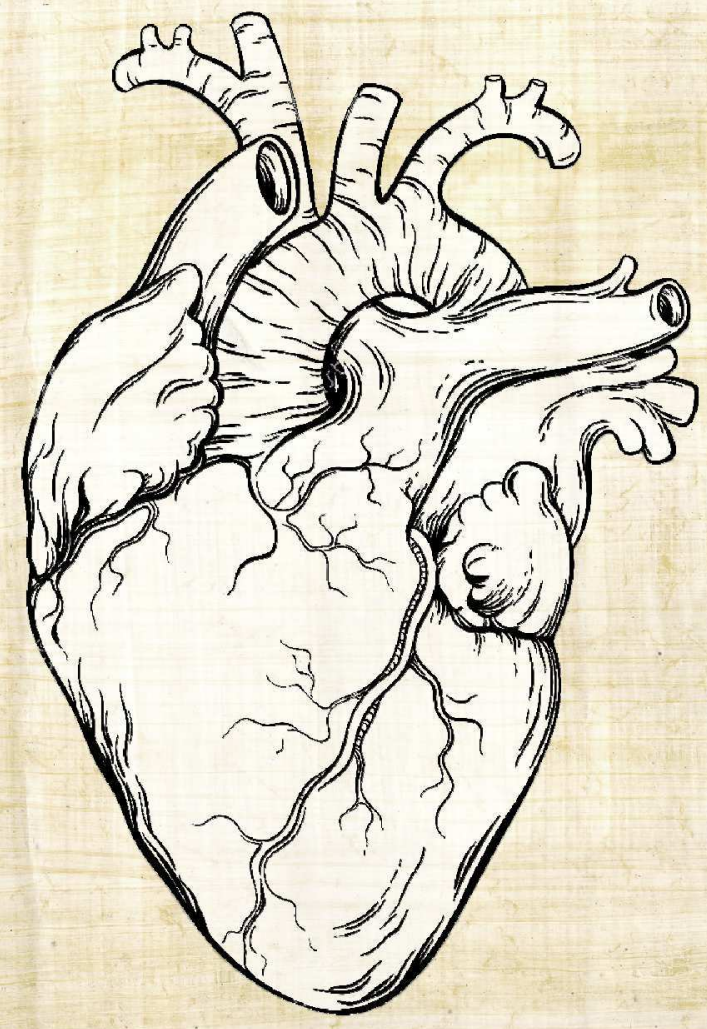




\section{Chapter}

\section{Prediction of optimal cardiac resynchronization by device-based vectorcardiography in dyssynchronous canine hearts}

Elien B. Engels, ${ }^{1}$ Marc Strik, ${ }^{1}$ Lars B. van Middendorp, ${ }^{1}$ Arne van Hunnik, ${ }^{1}$ Marion Kuiper, ${ }^{1}$ Kevin Vernooy, ${ }^{2}$ and Frits W. Prinzen ${ }^{1}$ (2016).

Prediction of optimal cardiac resynchronization by vectorcardiography in dyssynchronous canine hearts. [In preparation]

\footnotetext{
${ }^{1}$ Department of Physiology, CARIM School for Cardiovascular Diseases, Maastricht University, Maastricht, the Netherlands.

${ }^{2}$ Department of Cardiology, Maastricht University Medical Center, Maastricht, the Netherlands.
} 


\section{Abstract}

Introduction: The response to CRT is heterogeneous between patients. Proper optimization of atrioventricular (AV) and interventricular (VV) intervals may improve CRT response. In the present study, we explored the possibility of extracting a VCG from the electrograms (EGMs) obtained from unused pacing electrodes positioned on the epicardium. Furthermore, the possibility of using this EGM-based VCG (EGM-VCG) to optimize acute hemodynamic CRT response is investigated.

Methods and Results: CRT was performed in 8 canines with chronic left bundle branch block (LBBB). 100 randomized AV-VV settings were tested. Settings providing an increase in $\mathrm{LV} \mathrm{d} P / \mathrm{d} t_{\max } \geq 90 \%$ of the highest achieved value were defined as optimal. The prediction capabilities of the area of the QRS complex $\left(\mathrm{QRS}_{\text {area }}\right)$, derived from body surface VCG $\left(\mathrm{ECG}_{\mathrm{Q}} \mathrm{QRS}\right.$ area $)$ and EGM-VCG (EGM-QRS $\left.{ }_{\text {area }}\right)$ were compared. The ECG-QRS $\mathrm{Erea}_{\text {as }}$ moderately correlated with change in $\mathrm{LV} \mathrm{d} P / \mathrm{d} t_{\max }(\mathrm{R}=0.59 \pm 0.23)$, while the EGM$\mathrm{QRS}_{\text {area }}$ correlated well with $\mathrm{LV} \mathrm{d} P / \mathrm{d} t_{\max }(\mathrm{R}=0.73 \pm 0.19)$. This resulted in a significantly better performance of the EGM-QRS area $_{\text {to }}$ to predict the optimal CRT settings (AUC $=0.90$

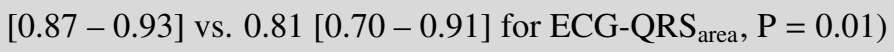

Conclusions: In canine hearts with chronic LBBB, the EGM-QRS ${ }_{\text {area }}$ predicts hemodynamic response and identifies optimal settings accurately. These data support the potency of electrogram based vectorcardiography as a non-invasive and easy tool to individually and continuously optimize the AV- and VV-intervals in CRT. 


\subsection{Introduction}

I $\mathrm{N}$ patients with heart failure combined with a reduced left ventricular (LV) ejection fraction (EF) and a delayed LV activation, mostly due to left bundle branch block (LBBB), cardiac resynchronization therapy (CRT) has been shown to improve morbidity and mortality. ${ }^{1}$ However, the response to CRT is very heterogeneous, leaving $30-50 \%$ of the patients as non-responders. ${ }^{2}$ An important factor for non-response may be suboptimal CRT device settings. ${ }^{3}$

Currently, most optimization techniques either use ventricular filling or systolic function variables, all of them having their own limitations. ${ }^{4-6}$ Alternative approaches are provided by algorithms implemented in CRT devices. These algorithms either use peak endocardial acceleration signals ${ }^{7}$ or lead electrograms $(E G M s)^{8-10}$. However, none of these methods are solely based on the individual but partially on an average relation found in a large patient population. Of these algorithms, only ADAPTIVECRT ${ }^{\mathrm{TM}}$ (trademark of Medtronic, Inc.) provides an almost continuous optimization ${ }^{10}$, but this optimization is based on baseline values and thus not on values found during pacing.

We considered that the main mechanism of CRT is electrical resynchronization, by collision of electrical wave fronts originating from the right ventricle (RV) and LV. van Deursen et al. ${ }^{11}$ already showed that vectorcardiography (VCG) reflects electrical interventricular dyssynchrony in canine hearts with LBBB. The $\mathrm{QRS}_{\text {ampl }}$ half-way between that seen during LV pacing and LBBB corresponded to optimal hemodynamic performance. ${ }^{11}$ In a subsequent study, it was shown that both the $\mathrm{QRS}_{\mathrm{ampl}}$ and $\mathrm{QRS}_{\text {area }}$ are reliable and reproducible variables for AV- and VV-optimization in patients. ${ }^{12}$ These methods can be used for regular check-up of patients when they come to the hospital. However, such measurements occur during rest and in supine position, while the optimal settings may change with time (e.g. myocardial remodeling due to the therapy or altering disease process) and patient activity (e.g. sleep, normal activity, and exercise).

In the present study, we explored the possibility of extracting a VCG from EGMs measured from the unused pacing electrodes (EGM-based VCG, EGM-VCG), to compare its behavior to the VCG and to relate these VCGs to the hemodynamic CRT response. The ultimate goal of this study is to develop a system than can optimize the CRT device using the EGM-VCG continuously and individually. The experiments were performed in canine hearts with chronic LBBB.

\subsection{Methods}

Animal handling was performed according to the Dutch Law on Animal Experimentation and the European Directive for the Protection of Vertebrate Animals Used for Experimental and 
Other Scientific Purposes. The protocol was approved by the Animal Experimental Committee of Maastricht University.

\subsubsection{Experimental model}

The experiments were performed on 8 mongrel canines of either sex and unknown age. The extensive protocol has already been described earlier. ${ }^{13}$ In short, in all canines radiofrequency ablation was used to create LBBB. CRT studies were performed 16 weeks after creation of LBBB, to allow for ventricular remodeling to occur. During these CRT studies, RV and LV pressure catheters were positioned and the right atrial pacing lead was inserted transvenously. In addition, an octapolar electrode catheter was placed against the right side of the septum, from which the most distal electrode was used for RV apical pacing. ${ }^{13}$ After opening the chest, two multi-electrode arrays holding 102 contact electrodes were placed around the heart to measure epicardial electrical potentials and a basal posterolateral electrode was selected for LV-pacing (see bottom-left panel in Fig. 7.1).

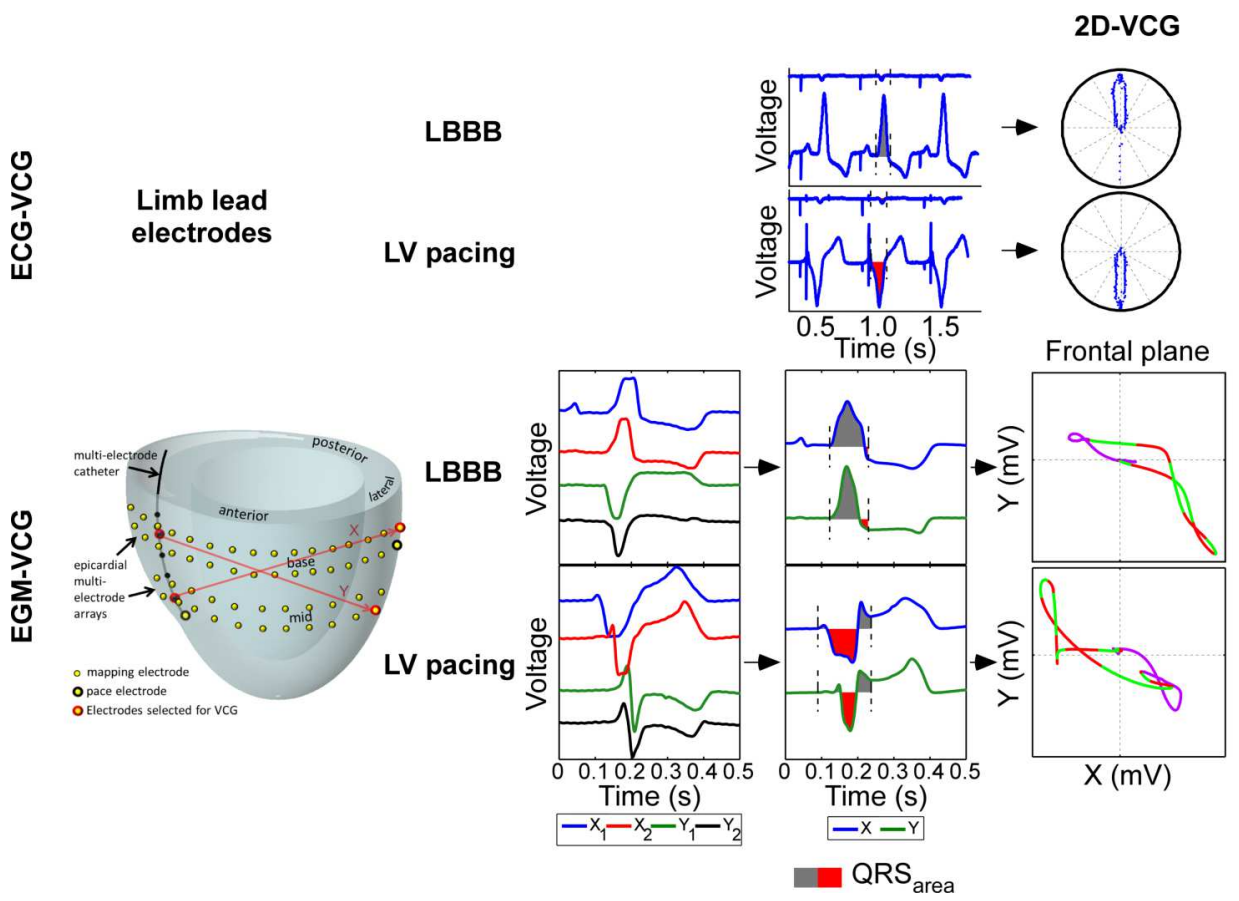

Figure 7.1: Flow-chart of the ECG-VCG derived $\mathrm{QRS}_{\text {area }}$ (top) and EGM-VCG derived $\mathrm{QRS}_{\text {area }}$ determination (bottom). 


\subsubsection{Pacing protocol}

During the pacing protocol, the delay between atrium and either the RV (A-RV delays) or LV (A-LV delays) ranged from $50 \mathrm{~ms}$ to $230 \mathrm{~ms}$ in steps of $20 \mathrm{~ms}$, resulting in a raster of 10x10 and thus 100 different pace settings. The occurrence of all 100 different combinations was randomly programmed. Four steps of pace settings were intertwined by a baseline measurement which was equal to atrial pacing at a heart rate $10 \mathrm{BPM}$ above intrinsic sinoatrial rate. These baseline measurements were used to calculate relative changes in $\mathrm{LV} \mathrm{d} P / \mathrm{d} t_{\text {max }}$ measurements. Both hemodynamic and electrophysiological data were recorded for a minimum of 2 respiratory cycles.

\subsubsection{Data analysis}

Surface ECGs were recorded from the limb lead electrodes and plotting lead I (approximating $\mathrm{X}$ ) against aVF (approximating $\mathrm{Y}$ ) resulted in a 2-dimensional VCG (Fig. 7.1, top right panel). Using custom MATLAB R2010b (MathWorks, Natick, MA) software, the ECG-VCG derived $\mathrm{QRS}_{\text {area }}\left(\mathrm{ECG}-\mathrm{QRS}_{\text {area }}\right)$ was computed using the formula $\mathrm{QRS}_{\text {area }}=\sqrt{\mathrm{QRS}_{\text {area,I }}^{2}+\mathrm{QRS}_{\text {area,aVF }}^{2}}$ where $\mathrm{QRS}_{\text {area,I }}$ and $\mathrm{QRS}_{\text {area,aVF }}$ are the area between the curve and baseline. ${ }^{14}$

Using the EGMs, a vectorcardiogram was extracted, which hereafter will be referred to as EGM-VCG. The required EGMs are measured from two electrodes from the octapolar electrode catheter (RV) and one electrode just above and one just below the LV pacing electrode on the contact electrode bands. The ' $\mathrm{X}$ ' direction of the EGM-VCG is calculated by subtracting the signal of the apical RV EGM from the basal LV EGM, and the ' $Y$ ' direction by subtracting the signal of the basal RV EGM from the apical LV EGM (bottom panel Fig. 7.1). Plotting the ' $\mathrm{X}$ ' and ' $\mathrm{Y}$ ' signal against each other results in a 2-dimensional VCG (Fig. 7.1, bottom right panel). The EGM-VCG derived $\mathrm{QRS}_{\text {area }}\left(\mathrm{EGM}-\mathrm{QRS}_{\text {area }}\right)$ could be calculated using the same formula as described for the ECG-QRS $S_{\text {area }}$ but now taking the leads $\mathrm{X}$ and $\mathrm{Y}$ into account.

The hemodynamic response was assessed by measuring the maximal rate of LV pressure rise $\left(\mathrm{LV} \mathrm{d} P / \mathrm{d} t_{\max }\right)$. For each setting, variables were plotted in relation to the $\mathrm{LV} / \mathrm{RV} \mathrm{AV}$ interval in three-dimensional surface plots. Quadratic fitting was applied to account for measurement variability. The settings resulting in a percentage increase of $\mathrm{LV} \mathrm{d} P / \mathrm{d} t_{\max }$ of at least $90 \%$ of the maximum (surface peak) were identified as optimal $\left(\mathrm{CRT}_{\mathrm{opt}}\right)$.

\subsubsection{Statistical analysis}

Continuous data are presented as mean \pm standard deviation. Correlations between surface plots of percentage change in $\mathrm{LV} \mathrm{d} P / \mathrm{d} t_{\max }$ compared to baseline and the surface plots of the electrophysiological variables ECG-QRS area and EGM-QRS ${ }_{\text {area }}$ were calculated using 
the Pearson correlation coefficient. The classification performance of electrical variables in identifying the $\mathrm{CRT}_{\text {opt }}$ settings was evaluated by receiver operating characteristic (ROC) curve analysis. The significance of the difference in classification performance between variables was evaluated by comparing the area under the ROC curves with the method proposed by DeLong et al. ${ }^{15}$. A P-value $<0.05$ was considered statistically significant.

\subsection{Results}

\subsubsection{Hemodynamic effect of different stimulation intervals during CRT}

Two examples of the hemodynamic changes at all 100 tested A-RV/A-LV combinations are shown in Fig. 7.2. LV- and RV-only pacing at short AV-intervals (left and right corner in Fig. 7.2, respectively) caused only small changes in $\mathrm{LV} \mathrm{d} P / \mathrm{d} t_{\max }$ and this was also the case during biventricular (BiV) pacing at long AV-intervals (top corner) Several combinations of $\mathrm{A}-\mathrm{RV}$ and A-LV intervals led to good hemodynamic improvement. At short AV-intervals, high LV $\mathrm{d} P / \mathrm{d} t_{\max }$ values were found during simultaneous BiV pacing, while at longer AVintervals the optimum was found during LV pre-excitation, most likely related to partial fusion of LV pacing with the wave front originating from the right bundle branch (RBB). ${ }^{13}$ The location of the leftward turn of the ridge was dependent on intrinsic conduction properties, e.g. a longer PR-interval results in fusion with the intrinsic conduction at longer AV-intervals (Fig. 7.2A vs. 7.2B). Indeed, when for all dogs the effective VV-interval (the actual time delay between onset of activation of the RV apex and LV lateral wall ${ }^{16}$ ) was calculated, all points transferred to one parabola with the optimum around an effective VV-interval of 0 (Fig. 7.3). In the 8 canines, the number of A-LV/A-RV combinations which resulted in $\mathrm{CRT}_{\text {opt }}$ varied between 1 and 6 (median of 4 combinations).

\subsubsection{ECG-VCG and EGM-VCG prediction performance}

Fig. 7.4A and Fig. 7.4B show the surface plots for the $\mathrm{QRS}_{\text {area }}$ as derived from the ECG-VCG and the EGM-VCG and the corresponding $\mathrm{LV} \mathrm{d} P / \mathrm{d} t_{\max }$ plots during all 100 tested A-RV/ALV combinations of two canines with different intrinsic PR-intervals. To improve the visual comparison between the $\mathrm{QRS}_{\text {area }}$ and $\mathrm{LV} \mathrm{d} P / \mathrm{d} t_{\max }$ plot, the $\mathrm{z}$-axis of the $\mathrm{QRS}_{\text {area }}$ plot was inverted.

During most of the $100 \mathrm{~A}-\mathrm{RV}$ and A-LV settings there was a good match between values of ECG-QRS ${ }_{\text {area }}$ and EGM-QRS ${ }_{\text {area }}$, with low values occurring during settings ranging from BiV-pacing at short AV-intervals to pronounced LV pre-excitation at longer AV intervals and higher values during LV-only pacing and LBBB. The number of $\mathrm{CRT}_{\mathrm{opt}}$ settings during BiVpacing before the leftward shift was higher for the canine with a longer PR-interval, in which the leftward shift occurred later (Fig. 7.4B). In both experiments the ECG-QRS $\mathrm{S}_{\text {area }}$ during 


\section{LV dP/dt $t_{\max }$}

A

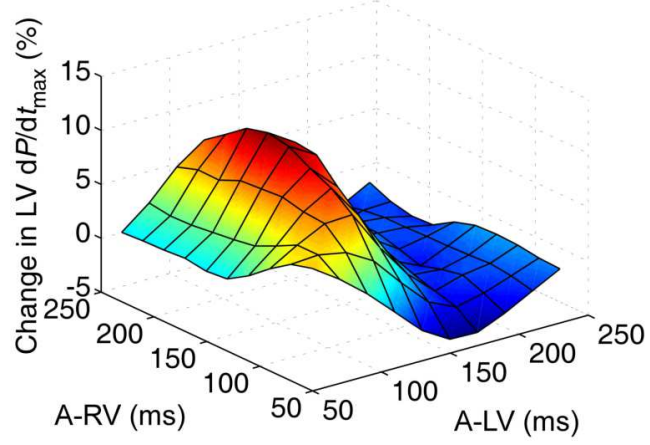

PR-interval $=141 \mathrm{~ms}$
B

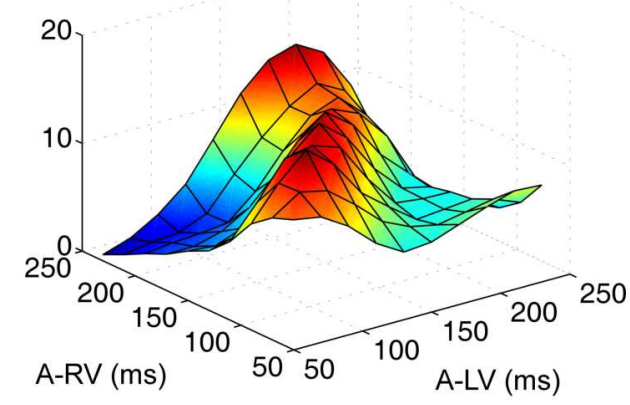

PR-interval $=201 \mathrm{~ms}$

Figure 7.2: Examples of the relative change in $L V \mathrm{~d} P / \mathrm{d} t_{\max }$ compared to baseline for the tested $A-R V$ and A-LV intervals in a canine with a PR-interval of $141 \mathrm{~ms}(\mathbf{A})$ and one with a PR-interval of $201 \mathrm{~ms}(\mathbf{B})$. At the diagonal line in the horizontal plane $(\mathrm{y}=\mathrm{x})$ the VV-interval was 0 , while at the points right from this line the RV was pre-excited and at points left from this line LV was pre-excited. A combination of a short A-LV and a long A-RV is equal to LV-only pacing, while a short A-RV and a long A-LV represents RV only pacing and A-LV and $\mathrm{A}-\mathrm{RV}$ values close to each other is BiV pacing with a certain VV-interval.

A

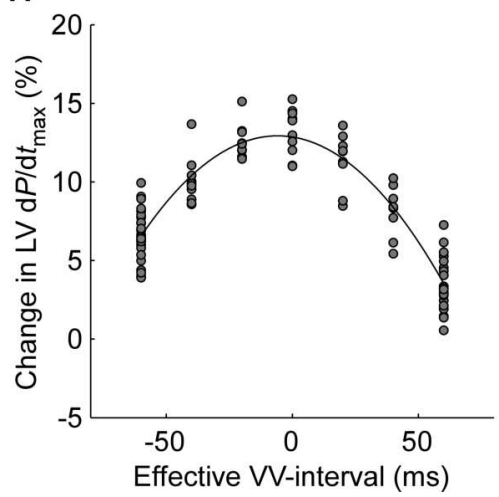

B

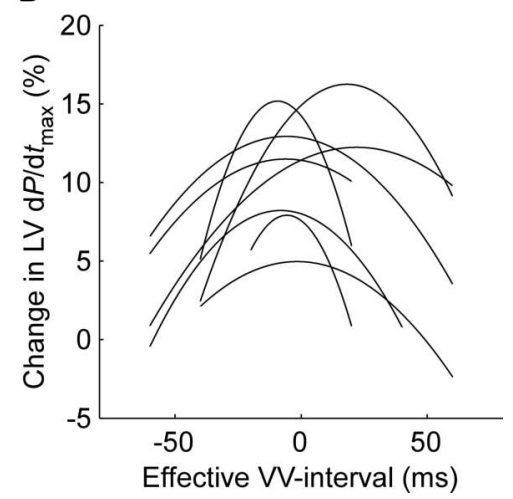

Figure 7.3: A: Typical example of the relationship between effective VV-interval and improvement in maximum rate of $\mathrm{LV}$ pressure rise $\left(\mathrm{LV} \mathrm{d} P / \mathrm{d} t_{\max }\right)$ compared to baseline for all pacing configurations. B: Relationship of effective VV-interval and change in $\mathrm{LV} \mathrm{d} P / \mathrm{d} t_{\max }$ compared to baseline for all animals.

$\mathrm{RV}$ pacing was lower than during LBBB. This difference in $\mathrm{QRS}_{\text {area }}$ between $\mathrm{RV}$ only pacing and LBBB was not found for the EGM-QRS area. As a consequence, the correlation between 
the ECG and EGM derived $\mathrm{QRS}_{\text {area }}$ was moderate $(\mathrm{R}=0.44 \pm 0.17$ for all experiments combined).

The small QRS $\mathrm{Qrea}_{\text {a }}$ found during RV pre-excitation for the ECG-VCG did not match with an increase in $\mathrm{LV} \mathrm{d} P / \mathrm{d} t_{\max }$, although small $\mathrm{QRS}_{\text {areas }}$ during other pace settings did correlate with a $\mathrm{LV} \mathrm{d} P / \mathrm{d} t_{\max }$ increase. As a consequence, the correlation between these two variables was moderate $(\mathrm{R}=0.59 \pm 0.23$ for all experiments), despite the fact that the location of minimal $\mathrm{QRS}_{\text {area }}$ matched quite well with that of the optimal hemodynamic benefit. For the EGM-QRS ${ }_{\text {area }}$ this low value during RV-pacing was absent and there was also a match between minimal $\mathrm{QRS}_{\text {area }}$ and optimal hemodynamic benefit leading to a higher correlation with the change in $\mathrm{LV} \mathrm{d} P / \mathrm{d} t_{\max }$ compared to baseline $(\mathrm{R}=0.73 \pm 0.19$ for all experiments).

\subsubsection{ROC curves}

Fig. 7.5 presents ROC curves that show the classifying abilities of ECG-QRS ${ }_{\text {area }}$ and $E_{\text {GM-QRS }}$ area to identify CRT opt $_{\text {. The area under the curve for the EGM-QRS }}$ area was high $\left(0.90\right.$ [0.87 - 0.93]), while the ECG-QRS ${ }_{\text {area }}$ and QRS duration were significantly less accurate in identifying the settings resulting in best hemodynamic improvement $(\mathrm{AUC}=0.81[0.70-0.91]$ and $0.74[0.64-0.84]$, respectively; $\mathrm{P} \leq 0.01$ comparing both

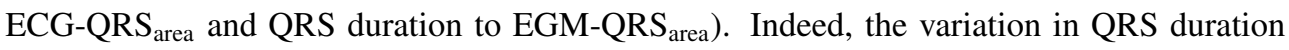
between different settings can be quite small, making it difficult to select the best settings using QRS duration (Fig. 7.6). 
A.

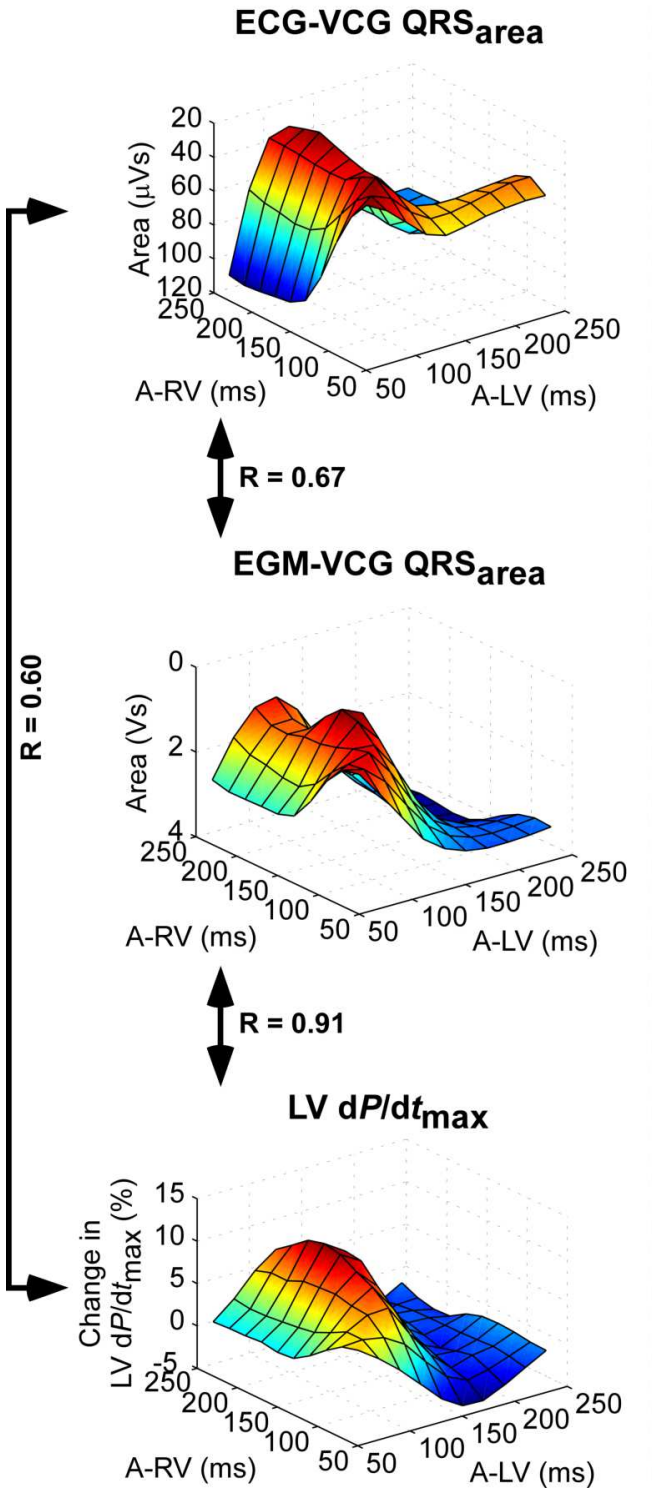

'B.

PR-interval $=201 \mathrm{~ms}$

ECG-VCG QRS area

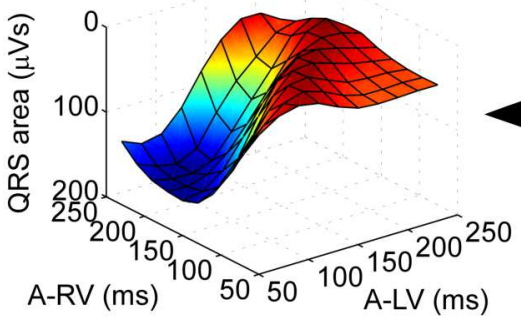

$\oint_{R}=0.33$

EGM-VCG QRS area

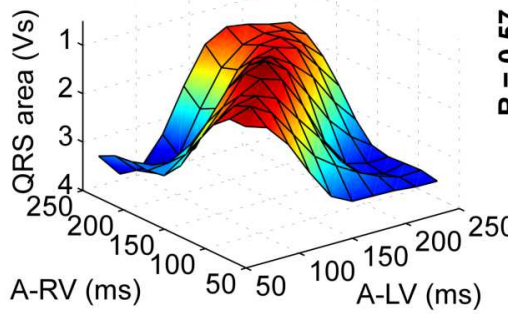

$\{\mathrm{R}=0.85$

\section{$\mathrm{LV} \mathrm{d} P / \mathrm{d} t_{\max }$}

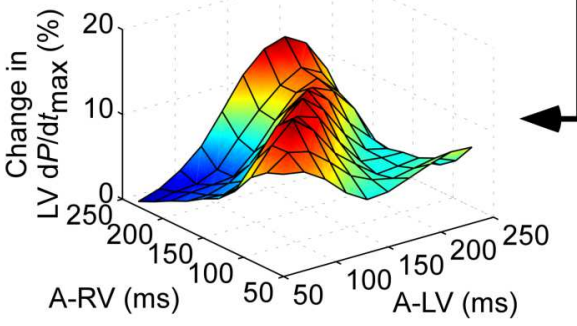

Figure 7.4: Examples of surface plots for the $\mathrm{QRS}_{\text {area }}$ derived from the ECG-VCG and EGM-VCG for the canine with a PR-interval of $141 \mathrm{~ms}(\mathbf{A})$ or a PR-interval of $201 \mathrm{~ms}(\mathbf{B})$. For visual comparison between the $\mathrm{QRS}_{\text {area }}$ and $\mathrm{LV} \mathrm{d} P / \mathrm{d} t_{\max }$ surface plots, the z-axis was inverted. The agreement between the two methods of $\mathrm{QRS}_{\text {area }}$ calculation is indicated between the two surface plots. The proximity of the minimal $\mathrm{QRS}_{\text {area }}$ derived from the EGM-VCG was a better indicator for response prediction and correlated better with response observation (defined as \% change in $\mathrm{LV} \mathrm{d} P / \mathrm{d} t_{\max }$ compared to baseline) compared with the ECG-VCG derived QRS area $_{\text {. }}$ 


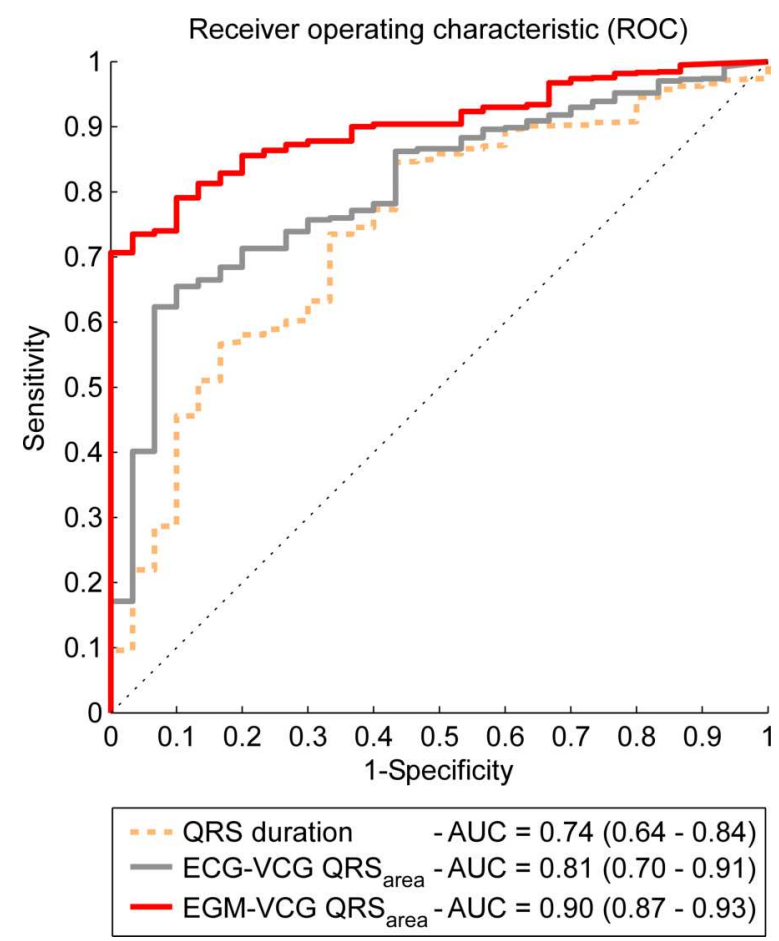

Figure 7.5: Receiver operating characteristics (ROC) curves for QRS duration, ECG-VCG QRS area,

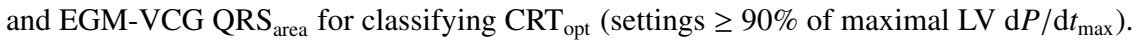
ROC area under the curve signifies performance of each variable in identifying the $\mathrm{CRT}_{\mathrm{opt}}$ settings.

QRS duration

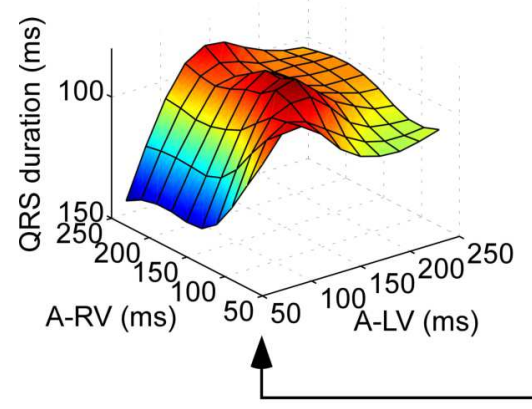

$R=0.22$
LV dPldt $t_{\max }$

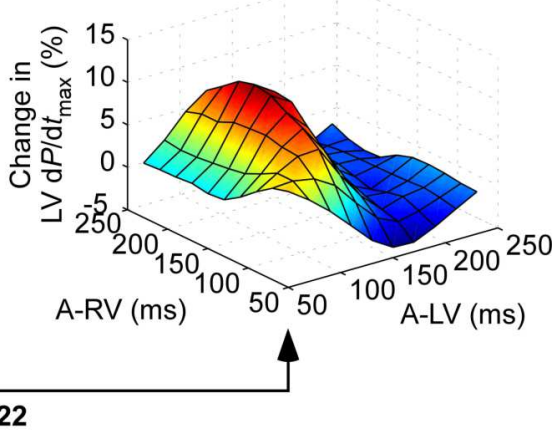

$(0.33 \pm 0.25$ for all experiments)

Figure 7.6: Relation between $\mathrm{QRS}$ duration and $\mathrm{LV} \mathrm{d} P / \mathrm{d} t_{\max }$ for the canine with a PR-interval of $141 \mathrm{~ms}$. For visual comparison, the z-axis of the QRS duration was inverted. 


\subsection{Discussion}

The present study performed in canine hearts with chronic LBBB demonstrates that there is a moderate relation between ECG-VCG and EGM-VCG derived $\mathrm{QRS}_{\text {area }}$ with the largest offset between the two methods during RV only pacing. However, both methods are capable of predicting the optimal CRT device settings resulting in the best acute hemodynamic response, with the EGM-VCG derived $\mathrm{QRS}_{\text {area }}$ being the significantly better one. These observations support the use of the vectorcardiogram derived from the electrograms obtained from the intracardiac unused pacing electrodes as an easy, non-invasive, accurate, and reproducible tool for routine optimization of AV- and VV-intervals in CRT. The EGM-QRS ${ }_{\text {area }}$ could potentially be used to optimize CRT device settings continuously and individually.

\subsubsection{Individual optimization of CRT using vectorcardiographic measurements}

In a previous study, our group already demonstrated that during LV-only pacing in canines the $\mathrm{QRS}_{\mathrm{ampl}}$ is a predictor for optimization of stimulation intervals ${ }^{11}$ while in patients it was shown that also the $\mathrm{QRS}_{\text {area }}$ could be used for this purpose ${ }^{12}$. The current study shows that also during BiV pacing in canines the ECG-QRS ${ }_{\text {area }}$ can be used for the optimization of CRT device settings. The lower correlation between ECG-QRS $S_{\text {area }}$ and $L V \mathrm{~d} P / \mathrm{d} t_{\max }$ may be explained by the use of only limb leads. When only looking in the frontal plane, as is done in the current canine study, some information might be lost. This idea seems supported by the finding that in dogs the EGM-VCG derived $\mathrm{QRS}_{\text {area }}$ correlated better with the acute hemodynamic response plots.

Even though some physicians use the setting with the smallest QRS duration as an optimization method, both ECG-QRS ${ }_{\text {area }}$ and EGM-QRS $S_{\text {area }}$ were better predictors of maximal hemodynamic response, as evidenced by the higher area under the ROC-curves. An explanation might be that QRS duration only reflects the total ventricular activation time, while the $\mathrm{QRS}_{\text {area }}$ better reflects the activation waves. ${ }^{11,17}$

Several factors may explain the not-perfect correlation between either the ECG-QRS ${ }_{\text {area }}$ or the EGM-QRS $S_{\text {area }}$ surface plots with the $\mathrm{LV} \mathrm{d} P / \mathrm{d} t_{\max }$ surface plot. Obviously, biological variability in hemodynamics and measurement errors affect this correlation. In the present experimental setting, variability was kept to a minimum by performing repeated baseline measurements and by applying quadratic fitting. Secondly, one could question whether changes observed in $\mathrm{LV} \mathrm{d} P / \mathrm{d} t_{\max }$ are entirely related to electrical dyssynchrony, or whether ventricular filling also plays a role. In an earlier study performed by Strik et al. ${ }^{13}$ it was shown that the LV end-diastolic volume did not change between baseline, CRT at short AV-intervals, and CRT at longer AV-intervals. This suggests that ventricular filling does not play a role in achieving the optimal acute hemodynamic effect and, therefore, electrical dyssynchrony 
seems to be the leading factor for changes in $\mathrm{LV} \mathrm{d} P / \mathrm{d} t_{\max }$. Finally, as discussed above, the use of only the limb leads for the VCG determination on the body surface may have led to the lower predictive values of the ECG-QRS ${ }_{\text {area }}$.

\subsubsection{Potential clinical implications}

Extrapolation of experimental data to the clinical situation should always be done with care. However, it has already been shown that the VCG-derived $\mathrm{QRS}_{\mathrm{ampl}}$ and $\mathrm{QRS}_{\text {area }}$ during LVonly pacing at a range of $\mathrm{AV}$-delays and during $\mathrm{BiV}$ pacing at different $\mathrm{VV}$-delays are good predictors of CRT response ${ }^{12}$, a finding similar to that in our study regarding the $\mathrm{QRS}_{\text {area }}$. Therefore, the results of this animal study might well be applicable in the clinical situation.

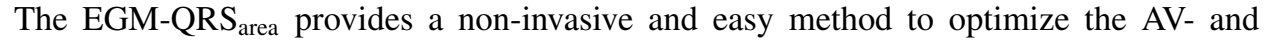
VV-intervals continuously and individually. In patients, one could use the electrodes on a quadripolar LV lead that are not being used for pacing as the two LV electrodes and the signal of the two RV electrodes might be extracted from the RV ring and the coil of the ICDs. This approach may be superior to currently available algorithms for automated optimization of CRT device settings using electrograms. All these algorithms use an estimated relation between measured variables and the optimal AV- and VV-interval, estimated using electrograms obtained in the unpaced (CRT-off) situation. ${ }^{8-10}$ Instead, the concept of EGM-QRS ${ }_{\text {area }}$ as presented here, continuously determines the effect of ventricular pacing on ventricular resynchronization.

\subsubsection{Limitations}

The current study only took the acute response to CRT into account using hemodynamic measurements. The acute CRT response may not correspond to CRT response on the longterm. ${ }^{18}$ Moreover, while the canines had long-term LBBB, the response in patients with a higher degree of heart failure and other comorbidities might be different.

\subsection{Conclusions}

In canine hearts with chronic LBBB, the $\mathrm{QRS}_{\text {area }}$ derived from a VCG extracted from myocardial EGM's from two RV and two LV electrodes predicts hemodynamic response and identifies optimal settings accurately. The worse performance of the QRS duration shows that variables reflecting patterns of activation perform better than those reflecting absolute electrical dyssynchrony. These data support the potency of device based vectorcardiography as a noninvasive and easy tool to individually and continuously optimize the AV-and VV-intervals in CRT. 


\subsection{Funding}

This work was supported within the framework of Center for Translational Molecular Medicine (www.ctmm.nl), Project COHFAR (Congestive Heart Failure and Arrhythmia) [Grant number 01C-203], and supported by the Dutch Heart Foundation. 


\section{References}

1. JGF Cleland, JC Daubert, E Erdmann, N Freemantle, D Gras, L Kappenberger, L Tavazzi, and Cardiac Resynchronization-Heart Failure (CARE-HF) Study Investigators. The effect of cardiac resynchronization on morbidity and mortality in heart failure. N Engl J Med (2005) 352:1539-1549.

2. European Heart Rhythm Association, European Society of Cardiology, Heart Rhythm Society, Heart Failure Society of America, American Society of Echocardiography, American Heart Association, European Association of Echocardiography, Heart Failure Association, JC Daubert, L Saxon, et al. 2012 EHRA/HRS expert consensus statement on cardiac resynchronization therapy in heart failure: implant and follow-up recommendations and management. Heart Rhythm (2012) 9:1524-1576.

3. W Mullens, RA Grimm, T Verga, T Dresing, RC Starling, BL Wilkoff, and WHW Tang. Insights from a cardiac resynchronization optimization clinic as part of a heart failure disease management program. J Am Coll Cardiol (2009) 53:765-773.

4. CE Raphael, A Kyriacou, S Jones, P Pabari, G Cole, R Baruah, AD Hughes, and DP Francis. Multinational evaluation of the interpretability of the iterative method of optimisation of AV delay for CRT. Int J Cardiol (2013) 168:407-413.

5. A Auricchio, C Stellbrink, M Block, S Sack, J Vogt, P Bakker, H Klein, A Kramer, J Ding, R Salo, B Tockman, T Pochet, and J Spinelli. Effect of pacing chamber and atrioventricular delay on acute systolic function of paced patients with congestive heart failure. The Pacing Therapies for Congestive Heart Failure Study Group. The Guidant Congestive Heart Failure Research Group. Circulation (1999) 99:2993-3001.

6. N Derval, P Steendijk, LJ Gula, A Deplagne, J Laborderie, F Sacher, S Knecht, M Wright, I Nault, S Ploux, et al. Optimizing hemodynamics in heart failure patients by systematic screening of left ventricular pacing sites: the lateral left ventricular wall and the coronary sinus are rarely the best sites. J Am Coll Cardiol (2010) 55:566-575.

7. P Ritter, PPHM Delnoy, L Padeletti, M Lunati, H Naegele, A Borri-Brunetto, and J Silvestre. A randomized pilot study of optimization of cardiac resynchronization therapy in sinus rhythm patients using a peak endocardial acceleration sensor vs. standard methods. Europace (2012) 14:1324-1333.

8. MR Gold, I Niazi, M Giudici, RB Leman, JL Sturdivant, MH Kim, Y Yu, J Ding, and $\mathrm{AD}$ Waggoner. A prospective comparison of AV delay programming methods for 
hemodynamic optimization during cardiac resynchronization therapy. J Cardiovasc Electrophysiol (2007) 18:490-496.

9. JH Baker 2nd, J McKenzie 3rd, S Beau, GS Greer, J Porterfield, M Fedor, S Greenberg, EG Daoud, R Corbisiero, JR Bailey, and L Porterfield. Acute evaluation of programmer-guided AV/PV and VV delay optimization comparing an IEGM method and echocardiogram for cardiac resynchronization therapy in heart failure patients and dual-chamber ICD implants. J Cardiovasc Electrophysiol (2007) 18:185-191.

10. H Krum, B Lemke, D Birnie, KLF Lee, K Aonuma, RC Starling, M Gasparini, J Gorcsan, T Rogers, A Sambelashvili, A Kalmes, and D Martin. A novel algorithm for individualized cardiac resynchronization therapy: rationale and design of the adaptive cardiac resynchronization therapy trial. Am Heart J (2012) 163:747-752.e1.

11. CJM van Deursen, M Strik, LM Rademakers, A van Hunnik, M Kuiper, L Wecke, HJGM Crijns, K Vernooy, and FW Prinzen. Vectorcardiography as a tool for easy optimization of cardiac resynchronization therapy in canine left bundle branch block hearts. Circ Arrhythm Electrophysiol (2012) 5:544-552.

12. CJM van Deursen, L Wecke, WM van Everdingen, M Ståhlberg, MHG Janssen, F Braunschweig, L Bergfeldt, HJGM Crijns, K Vernooy, and FW Prinzen. Vectorcardiography for optimization of stimulation intervals in cardiac resynchronization therapy. J Cardiovasc Transl Res (2015) 8:128-137.

13. M Strik, LB van Middendorp, P Houthuizen, S Ploux, A van Hunnik, M Kuiper, A Auricchio, and FW Prinzen. Interplay of electrical wavefronts as determinant of the response to cardiac resynchronization therapy in dyssynchronous canine hearts. Circ Arrhythm Electrophysiol (2013) 6:924-931.

14. DL Cortez and TT Schlegel. When deriving the spatial QRS-T angle from the 12-lead electrocardiogram, which transform is more Frank: regression or inverse Dower? $J$ Electrocardiol (2010) 43:302-309.

15. ER DeLong, DM DeLong, and DL Clarke-Pearson. Comparing the areas under two or more correlated receiver operating characteristic curves: a nonparametric approach. Biometrics (1988) 44:837-845.

16. K Vernooy, XA Verbeek, RN Cornelussen, B Dijkman, HJ Crijns, T Arts, and FW Prinzen. Calculation of effective VV interval facilitates optimization of AV delay and VV interval in cardiac resynchronization therapy. Heart Rhythm (2007) 4:75-82.

17. N Varma, P Jia, and Y Rudy. Electrocardiographic imaging of patients with heart failure with left bundle branch block and response to cardiac resynchronization therapy. J Electrocardiol (2007) 40:S174-S178.

18. MD Bogaard, P Houthuizen, FA Bracke, PA Doevendans, FW Prinzen, M Meine, and $\mathrm{BM}$ van Gelder. Baseline left ventricular $\mathrm{dP} / \mathrm{dtmax}$ rather than the acute improvement in $\mathrm{dP} / \mathrm{dtmax}$ predicts clinical outcome in patients with cardiac resynchronization ther- 
Chapter 7

apy. Eur J Heart Fail (2011) 13:1126-1132. 



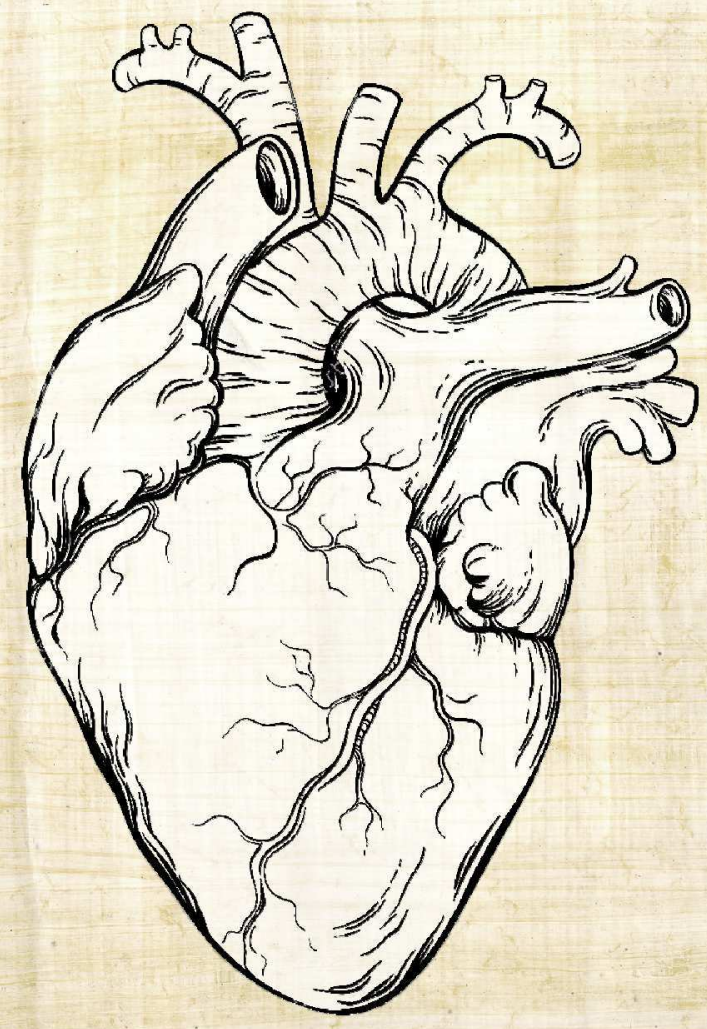




\section{Chapter}

\section{Tailoring device settings in cardiac resynchronization therapy by vectorcardiography using the implanted pacing electrodes.}

Elien B. Engels, ${ }^{1}$ Masih Mafi-Rad, ${ }^{2}$ Ben Hermans, ${ }^{1}$ Alfonso A. Hernandez, ${ }^{3}$

Antonius M.W. van Stipdonk, ${ }^{2}$ Michiel Rienstra, ${ }^{4}$ Coert Scheerder, ${ }^{3}$ Alexander H. Maass, ${ }^{4}$ Kevin Vernooy, ${ }^{2}$ and Frits W. Prinzen ${ }^{1}$ (2016).

Tailoring device settings in cardiac resynchronization therapy by vectorcardiography using the implanted pacing electrodes. [In preparation]

\footnotetext{
${ }^{1}$ Department of Physiology, CARIM School for Cardiovascular Diseases, Maastricht University, Maastricht, the Netherlands.

${ }^{2}$ Department of Cardiology, Maastricht University Medical Center, Maastricht, the Netherlands.

${ }^{3}$ Medtronic Bakken Research Center, Maastricht, the Netherlands.

${ }^{4}$ Department of Cardiology, University Medical Center Groningen, Groningen, the Netherlands.
} 


\section{Abstract}

Introduction: Left ventricular (LV) pacing fused with intrinsic ventricular activation augments CRT benefit as compared to conventional biventricular pacing. In the present study we explored the possibility to use an electrogram (EGM)-based vectorcardiogram (EGM-VCG) for patient-specific LV fusion pacing.

Methods and Results: During CRT device implantation of 28 patients, hemodynamic measurements and 12-lead ECG recordings were performed during various AV-delays. In addition, unipolar EGMs were recorded from the implanted ventricular pacing leads. The VCG was reconstructed from the 12-lead ECG and the EGM-VCG from ventricular EGM signals. QRS area $\left(\mathrm{QRS}_{\text {area }}\right)$ and amplitude $\left(\mathrm{QRS}_{\mathrm{ampl}}\right)$ were extracted from both methods. Optimal hemodynamic response was defined as the largest increase in LV systolic pressure $\left(\mathrm{LVP}_{\text {syst }}\right)$ or in the maximal rate of $\mathrm{LV}$ pressure rise $\left(\mathrm{LV} \mathrm{d} P / \mathrm{d} t_{\max }\right)$. Over all patients and pacing modes there was a good agreement between the surface VCG and EGM-VCG derived $\mathrm{QRS}_{\text {area }}(\mathrm{R}=0.74)$ and $\mathrm{QRS}_{\text {ampl }}(\mathrm{R}=0.80)$. VCG and EGM-VCG derived $\mathrm{QRS}$ area predicted the AV-delay resulting in highest LV systolic pressure with reasonable accuracy. However, prediction of the $\mathrm{AV}$-delay resulting in highest $\mathrm{LV} \mathrm{d} P / \mathrm{d} t_{\max }$ was poor, because in one third of patients highest $\mathrm{LV} \mathrm{d} P / \mathrm{d} t_{\max }$ occurred at short AV-delays. Determination of the onset of right ventricular (RV) activation to employ LV fusion pacing could be extracted individually using the $\mathrm{QRS}_{\mathrm{ampl}}$ derived from either the VCG or EGM-VCG.

Conclusions: $\mathrm{QRS}_{\text {area }}$ derived from the VCG or EGM-VCG, can be used to predict the AV-delay resulting in highest LV systolic pressure. The onset of contribution of the intrinsic RV activation to obtain the best fusion with LV pacing can be determined using the VCG or EGM-VCG. 


\subsection{Introduction}

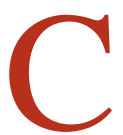

ARDIAC resynchronization therapy (CRT) is an established therapy for patients with dyssynchrony induced heart failure, mainly due to left bundle branch block (LBBB), in combination with a reduced left ventricular (LV) ejection fraction (EF). At the population level, CRT is known to improve both morbidity and mortality. ${ }^{1}$ However, at the individual level there is considerable variability in the response. ${ }^{2}$ Part of a poor CRT response is attributed to suboptimal atrioventricular (AV) timing. ${ }^{3}$

In CRT, the time-delay between stimulation of the right atrium and the ventricles (AVdelay) determines the LV filling characteristics that contribute to stroke volume and cardiac output. In addition, AV-delay has impact on the amount of fusion of intrinsic conduction with pacing-generated activation waves. ${ }^{4,5}$ Multiple techniques have been used for optimization of the AV-delay, such as different echocardiographic measures ${ }^{1,6}$, invasive hemodynamic measures $(\mathrm{d} P / \mathrm{d} t \text {, stroke work })^{7-9}$, finger photoplethysmography ${ }^{10,11}$ and peak endocardial acceleration ${ }^{12}$. With exception of the last technique, these measurements can only be performed during in-office visits. While acute hemodynamic improvements of up to $\sim 15 \%$ for $\mathrm{AV}$ - and VV-optimization compared to nominal settings have been described ${ }^{13}$, favorable long-term effects in large clinical trials have not been observed. ${ }^{6}$ Moreover, most methods are time and resource consuming and subject to large measurement variability. Therefore, many clinicians leave CRT device settings at the nominal values ('out-of-the-box'). ${ }^{14}$

While a single AV-delay optimization is probably valuable, regular optimization, preferably in an automated fashion, may be more desirable. To this purpose, algorithms have been developed that have been implemented in devices. Most of these algorithms are based on parameters measured during intrinsic activation and estimating optimal stimulation based on average data from a group of patients. ${ }^{15-17}$ Doing so, they do not consider individual differences during intrinsic conduction nor during pacing. The electrogram (EGM)-based ADAPTIVECRT $^{\mathrm{TM}}$ (trademark of Medtronic, Inc.) algorithm is the only method that provides an almost continuous automatic optimization and enables both LV pacing and BiV pacing. ${ }^{17}$ In the case of $\mathrm{LV}$ pacing, the A-LV-delay is set to the onset of intrinsic right ventricular (RV) activation because optimal fusion between the intrinsic activation wave and the activation wave originating from the pacing site lead to the largest hemodynamic improvement. ${ }^{4,18}$

In the present study we explored the possibility of using data derived from the implanted leads during ventricular pacing for patient-specific device optimization. The basis of this approach is data from previous studies from our group, indicating that the QRS vector extracted from the vectorcardiogram reflects the degree of ventricular resynchronization during various AV-delays. ${ }^{19,20}$ Vectorcardiography (VCG) is a 3-dimensional representation of the electrical forces present in the heart and might thus provide a valuable description of the amount of resynchronization during LV pacing. The minimal QRS area $\left(\mathrm{QRS}_{\text {area }}\right)$ and the QRS amplitude 
$\left(\mathrm{QRS}_{\mathrm{ampl}}\right)$ closest to a value halfway between $\mathrm{LV}$ pacing and $\mathrm{LBBB}$ were shown to predict the AV-delay settings resulting in best hemodynamic improvement in patients. In addition, in a previous animal study we showed that the principle of optimization based on the body surface VCG could be extended to a VCG derived from the EGMs $\emptyset$ obtained from the intracardiac pacing electrodes (EGM-VCG). ${ }^{21}$

The objectives of the current study were to investigate 1) whether EGM-VCG derived $\mathrm{QRS}_{\text {area }}$ or $\mathrm{QRS}_{\mathrm{ampl}}$ can be used to determine the AV-delay that provides the best hemodynamic effect and 2) how the patient-specific onset of intrinsic activation of the RV can be extracted from the EGM-VCG to enable LV fusion pacing.

\subsection{Methods}

\subsubsection{Study population}

The current study population consisted of 28 consecutive patients referred for CRT implantation with a class I indication according to the European society of cardiology (ESC) guidelines (New York Heart Association class II, III or ambulatory IV despite adequate medical treatment, in sinus rhythm, LVEF $\leq 35 \%$ and QRS duration $>120 \mathrm{~ms}$ with LBBB morphology). ${ }^{22}$ All patients were prospectively enrolled in this dual center study. Patients presenting with $\geq 4$ premature ventricular complexes (PVCs) on the 12-lead ECG and with moderate to severe aortic valve stenosis were excluded. In addition, all participants had to be between 18 and 80 years old.

This study was performed according to the principles of the Declaration of Helsinki and approved by the ethics committee of Maastricht University Medical Center+ (MUMC+) and University Medical Center Groningen (UMCG). All participants gave written informed consent prior to investigation.

\subsubsection{Procedure}

Standard digital 12-lead ECGs were recorded throughout the entire procedure. All participants underwent routine CRT-defibrillator implantation; all with a quadripolar LV lead (QuartetTM Model 1458Q, St. Jude Medical, St. Paul, USA). The RV lead was placed in the apex, the right atrial lead in the right auricle, and the LV lead in the most optimal vein. After implantation of all leads, the pressure wire was introduced via the femoral artery into the LV cavity and the unpaced electrodes were connected to an electrophysiological system to enable EGM registration during the pacing protocol (described below). Once the pacing protocol was completed, the leads were connected to the CRT device and the procedure was completed. 


\subsubsection{Pressure measurements}

The acute hemodynamic response to CRT was assessed using invasive LV pressure measurements. From the LV pressure signals, the systolic LV pressure $\left(\mathrm{LVP}_{\text {syst }}\right)$ and the maximum rate of $\mathrm{LV}$ pressure rise $\left(\mathrm{LV} \mathrm{d} P / \mathrm{d} t_{\max }\right)$ were determined. These variables were determined per heart beat and averaged over 10-20 seconds. The LV pressure measurements were performed with a 0.014 inch pressure sensor tipped transluminal guidewire (PressureWire, Certus, St. Jude Medical, St. Paul, USA). Ventricular pacing measurements were alternated by baseline measurements which was equal to atrial pacing (AAI pacing). After each transition, at least 10 seconds were used to let the pressure stabilize, after which the LV pressure was measured for at least 10 seconds without any premature ventricular contractions. In order to identify the AV-delay with the largest increase in $\mathrm{LV} \mathrm{d} P / \mathrm{d} t_{\max }$ or $\mathrm{LVP}_{\text {syst }}$, a parabola was fitted to the data obtained during the various AV-delays. ${ }^{23}$

\subsubsection{Pacing protocol}

LV-only pacing at different AV-delays was performed during atrial overdrive pacing (10 BPM above intrinsic heart rate). AV-delays were varied from a very short AV-delay (between 30 and $50 \mathrm{~ms}$ ) to an AV-delay where the paced-ECG almost resembled the intrinsic ECG (pseudofusion), in steps of $30 \mathrm{~ms}$. Before and after each ventricular pace setting, AAI pacing at the same heart rate was used as baseline.

\subsubsection{Vectorcardiography}

12-lead ECG and EGM recordings were made at a sampling frequency of at least $1000 \mathrm{~Hz}$ for at least 10 seconds. From the 12-lead ECGs vectorcardiograms (VCGs) were constructed using the Kors matrix. ${ }^{24}$

A two dimensional EGM-VCG was constructed by plotting two bipolar leads, A and B, against each other. Bipolar lead A of the EGM-VCG was calculated by subtracting the unipolar EGM signal from the RV ring from the unipolar EGM of the proximal electrode on the LV lead and bipolar lead B was calculated by subtracting the unipolar EGM signal of the same RV lead from the unipolar EGM of the distal electrode of the LV lead (Fig. 8.1).

The VCGs and EGM-VCGs were analyzed offline using customized software programmed in MATLAB R2010b (MathWorks, Natick, MA). ${ }^{25}$ The magnitude and direction of the maximum QRS vector in space were expressed as amplitude and angle. For the VCG, the angle of the vector was described by the azimuth (angle in transversal plane) and elevation (angle between the vector and an axis perpendicular to the transversal plane). In order to express the direction of the $\mathrm{QRS}_{\mathrm{ampl}}$, the $\mathrm{QRS}_{\mathrm{ampl}}$ was defined negative when the vector was directed towards the back (negative azimuth), or in the case of the EGM-VCG when it was directed towards the positive B-axis. Furthermore, the area of the QRS loop was calculated from the 


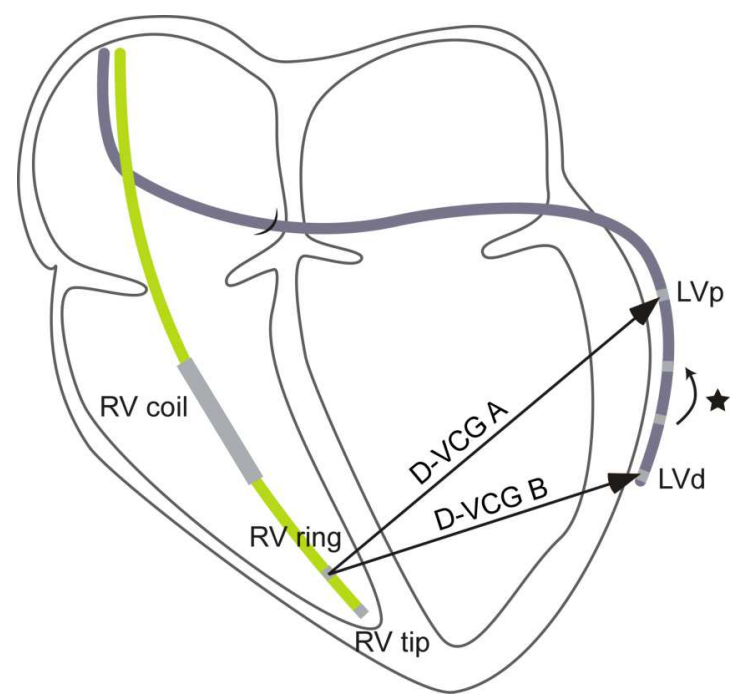

Figure 8.1: Schematic representation of the EGM-VCG construction. The LV-pacing electrode is designated with a star. LVd and LVp are the most distal and proximal LV electrodes, respectively.

area under the curve from beginning to end of the QRS complex in the three orthonormal axes $\mathrm{X}$, Y, and Z, using the equation $\mathrm{QRS}_{\text {area }}=\sqrt{\mathrm{QRS}_{\text {area }, \mathrm{x}}^{2}+\mathrm{QRS}_{\text {area }, \mathrm{y}}^{2}+\mathrm{QRS}_{\text {area, } \mathrm{z}}^{2}}$. Because in EGM-VCG the third dimension was missing, the QRS-vector angle was expressed in the plane formed by the unipolar EGMs and an area was calculated using the equation $\mathrm{QRS}_{\text {area }}=\sqrt{\mathrm{QRS}_{\text {area }, \mathrm{A}}^{2}+\mathrm{QRS}_{\mathrm{area}, \mathrm{B}}^{2}}$.

\subsubsection{Determination of onset of intrinsic ventricular activation}

In order to obtain fusion of LV-only pacing with intrinsic RV activation, it is important to determine the exact onset of intrinsic RV activation. This onset in each individual patient was determined visually during RV-only pacing at different AV-delays. The AV-delay at which the shape of the QRS complex of the 12-lead ECG changed, indicating contribution of intrinsic activation of the RV, was defined as the delay between atrial and RV activation $\left(A-R_{v i s}\right.$; Fig. 8.2A). ${ }^{4}$ The onset of intrinsic ventricular activation was assessed as A-QRS ${ }_{\text {onset }}$ : the interval between atrial pace spike and the onset of the QRS complex (Fig. 8.2B). Finally, the ADAPTIVECRT $^{\mathrm{TM}}$ algorithm uses a formula that estimates the A-RV-delay as the onset of contribution of intrinsic $\mathrm{RV}$ activation $\left(\mathrm{A}-\mathrm{RV}_{\mathrm{aCRT}}\right)$ : the delay between atrial sensing or pacing and RV sensing (A-RVsense) is pre-empted by $40 \mathrm{~ms}$ or $70 \%$ of this amount, whichever is smaller (Fig. 8.2C). ${ }^{26}$ 
A
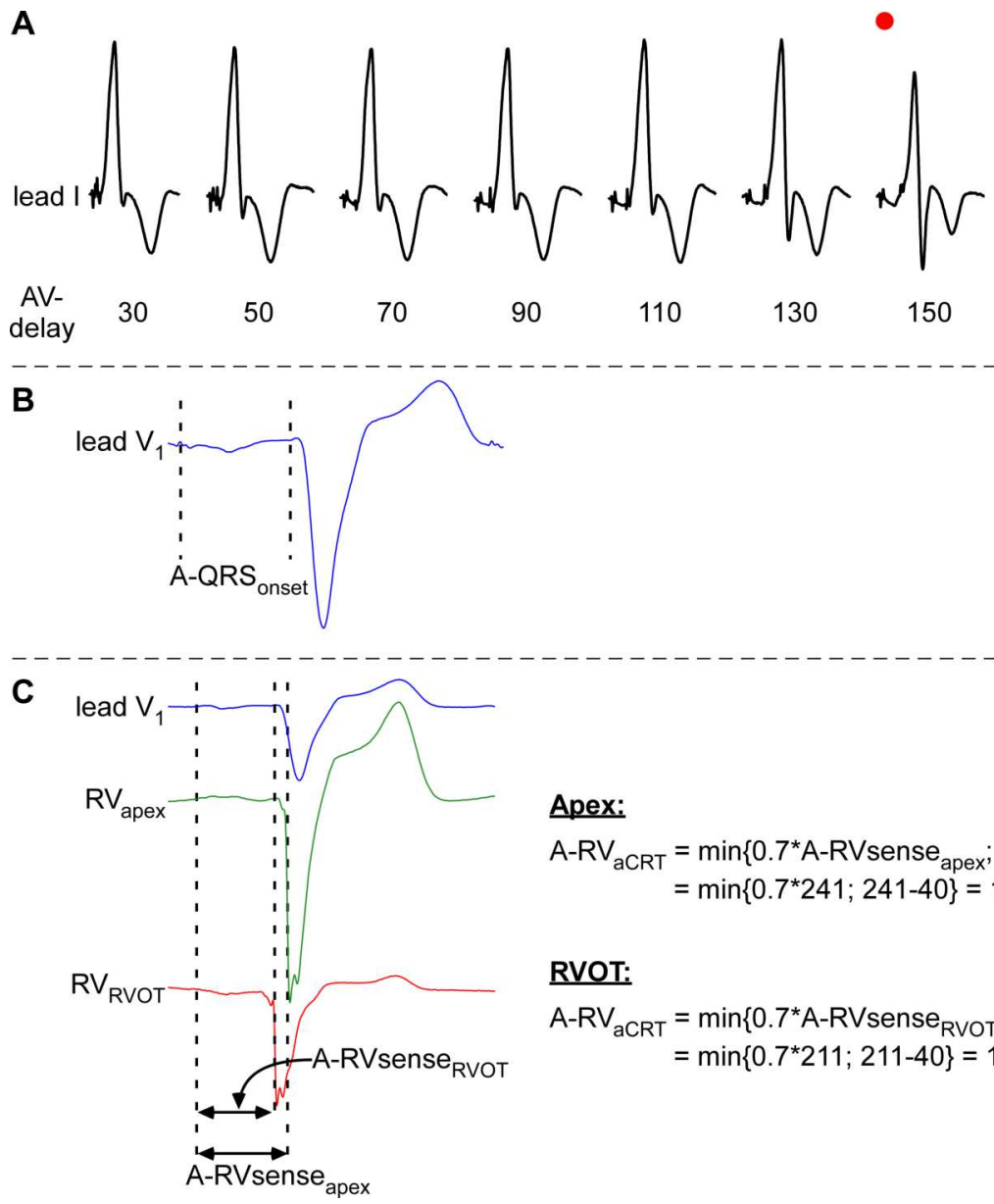

Apex:

$\begin{aligned} A-R V_{a C R T} & =\min \left\{0.7^{\star} A-R V \text { sense }_{\text {apex }} ; A-R V \text { sense }_{\text {apex }-40\}}\right. \\ & =\min \left\{0.7^{*} 241 ; 241-40\right\}=169 \mathrm{~ms}\end{aligned}$

RVOT:

$A-R V_{a C R T}=\min \left\{0.7^{*} A-R V\right.$ sense $_{\text {RVOT }} ; A-R V$ sense $\left._{\text {RVOT }}-40\right\}$

$=\min \left\{0.7^{*} 211 ; 211-40\right\}=148 \mathrm{~ms}$

Figure 8.2: Three different methods to determine the onset of contribution of ventricular contraction.

Panel A illustrated the A- $\mathrm{RV}_{\text {vis }}$ method, B) $\mathrm{A}-\mathrm{QRS}_{\text {onset }}$, and $\mathbf{C}$ ) the $\mathrm{A}-\mathrm{RV}_{\mathrm{aCRT}}$ method. The EGM signal for $\mathrm{RV}_{\text {apex }}$ and $\mathrm{RV}_{\mathrm{RVOT}}$ were obtained by temporarily placing the $\mathrm{RV}$ lead in the apex and RVOT, respectively, and measuring its signal. In panel A the red dot indicates the optimal setting.

RVOT $=$ RV outflow tract.

\subsubsection{Statistical analysis}

Continuous variables are presented as mean values \pm standard deviation (SD) whereas discrete variables are presented as counts (percentages). Linear correlations were evaluated by Pearson's correlation. Possible differences between different patient groups were tested using the Kruskal-Wallis and Wilcoxon rank-sum test with Bonferroni correction consecutively. Different A-RV methods were statistically tested using a combination of the Friedman 
test and the Wilcoxon signed rank test with a Bonferroni correction. Agreement between the various predictions of $\mathrm{AV}$-delays was evaluated with a Bland-Altman analysis, containing the mean differences (bias) and the limits of agreement (defined as \pm 1.96·SD). A two-sided Pvalue $<0.05$ was considered statistically significant. The statistical analysis was performed using IBM SPSS statistics software version 21 (SPSS Inc., Chicago, IL).

\subsection{Results}

\subsubsection{Patient characteristics}

Of the 28 included patients, 25 patients completed all measurements. Failure to acquire all measurements in three patients occurred due to an early stop because of back pain as a result of the prolonged procedure time in one, the inability to cross the aortic bioprosthesis with the pressure wire in one, and technical problems with the LV pressure measurement device in one patient. The baseline characteristics of the 25 patients are presented in Table 8.1. The patient population was a typical CRT population with mostly males, half of the patients with ischemic cardiomyopathy, reduced LVEF, and prolonged QRS duration. During the procedure, the LV lead was aimed at a postero-lateral wall and $30 \%$ of the patients were acute non-responders (maximal change in $\mathrm{LV} \mathrm{d} P / \mathrm{d} t_{\max } \leq 10 \%$ ).

Table 8.1: Patient characteristics $(\mathrm{n}=25)$

\begin{tabular}{lc}
\hline Baseline characteristics & $68 \pm 9$ \\
Age (years) & $15(60)$ \\
Male gender (n, \%) & $14(44)$ \\
Ischemic heart disease (n, \%) & \\
NYHA functional class (n, \%) & \\
II & $21(84)$ \\
III & $4(16)$ \\
LVEF (\%) & $26 \pm 6$ \\
QRS duration (ms) & $160 \pm 15$ \\
Treatment (n, \%) & \\
Diuretics & $15(60)$ \\
ACE-I/ARB & $23(92)$ \\
$\beta$-blockers & $21(84)$ \\
Spironolactone & $17(68)$ \\
Nitrates & $4(16)$ \\
Digoxin & $0(0)$ \\
Amiodarone & $1(4)$ \\
During procedure & \\
LV lead location (n, \%) & \\
Lateral & $15(60)$ \\
Posterolateral & $9(36)$ \\
Posterior & $1(4)$ \\
Acute-responder (n, \%) & $18(72)$ \\
\hline
\end{tabular}

NYHA class: New York heart association class; LVEF = left ventricular ejection fraction; $A C E-I=$ angiotensin-converting enzyme inhibitor; $\mathrm{ARB}=$ angiotensin receptor blocker. 


\subsubsection{Relation between VCG and pressure measurements during AV-delay optimization}

Fig. 8.3 displays the changes in ECG, VCG, and EGM-VCG during LV pacing at different $\mathrm{AV}$-delays in one patient. While increasing AV-delays, lead $\mathrm{V}_{1}$ changed from a positive to a negative QRS polarity. These changes were likely due to increasing fusion between the paced $\mathrm{LV}$ wave front and the intrinsic activation wave front starting from the right bundle branch (RBB). The changes in orientation of the QRS complex corresponded with the QRS vector, pointing towards the front during LV pacing and towards the back during LBBB. Similarly, the angle of the maximal QRS vector extracted from the EGM-VCG changed by $\sim 180^{\circ}$. The shape of the EGM-VCG loops were similar to the VCG loops, though more irregular and narrower (Fig. 8.3).
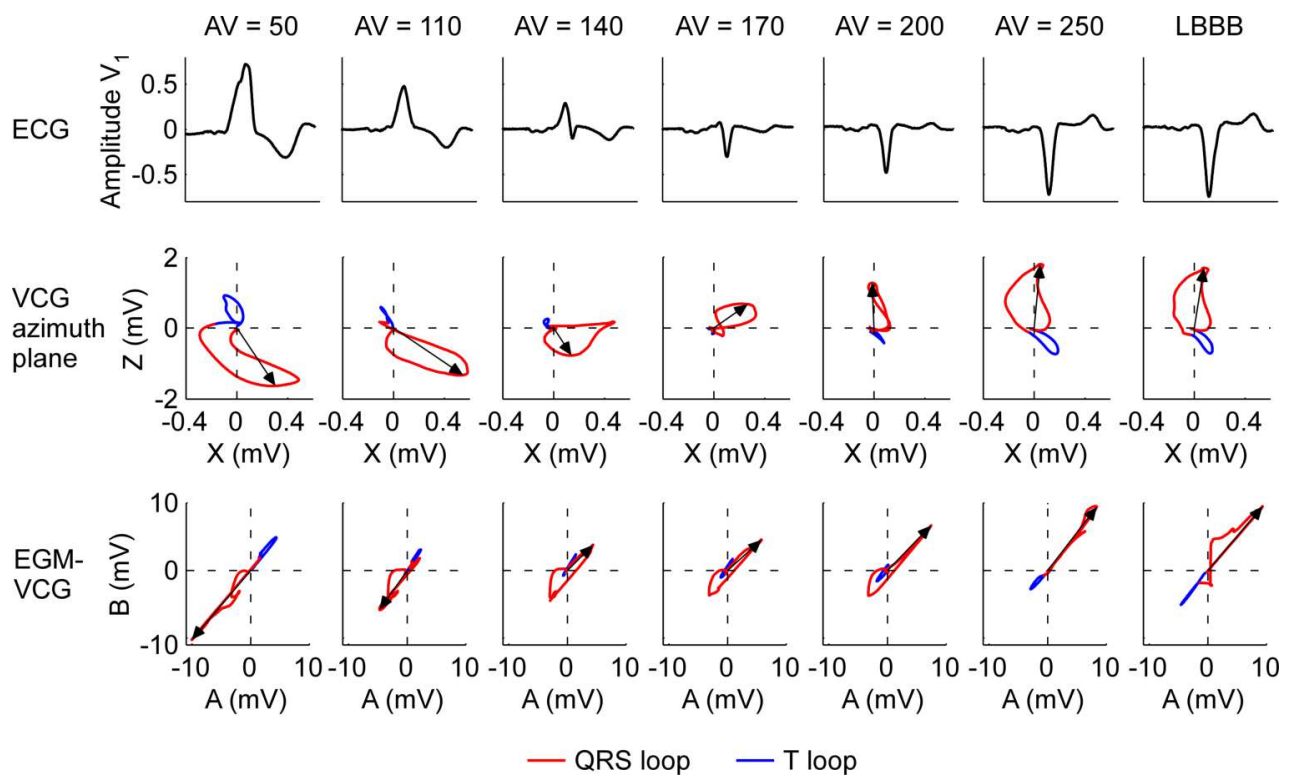

Figure 8.3: Observed changes in ECG lead $\mathrm{V}_{1}$ (upper row), VCG azimuth plane (middle row), and EGM-VCG (lower row) during LV pacing with different AV-delays in one patient.

Within the entire cohort three subgroups of patients were identified, based on their hemodynamic response to $\mathrm{LV}$ pacing: 1) non-responders in whom the increase in $\mathrm{LV} \mathrm{d} P / \mathrm{d} t_{\max } \leq 10 \%$ $(\mathrm{n}=7), 2)$ mismatch-responders in whom the $\mathrm{LV} \mathrm{d} P / \mathrm{d} t_{\max }$ increased $>10 \%$, and in whom the highest $\mathrm{LV} \mathrm{d} P / \mathrm{d} t_{\max }$ occurred at a considerably shorter $\mathrm{AV}$-delay than the highest $\mathrm{LVP}_{\text {syst }}$ $(\mathrm{n}=8)$, and 3) match-responders in whom the highest $\mathrm{LV} \mathrm{d} P / \mathrm{d} t_{\max }$ was $>10 \%$ and occurred at the same AV-delay as the highest $\operatorname{LVP}_{\text {syst }}(\mathrm{n}=10$ ) (examples shown in Fig. 8.4). In all three examples the AV-delay corresponding to the lowest VCG- and EGM-VCG-derived QRS $_{\text {area }}$ was $\sim 30 \mathrm{~ms}$ later than the AV-delay with the highest $\mathrm{LVP}_{\text {syst }}$. On the other hand, LV pacing 
at the AV-delay at which $\mathrm{QRS}_{\mathrm{ampl}}$ was the halfway value of the $\mathrm{QRS}_{\mathrm{ampl}}$ derived from the VCG or EGM-VCG between LV-only pacing and intrinsic conduction was associated with a large increase in $\mathrm{LVP}_{\text {syst }}$. In all three examples the $\mathrm{QRS}_{\mathrm{ampl}}$ halfway value derived from the EGM-VCG occurred at a $30 \mathrm{~ms}$ longer AV-delay than the $\mathrm{QRS}_{\text {ampl }}$ halfway value derived from the VCG, but the differences in $\mathrm{LVP}_{\text {syst }}$ between these two AV-delay steps were small. Due to the mismatch between $\mathrm{LVP}_{\text {syst }}$ and $\mathrm{LV} \mathrm{d} P / \mathrm{d} t_{\max }$ in the 'mismatch-responders', the AV-delay with the lowest $\mathrm{QRS}_{\text {area }}$ did not predict the AV-delay accompanied by the highest $\mathrm{LV} \mathrm{d} P / \mathrm{d} t_{\max }$ (Fig. 8.4).

Overall, throughout the LV pacing protocol there was a good agreement between the surface VCG and EGM-VCG derived $\mathrm{QRS}_{\text {area }}(\mathrm{R}=0.74)$ and $\mathrm{QRS}_{\mathrm{ampl}}(\mathrm{R}=0.80)$. The VCG or EGM-VCG derived QRS areas were able to predict the AV-delay resulting in highest LV systolic pressure with reasonable accuracy (Fig. 8.5A and $\mathrm{C}$ ), but not the AV-delay resulting in highest $\mathrm{LV} \mathrm{d} P / \mathrm{d} t_{\max }$, especially in the mismatch responders (Fig. 8.5B and D). In the mismatch-responders group, the predicted AV-delays, according to the $\mathrm{QRS}_{\text {area }}$, EGM-

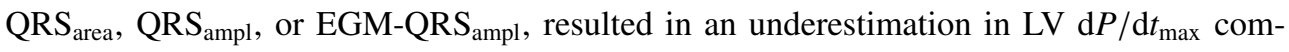
pared to the maximal increase $(50 \pm 22 \%, 67 \pm 20 \%, 35 \pm 21 \%$, and $36 \pm 20 \%$, respectively). For the match-responders group, this underestimation in LV $\mathrm{d} P / \mathrm{d} t_{\max }$ was less $(32 \pm 29 \%$, $51 \pm 38 \%, 22 \pm 31 \%$, and $23 \pm 30 \%$, respectively).

In an attempt to explain the different hemodynamic responses to LV pacing, the baseline characteristics of the three different groups were compared (Table 8.2). It was observed that the match-responder group had a lower baseline LVEF and baseline $\mathrm{LV} \mathrm{d} P / \mathrm{d} t_{\max }$ than the non-responder group. Furthermore, there was a trend towards a lower baseline $\mathrm{QRS}_{\text {area }}$ for the non-responder patients ( $\mathrm{P}=0.06$ compared to mismatch-responder group; $\mathrm{P}=0.10$ compared to match-responder group). The only observed difference between the mismatch and match responder groups was the lack of patients with ischemic cardiomyopathy (ICM) in the mismatch-responder group, while in the match-responder group $70 \%$ of the patients had ICM. 

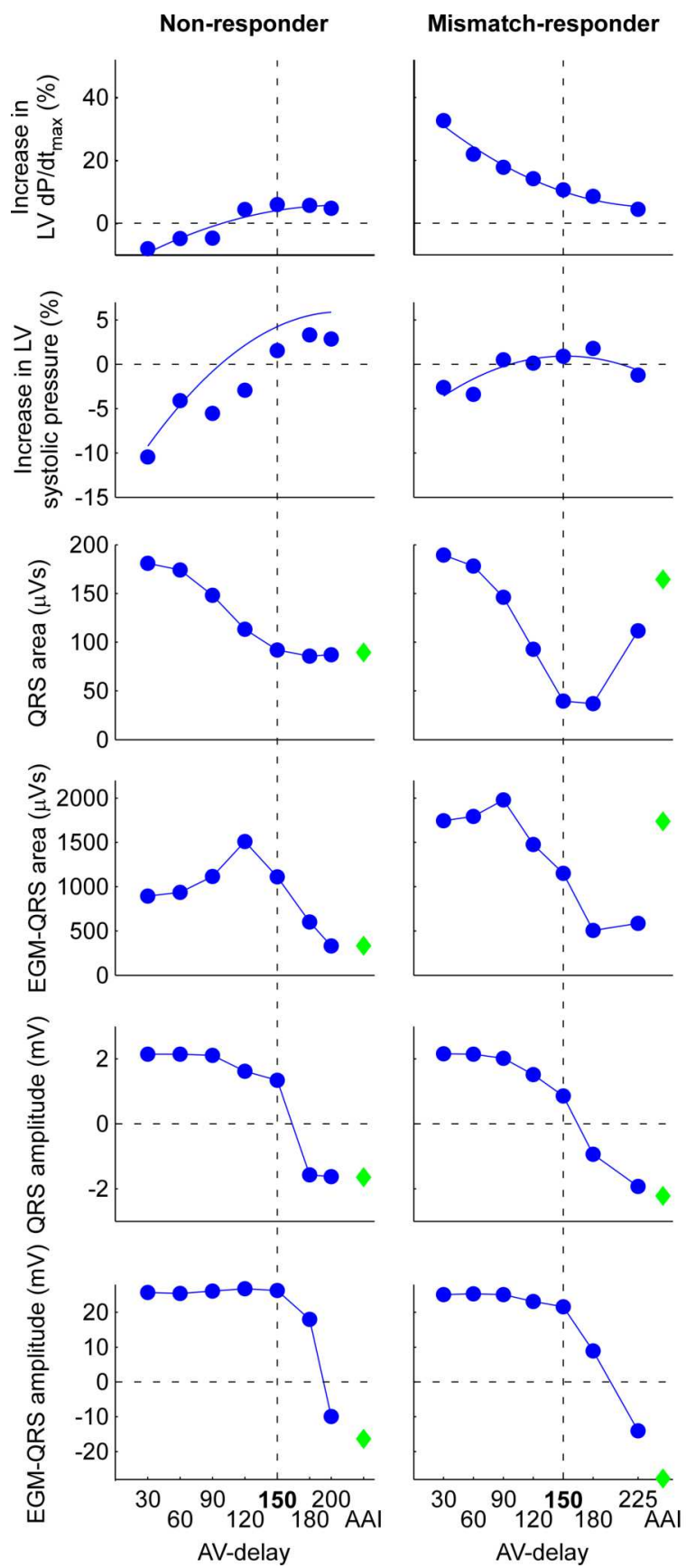

Match-responder
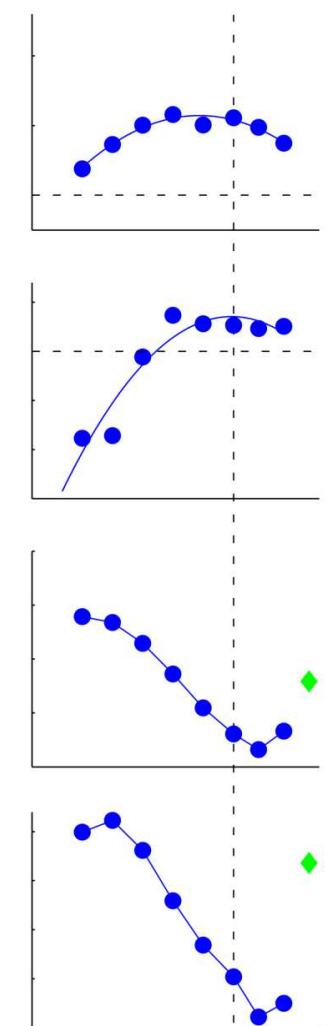

Figure 8.4: Examples of three patients: one non-responders, one mismatch-responder, and one matchresponder. Shown are the relative $\mathrm{LV} \mathrm{d} P / \mathrm{d} t_{\max }$ and $\mathrm{LV}$ systolic pressure increases compared to baseline at various AV-delays during LV pacing. Corresponding changes in QRS area and amplitude extracted from the VCG or EGM-VCG are shown. AAI-pacing ( LBBB) results are illustrated by a green diamond. Bold AV-delays and the corresponding vertical dashed lines indicate the patients $\mathrm{A}-\mathrm{RV}_{\text {vis }}$. 
A

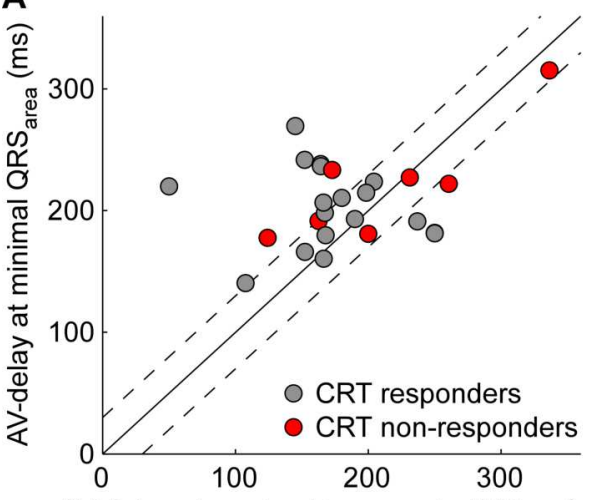

AV-delay at maximal increase in $\mathrm{LVP}_{\text {syst }}(\mathrm{ms})$

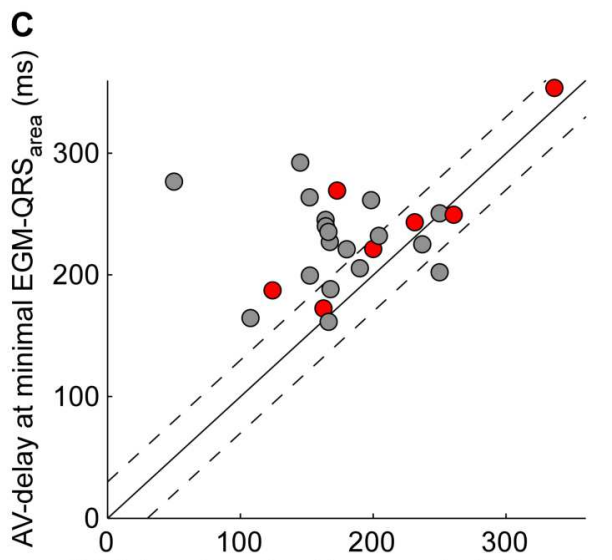

AV-delay at maximal increase in $\mathrm{LVP}_{\text {syst }}(\mathrm{ms})$

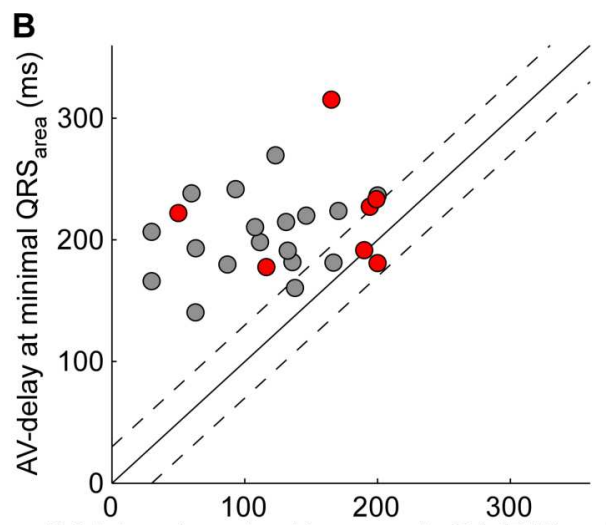

AV-delay at maximal increase in $\mathrm{LV} \mathrm{dP/dt}$ max $(\mathrm{ms})$

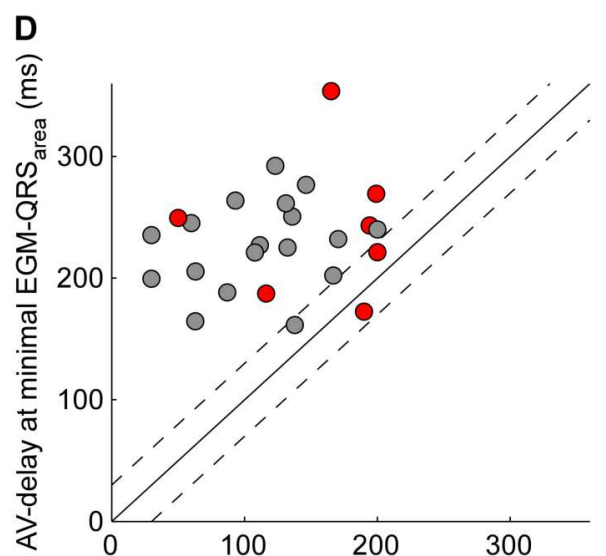

$\mathrm{AV}$-delay at maximal increase in $\mathrm{LV} \mathrm{dP/dt} t_{\max }(\mathrm{ms})$

Figure 8.5: Agreement between VCG or EGM-VCG derived $\mathrm{QRS}_{\text {area }}$ and hemodynamic predicted AV-delays defined as maximal increase in LV systolic pressure $\left(\mathrm{LVP}_{\text {syst }} ; \mathbf{A}\right.$ and $\left.\mathbf{C}\right)$ or $\mathrm{LV} \mathrm{d} P / \mathrm{d} t_{\max }(\mathbf{B}$ and $\mathbf{D})$. Patients with a maximal $\mathrm{LV} \mathrm{d} P / \mathrm{d} t_{\max }$ increase of $\leq 10 \%$ are indicated by red dots (CRT non-responders). Shown is the line of identity $(\mathrm{Y}=\mathrm{X})$ and the range within $30 \mathrm{~ms}$ of this line. 
Table 8.2: Patient characteristics of the three subgroups (non-responders; mismatch-responders; matchresponders)

\begin{tabular}{|c|c|c|c|}
\hline & $\begin{array}{l}\text { Non-responders } \\
\qquad(\mathrm{n}=7)\end{array}$ & $\begin{array}{l}\text { Mismatch-responders } \\
\qquad(\mathrm{n}=8)\end{array}$ & $\begin{array}{c}\text { Match-responders } \\
\quad(\mathrm{n}=10)\end{array}$ \\
\hline Age (y) & $64 \pm 10$ & $70 \pm 9$ & $69 \pm 8$ \\
\hline Male (n, \%) & $6(86)$ & $3(38)$ & $6(60)$ \\
\hline $\operatorname{LVEF}(\%)$ & $31 \pm 3$ & $28 \pm 5$ & $22 \pm 7^{\star}$ \\
\hline $\operatorname{ICM}(\mathrm{n}, \%)$ & $4(57)$ & $0(0)^{\dagger \dagger}$ & $7(70)$ \\
\hline \multicolumn{4}{|l|}{ NYHA class } \\
\hline $\mathrm{II}(\mathrm{n}, \%)$ & $6(86)$ & $7(88)$ & $8(80)$ \\
\hline III $(\mathrm{n}, \%)$ & $1(14)$ & $1(13)$ & $2(20)$ \\
\hline Diuretics (n, \%) & $4(57)$ & $4(50)$ & $7(70)$ \\
\hline ACE-I/ARB (n, \%) & $7(100)$ & $8(100)$ & $8(80)$ \\
\hline$\beta$-blockers (n, \%) & $6(86)$ & $7(88)$ & $8(80)$ \\
\hline Spironolactone (n, \%) & $7(100)$ & $6(75)$ & $4(40)^{\dagger}$ \\
\hline Nitrates (n, \%) & $1(14)$ & $2(25)$ & $1(10)$ \\
\hline Digoxin $(\mathrm{n}, \%)$ & $0(0)$ & $0(0)$ & $0(0)$ \\
\hline Amiodarone (n, \%) & $1(14)$ & $0(0)$ & $0(0)$ \\
\hline \multicolumn{4}{|l|}{ Mitral regurgitation } \\
\hline No & $0(0)$ & $2(25)$ & $1(10)$ \\
\hline Grade 1 & $2(28)$ & $4(50)$ & $7(70)$ \\
\hline Grade 2 & $2(28)$ & $0(0)$ & $0(0)$ \\
\hline Grade 3 & $0(0)$ & $0(0)$ & $1(10)$ \\
\hline Unknown & $3(43)$ & $2(25)$ & $1(10)$ \\
\hline $\mathrm{LVP}_{\text {syst }}(\mathrm{mmHg})$ & $122 \pm 9$ & $130 \pm 30$ & $119 \pm 16$ \\
\hline $\mathrm{LV} \mathrm{d} P / \mathrm{d} t_{\max }(\mathrm{mmHg} / \mathrm{s})$ & $1088 \pm 160$ & $1045 \pm 219$ & $835 \pm 139^{\star}$ \\
\hline PR interval (ms) & $200 \pm 38$ & $179 \pm 23$ & $189 \pm 27$ \\
\hline QRS duration (ms) & $152 \pm 14$ & $158 \pm 12$ & $168 \pm 15$ \\
\hline $\mathrm{QRS}_{\text {area }}(\mu \mathrm{Vs})$ & $68 \pm 23$ & $107 \pm 39^{\S}$ & $111 \pm 43$ \\
\hline $\mathrm{EGM}-\mathrm{QRS}_{\text {area }}(\mu \mathrm{Vs})$ & $949 \pm 777$ & $1318 \pm 335$ & $1771 \pm 712$ \\
\hline \multicolumn{4}{|l|}{ Pace location } \\
\hline Lateral (n, \%) & $2(29)$ & $5(63)$ & $8(80)$ \\
\hline Posterolateral (n, \%) & $4(57)$ & $3(38)$ & $2(20)$ \\
\hline Posterior (n, \%) & $1(14)$ & $0(0)$ & $0(0)$ \\
\hline
\end{tabular}

LVEF = left ventricular ejection fraction; ICM: ischemic cardiomyopathy; NYHA class: New York heart association class; ACE-I = angiotensin-converting enzyme inhibitor; $\mathrm{ARB}=$ angiotensin receptor blocker; $\mathrm{LVP}_{\mathrm{syst}}=$ left ventricular systolic pressure.

${ }^{\star} \mathrm{P}<0.05$ compared to non-responders using the Wilcoxon rank-sum test with Bonferroni correction.

${ }^{\S} \mathrm{P}=0.06$ compared to non-responders using the Wilcoxon rank-sum test with Bonferroni correction.

${ }^{\dagger} \mathrm{P}<0.05$ compared to non-responders using the $\chi^{2}$-test with Bonferroni correction.

${ }^{\ddagger} \mathrm{P}<0.05$ compared to match-responders using the $\chi^{2}$-test with Bonferroni correction.

\subsubsection{Comparing different measures of onset of intrinsic ventricular activation}

In the two responders shown in Fig. 8.4, the moment of onset of intrinsic RV activation, as determined by $\mathrm{A}-\mathrm{RV}_{\text {vis }}$ matched well with the AV-delay during LV pacing that resulted in the highest $\mathrm{LVP}_{\text {syst }}$. Importantly, A-RV vis corresponded with the longest AV-delay

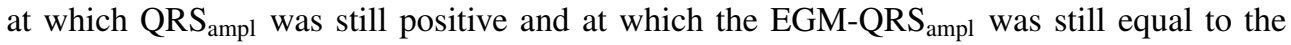
EGM-QRS ${ }_{\text {ampl }}$ during LV-only pacing at a very short AV-delay. This indicates that the EGM- 
VCG and VCG-derived $\mathrm{QRS}_{\mathrm{ampl}}$ could also be used to find the delay between atrial activation and onset of RV activation (A-RV $\mathrm{EGM}_{\mathrm{VCG}}$ and $\mathrm{A}-\mathrm{RV} \mathrm{VCG}_{\mathrm{VC}}$, Fig. 8.4).

The different methods to find the values of the time to onset of contribution of intrinsic ventricular activation (A-RV) were compared to the $A-R V_{\text {vis }}$, the $A V$-delay at which the shape of the QRS complex of the 12-lead ECG changed during DDD-RV pacing. There was no significant difference between $A-R V_{E G M-V C G}, A-R V_{V C G}$ and $A-R V_{\text {vis }}$ (Table 8.3). A-RV $V_{a C R T}$ was significantly longer than $A-R_{\text {vis }}$. Furthermore, $A-Q R S_{\text {onset }}$ was significantly longer than the other four indices of intrinsic RV activation. These values held for the RV apex as site of implantation of the RV lead. In order to investigate the sensitivity of the four methods for the location of the RV lead, in five patients the RV lead was temporarily placed at the RV

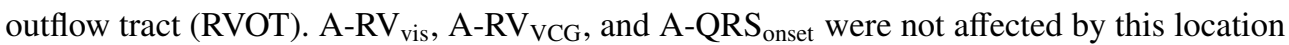
change of the RV lead. However, A-RV $\mathrm{aCRT}_{\mathrm{C}}$ was generally shorter at the RVOT position, the difference with the RV apex position ranging from $-27 \mathrm{~ms}$ to $+9 \mathrm{~ms}$ (example in Fig. 8.2B). Moreover, during LV pacing some patients revealed a time delay between pacing stimulus and onset of QRS complex, often referred to as LV pacing latency (example is shown in Fig. 8.6). In this example the LV pacing latency was $44 \mathrm{~ms}$, leading to a relative prolongation of the $\mathrm{A}-\mathrm{RV}_{\mathrm{aCRT}}$ compared to $\mathrm{A}-\mathrm{RV}_{\mathrm{vis}}$, while $\mathrm{A}-\mathrm{RV} \mathrm{EGM}_{\mathrm{VCG}}$ and $\mathrm{A}-\mathrm{RV} \mathrm{VCG}_{\mathrm{V}}$ adjust for this $\mathrm{LV}$ pacing latency by shortening the A-RV compared to A-RV $\mathrm{aCRT}$.

Table 8.3: Optimal AV-delay using different methods

\begin{tabular}{|c|c|}
\hline AV-delay method & Mean \pm SD \\
\hline $\mathrm{A}-\mathrm{RV}_{\text {vis }}$ & $170 \pm 33$ \\
\hline $\mathrm{A}-\mathrm{RV}_{\mathrm{EGM}-\mathrm{VCG}}$ & $180 \pm 43$ \\
\hline $\mathrm{A}-\mathrm{RV}_{\mathrm{VCG}}$ & $181 \pm 38$ \\
\hline $\mathrm{A}-\mathrm{RV}_{\mathrm{aCRT}}$ & $189 \pm 29^{\star}$ \\
\hline $\mathrm{A}-\mathrm{QRS}_{\text {onset }}$ & $228 \pm 36^{\star \dagger+}$ \\
\hline
\end{tabular}

$\mathrm{A}-\mathrm{RV}_{\text {vis }}=\mathrm{A}-\mathrm{RV}$ as visually observed; $\mathrm{A}-\mathrm{RV} \overline{\mathrm{EGM}-\mathrm{VCG}}=\mathrm{A}-\mathrm{RV}$ according to the EGM-VCG$; \mathrm{A}-\mathrm{RV} \mathrm{VCG}=\mathrm{A}-\mathrm{RV}$ according to the $\mathrm{VCG} ; \mathrm{A}-\mathrm{RV}_{\mathrm{aCRT}}=\mathrm{A}-\mathrm{RV}$ according to $\mathrm{ADAPTIVECRT}^{\mathrm{TM}}$ algorithm; $\mathrm{A}-\mathrm{QRS}_{\text {onset }}=$ time between atrial pace spike and $\mathrm{QRS}$ onset; most definitions are illustrated in Fig. 8.2.

${ }^{\star} \mathrm{P}<0.05$ compared to $\mathrm{A}-\mathrm{RV}_{\text {vis }}$ using the Wilcoxon signed rank test.

${ }^{\dagger} \mathrm{P}<0.05$ compared to A-RV $\mathrm{EGM}_{\mathrm{V}-\mathrm{VC}}$ using the Wilcoxon signed rank test.

${ }^{\ddagger} \mathrm{P}<0.05$ compared to A-RV $\mathrm{VCG}$ using the Wilcoxon signed rank test.

$\cdot \mathrm{P}<0.05$ compared to $\mathrm{A}-\mathrm{RV}_{\mathrm{aCRT}}$ using the Wilcoxon signed rank test.

Performances of the various algorithms were investigated by comparing the measured $\mathrm{LV} \mathrm{d} P / \mathrm{d} t_{\max }$ or $\mathrm{LVP}_{\text {syst }}$ during $\mathrm{LV}$ pacing with an $\mathrm{AV}$-delay equal to the calculated $\mathrm{A}-\mathrm{RV}$ delays. The longer AV-delay found using A-QRS onset resulted in a significantly smaller increase in $\mathrm{LV} \mathrm{d} P / \mathrm{d} t_{\max }$ than using the other four methods $\left(\mathrm{A}-\mathrm{RV}_{\mathrm{vis}}, \mathrm{A}-\mathrm{RV} \mathrm{EGM}_{\mathrm{VCG}}, \mathrm{A}-\mathrm{RV} \mathrm{VCG}_{\mathrm{V}}\right.$, and $A-R_{\mathrm{aCRT}}$; Fig. 8.7A). Furthermore, $\mathrm{A}-\mathrm{RV}_{\mathrm{vis}}, \mathrm{A}-\mathrm{RV}_{\mathrm{EGM}-\mathrm{VCG}}$, and $\mathrm{A}-\mathrm{RV}_{\mathrm{VCG}}$ resulted in a comparable increase in $\mathrm{LV} \mathrm{d} P / \mathrm{d} t_{\max }$, while $\mathrm{A}-\mathrm{RV}_{\mathrm{aCRT}}$ led to a lower increase in $\mathrm{LV} \mathrm{d} P / \mathrm{d} t_{\max }$ compared to $\mathrm{A}-\mathrm{RV}_{\text {vis }}(\mathrm{P}<0.01), \mathrm{A}-\mathrm{RV}_{\mathrm{EGM}-\mathrm{VCG}}(\mathrm{P}=0.24)$, and $\mathrm{A}-\mathrm{RV}_{\mathrm{VCG}}(\mathrm{P}=0.19)$. These differences between $\mathrm{A}-\mathrm{RV}_{\mathrm{vis}}, \mathrm{A}-\mathrm{RV}_{\mathrm{EGM}-\mathrm{VCG}}$ or $\mathrm{A}-\mathrm{RV}_{\mathrm{VCG}}$ and $\mathrm{A}-\mathrm{RV}_{\mathrm{aCRT}}$ were also present 


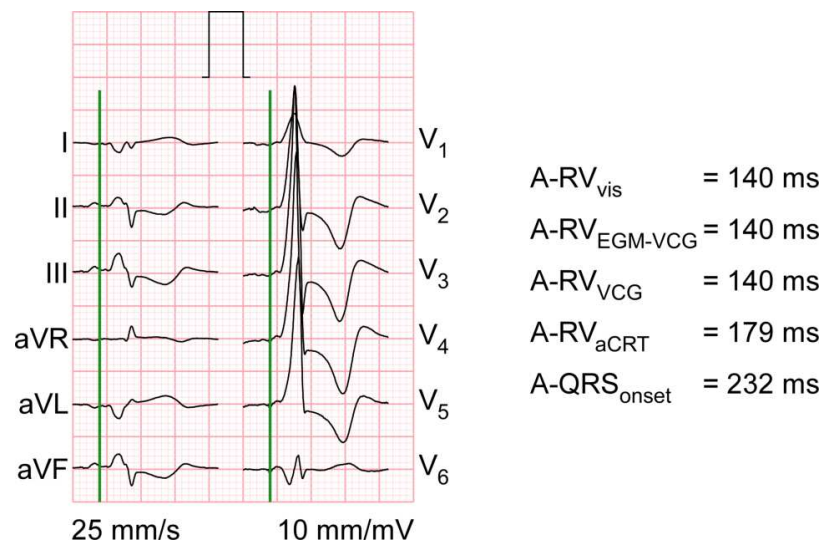

Figure 8.6: Example of a patient with latency during LV-only pacing. The green line indicates the timing of the pace-artefact. The time interval between pacemaker stimulus and the onset of the earliest paced QRS complex was $\sim 44 \mathrm{~ms}$. The latency caused a prolongation of $\mathrm{A}-\mathrm{RV}_{\mathrm{aCRT}}$ of $39 \mathrm{~ms}$. A-RV $\mathrm{EGM}_{\mathrm{VCG}}$ and $\mathrm{A}-\mathrm{RV}_{\mathrm{VCG}}$ were not affected.

at the individual level (Fig. 8.7B). Absolute changes in $\mathrm{LVP}_{\text {syst }}$ were smaller, but there was

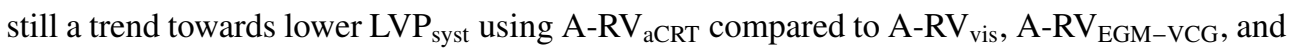
A-RV $V_{\text {VCG }}$ (Fig. 8.7C and D).

\subsection{Discussion}

The current study shows that the EGM-VCG resembles the normal VCG and that, during $\mathrm{LV}$ pacing, the $\mathrm{QRS}_{\text {area }}$ and $\mathrm{QRS}_{\mathrm{ampl}}$ derived from the VCG or EGM-VCG can predict the AV-delay resulting in highest LV systolic pressure with reasonable accuracy, but not that with highest $\mathrm{LV} \mathrm{d} P / \mathrm{d} t_{\max }$. Also, both methods seem useful to determine the exact onset of intrinsic $\mathrm{RV}$ activation (A-RV $\mathrm{VCG}_{\mathrm{VG}}$ ) and may therefore assist to individualize $\mathrm{LV}$ fusion pacing. Using either the A-RV $\mathrm{EGM}_{\mathrm{VCG}}$ or A-RV $\mathrm{VCG}_{\mathrm{V}}$ the ADAPTIVECRT ${ }^{\mathrm{TM}}$ algorithm can be fully individualized, leading to a possible improvement in hemodynamic response, especially since it overcomes variability induced by RV lead placement and LV latency.

\subsubsection{Relation between VCG and EGM-VCG}

The demonstration that the EGM-VCG resembles the VCG, especially with regards to the behavior of $\mathrm{QRS}_{\text {area }}$ and $\mathrm{QRS}_{\mathrm{ampl}}$ during an $\mathrm{LV}$ pacing protocol, is not trivial. After all the VCG has a 3D vector while the EGM-VCG has only been derived from three electrodes on the LV and RV leads, forming a 2D plane. This plane varies per patient since every patient is different and the LV lead was placed at various locations. The good performance of the EGM- 
A

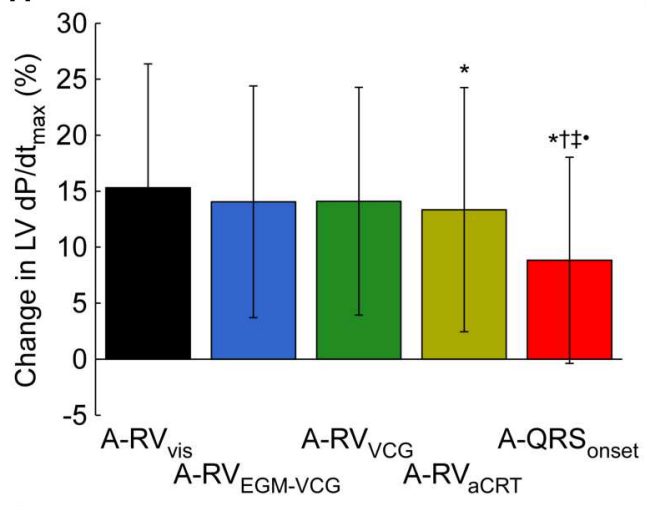

C

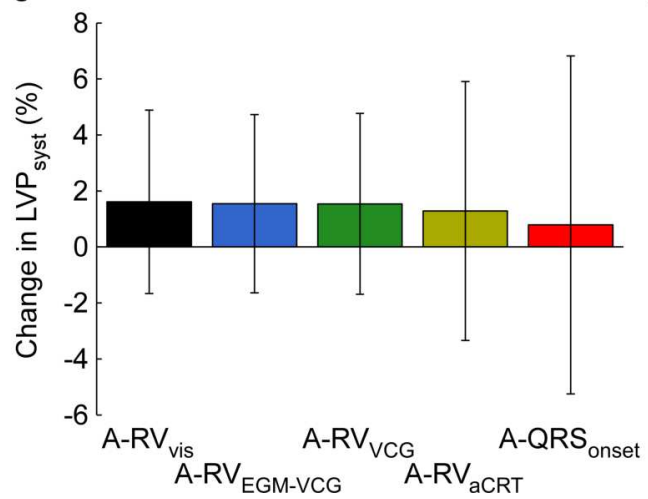

B

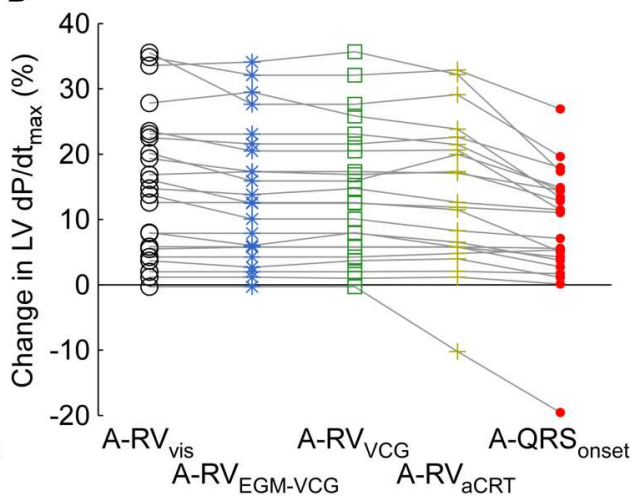

D

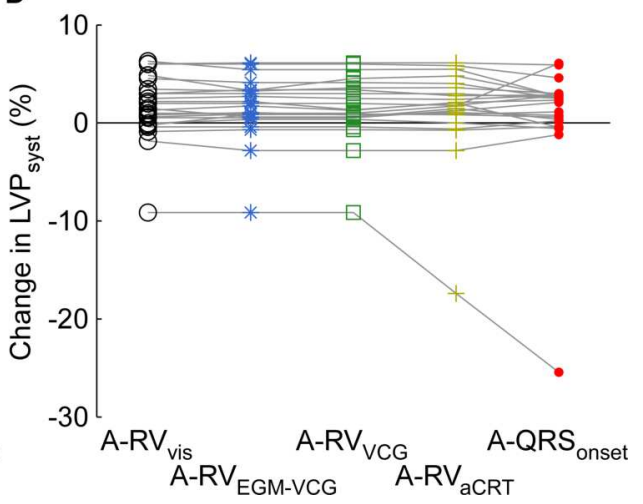

Figure 8.7: Hemodynamic response (relative change compared to baseline in $\mathrm{LV} \mathrm{d} P / \mathrm{d} t_{\max }[\mathbf{A}$ and $\mathbf{B}]$ and $\mathrm{LVP}_{\text {syst }}[\mathbf{C}$ and $\mathbf{D}]$ ) at settings with an $\mathrm{AV}$-delay equal to $\mathrm{A}-\mathrm{RV}_{\text {vis }}$ (black), $\mathrm{A}-\mathrm{RV} \mathrm{EGM}_{\mathrm{EGCG}}$ (blue), A-RV $V_{\mathrm{VCG}}$ (green), $\mathrm{A}-\mathrm{RV}_{\mathrm{aCRT}}$ (yellow), and $\mathrm{A}-\mathrm{QRS}_{\text {onset }}$ (red). Overall differences in change in hemodynamic measures are shown in the left panels, individual changes are shown in the right panels. ${ }^{\star} \mathrm{P}<0.05$ compared to $\mathrm{A}-\mathrm{RV}_{\text {vis }},{ }^{\dagger} \mathrm{P}<0.05$ compared to A$\mathrm{RV}_{\mathrm{aCRT}},{ }^{\ddagger} \mathrm{P}<0.05$ compared to $\mathrm{A}-\mathrm{RV}_{\mathrm{VCG}},{ }^{\bullet} \mathrm{P}<0.05$ compared to A-RV $\mathrm{E}_{\mathrm{EGM}-\mathrm{VCG}}$ using the Wilcoxon signed rank test with a Bonferroni correction.

$\mathrm{LVP}_{\text {syst }}=\mathrm{LV}$ systolic pressure; $\mathrm{A}-\mathrm{RV}_{\mathrm{vis}}=\mathrm{A}-\mathrm{RV}$ as visually observed; $\mathrm{A}-\mathrm{RV}_{\mathrm{EGM}-\mathrm{VCG}}=\mathrm{A}-$ $\mathrm{RV}$ according to the EGM-VCG; $\mathrm{A}-\mathrm{RV}_{\mathrm{VCG}}=\mathrm{A}-\mathrm{RV}$ according to the $\mathrm{VCG} ; \mathrm{A}-\mathrm{RV}_{\mathrm{aCRT}}=\mathrm{A}-$ $\mathrm{RV}$ according to $\mathrm{ADAPTIVECRT}^{\mathrm{TM}}$ algorithm; $\mathrm{A}-\mathrm{QRS}_{\text {onset }}=$ time between atrial pace spike and QRS onset.

VCG in this regard may be explained by the fact that the plane of the EGM-VCG is exactly the plane containing most information. This can be explained by the fact that in LBBB the ventricular activation occurs from RV to LV and the LV lead is positioned in a vein on the LV lateral wall. 


\subsubsection{Relation between VCG and pressure measurements}

The present study corroborates previous findings in patients that during LV pacing the minimal $\mathrm{QRS}_{\text {area }}$ occurs somewhere between LV-only pacing and LBBB, that the QRS vector rotates by almost $180^{\circ}$ between LV-only pacing and LBBB, and that the $\mathrm{QRS}_{\text {area }}$ can predict the AV-delay resulting in highest LV systolic pressure with reasonable accuracy. ${ }^{19}$ The present study extends the latter observation by showing that also the EGM-VCG derived $\mathrm{QRS}_{\text {area }}$ and $\mathrm{QRS}_{\mathrm{ampl}}$ can be used to this purpose. Differences between the present and the previous study were that van Deursen et al. ${ }^{19}$ used a combination of echocardiography (LV outflow tract velocity time integral) and finger blood pressure as a measure of hemodynamic response. This combination includes both pressure and flow information whereas the present hemodynamic response was purely pressure based. Furthermore, for the finger blood pressure 10 beats before and after each transition were averaged to calculate the change in order to avoid influence of the baroreflex. ${ }^{27}$ In our study however, measurements were performed 10 seconds after changing the pace setting, thus probably leading to smaller observed changes.

The mismatch between $\mathrm{LV} \mathrm{d} P / \mathrm{d} t_{\max }$ and $\mathrm{LVP}_{\text {syst }}$ in $8 / 25$ patients is remarkable, because in other studies these parameters appear to match and the highest $\mathrm{LV} \mathrm{d} P / \mathrm{d} t_{\max }$ is rarely seen at the shortest AV-delays.

\subsubsection{Differences between different measures of onset of intrinsic RV activation}

This study shows that both A-RV $\mathrm{EGM}_{\mathrm{VCG}}$ and $\mathrm{A}-\mathrm{RV}_{\mathrm{VCG}}$ can be used as a robust and objective measure to assess the ideal AV-delay during LV-only pacing to create 'fusion' pacing. Compared to the ADAPTIVECRT ${ }^{\mathrm{TM}}$ algorithm, optimization performed by EGM-VCG or VCG leads to a fully individualized optimization of the AV-delay. The ADAPTIVECRT ${ }^{\mathrm{TM}}$ algorithm allows continuous automated adaptation of AV-delay, but it uses an averaged, general relation to find A-RV. As the present study shows, using such average relation at the individual level may result in suboptimal hemodynamic response. In addition, A-RV $\mathrm{aCRT}_{\mathrm{T}}$ is operator-dependent, as the moment of RVsense has to be indicated manually in the EGM sig-

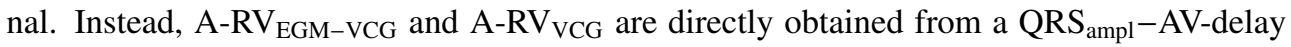
plot. Furthermore, this study shows that $A-R_{a C R T}$ is dependent on the location of the RV lead. Temporary placement of the RV lead in the RVOT, led to a difference in A-RV $\mathrm{aCRT}_{\mathrm{a}}$ compared to when the lead was placed in the RV apex. Finally, the A-RV $\mathrm{aCRT}_{\text {algorithm does }}$ not adjust for the possible presence of latency, resulting in an overestimation of the real time of onset of intrinsic RV activation.

Assuming that in a patient the difference between A-RVsense and A-RV $\mathrm{VCG}_{\text {does not }}$ depend on heart rate changes, and RV lead location does not change, a single A-RV $\mathrm{VCG}_{\mathrm{V}}$ measurement during or briefly after the implantation of the device may suffice to adjust the 
ADAPTIVECRT $^{\mathrm{TM}}$ algorithm at the individual level. Another possibility would be that the algorithm to find $\mathrm{A}-\mathrm{RV}_{\mathrm{EGM}-\mathrm{VCG}}$ is embedded in the CRT device, resulting in the possibility to adjust for the delay between A-RVsense and A-RV $\mathrm{EGM}_{\mathrm{VCG}}$ more regularly. Obviously, future studies are required to investigate whether the difference between A-RV and A-RVsense indeed is independent of heart rate.

\subsubsection{Limitations}

The current study was a relatively small study, designed to proof the principle of electrical optimization of CRT using VCG and EGM-VCG. The study was performed in two centers (MUMC+ and UMCG) and the patients were consecutive patients. Furthermore, as indicated by the baseline patient characteristics (Table 8.1), the patient population is representative for the CRT population. A larger multicenter trial should be performed to confirm our results.

A limitation of the current study is that it only investigated acute hemodynamic CRT response. Acute changes in $\mathrm{LV} \mathrm{d} P / \mathrm{d} t_{\max }$ or $\mathrm{LVP}_{\text {syst }}$ may not correspond to the chronic longterm changes. ${ }^{28}$

The current study only investigated the response in patients with a LBBB, while the response and the A-RV determination could be different in right bundle branch block and intraventricular conduction delay patients. However, the current indication for CRT regarding these conduction disturbances is class I for LBBB and class II for non-LBBB patients. ${ }^{22}$

\subsection{Conclusions}

The present study shows that during LV pacing the $\mathrm{QRS}_{\text {area }}$ or $\mathrm{QRS}_{\mathrm{ampl}}$ derived from the VCG or EGM-VCG, can be used to predict the AV-delay resulting in highest LV systolic pressure. Furthermore, the onset of contribution of the intrinsic RV activation can be determined using the VCG or EGM-VCG, which can be used to objectively and easily tailor the ADAPTIVECRT ${ }^{\mathrm{TM}}$ algorithm, possibly leading to a further increase in hemodynamic response by CRT.

\subsection{Funding}

This work was supported within the framework of Center for Translational Molecular Medicine (www.ctmm.nl), Project COHFAR (Congestive Heart Failure and Arrhythmia) [Grant number 01C-203], and supported by the Dutch Heart Foundation. 


\section{References}

1. JGF Cleland, JC Daubert, E Erdmann, N Freemantle, D Gras, L Kappenberger, L Tavazzi, and Cardiac Resynchronization-Heart Failure (CARE-HF) Study Investigators. The effect of cardiac resynchronization on morbidity and mortality in heart failure. N Engl J Med (2005) 352:1539-1549.

2. European Heart Rhythm Association, European Society of Cardiology, Heart Rhythm Society, Heart Failure Society of America, American Society of Echocardiography, American Heart Association, European Association of Echocardiography, Heart Failure Association, JC Daubert, L Saxon, et al. 2012 EHRA/HRS expert consensus statement on cardiac resynchronization therapy in heart failure: implant and follow-up recommendations and management. Heart Rhythm (2012) 9:1524-1576.

3. W Mullens, RA Grimm, T Verga, T Dresing, RC Starling, BL Wilkoff, and WHW Tang. Insights from a cardiac resynchronization optimization clinic as part of a heart failure disease management program. J Am Coll Cardiol (2009) 53:765-773.

4. K Vernooy, XA Verbeek, RN Cornelussen, B Dijkman, HJ Crijns, T Arts, and FW Prinzen. Calculation of effective VV interval facilitates optimization of AV delay and VV interval in cardiac resynchronization therapy. Heart Rhythm (2007) 4:75-82.

5. M Strik, LB van Middendorp, P Houthuizen, S Ploux, A van Hunnik, M Kuiper, A Auricchio, and FW Prinzen. Interplay of electrical wavefronts as determinant of the response to cardiac resynchronization therapy in dyssynchronous canine hearts. Circ Arrhythm Electrophysiol (2013) 6:924-931.

6. KA Ellenbogen, MR Gold, TE Meyer, I Fernndez Lozano, S Mittal, AD Waggoner, B Lemke, JP Singh, FG Spinale, JE Van Eyk, J Whitehill, S Weiner, M Bedi, J Rapkin, and KM Stein. Primary results from the SmartDelay determined AV optimization: a comparison to other AV delay methods used in cardiac resynchronization therapy (SMART-AV) trial: a randomized trial comparing empirical, echocardiography-guided, and algorithmic atrioventricular delay programming in cardiac resynchronization therapy. Circulation (2010) 122:2660-2668.

7. A Auricchio, C Stellbrink, M Block, S Sack, J Vogt, P Bakker, H Klein, A Kramer, J Ding, R Salo, B Tockman, T Pochet, and J Spinelli. Effect of pacing chamber and atrioventricular delay on acute systolic function of paced patients with congestive heart failure. The Pacing Therapies for Congestive Heart Failure Study Group. The Guidant 
Congestive Heart Failure Research Group. Circulation (1999) 99:2993-3001.

8. A Auricchio, C Stellbrink, S Sack, M Block, J Vogt, P Bakker, P Mortensen, H Klein, PATH-CHF Study Group, et al. The Pacing Therapies for Congestive Heart Failure (PATH-CHF) study: rationale, design, and endpoints of a prospective randomized multicenter study. The American journal of cardiology (1999) 83:130-135.

9. DA Kass, CH Chen, C Curry, M Talbot, R Berger, B Fetics, and E Nevo. Improved left ventricular mechanics from acute VDD pacing in patients with dilated cardiomyopathy and ventricular conduction delay. Circulation (1999) 99:1567-1573.

10. ZI Whinnett, JE Davies, K Willson, AW Chow, RA Foale, DW Davies, AD Hughes, DP Francis, and J Mayet. Determination of optimal atrioventricular delay for cardiac resynchronization therapy using acute non-invasive blood pressure. Europace (2006) 8:358-366.

11. C Butter, C Stellbrink, A Belalcazar, D Villalta, M Schlegl, A Sinha, F Cuesta, and C Reister. Cardiac resynchronization therapy optimization by finger plethysmography. Heart Rhythm (2004) 1:568-575.

12. P Ritter, PPHM Delnoy, L Padeletti, M Lunati, H Naegele, A Borri-Brunetto, and J Silvestre. A randomized pilot study of optimization of cardiac resynchronization therapy in sinus rhythm patients using a peak endocardial acceleration sensor vs. standard methods. Europace (2012) 14:1324-1333.

13. ZI Whinnett, DP Francis, A Denis, K Willson, P Pascale, I van Geldorp, M De Guillebon, S Ploux, K Ellenbogen, M Haïssaguerre, et al. Comparison of different invasive hemodynamic methods for AV delay optimization in patients with cardiac resynchronization therapy: implications for clinical trial design and clinical practice. International journal of cardiology (2013) 168:2228-2237.

14. D Gras, MS Gupta, E Boulogne, L Guzzo, and WT Abraham. Optimization of AV and VV Delays in the Real-World CRT Patient Population: An International Survey on Current Clinical Practice. Pacing and Clinical Electrophysiology (2009) 32:S236S239.

15. MR Gold, I Niazi, M Giudici, RB Leman, JL Sturdivant, MH Kim, Y Yu, J Ding, and AD Waggoner. A prospective comparison of AV delay programming methods for hemodynamic optimization during cardiac resynchronization therapy. J Cardiovasc Electrophysiol (2007) 18:490-496.

16. JH Baker 2nd, J McKenzie 3rd, S Beau, GS Greer, J Porterfield, M Fedor, S Greenberg, EG Daoud, R Corbisiero, JR Bailey, and L Porterfield. Acute evaluation of programmer-guided AV/PV and VV delay optimization comparing an IEGM method and echocardiogram for cardiac resynchronization therapy in heart failure patients and dual-chamber ICD implants. J Cardiovasc Electrophysiol (2007) 18:185-191. 
17. H Krum, B Lemke, D Birnie, KLF Lee, K Aonuma, RC Starling, M Gasparini, J Gorcsan, T Rogers, A Sambelashvili, A Kalmes, and D Martin. A novel algorithm for individualized cardiac resynchronization therapy: rationale and design of the adaptive cardiac resynchronization therapy trial. Am Heart J (2012) 163:747-752.e1.

18. BM van Gelder, FA Bracke, A Meijer, and NH Pijls. The hemodynamic effect of intrinsic conduction during left ventricular pacing as compared to biventricular pacing. Journal of the American College of Cardiology (2005) 46:2305-2310.

19. CJM van Deursen, L Wecke, WM van Everdingen, M Ståhlberg, MHG Janssen, F Braunschweig, L Bergfeldt, HJGM Crijns, K Vernooy, and FW Prinzen. Vectorcardiography for optimization of stimulation intervals in cardiac resynchronization therapy. J Cardiovasc Transl Res (2015) 8:128-137.

20. CJM van Deursen, M Strik, LM Rademakers, A van Hunnik, M Kuiper, L Wecke, HJGM Crijns, K Vernooy, and FW Prinzen. Vectorcardiography as a tool for easy optimization of cardiac resynchronization therapy in canine left bundle branch block hearts. Circ Arrhythm Electrophysiol (2012) 5:544-552.

21. EB Engels, M Strik, LB van Middendorp, A van Hunnik, M Kuiper, K Vernooy, and F Prinzen. Prediction of optimal cardiac resynchronization by vectorcardiography in dyssynchronous canine hearts. Unpublished.

22. M Brignole, A Auricchio, G Baron-Esquivias, P Bordachar, G Boriani, OA Breithardt, J Cleland, JC Deharo, V Delgado, PM Elliott, et al. 2013 ESC Guidelines on cardiac pacing and cardiac resynchronization therapy: the Task Force on cardiac pacing and resynchronization therapy of the European Society of Cardiology (ESC). Developed in collaboration with the European Heart Rhythm Association (EHRA). Eur Heart J (2013) 34:2281-2329.

23. Z Whinnett, J Davies, K Willson, C Manisty, A Chow, R Foale, DW Davies, A Hughes, J Mayet, and D Francis. Haemodynamic effects of changes in atrioventricular and interventricular delay in cardiac resynchronisation therapy show a consistent pattern: analysis of shape, magnitude and relative importance of atrioventricular and interventricular delay. Heart (2006) 92:1628-1634.

24. JA Kors, G van Herpen, AC Sittig, and JH van Bemmel. Reconstruction of the Frank vectorcardiogram from standard electrocardiographic leads: diagnostic comparison of different methods. Eur Heart J (1990) 11:1083-1092.

25. EB Engels, EM Végh, CJM Van Deursen, K Vernooy, JP Singh, and FW Prinzen. Twave area predicts response to cardiac resynchronization therapy in patients with left bundle branch block. J Cardiovasc Electrophysiol (2015) 26:176-183.

26. DO Martin, B Lemke, D Birnie, H Krum, KLF Lee, K Aonuma, M Gasparini, RC Starling, G Milasinovic, T Rogers, A Sambelashvili, J Gorcsan 3rd, M Houmsse, and Adaptive CRT Study Investigators. Investigation of a novel algorithm for synchron- 
ized left-ventricular pacing and ambulatory optimization of cardiac resynchronization therapy: results of the adaptive CRT trial. Heart Rhythm (2012) 9:1807-1814.

27. A Kyriacou, PA Pabari, ZI Whinnett, S Arri, K Willson, R Baruah, B Stegemann, J Mayet, P Kanagaratnam, AD Hughes, et al. Fully automatable, reproducible, noninvasive simple plethysmographic optimization: proof of concept and potential for implantability. Pacing and Clinical Electrophysiology (2012) 35:948-960.

28. MD Bogaard, P Houthuizen, FA Bracke, PA Doevendans, FW Prinzen, M Meine, and $\mathrm{BM}$ van Gelder. Baseline left ventricular $\mathrm{dP} / \mathrm{dtmax}$ rather than the acute improvement in $\mathrm{dP} / \mathrm{dtmax}$ predicts clinical outcome in patients with cardiac resynchronization therapy. Eur J Heart Fail (2011) 13:1126-1132. 



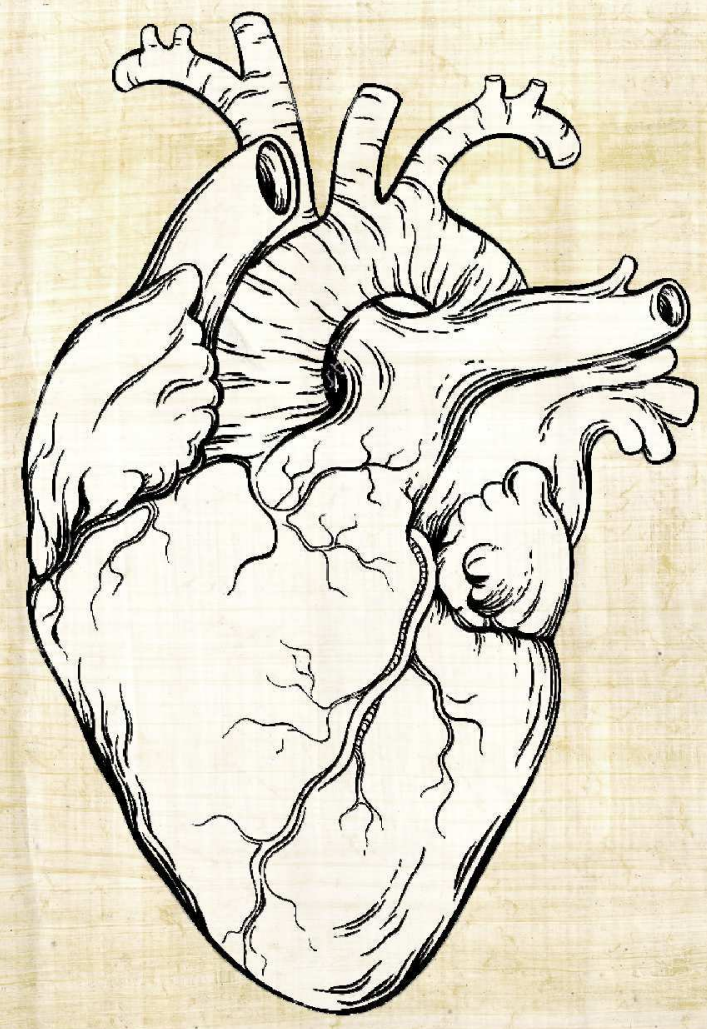




\section{Chapter}

\section{General discussion}




\subsection{Introduction}

HE ultimate goal of this thesis is to improve the response to cardiac resynchronization therapy (CRT) using vectorcardiographic (VCG) analysis.

In chapter 3 we showed that the Kors-VCG can be calculated from the 12-lead electrocardiogram (ECG) and closely resembles the measured Frank-VCG in patients eligible for CRT. This enables retrospective as well as prospective VCG analysis of routinely recorded 12-lead ECGs, which was used in all other chapters in the present thesis.

Patients with heart failure and left bundle branch block (LBBB) benefit from CRT. To better understand the natural history of LBBB we took advantage of the fact that LBBB develops in part of the patients undergoing transcatheter aortic valve implantation (TAVI). In chapter 4 we showed that in the majority of patients who developed LBBB during a TAVI procedure, electrical remodeling occurred in the first month of LBBB, as evidenced by a reduction in repolarization variables. However, the extent of electrical remodeling was highly variable between patients.

In chapters 5 and $\mathbf{6}$ we investigated the potential role of the VCG in patient selection for CRT. CRT response was assessed echocardiographically (left ventricular [LV] ejection fraction $[E F]$ ) as well as clinically (e.g., mortality and HF hospitalization). We showed that in patients presenting with LBBB morphology, a larger baseline $\mathrm{T}_{\text {area }}$ is an important predictor of both LVEF increase and of improved long-term clinical outcomes following CRT. This effect was larger than the prediction ability of the $\mathrm{QRS}_{\text {area }}$.

Once a CRT device is implanted, the benefit of CRT might be increased by optimizing the CRT device settings continuously and individually using the VCG or an electrogram (EGM) based VCG (EGM-VCG). In canines with LBBB (chapter 7) as well as in patients undergoing a CRT implantation (chapter 8), the EGM-VCG proved to be able to predict the AV settings providing the largest increase in LV pump function, especially during LV fusion pacing. In chapter 8 it was also shown that both the VCG and EGM-VCG can be used to find the onset of intrinsic right ventricular (RV) activation in the individual patient, which is useful to optimize LV fusion pacing.

\subsection{Use and advantages of the VCG}

As was pointed out in chapter 3 of this thesis, it is justified to use the Kors-VCG as calculated from the 12-lead ECG for VCG analysis in patients eligible for CRT, so with wide QRS complexes. This good correlation in this patient group extends previously published articles on the good performance of the Kors-VCG in other patient cohorts. ${ }^{1-4}$

To be able to calculate a VCG from the 12-lead ECG it is preferable to have a digital ECG. However, in many hospitals the ECG is only stored semi-digitally in a pdf-file. In chapter $\mathbf{5}$ 
we described a method to extract the digital 12-lead ECG information from these pdf-files. The pdf-files include vector graphics which can be extracted using a vector graphics editor, such as the program Inkscape (Boston, MA, USA). Using these extracted vector graphics, the digital 12-lead ECG can be reconstructed using MATLAB (MathWorks, Natick, MA, USA). One critical aspect is that most ECGs are stored in a format of $6 \times 2$ or $4 \times 3$ leads. However, only visible information on the pdf-file will be embedded in the vector graphics, so in case of $6 \times 2$ leads or $4 \times 3$ leads, the heartbeats registered in the first column are often not the same heartbeats as registered in the subsequent column(s). Therefore, to align all heartbeats to eventually be able to calculate a VCG, at least one common running lead is necessary. Even though this running lead is not always present at first, in most ECG systems it can be added retrospectively. Alternatively, at least one common reference point, such as a pace artefact, should be present.

In case only paper ECG recordings are available and a common running lead is present, the ECG could be scanned and digitized using the program ECGScan (AMPS LLC, New York, NY, USA) ${ }^{5}$, making it possible to also calculate a VCG from paper 12-lead ECGs.

VCG is an almost forgotten technique that records the magnitude and direction of the electrical forces that are generated by the heart, resulting in a resultant electrical force depicted by a vector for each time-point. Connecting the arrow heads of all vectors, a 3-dimensional vector loop can be constructed. Therefore, even though the VCG can be calculated from the 12-lead ECG and thus contains the same information, the spatial visualization of the 3D phenomenon of electrical activation in a single image allows for an improved interpretation of the electric activity as compared to the $121 \mathrm{D}$ projections of a scalar ECG.

The VCG can be of special importance when changes that occur over time, such as electrical remodeling as evidenced by changes in repolarization (chapter 4), are of interest. When aiming to quantify this electrical remodeling using a 12-lead ECG, the conventional variables that are used are the JTc or QTc intervals, and the directional change of the T-wave compared to the QRS complex. However, studying changes in T-wave size can only be done per lead. Using the VCG the global change in T-wave size can be calculated more easily and accurately. Furthermore, the VCG provides information in all directions, making it easier to observe 3D T-wave changes. Overall, changes in loop size, loop shape, and vector orientation are more easily detected in one 3D image than in $121 \mathrm{D}$ images.

The VCG variables related to loop size, loop shape, or vector orientation can automatically be analyzed using computer programs. This provides a more objective way of analyzing the VCG than the current analysis of the 12-lead ECG. It would even be possible to add the vectorcardiographic loop size as depicted by the area, to the already present information at the top of an ECG, without showing the VCG. 


\subsection{Electrical remodeling in patients with LBBB}

Until now the exact natural history of LBBB in patients was poorly understood because the onset of LBBB is silent and, consequently, it is usually not known when LBBB started. The TAVI-induced LBBB patients established the first human 'model' of LBBB in that respect. In chapter 4 we showed that in these patients electrical remodeling, as indicated by changes in repolarization variables, is present, but also that the extent of these changes differs greatly between patients. Possibly, this variability may be caused by the fact that these old ( $~ 80$ years) patients may have multiple other co-morbidities. However, we did not discover significant baseline differences between subgroups of TAVI-LBBB patients presenting with minor or major electrical remodeling. Therefore it is not known whether this variability is due to the aging and disease processes of the patients or due to other factors such as genetic variation.

The phenomenon of electrical remodeling can be divided into primary and secondary remodeling. Primary remodeling, better known as cardiac memory, describes persistent T-wave changes after the resumption of normal activation following a period of altered ventricular activation. ${ }^{6,7}$ Secondary remodeling develops as a consequence of a structural alteration such as heart failure and is believed to play a role in the resynchronization of ventricular repolarization in the new activation sequence. ${ }^{7,8}$ Cardiac memory was first introduced by Rosenbaum et al. ${ }^{6}$ in 1982 and has previously been observed in patients after a period of RV pacing 9 , intermittent $\mathrm{LBBB}^{10}$, pre-excitation with Wolff-Parkinson-White ${ }^{11}$, and in patients receiving $\mathrm{CRT}^{12}$. Shvilkin et al. ${ }^{13}$ demonstrated that the repolarization changes, associated with cardiac memory, can be observed not only when normal ventricular activation is restored but even when abnormal activation (e.g., ventricular pacing) continues. These repolarization changes occur between one day and one week. ${ }^{12,14}$ Shvilkin et al. ${ }^{15}$ also showed that patients with longer lasting LBBB ( $>24$ hours) have a smaller T-wave amplitude compared to patients with new LBBB ( $\leq 24$ hours), which is consistent with our finding in the TAVI-induced LBBB population (chapter 4). Importantly, the patient population described by Shvilkin et al. ${ }^{15}$ differed from our population in that they were younger, had no aortic valve disease, and (presumably) less severe heart failure. Furthermore, in our study the time course of LBBB was more precise than in the study presented by Shvilkin et al. ${ }^{15}$. Therefore, a reduction in repolarization variables (like JTc interval, T-wave amplitude, and $\mathrm{T}_{\text {area }}$ ) during longer lasting dyssynchrony of any cause (LBBB, RV pacing) appears to be a common behavior.

To better understand the changes in the T-wave following the presence of LBBB, we first need to go back to the T-wave in the normal situation. The exact reason for the concordant T-wave in normal individuals is not clear. It appears that the sequence depends on segmental and transmural differences in action potential duration. In the normally activated ventricles, the sequences of depolarization and repolarization across the ventricular wall are opposite, 
i.e., the earliest activated regions are repolarized latest, leading to a concordance between the QRS complex and T-wave. ${ }^{16,17}$ Under these conditions segmental differences are smaller than transmural differences. When LBBB is induced, large segmental differences develop which may explain the onset of a discordant T-wave. During sustained abnormal activation, however, studies have shown that also in case of such segmental differences, the earlier activated regions develop longer action potential duration while the later activated regions develop shorter action potential duration ${ }^{8}$, leading to a more synchronous repolarization. This may explain the reduction in the T-wave variables such as the JTc interval, T-wave amplitude, and $\mathrm{T}_{\text {area }}$. Whether also in these cases a complete normalization to concordant T-wave can be expected is not clear. However, in the general LBBB population, the T-waves are discordant which might be due to the fact that the depolarization phase in these patients is so severely delayed that the sequence of repolarization cannot be reversed totally by adaptation in action potential duration.

\section{Future perspectives}

The question remains whether the occurrence of electrical remodeling affects the LV function and eventually mortality rates. Also for cardiac memory it has never been demonstrated whether the presence of cardiac memory is beneficial or deleterious. A large prospective clinical trial should be performed in which TAVI-induced LBBB patients are followed over time and in which the relation between changes in the $\mathrm{T}_{\text {area }}$ and reverse remodeling or, on the long term, mortality is investigated.

\subsection{Differences between TAVI-induced LBBB patients and CRT candidates}

It is interesting to compare TAVI-LBBB patients with CRT candidates, because TAVI most likely causes a 'typical' proximal $\mathrm{LBBB}$, due to the pressure of the artificial valve on the proximal part of the left bundle branch. In CRT candidates the exact location of the block is unknown, but the fact that in at least a subset of LBBB patients His-bundle pacing can shorten the QRS complex suggests that also some of those patients have a proximal LBBB. ${ }^{18-20}$

Because the CRT candidates most likely had LBBB for a longer period of time, their ECG characteristics can be best compared with the chronic data of the TAVI-induced LBBB patients. There are several differences between these patients. Looking at the baseline characteristics (Table 9.1) the TAVI-population was older, included more men, had less ischemia but the patients were more often in NYHA class III than the patients in the CRT-population. Moreover, most likely ejection fraction was considerably larger and LV volumes smaller in TAVI patients. ${ }^{21-26}$ Keeping these differences in mind, it is interesting to observe that QRS 
duration was shorter but $\mathrm{QRS}_{\text {area }}$ and $\mathrm{QRS}_{\mathrm{ampl}}$ were larger for the TAVI-population. Similarly, QTc and JTc interval were shorter while $\mathrm{T}_{\text {area }}$ and direction of the maximal T-vector were similar between the two patient groups (Table 9.1). The shorter QRS duration and larger $\mathrm{QRS}_{\text {area }}$ in the TAVI-induced LBBB population could be explained by the fact that the TAVI patients are subject to concentric LV hypertrophy $(\mathrm{LVH})^{27}$ while CRT candidates often show signs of dilated cardiomyopathy. The smaller LV cavity in the TAVI patients may have led to a shorter QRS duration. This idea is supported by the notion that, in patients with a narrow QRS complex, LVH is known to result in a larger R-wave due to a higher LV mass. ${ }^{28,29}$ The larger QRS $_{\text {area }}$ in the TAVI-induced LBBB patients may relate further to the lower number of patients with ischemic HF etiology. van Deursen et al. ${ }^{30}$ previously showed that the $\mathrm{QRS}_{\text {area }}$ is lower in LBBB patients with an ischemic HF etiology compared to the ones without ischemic HF etiology. Moreover, the TAVI-induced population all had LBBB, while $43 \%$ of the CRT candidates had non-LBBB. Non-LBBB has been associated with a lower $\mathrm{QRS}_{\text {area }}$ than LBBB patients, resulting in an overall lower average $\mathrm{QRS}_{\text {area }}$ in the CRT candidates. ${ }^{30-32}$

Table 9.1: Patient characteristics in chronic TAVI-induced LBBB patients and CRT candidates. Extracted from Table 4.1, Table 4.3, and Table 6.1.

\begin{tabular}{lcc}
\hline Variable & $\begin{array}{c}\text { Chronic TAVI-induced LBBB } \\
\mathrm{n}=67\end{array}$ & $\begin{array}{c}\text { CRT candidates } \\
\mathrm{n}=335\end{array}$ \\
\hline Baseline characteristics & & \\
Age (years) & $79 \pm 6$ & $67 \pm 13$ \\
Male gender (n, \%) & $32(48)$ & $265(79)$ \\
Ischemic HF etiology (n, \%) & $14(21)$ & $192(57)$ \\
NYHA class & & \\
I (n, \%) & $2(3)$ & $0(0)$ \\
II (n, \%) & $10(15)$ & $8(3)$ \\
III (n, \%) & $47(70)$ & $236(70)$ \\
IV (n, \%) & $8(12)$ & $31(9)$ \\
Unknown (n, \%) & $0(0)$ & $60(18)$ \\
LBBB (n, \%) & $67(100)$ & $199(59)$ \\
VCG measurements & & $172 \pm 33$ \\
QRS duration (ms) & $159 \pm 20$ & $516 \pm 77$ \\
QTc interval (ms) & $488 \pm 51$ & $325 \pm 62$ \\
JTc interval (ms) & $307 \pm 39$ & $1.5 \pm 0.5$ \\
QRS amplitude (mV) & $1.7 \pm 0.4$ & $88 \pm 46$ \\
QRS & $113 \pm 35$ & $0.5 \pm 0.2$ \\
T amplitude (mV) & $0.6 \pm 0.2$ & $82 \pm 47$ \\
Tarea $_{\text {area }}(\mu \mathrm{Vs})$ & $84 \pm 34$ & \\
\hline
\end{tabular}

Variables are shown as counts (percentage) or mean \pm standard deviation when appropriate. HF $=$ heart failure; NYHA $=$ New York Heart Association. 


\subsection{CRT after TAVI?}

From previous studies it is known that TAVI-induced LBBB affects LV function and has been associated with increased mortality. ${ }^{33}$ Therefore the question rises whether these patients should receive CRT, as LBBB is considered the ideal electrical substrate for CRT in patients with dilated cardiomyopathy and TAVI-induced LBBB patients have the most typical form of LBBB. However, several factors may withhold the application of CRT in the TAVI-LBBB patients. The current TAVI cohort is older than most CRT patients. This is due to the fact that currently TAVI is only applied in patients whom are considered high risk patients for standard open chest surgery. Several prior studies evaluating the effects of CRT reported that octogenarians derive similar benefits from CRT to younger patients. ${ }^{34-36}$ Nevertheless, it may be questionable to add implantation of one device after another in such old and often frail patients. However, on the long term it may be expected that TAVI procedures will also be applied in younger patients. In the ESC guidelines for the use of TAVI there is already a IIa indication for high-risk patients with symptomatic aortic stenosis who may still be suitable for surgery but in whom TAVI is favored by the Heart Team. ${ }^{37}$ Clearly, in these younger patients the age argument against CRT does not hold. Furthermore, according to current CRT guidelines, CRT is indicated in patients with dyssynchronous heart failure accompanied by a reduced LVEF, but the TAVI-induced LBBB patients do not have a reduced LVEF and thus do not qualify for CRT implantation. Nevertheless, based on various experimental and clinical studies, the benefit of CRT does not depend on LVEF. ${ }^{38-40}$ Given the effects of TAVIinduced LBBB on LV function and mortality, these patients should be monitored closely. If heart failure with LV dysfunction develops in presence of persistent LBBB, CRT may be considered irrespective of LVEF.

In chapter 4 we showed that there was a high variability in the TAVI-induced LBBB patients regarding the amount of remodeling. However, it is unknown whether the amount of remodeling relates to changes in LV function and clinical outcome. Patients showing signs of electrical remodeling might also be expected to show reverse remodeling after CRT. However, as shown in chapter 5 and $6 \mathrm{LBBB}$ patients with a $\mathrm{T}_{\text {area }} \geq 72 \mu \mathrm{Vs}$ have a larger chance of CRT response than patients with a lower $\mathrm{T}_{\text {area }}$. The TAVI patients showing a high degree of reverse remodeling almost all had a $\mathrm{T}_{\text {area }}$ lower than this cut-off value. This would suggest that LBBB patients who underwent the least electrical remodeling after onset of LBBB may be the best CRT responders.

\section{Future perspectives}

In order to achieve a better understanding of the relation between electrical, structural, and mechanical changes in the heart of patients who undergo a TAVI procedure and develop LBBB a large multicenter prospective study is required that collects data on electrocardio- 
graphy, echocardiography, and clinical outcome. On the basis of this data patients may be selected who might benefit from CRT after developing TAVI-LBBB.

\subsection{The role of repolarization in patient selection for CRT}

In chapter 5 and 6 we showed that $T_{\text {area }}$ predicts CRT response even better than $\mathrm{QRS}_{\text {area }}$. The predictive power for both echocardiographic and long term clinical CRT response was found to be primarily evident in the group of patients with LBBB, who already are known to benefit most from CRT. As a logical consequence also sum QRST is a good predictor.

This latter observation is supported by a recent study in which it was shown that the sum absolute QRST integral (SAI QRST) can also be used for prediction of CRT response. ${ }^{41}$ The method used to calculate SAI QRST was however different from our calculation of the sum QRST area; the SAI QRST was equal to the absolute area under the QRST curve, while for our sum QRST area the area under the QRST curve below baseline was subtracted from the positive area under the curve. Moreover, in the article of Tereshchenko et al. ${ }^{41}$ the inverse Dower method was used to calculate the VCG which might induce a larger error compared to a measured Frank-VCG. Despite these differences with our studies, this study supports the possible importance of the $\mathrm{T}_{\text {area }}$ in the patient selection for CRT.

The use of VCG for CRT response prediction was initiated by van Deursen et al. ${ }^{30}$ who showed that a large $\mathrm{QRS}_{\text {area }}$ is associated with high odds of long-term volumetric CRT response. Moreover, $\mathrm{QRS}_{\text {area }}$ predicted CRT response better than QRS duration and then conventionally defined LBBB and at least as good as the most refined LBBB definition. ${ }^{30}$ It was hypothesized that large electrical dyssynchrony, amenable to CRT, would lead to large unopposed electrical forces during ventricular depolarization and that the size of these forces may be well represented by the $\mathrm{QRS}_{\text {area }}$. Similarly, the size of the $\mathrm{T}_{\text {area }}$ is a reflection of the extent of unopposed electrical forces during the repolarization phase. The $\mathrm{T}_{\text {area }}$ is partially determined by the size of the $\mathrm{QRS}_{\text {area }}{ }^{32}$, but other factors such as changes in $\mathrm{K}^{+}$and $\mathrm{Ca}^{2+}$ ion channel expression might also play a role. Important to note is also that a larger $\mathrm{T}_{\text {area }}$ was primarily caused by larger amplitude and not so much by a longer JTc-interval, the most commonly applied measure of repolarization. Further research is needed to investigate which other factors are exactly reflected in the $\mathrm{T}_{\text {area }}$.

\section{Future perspectives}

The exact mechanism why the T-wave is such a good predictor of CRT response is still unknown. Therefore, the different roles of ion channels such as the L-type $\mathrm{Ca}^{2+}$ channel, transient outward potassium current or the rapidly activated delayed rectifying potassium current should be investigated. This can for instance be performed using a dedicated computer 
model, as was previously done for the L-type $\mathrm{Ca}^{2+}$ channel by Kuijpers et al. ${ }^{42}$. It would also be interesting to see how the T-wave changes after CRT implantation; do the patients with a large $\mathrm{T}_{\text {area }}$ show a larger reduction in $\mathrm{T}_{\text {area }}$ after CRT compared to the patients with a small $\mathrm{T}_{\text {area }}$ ? This analysis is currently being performed in our group in a small patient population. Furthermore, we only showed the importance of the $\mathrm{T}_{\text {area }}$ in a retrospective study, it should be investigated whether the importance of the $\mathrm{T}_{\text {area }}$ over the $\mathrm{QRS}_{\text {area }}$ is still present when performed in a larger prospective clinical trial.

\subsection{Tailor-CRT: optimizing stimulation intervals}

While the results from dogs with LBBB (chapter 7) and CRT patients (chapter 8) support the use of VCG for optimization of AV-delay of CRT devices, comparison between these studies is complicated by the observation that on one third of the patients the highest $\mathrm{LV} \mathrm{d} P / \mathrm{d} t_{\max }$ occurred at an unphysiologically short AV-delay ('mismatch-responders'). However, in patients the EGM-VCG was able to predict the AV-delay resulting in highest LV systolic pressure with reasonable accuracy (chapter 8). Moreover, chapter $\mathbf{8}$ provides evidence that the VCG and the EGM-VCG can be used to identify the time of onset of intrinsic RV activation (A-RV) in each patient individually, a time that is extremely helpful for programming LV fusion pacing.

\subsubsection{Robustness of VCG-mediated CRT optimization}

The way the EGM-VCG was calculated differed between the canines and the patients. In canines we showed that the device-based VCG could be extracted from the non-paced electrodes using two electrodes in the RV and one electrode just above and one just below the LV pacing electrode (chapter 7). However, in patients, only one RV electrode was available, being the RV ring. For the LV electrodes, the most distal and most proximal electrodes from the quadripolar lead were available (distance of $47 \mathrm{~mm}$ ). Since the proximal RV electrode was missing we chose to use the RV ring as RV reference electrode for both the A and B lead. This might have resulted in some information loss. However, when performing both methods in the canine study, the patient method performed almost as good in predicting the optimal CRT setting as the canine method (Fig. 9.1). Therefore, as long as the recorded EGMs are in RV-LV direction, the EGM-VCG seems to work.

In the canine study described in chapter 7 , LBBB dogs without any comorbidities were used. Since half of the CRT patients have ischemic cardiomyopathy, we also tested the performance of the EGM-VCG in dogs with infarction. The results were similar compared to LBBB canines without ischemia (Fig. 9.2). Therefore, EGM-VCG derived $\mathrm{QRS}_{\text {area }}$ also works in the presence of ischemic cardiomyopathy. 
Receiver operating characteristic (ROC)

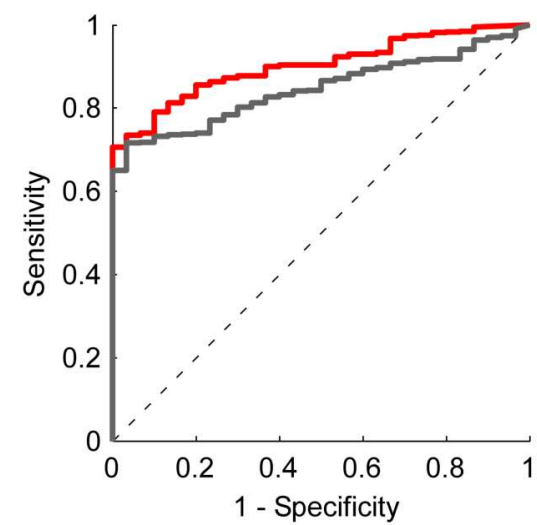

Dog method - AUC $=0.90(0.87-0.93)$
Patient method - AUC $=0.85(0.81-0.89)$

Figure 9.1: ROC-curves for $\mathrm{QRS}_{\text {area }}$ derived from the EGM-VCG in LBBB dogs, using the dog (2 RV and 2 LV EGM signals; red) or patient (1 RV and 2 LV EGM signals; grey) method for classifying $\mathrm{CRT}_{\text {opt }}$ (settings $\geq 90 \%$ of maximal $\mathrm{LV} \mathrm{d} P / \mathrm{d} t_{\max }$ ).

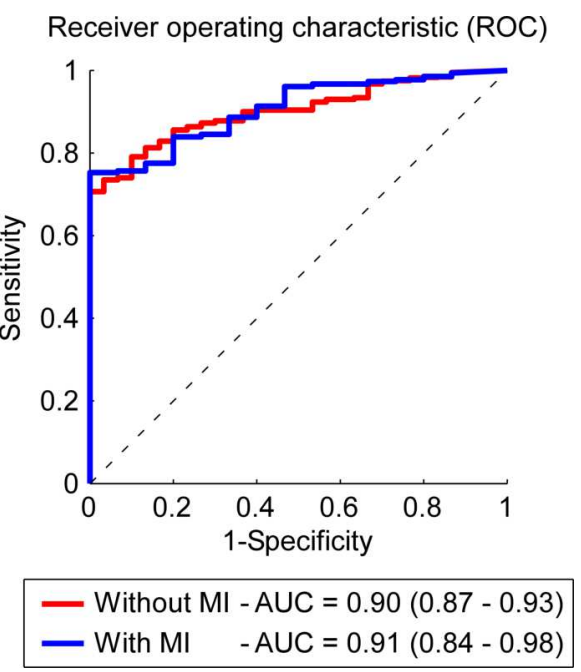

Figure 9.2: ROC-curves for $\mathrm{QRS}_{\text {area }}$ derived from the EGM-VCG for classifying $\mathrm{CRT}_{\text {opt }}$ (settings $\geq 90 \%$ of maximal $\mathrm{LV} \mathrm{d} P / \mathrm{d} t_{\max }$ ) in LBBB canines with (blue line) and without (red line) ischemia. MI: myocardial infarction. 


\subsubsection{Device-based VCG and the body surface VCG}

The results observed in chapter $\mathbf{8}$ are in line with the results reported by van Deursen et al. ${ }^{43}$ who showed that the QRS vector is a reliable tool for optimizing stimulation intervals in patients. As the acute measure of response, they used a combination of echocardiography (LV outflow tract velocity time integral) and finger blood pressures whereas in our study the hemodynamic response was purely pressure based. A combination of outcome measures might result in a lower signal-to-noise ratio resulting in a more accurate estimation of the optimal AV-delay. In addition, optimization in our study was performed during CRT implantation while in the study performed by van Deursen et al. ${ }^{43}$ it was performed at least 3 months after CRT implantation. Some myocardial remodeling might have already taken place during these 3 months, but this did not influence the ability of the QRS vector to optimize the AV-delay.

Beside LV-only pacing, as represented in chapter 8, the performance of the VCG and EGM-VCG in optimizing the CRT device settings during simultaneous biventricular (BiV) pacing was also investigated (Fig. 9.3). During the BiV pacing protocol, almost no changes were observed for $\mathrm{QRS}_{\text {area }}$ and $\mathrm{QRS}_{\mathrm{ampl}}$ under conditions when the AV-delay was shorter than the A-RV. At these relatively short AV-delays, the electrical activation is only originating from the RV and LV pacing electrodes, resulting in an unchanged activation pattern. At AV-delays longer than the intrinsic activation of the RV, the intrinsic activation of the right bundle branch is contributing leading to changes in the $\mathrm{QRS}_{\text {area }}$ derived from the VCG while still no changes are observed in the EGM-VCG derived $\mathrm{QRS}_{\text {area }}$. The latter observation can be explained by the fact that all three electrodes used to derive the EGM-VCG are close to the pacing electrodes. This shortcoming may be solved by adding more electrodes on the leads, especially at larger distance from the sites of pacing.

In all patients included for the study described in chapter 8 the possible role of the EGMVCG was also investigated during sequential BiV pacing by changing the interventricular delay (VV-delay; Fig. 9.4). The VV-delay varied between LV pre-excitation by $60 \mathrm{~ms}$ until RV pre-excitation by $40 \mathrm{~ms}$ in steps of $20 \mathrm{~ms}$. During all different VV-delays, the AV-delay was set to A-RV-60 ms. Due to the delay between activation of the ventricles, depolarization waves other than directly from the pacing electrode could be measured. Therefore, both the VCG and EGM-VCG variables provided a good estimation of the optimal VV-delay, confirming the observations during VV-delay optimization by van Deursen et al. ${ }^{43}$ Interestingly, $\mathrm{QRS}_{\text {area }}$ and $\mathrm{QRS}_{\mathrm{ampl}}$ were able to estimate the delay with highest $\mathrm{LV} \mathrm{d} P / \mathrm{d} t_{\max }$ even in the 'mismatch responders'. 


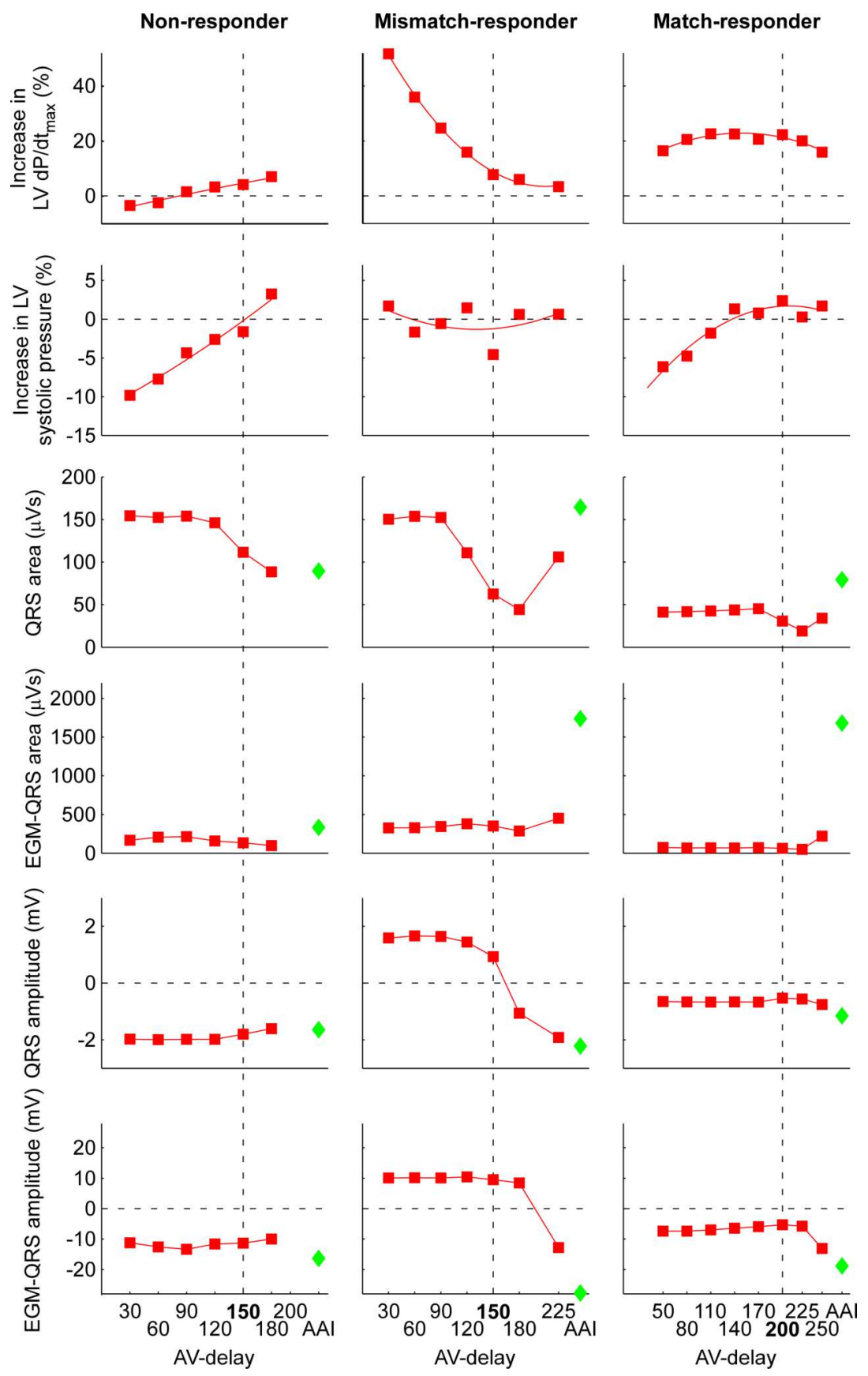

Figure 9.3: Examples of the same three patients as in Fig. 8.4: one non-responders, one mismatchresponder, and one match-responder. Relative $\mathrm{LV} \mathrm{d} P / \mathrm{d} t_{\max }$ and $\mathrm{LV}$ systolic pressure increase at various $\mathrm{AV}$-delays during $\mathrm{BiV}$ pacing. Corresponding changes in QRS area and amplitude extracted from the VCG or EGM-VCG are shown. AAI-pacing ( LBBB) results are illustrated by a green diamond. Bold AV-delays and the corresponding vertical dashed lines indicate the individual onset of RV activation. 


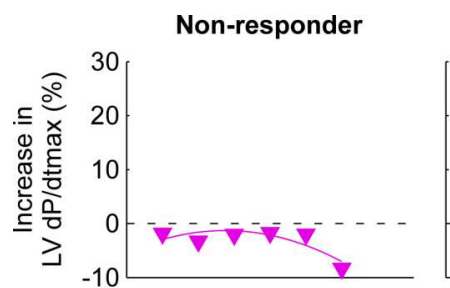

Mismatch-responders

Match-responder
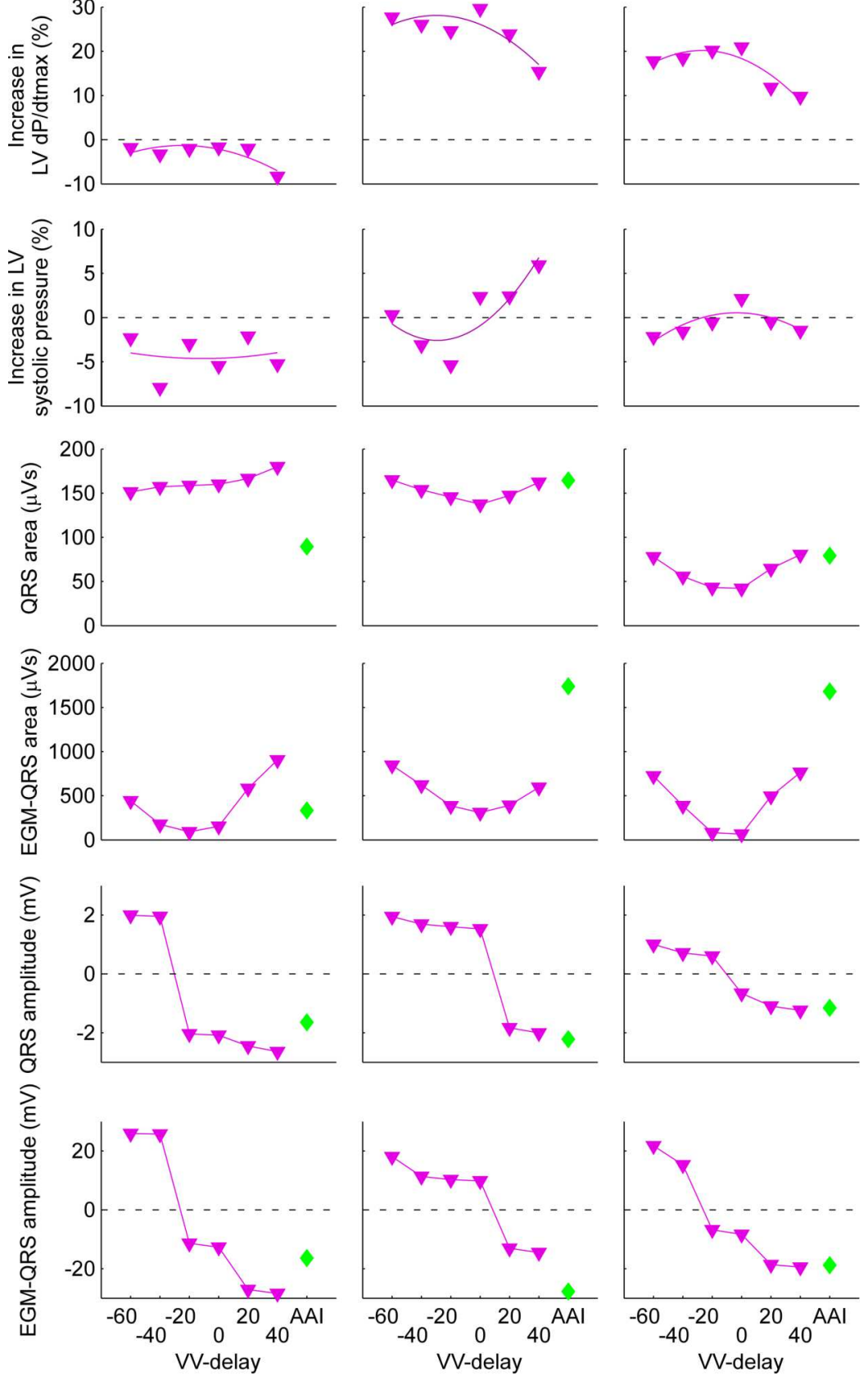

Figure 9.4: Examples of the same three patients as in Fig. 8.4 and Fig. 9.3: one non-responders, one mismatch-responder, and one match-responder. The AV-delay was set to A-RV-60 ms. Relative $\mathrm{LV} \mathrm{d} P / \mathrm{d} t_{\max }$ and $\mathrm{LV}$ systolic pressure increase at various VV-delays. A negative VV-delay indicates LV pre-excitation, a positive VV-delay indicates RV pre-excitation. Corresponding changes in QRS area and amplitude extracted from the VCG or EGM-VCG are shown. AAI-pacing $(\sim \mathrm{LBBB})$ results are illustrated by a green diamond. 


\subsubsection{Mismatch between $L V \mathrm{~d} P / \mathrm{d} t_{\max }$ and $L V$ systolic pressures measures}

Even though the QRS vector was able to find the optimal AV-delay when LV systolic pressure is the outcome measure, this was not the case when using $\mathrm{LV} \mathrm{d} P / \mathrm{d} t_{\max }$ as outcome measure. This discrepancy was mainly due to the fact that in the patient population presented in chapter 8, there was a 'mismatch' subgroup in which the optimal AV-delay according to the maximal increase in $\mathrm{LV} \mathrm{d} P / \mathrm{d} t_{\max }$ and the AV-delay matching the maximal increase in $\mathrm{LV}$ systolic pressure did not match $(\mathrm{n}=8)$. In fact, in these patients the AV-delay corresponding to a maximal increase in $\mathrm{LV} \mathrm{d} P / \mathrm{d} t_{\max }$ was very short. The only observed difference between these 'mismatch' patients and the 'match' patients is that none of the 'mismatch' patients had ischemic cardiomyopathy, whereas in the 'match' patients, 7 out of 10 had ischemic cardiomyopathy.

In the literature, most studies show a bell-shaped curve for $\mathrm{LV} \mathrm{d} P / \mathrm{d} t_{\max }$ as function of AV-delay. ${ }^{44-46}$ However, in some patients in these studies, $\mathrm{LV} \mathrm{d} P / \mathrm{d} t_{\max }$ only decreases to a limited extent at very short AV-delays compared to their maximal increase in $\mathrm{LV} \mathrm{d} P / \mathrm{d} t_{\max }$. Whinnett et al. ${ }^{47}$ observed an unphysiologically short optimal AV-delay of $40 \mathrm{~ms}$ for some patients. However, they did not provide an explanation for this short AV-delay and it is unknown whether these patients with a very short optimal AV-delay also showed a mismatch between $\mathrm{LV} \mathrm{d} P / \mathrm{d} t_{\max }$ and LV systolic pressure.

When comparing the relative increases in LV systolic pressure by CRT in our patient study with those from others, our values were smaller. This may be explained by the fact that others measured the relative change in LV systolic pressure measured at the transition between a reference and tested AV-delay ${ }^{43,48,49}$, whereas we measured this relative change in LV systolic pressure at a certain delay after the transition. This delay allows some time for stabilization before recording but also allows the start of the influence of the baroreflex, leading to smaller differences in LV systolic pressure.

\subsubsection{Future application of the EGM-VCG for optimization of the CRT device settings}

To some extent the idea of using electrical parameters for optimization has already been used by several device manufacturers to automatically optimize CRT device settings. The SmartDelay algorithm calculates the optimal AV-interval using an equation that was formed based on the results of several clinical studies and uses as input the intrinsic sensed or paced AV-interval, QRS duration, and a series of constants. ${ }^{50}$ The QuickOpt method is an empirical method also resulting from clinical observations, in which the AV-interval is calculated as the width of atrial intrinsic depolarization added to an offset factor. ${ }^{51}$ This offset is equal to $30 \mathrm{~ms}$ when the electrogram duration is $>100 \mathrm{~ms}$ and $60 \mathrm{~ms}$ when it is smaller than $100 \mathrm{~ms}$, which 
is a zigzag relationship. Therefore, some patients with long EGM duration have the same $\mathrm{AV}$-interval as those with a short duration. Furthermore, patients with EGM duration around $100 \mathrm{~ms}$ can have very different AV-intervals. Both the SmartDelay and QuickOpt method optimize the delays only once, while this may not translate into full long-term clinical benefit because optimal settings may change with time and patient activity. The patient's disease state evolves, for example due to an acute heart failure decompensation event or because of deleterious remodeling that occurs in the progression of heart failure or otherwise during the course of heart failure treatment and therapy. Furthermore, the optimal AV-interval may change between physician visits and thus would benefit from a closed loop method and apparatus for adapting. A similar condition may arise during physical exercise, when conduction properties of the heart may change due to activation of the sympathetic and parasympathetic nervous system. The continuous optimization as well as being able to optimize relatively fast could potentially result in a higher response rate for CRT. A method that adjusts CRT pacing based on periodic ambulatory evaluation of intrinsic electrical conduction intervals is the ADAPTIVECRT ${ }^{\mathrm{TM}}$ (trademark of Medtronic, Inc.) algorithm. This algorithm also uses a definition of optimal AV-interval based on a relation found in earlier studies, the AVinterval is calculated as the intrinsic interval between atrial pacing or sensing and RV sensing (A-RVsense) and is pre-empted by at least $40 \mathrm{~ms}$ or $70 \%$ of the total interval. ${ }^{52}$

While the above described algorithms use predictions of optimal fusion extrapolated from the mean values taken from a group of patients and based on measurements when the CRT was off, our method using the EGM-VCG or VCG traces the predicted optimal resynchronization parameter during pacing for each patient individually. Using the $\mathrm{QRS}_{\mathrm{ampl}}-\mathrm{AV}$-delay plot, the exact onset of contribution of intrinsic RV activation can be determined. While the equation used in the ADAPTIVECRT ${ }^{\mathrm{TM}}$ algorithm depends among others on RV lead location and latency during LV pacing, the $\mathrm{QRS}_{\mathrm{ampl}}$ either derived from the VCG or the EGM-VCG is not dependent on these factors.

The individual and exact A-RV found using the VCG or EGM-VCG could be used to individualize the ADAPTIVECRT ${ }^{\mathrm{TM}}$ algorithm even more. One could imagine two options: 1) A single determination of A-RV, at time of implant or shortly after, using the regular ECG from which the maximal QRS vector can be calculated. Instead of taking $70 \%$ of A-RVsense or pre-empt A-RVsense with $40 \mathrm{~ms}$, the exact difference between A-RVsense and A-RV can be programmed into the CRT device. The continuous optimization process already present in the adaptive CRT algorithm can now still be performed, but with an individual optimal AV-delay. 2) It is possible that conduction between RV and LV may change over a period of time (e.g. due to remodeling of the heart). Therefore, multiple determinations of A-RV using the EGM-VCG could be performed, for instance once a week. During this automatic measurement, the AV-delay will be varied around the programmed AV-delay to again find the exact A-RV. Also in this method, the difference between A-RVsense and A-RV will be 
programmed into the device.

\subsection{Conclusions}

Throughout this thesis, we have tried to find ways to reduce the number of non-responders to cardiac resynchronization therapy using vectorcardiography. We showed that repolarization might play an important role in how the heart adapts to LBBB as well as in the patient selection for CRT. Furthermore, for those patients suitable for CRT, a device-based VCG can be extracted from the leads which could eventually be used for continuous and individual optimization of the stimulation intervals. 


\section{References}

1. S Man, AM Algra, CA Schreurs, CJW Borleffs, RWC Scherptong, L van Erven, EE van der Wall, SC Cannegieter, MJ Schalij, and CA Swenne. Influence of the vectorcardiogram synthesis matrix on the power of the electrocardiogram-derived spatial QRS-T angle to predict arrhythmias in patients with ischemic heart disease and systolic left ventricular dysfunction. J Electrocardiol (2011) 44:410-415.

2. DL Cortez and TT Schlegel. When deriving the spatial QRS-T angle from the 12-lead electrocardiogram, which transform is more Frank: regression or inverse Dower? $J$ Electrocardiol (2010) 43:302-309.

3. JA Kors, G van Herpen, AC Sittig, and JH van Bemmel. Reconstruction of the Frank vectorcardiogram from standard electrocardiographic leads: diagnostic comparison of different methods. Eur Heart J (1990) 11:1083-1092.

4. CA Schreurs, AM Algra, SC Man, SC Cannegieter, EE van der Wall, MJ Schalij, JA Kors, and CA Swenne. The spatial QRS-T angle in the Frank vectorcardiogram: accuracy of estimates derived from the 12-lead electrocardiogram. J Electrocardiol (2010) 43:294-301.

5. F Badilini, T Erdem, W Zareba, and AJ Moss. ECGScan: a method for conversion of paper electrocardiographic printouts to digital electrocardiographic files. J Electrocardiol (2005) 38:310-318.

6. MB Rosenbaum, HH Blanco, MV Elizari, JO Lázzari, and JM Davidenko. Electrotonic modulation of the $\mathrm{T}$ wave and cardiac memory. The American journal of cardiology (1982) 50:213-222.

7. MJ Cutler, D Jeyaraj, and DS Rosenbaum. Cardiac electrical remodeling in health and disease. Trends Pharmacol Sci (2011) 32:174-180.

8. A Costard-Jäckle, B Goetsch, M Antz, and MR Franz. Slow and long-lasting modulation of myocardial repolarization produced by ectopic activation in isolated rabbit hearts. Evidence for cardiac "memory". Circulation (1989) 80:1412-1420.

9. K Chatterjee, A Harris, G Davies, and A Leatham. Electrocardiographic changes subsequent to artificial ventricular depolarization. British heart journal (1969) 31:770.

10. TR Engel, R Shah, LA DePodesta, WS Frankl, and RL Krause. T-wave abnormalities of intermittent left bundle-branch block. Annals of internal medicine (1978) 89:204206. 
11. P Nicolai, J Medvedowsky, M Delaage, C Barnay, E Blache, and A Pisapia. WolffParkinson-White syndrome: T wave abnormalities during normal pathway conduction. Journal of electrocardiology (1981) 14:295-300.

12. L Wecke, CJ van Deursen, L Bergfeldt, and FW Prinzen. Repolarization changes in patients with heart failure receiving cardiac resynchronization therapy-signs of cardiac memory. Journal of electrocardiology (2011) 44:590-598.

13. A Shvilkin, B Bojovic, B Vajdic, I Gussak, P Zimetbaum, and ME Josephson. Vectorcardiographic determinants of cardiac memory during normal ventricular activation and continuous ventricular pacing. Heart Rhythm (2009) 6:943-948.

14. L Wecke, A Rubulis, G Lundahl, MR Rosen, and L Bergfeldt. Right ventricular pacinginduced electrophysiological remodeling in the human heart and its relationship to cardiac memory. Heart Rhythm (2007) 4:1477-1486.

15. A Shvilkin, B Bojovic, B Vajdic, I Gussak, KK Ho, P Zimetbaum, and ME Josephson. Vectorcardiographic and electrocardiographic criteria to distinguish new and old left bundle branch block. Heart Rhythm (2010) 7:1085-1092.

16. D Jeyaraj, LD Wilson, J Zhong, C Flask, JE Saffitz, I Deschênes, X Yu, and DS Rosenbaum. Mechanoelectrical feedback as novel mechanism of cardiac electrical remodeling. Circulation (2007) 115:3145-3155.

17. E Hermeling, T Delhaas, FW Prinzen, and NH Kuijpers. Mechano-electrical feedback explains T-wave morphology and optimizes cardiac pump function: Insight from a multi-scale model. Progress in biophysics and molecular biology (2012) 110:359371.

18. OS Narula. Longitudinal dissociation in the His bundle. Bundle branch block due to asynchronous conduction within the His bundle in man. Circulation (1977) 56:9961006.

19. DL Lustgarten, S Calame, EM Crespo, J Calame, R Lobel, and PS Spector. Electrical resynchronization induced by direct His-bundle pacing. Heart Rhythm (2010) 7:15-21.

20. R Barba-Pichardo, AM Sánchez, JM Fernández-Gómez, P Moriña-Vázquez, J Venegas-Gamero, and M Herrera-Carranza. Ventricular resynchronization therapy by direct His-bundle pacing using an internal cardioverter defibrillator. Europace (2013) 15:83-88.

21. P Houthuizen, RMA van der Boon, M Urena, N Van Mieghem, GBR Brueren, TT Poels, LAFM Van Garsse, J Rodés-Cabau, FW Prinzen, and P de Jaegere. Occurrence, fate and consequences of ventricular conduction abnormalities after transcatheter aortic valve implantation. EuroIntervention (2014) 9:1142-1150.

22. TM Nazif, MR Williams, RT Hahn, S Kapadia, V Babaliaros, J Rodés-Cabau, WY Szeto, H Jilaihawi, WF Fearon, D Dvir, et al. Clinical implications of new-onset left bundle branch block after transcatheter aortic valve replacement: analysis of the PART- 
NER experience. European heart journal (2014) 35:1599-1607.

23. M Urena, JG Webb, A Cheema, V Serra, S Toggweiler, M Barbanti, A Cheung, J Ye, E Dumont, R DeLarochellière, et al. Impact of new-onset persistent left bundle branch block on late clinical outcomes in patients undergoing transcatheter aortic valve implantation with a balloon-expandable valve. JACC: Cardiovascular Interventions (2014) 7:128-136.

24. A Tzikas, BM van Dalen, NM Van Mieghem, JL Gutierrez-Chico, RJ Nuis, F Kauer, C Schultz, PW Serruys, PP de Jaegere, and ML Geleijnse. Frequency of conduction abnormalities after transcatheter aortic valve implantation with the Medtronic-CoreValve and the effect on left ventricular ejection fraction. The American journal of cardiology (2011) 107:285-289.

25. M Urena, M Mok, V Serra, E Dumont, L Nombela-Franco, R DeLarochellière, D Doyle, A Igual, E Larose, I Amat-Santos, et al. Predictive factors and long-term clinical consequences of persistent left bundle branch block following transcatheter aortic valve implantation with a balloon-expandable valve. Journal of the American College of Cardiology (2012) 60:1743-1752.

26. R Hoffmann, R Herpertz, S Lotfipour, Ö Aktug, K Brehmer, W Lehmacher, R Autschbach, N Marx, and S Lotfi. Impact of a new conduction defect after transcatheter aortic valve implantation on left ventricular function. JACC: Cardiovascular Interventions (2012) 5:1257-1263.

27. PW Macfarlane, A van Oosterom, and M Janse. Comprehensive electrocardiology. Vol. 4. Springer Science \& Business Media, 2010.

28. DW Romhilt and EH Estes. A point-score system for the ECG diagnosis of left ventricular hypertrophy. American heart journal (1968) 75:752-758.

29. M Sokolow and TP Lyon. The ventricular complex in left ventricular hypertrophy as obtained by unipolar precordial and limb leads. American heart journal (1949) 37:161-186.

30. CJM van Deursen, K Vernooy, E Dudink, L Bergfeldt, HJGM Crijns, FW Prinzen, and L Wecke. Vectorcardiographic QRS area as a novel predictor of response to cardiac resynchronization therapy. J Electrocardiol (2015) 48:45-52.

31. M Mafi Rad, GWM Wijntjens, EB Engels, Y Blaauw, JGLM Luermans, L Pison, HJ Crijns, FW Prinzen, and K Vernooy. Vectorcardiographic QRS area identifies delayed left ventricular lateral wall activation determined by electroanatomic mapping in candidates for cardiac resynchronization therapy. Heart Rhythm (2016) 13:217-225.

32. EB Engels, EM Végh, CJM Van Deursen, K Vernooy, JP Singh, and FW Prinzen. Twave area predicts response to cardiac resynchronization therapy in patients with left bundle branch block. J Cardiovasc Electrophysiol (2015) 26:176-183. 
33. P Houthuizen, LAFM Van Garsse, TT Poels, P de Jaegere, RMA van der Boon, BM Swinkels, JM Ten Berg, F van der Kley, MJ Schalij, J Baan Jr, et al. Left bundlebranch block induced by transcatheter aortic valve implantation increases risk of death. Circulation (2012) 126:720-728.

34. PW Foley, S Chalil, K Khadjooi, RE Smith, MP Frenneaux, and F Leyva. Long-term effects of cardiac resynchronization therapy in octogenarians: a comparative study with a younger population. Europace (2008) 10:1302-1307.

35. A Achilli, F Turreni, M Gasparini, M Lunati, M Sassara, M Santini, M Landolina, L Padeletti, A Puglisi, M Bocchiardo, et al. Efficacy of cardiac resynchronization therapy in very old patients: the Insync/Insync ICD Italian Registry. Europace (2007) 9:732738.

36. J Penn, I Goldenberg, AJ Moss, S McNitt, W Zareba, HU Klein, DS Cannom, SD Solomon, A Barsheshet, DT Huang, and MADIT-CRT Trial investigators. Improved outcome with preventive cardiac resynchronization therapy in the elderly: a MADITCRT substudy. J Cardiovasc Electrophysiol (2011) 22:892-897.

37. A Vahanian, O Alfieri, F Andreotti, MJ Antunes, G Barón-Esquivias, H Baumgartner, MA Borger, TP Carrel, M De Bonis, A Evangelista, et al. Guidelines on the management of valvular heart disease (version 2012). European heart journal (2012) 33:24512496.

38. K Vernooy, RNM Cornelussen, XAAM Verbeek, WYR Vanagt, A van Hunnik, M Kuiper, T Arts, HJGM Crijns, and FW Prinzen. Cardiac resynchronization therapy cures dyssynchronopathy in canine left bundle-branch block hearts. Eur Heart J (2007) 28:2148-2155.

39. IE van Geldorp, K Vernooy, T Delhaas, MH Prins, HJ Crijns, FW Prinzen, and B Dijkman. Beneficial effects of biventricular pacing in chronically right ventricular paced patients with mild cardiomyopathy. Europace (2010) 12:223-229.

40. AB Curtis, SJ Worley, PB Adamson, ES Chung, I Niazi, L Sherfesee, T Shinn, and M St. John Sutton. Biventricular pacing for atrioventricular block and systolic dysfunction. New England Journal of Medicine (2013) 368:1585-1593.

41. LG Tereshchenko, A Cheng, J Park, N Wold, TE Meyer, MR Gold, S Mittal, J Singh, KM Stein, KA Ellenbogen, et al. Novel measure of electrical dyssynchrony predicts response in cardiac resynchronization therapy: Results from the SMART-AV Trial. Heart Rhythm (2015) 12:2402-2410.

42. NHL Kuijpers, E Hermeling, J Lumens, HMM ten Eikelder, T Delhaas, and FW Prinzen. Mechano-electrical coupling as framework for understanding functional remodeling during LBBB and CRT. Am J Physiol Heart Circ Physiol (2014) 306:H1644H1659. 
43. CJM van Deursen, L Wecke, WM van Everdingen, M Ståhlberg, MHG Janssen, F Braunschweig, L Bergfeldt, HJGM Crijns, K Vernooy, and FW Prinzen. Vectorcardiography for optimization of stimulation intervals in cardiac resynchronization therapy. J Cardiovasc Transl Res (2015) 8:128-137.

44. A Auricchio, C Stellbrink, M Block, S Sack, J Vogt, P Bakker, H Klein, A Kramer, J Ding, R Salo, B Tockman, T Pochet, and J Spinelli. Effect of pacing chamber and atrioventricular delay on acute systolic function of paced patients with congestive heart failure. The Pacing Therapies for Congestive Heart Failure Study Group. The Guidant Congestive Heart Failure Research Group. Circulation (1999) 99:2993-3001.

45. DA Kass, CH Chen, C Curry, M Talbot, R Berger, B Fetics, and E Nevo. Improved left ventricular mechanics from acute VDD pacing in patients with dilated cardiomyopathy and ventricular conduction delay. Circulation (1999) 99:1567-1573.

46. XA Verbeek, A Auricchio, Y Yu, J Ding, T Pochet, K Vernooy, A Kramer, J Spinelli, and FW Prinzen. Tailoring cardiac resynchronization therapy using interventricular asynchrony. Validation of a simple model. American Journal of Physiology-Heart and Circulatory Physiology (2006) 290:H968-H977.

47. ZI Whinnett, DP Francis, A Denis, K Willson, P Pascale, I van Geldorp, M De Guillebon, S Ploux, K Ellenbogen, M Haïssaguerre, et al. Comparison of different invasive hemodynamic methods for AV delay optimization in patients with cardiac resynchronization therapy: implications for clinical trial design and clinical practice. International journal of cardiology (2013) 168:2228-2237.

48. A Kyriacou, PA Pabari, ZI Whinnett, S Arri, K Willson, R Baruah, B Stegemann, J Mayet, P Kanagaratnam, AD Hughes, et al. Fully automatable, reproducible, noninvasive simple plethysmographic optimization: proof of concept and potential for implantability. Pacing and Clinical Electrophysiology (2012) 35:948-960.

49. ZI Whinnett, JE Davies, K Willson, AW Chow, RA Foale, DW Davies, AD Hughes, DP Francis, and J Mayet. Determination of optimal atrioventricular delay for cardiac resynchronization therapy using acute non-invasive blood pressure. Europace (2006) 8:358-366.

50. MR Gold, I Niazi, M Giudici, RB Leman, JL Sturdivant, MH Kim, Y Yu, J Ding, and AD Waggoner. A prospective comparison of AV delay programming methods for hemodynamic optimization during cardiac resynchronization therapy. J Cardiovasc Electrophysiol (2007) 18:490-496.

51. JH Baker 2nd, J McKenzie 3rd, S Beau, GS Greer, J Porterfield, M Fedor, S Greenberg, EG Daoud, R Corbisiero, JR Bailey, and L Porterfield. Acute evaluation of programmer-guided AV/PV and VV delay optimization comparing an IEGM method and echocardiogram for cardiac resynchronization therapy in heart failure patients and dual-chamber ICD implants. J Cardiovasc Electrophysiol (2007) 18:185-191. 
52. H Krum, B Lemke, D Birnie, KLF Lee, K Aonuma, RC Starling, M Gasparini, J Gorcsan, T Rogers, A Sambelashvili, A Kalmes, and D Martin. A novel algorithm for individualized cardiac resynchronization therapy: rationale and design of the adaptive cardiac resynchronization therapy trial. Am Heart J (2012) 163:747-752.e1. 




\section{Summary}

A $\mathrm{N}$ increasing number of people suffer from heart failure (HF). In about one quarter of HF patients the electrical conduction pattern is disturbed. One of the most severe disturbances is left bundle branch block (LBBB) which causes a delayed electrical impulse conduction through the left ventricle (LV). In LBBB, the electrical activation starts in the septum and right ventricle (RV) and proceeds through the slowly conducting septum to activate the LV. Cardiac resynchronization therapy (CRT) is an established treatment for HF patients with LBBB and comparable conduction disturbances. Since initial approval of the therapy 15 years ago, there have been hundreds of thousands of implants worldwide. On the group level, CRT has been shown to improve LV systolic function, reduce the amount of HF hospitalizations, and improve survival rates. However, $30-50 \%$ of the patients do not respond significantly to the therapy. Such lack of response is not desirable for a treatment which involves a relatively expensive therapy and that requires essentially irreversible lifelong implantation of a device.

\section{Improvement of response to CRT}

The main aim of this thesis is to improve the response to CRT using vectorcardiographic (VCG) analysis. To this purpose, the underlying disease LBBB is investigated in more detail as well as the role of improved patient selection and better therapy application.

In the past, already a great deal of research has been performed towards improved selection of the appropriate candidates for CRT. An extensive overview regarding this matter is presented in chapter 2. There it is reviewed that the currently used electrocardiogram (ECG) selection criteria, QRS duration and morphology, both have their shortcomings: QRS duration may not be specific enough, while LBBB criteria may be too complex and/or userdependent. The VCG derived $\mathrm{QRS}_{\text {area }}$ might be a good alternative measure to improve patient selection, because it provides an objectively determined index with continuous values and because $\mathrm{QRS}_{\text {area }}$ reflects LV activation delays, the primary substrate for CRT. Small studies showed better performance of prediction of CRT response by $\mathrm{QRS}_{\text {area }}$ compared to QRS duration. Of note, in these studies $\mathrm{QRS}_{\text {area }}$ was determined with a dedicated system to measure the ('Frank-')VCG.

In order to further investigate the role of the VCG in improving the response to CRT, it 
would be easier to synthesize the VCG from the often employed 12-lead ECG. A few studies had already demonstrated in healthy subjects that a VCG can be calculated from the 12-lead ECG using the Kors matrix. In chapter 3, we showed that also in CRT candidates the KorsVCG nicely resembles the Frank-VCG. This enables retrospective as well as prospective VCG analysis of routinely recorded 12-lead ECGs, which is used in all other chapters in the present thesis.

\section{Electrical remodeling in patients with $\mathrm{LBBB}$}

It is known that patients with LBBB have a high response rate to CRT. The way the heart adapts electrically to a new situation of LBBB is unknown mainly because in the general population the onset of LBBB is often unknown. In chapter 4 we investigated the electrical adaptations to LBBB in patients who developed LBBB during a transcatheter aortic valve implantation (TAVI) procedure. In this procedure LBBB is an undesired complication, occurring in approximately one third of all TAVI patients, presumably caused by the valve pressing against the left bundle branch. For our purposes, the advantage of the developed LBBB is that the exact onset time of LBBB is known. Therefore, these patients can be used as a 'human model' to study the time course of electrical remodeling with LBBB. In the majority of patients (67 out of 107 patients) who developed LBBB during a TAVI procedure, electrical remodeling occurs in the first month of LBBB, as evidenced by a reduction in various repolarization variables (like JTc interval, T-wave amplitude and $\mathrm{T}_{\text {area }}$ ). However, the extent of electrical remodeling was highly variable between patients. The role of the extent of electrical remodeling for CRT response and patient prognosis in general requires further investigation.

\section{The role of repolarization in patient selection for CRT}

In chapter 5 and $\mathbf{6}$ the potential role of repolarization in the patient selection for CRT was investigated. In a study population of 244 CRT recipients, retrospective VCG analysis revealed that the responders to CRT have a larger area under the curve for the T-wave $\left(\mathrm{T}_{\text {area }}\right.$; chapter 5) and the predictive value of the $T_{\text {area }}$ was even better than for $Q R S_{\text {area }}$. The $T_{\text {area }}$ was especially of added value in the patients diagnosed with LBBB. In a larger patient population consisting of 335 CRT recipients, again the patients with a large $\mathrm{T}_{\text {area }}$ and LBBB less frequently reached the combined endpoint of HF hospitalization, heart transplantation, left ventricular assist device implantation or death after 3 years compared to the other patients (chapter 6). The predictive power of $\mathrm{T}_{\text {area }}$ may be due to a combination of a reflection of good intrinsic myocardial properties as well as a reflection of a substrate for CRT, i.e., in the LBBB patients with a large $\mathrm{T}_{\text {area }}$, females and patients with non-ischemic HF were overrep- 
resented. The combined analysis of QRS morphology and $\mathrm{T}_{\text {area }}$ provides an easy and widely applicable approach to improve selection of CRT candidates.

\section{Tailor-CRT: optimizing stimulation intervals}

Once a patient is selected for CRT and the implantation has been performed, the timing of atrial to RV and LV stimulation could be optimized to achieve maximal benefit from CRT. The different timings affect the amount of ventricular filling and timing of contraction (atrioventricular $[\mathrm{AV}]$ interval during biventricular $[\mathrm{BiV}]$ pacing) and the amount of resynchronization (AV-interval during LV only pacing, and interventricular [VV] interval during BiV pacing). Optimization of these timings can be performed using different measures such as echocardiography or hemodynamic measures. However, all measurements are often time-consuming and are limited in their accuracy, contributing to the scarce evidence of long-term benefit of CRT optimization. Therefore, most physicians leave the timings at the 'out-of-the-box' settings.

VCG has been shown to be more reliable in finding the optimal timing settings than the traditional hemodynamic measurements. However, these measurements can only be performed during in-office visits. While a single optimization is probably valuable, regular optimization, preferably in an automated fashion, may be more desirable. Therefore, in chapter 7 the possibility to extract a VCG from the electrograms (EGMs) derived from unpaced implanted electrodes (EGM-based VCG, EGM-VCG) was investigated in dogs. In these dogs the proximal left bundle branch was ablated, creating a typical LBBB activation pattern. In eight dogs with chronic LBBB the EGM-VCG derived $\mathrm{QRS}_{\text {area }}$ predicted hemodynamic response as measured by $\mathrm{LV} \mathrm{d} P / \mathrm{d} t_{\max }$ and identified optimal settings accurately. A minimal $\mathrm{QRS}_{\text {area }}$, indicating maximal cancelation of opposing electrical forces, coincided with the optimal settings. These data support the potency of EGM-VCG as a non-invasive and easy tool to individually and continuously optimize the AV- and VV-intervals in CRT.

Subsequently, these results were validated in patients receiving CRT (chapter 8). The study population consisted of 25 patients whom represented a typical CRT population with mostly males and half of the patients having ischemic cardiomyopathy. However, the results regarding the optimization guided by EGM-VCG derived $\mathrm{QRS}_{\text {area }}$ in these patients were more complicated than those observed in the dogs. A minimal $\mathrm{QRS}_{\text {area }}$ did not correspond to a maximal hemodynamic response as defined by $\mathrm{LV} \mathrm{d} P / \mathrm{d} t_{\max }$, but a better match was found when LV systolic pressure was taken as index of hemodynamic response. Possibly the most practically applicable finding was that the onset of contribution of intrinsic RV activation could be determined from both the VCG and EGM-VCG. This point in time, is required when optimizing CRT in the 'LV fusion pacing' mode: using RV activation from the intact $\mathrm{RV}$ conduction system in combination with LV only pacing. 


\section{Conclusions}

The studies presented provide evidence that the relatively old method of VCG can be used to improve the response of the new technique of CRT. The studies presented provide evidence that the relatively simple and widely available measures of VCG-derived $\mathrm{QRS}_{\text {area }}$ can be used to improve the patient selection, and that besides the importance of depolarization, repolarization also plays a significant role. Furthermore, an EGM-VCG can be extracted from unpaced electrodes which could be used for continuous and individual optimization of the stimulation intervals, especially in the setting of LV fusion pacing. 




\section{Samenvatting}

S

TEEDS meer mensen in de westerse wereld leiden aan hartfalen. In ongeveer een kwart van deze patiënten gaat dit gepaard met een geleidingsstoornis in de hartkamers (ventrikels). Eén van de meeste voorkomende geleidingsstoornissen is linker bundeltakblok (LBTB). Bij een LBTB start de elektrische activatie in de rechter ventrikel (RV) en het kamertussenchot (septum), waarna de linker ventrikel (LV) via het langzaam geleidende septum vertraagd geactiveerd wordt. Sinds ongeveer 15 jaar is cardiale resynchronisatie therapie (CRT) een belangrijke behandeling voor patiënten die symptomatisch hartfalen hebben in combinatie met een geleidingsstoornis. Inmiddels zijn er wereldwijd honderdduizenden CRT-implantaties uitgevoerd. Gemiddeld zorgt CRT voor een verbeterde LV-pompfunctie, minder opnames voor hartfalen en een verbeterde overlevingskans. Echter, bij 30-50\% van de patiënten leidt CRT niet tot duidelijke verbeteringen. Aangezien CRT de implantatie van een pacemaker vereist, die bijkomende kosten en risico's op complicaties met zich meebrengt, is het wenselijk om de pacemaker alléén te implanteren bij die patiënten die er ook baat bij zullen hebben en om de therapie te verbeteren.

\section{Verbeteren van respons na CRT}

De hoofddoelstelling van dit proefschrift is om met behulp van vectorcardiografie de respons na een CRT-implantatie te verbeteren. Om het succespercentage te verbeteren wordt de onderliggende ziekte LBTB in meer detail onderzocht, alsook de mogelijke rol van het vectorcardiogram (VCG) in de selectie van patiënten en in de verbetering van het effect van CRT.

In het verleden is reeds veel onderzoek gedaan naar de optimale selectie van CRTkandidaten. Een uitgebreid overzicht van deze studies en hun bevindingen staat beschreven in hoofdstuk 2. In dit hoofdstuk worden de tekortkomingen van de op dit moment gebruikte criteria, QRS-duur en -morfologie, besproken. QRS-duur is waarschijnlijk niet specifiek genoeg, terwijl de vaststelling van de aanwezige QRS-morfologie subjectief en complex is. Er zijn aanwijzingen dat gebruik van de oppervlakte van het QRS-complex ( $\left.Q R S_{\text {area }}\right)$, gemeten met behulp van het VCG, de patiënt selectie zou kunnen verbeteren. QRS ${ }_{\text {area }}$ is een objectieve en continue maat die mogelijke vertraging in LV-activatie weerspiegelt, het primaire substraat voor CRT. 
Tot nu toe werd de $\mathrm{QRS}_{\text {area }}$ bepaald met behulp van het zelden gebruikte ('Frank-')VCG. Voor toekomstige studies zou het praktisch zijn als het VCG kon worden berekend uit het standaard 12-afleidingen elektrocardiogram (ECG). In hoofdstuk 3 laten we zien dat in kandidaten voor CRT het Frank-VCG en Kors-VCG erg op elkaar lijken. Hierdoor kunnen zowel retrospectieve als prospectieve VCG-analyses worden uitgevoerd met behulp van de routinematig opgenomen 12-afleidingen ECG. Van deze techniek wordt dan ook gebruikgemaakt in alle volgende hoofdstukken van dit proefschrift.

\section{Elektrische remodellering in patiënten met LBTB}

De belangrijkste doelgroep voor CRT zijn patiënten met LBTB. Echter, de manier waarop het hart zich aanpast na het ontstaan van een LBTB is onbekend, omdat het exacte aanvangsmoment van LBTB vaak niet bekend is. In hoofdstuk $\mathbf{4}$ hebben we onderzocht hoe het hart zich elektrisch aanpast aan de nieuwe LBTB-situatie in patiënten die een LBTB ontwikkelen tijdens een transkatheter aortaklep implantatie (TAVI). LBTB ontstaat in een deel van de patiënten die een TAVI-procedure ondergaan. Bij hen drukt de nieuwe aortaklep vermoedelijk tegen de linker bundeltak, waardoor een 'typisch' LBTB ontstaat. Voor onze studie hebben deze TAVI-patiënten het voordeel, dat bij hen het exacte aanvangsmoment van LBTB bekend is. Hierdoor kunnen deze patiënten gebruikt worden als een 'menselijk' model van LBTB om het tijdsverloop van elektrische remodellering te onderzoeken. In de meerderheid van de patiënten die tijdens een TAVI procedure LBTB ontwikkelt (67 van de 107 patiënten) treedt er binnen één maand elektrisch remodelering op, zoals blijkt uit een afname in meerdere repolarisatie variabelen (JTc-interval, T-golfamplitude, en oppervlakte van de T-golf $\left[\mathrm{T}_{\text {area }}\right]$ ). De mate van elektrische remodellering was echter zeer variabel tussen patiënten. Daarnaast is het nog onbekend wat de rol van de mate van elektrische remodellering is voor de response na CRT, alsook voor de algemene prognose voor de patiënt.

\section{De rol van de repolarisatie in patiëntenselectie voor CRT}

In hoofdstuk 5 en 6 werd de potentiële rol van VCG in de patiëntenselectie voor CRT onderzocht. In 244 CRT-kandidaten werd retrospectief een VCG-analyse uitgevoerd en hieruit bleek dat $\mathrm{T}_{\text {area }}$ groter was in patiënten met echocardiografische verbetering door CRT dan in patiënten zonder deze verbetering (hoofdstuk 5). $\mathrm{T}_{\text {area }}$ had zelfs een betere voorspellende waarde dan $\mathrm{QRS}_{\text {area }}$ en had de best voorspellende waarde in LBTB-patiënten. In een grotere groep van 335 CRT-kandidaten bleek ook dat patiënten met een grotere $\mathrm{T}_{\text {area }}$ in 3 jaar minder vaak het gecombineerde eindpunt van opname voor hartfalen, harttransplantatie, steunhart, of dood bereikten (hoofdstuk 6). Deze voorspellende waarde van $\mathrm{T}_{\text {area }}$ zou verklaard kunnen worden doordat vrouwen en patiënten met niet-ischemisch hartfalen relatief een grotere $T_{\text {area }}$ 
lieten zien. Van deze groepen is bekend dat ze in het algemeen goed reageren op CRT. De gecombineerde analyse van QRS-morfologie en $\mathrm{T}_{\text {area }}$ biedt een eenvoudige en breed toepasbare aanpak om de selectie van CRT-kandidaten te verbeteren.

\section{Tailor-CRT: het optimaliseren van stimulatie-intervallen}

Als een patiënt eenmaal geselecteerd is voor CRT en de implantatie is uitgevoerd, kunnen de tijdsintervallen tussen de stimulatie van de rechterboezem (atrium) en de RV of LV worden geoptimaliseerd om maximaal voordeel te bereiken van CRT. De verschillende timings beïnvloeden de ventriculaire vulling en het moment van ventrikelcontractie, alsmede de mate van resynchronisatie. Voor het optimaliseren van de atrioventriculaire (AV-) en interventriculaire (VV-) intervallen is een maat voor hartfunctie nodig. Deze kan bijvoorbeeld uit echocardiografie afgeleid worden, of uit hemodynamische kathetermetingen. Alle bestaande metingen zijn echter tijdrovend en beperkt in nauwkeurigheid, waardoor er weinig bewijs is voor de lange termijn voordelen van CRT-optimalisatie. Hierdoor gebruiken de meeste artsen vaak de standaardinstellingen van het CRT-apparaat.

Het VCG is een betrouwbaar alternatief voor het optimaliseren van het AV- en VV-interval in vergelijking met hemodynamische metingen. Het nadeel van deze VCG-metingen is dat ze nog steeds alleen kunnen worden uitgevoerd wanneer de patiënt het ziekenhuis bezoekt. Hoewel een eenmalige optimalisatie waarschijnlijk al waardevol is, zou een regelmatige en bij voorkeur automatische optimalisatie wenselijker zijn. Daarom werd er in hoofdstuk 7 in honden onderzocht of de pacemaker-draad elektroden die niet gebruikt worden om te stimuleren, gebruikt kunnen worden om de elektrische activiteit van het hart te meten. Uit deze metingen kan vervolgens ook een soort vectorcardiogram worden geëxtraheerd (het electrogram-VCG, EGM-VCG). In 8 honden werd een typisch LBTB gecreëerd door ablatie van de proximale linker bundeltak. De veranderingen in $\mathrm{QRS}_{\text {area }}$ berekend uit het EGM$\mathrm{VCG}$ en veranderingen in $\mathrm{LV} \mathrm{d} P / \mathrm{d} t_{\max }$ kwamen overeen en $\mathrm{QRS}_{\text {area }}$ voorspelde de optimale stimulatie intervallen. De kleinste $\mathrm{QRS}_{\text {area }}$, overeenkomend met maximale opheffing van tegenovergestelde elektrische krachten van LV en RV, voorspelde de optimale stimulatie intervallen goed. Deze gegevens ondersteunen het gebruik van EGM-VCG als een niet-invasieve en eenvoudige methode om de AV- en VV-intervallen voor CRT individueel en continu te optimaliseren.

Deze bevindingen in honden werden vervolgens gevalideerd in patiënten (hoofdstuk 8). De 25 patiënten geïncludeerd in dit onderzoek representeerden een typische CRT-populatie met veelal mannen en waarin de helft van de patiënten een ischemische cardiomyopathie had. In deze patiëntenstudie kwam een minimale $\mathrm{QRS}_{\text {area }}$ niet overeen met een maximale toename in $\mathrm{LV} \mathrm{d} P / \mathrm{d} t_{\max }$, maar wel met een maximale toename in de LV systolische druk. Echter, misschien wel de meest praktisch toepasbare bevinding was dat het begin van de bijdrage van 
de intrinsieke RV activatie aan de totale ventrikel activatie tijdens LV stimulatie kan worden bepaald uit zowel het VCG als het EGM-VCG. Dit begin van RV activatie is van belang als men gebruik wil maken van zogenaamde LV-fusiestimulatie. Hierbij dient de LV simultaan met de intrinsieke RV-activatie te worden gestimuleerd, een methode waarvan steeds meer duidelijk wordt dat dit een goede CRT response geeft.

\section{Conclusies}

De studies beschreven in dit proefschrift tonen aan dat de relatief oude VCG-methode kan worden gebruikt om de respons na de relatief nieuwe CRT te verbeteren. De studies laten zien dat de eenvoudige en ruim beschikbare $\mathrm{QRS}_{\text {area }}$ als maat kan worden gebruikt om de selectie van patiënten voor CRT te verbeteren en dat naast depolarisatie ook repolarisatie een belangrijke rol speelt. Verder kan een EGM-VCG worden geëxtraheerd uit geïmplanteerde elektroden die niet gebruikt worden voor het stimuleren, en kan EGM-VCG gebruikt worden voor continue en individuele optimalisatie van stimulatie-intervallen, voornamelijk tijdens LV-fusiestimulatie. 




\section{Valorization}

I $\mathrm{N}$ the Netherlands, approximately 150,000 people suffer from heart failure (HF). Annually approximately 7000 patients die due to $\mathrm{HF}$ and there are around 30,000 $\mathrm{HF}$ hospitalizations. ${ }^{1}$ These hospital admissions and treatment of patients with severe symptoms are associated with high costs. In 2007 the costs for HF amounted 455 million euros, of which $60 \%$ was due to hospitalizations.

In approximately $25 \%$ of all $\mathrm{HF}$ patients ${ }^{2}$, the electrical conduction pattern is disturbed leading to a dyssynchronous electrical activation and contraction of the right and left ventricle (LV), resulting in a reduced pump function. In 2001 a new therapy was approved by the FDA, cardiac resynchronization therapy (CRT), which aims to resynchronize the right and left ventricle leading to a better pump function of the heart. In the last few years, the CRT implantation rate was $>2000 /$ year in the Netherlands alone. ${ }^{3}$ CRT has been shown to improve cardiac pump function and quality of life, and reduce HF symptoms, hospitalization, and mortality at the population level. ${ }^{4}$ However, benefits at the individual level vary considerably. On the one hand, $\sim 20 \%$ of patients that are implanted according to current guidelines ${ }^{5,6}$ show complete normalization of LVEF whereas a significant portion (30-50\%) of patients benefit little from this therapy. ${ }^{7}$ Such lack of response is especially undesirable since CRT requires the implantation of a costly device during an invasive procedure. Improved patient selection and optimal programming of the CRT device could lead to a higher response rate to CRT.

\section{Improving patient selection}

In this thesis it was shown that the baseline value of $\mathrm{QRS}_{\text {area }}$ and $\mathrm{T}_{\text {area }}$, both indices derived from the vectorcardiogram (VCG), are good predictors of response to CRT. They perform better than the established criteria QRS duration and certain LBBB criteria. Patients with a higher baseline value of $\mathrm{QRS}_{\text {area }}$ or $\mathrm{T}_{\text {area }}$ have a higher change of CRT response, making both variables good measures to improve patient selection for CRT. The advantage of these measures is that they are easily obtained and widely applicable.

As was pointed out in chapter 3 it is justified to synthesize a VCG from a 12-lead electrocardiogram (ECG) using the Kors matrix. This conversion can be applied to almost any 12-lead ECG, with the only requirement being that either a common running lead or a common reference point, such as a pacing artefact, must be present. Ideally, the ECGs are stored 
digitally but semi-digital ECGs as stored in a pdf-file or even paper ECGs could also be used to calculate the $\mathrm{QRS}_{\text {area }}$ and $\mathrm{T}_{\text {area }}$. As we described in this thesis, the pdf-files contain vectorgraphics that embed the digital information of the displayed ECG. The digital information can thus be extracted, making it possible to synthesize a VCG and calculate the $\mathrm{QRS}_{\text {area }}$ and $\mathrm{T}_{\text {area }}$. For scanned ECGs, the program ECGscan (AMPS LLC, New York, NY, USA) can be used to digitize the ECGs. This enables retrospective as well as prospective VCG analysis of routinely recorded 12-lead ECGs in large patient populations.

VCG indices like $\mathrm{QRS}_{\text {area }}$ and $\mathrm{T}_{\text {area }}$ can also be calculated in a prospective manner. Most commercially available ECG machines already have algorithms to construct a VCG from standard 12-lead ECGs and the beginning and ending of the QRS complex and T-wave are often indicated. The excellent predictive power of $\mathrm{QRS}_{\text {area }}$ and $\mathrm{T}_{\text {area }}$ for CRT response indicates that these parameters deserve to be applied more frequently in clinical practice to identify appropriate candidates for CRT.

Furthermore, if the predictive power of these VCG indices is proven in larger clinical trials, they may be included in the official guidelines as a selection criterion for CRT implantation. The present thesis provides important supportive data for this introduction.

\section{Optimal programming of the CRT device}

Beside optimal patient selection, optimal programming of the CRT device settings can also play an important role in increasing the response rate to CRT. Currently, all available tools to optimize CRT device settings are time-consuming and/or subject to noise, leading to the use of the 'out-of-the-box' default settings by a vast majority of cardiologists. Furthermore, the optimization can often only be performed during in-hospital visits, while the optimal setting might change over time or during different levels of activity.

CRT is often employed by pacing both the right end left ventricle of the heart (biventricular

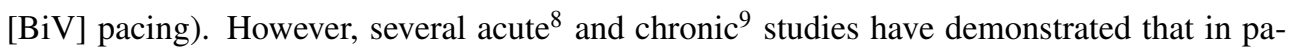
tients with sinus rhythm and intact AV conduction, LV-only pacing can be at least as effective as BiV pacing. CRT using LV-only pacing has been shown to be most effective when the paced LV impulse is properly timed with respect to the intrinsic activation of the right ventricle (RV), ensuring appropriate fusion with intrinsically conducted activation wave fronts. In chapter 8 of this thesis, we showed that using either the normal VCG or an electrogram (EGM) based VCG (EGM-VCG) that can be extracted from the EGM signals measured from the unused implanted electrodes, this exact optimal timing can easily be found. The point at which the maximal QRS vector amplitude changes or flips direction was equal to the onset of intrinsic activation of the RV.

A few years ago, the ADAPTIVECRT ${ }^{\mathrm{TM}}$ (trademark of Medtronic, Inc.) algorithm has been developed that switches between BiV pacing and LV only pacing depending on con- 
duction measurements. ${ }^{10}$ When LV only pacing is applied, the ADAPTIVECRT ${ }^{\mathrm{TM}}$ algorithm aims to perform fusion pacing which estimates the delay between atrial activation and intrinsic RV activation (A-RV) based on an average, general relation. With the VCG or EGMVCG the A-RV can be determined individually, making it more precise. It does so by obtaining information during LV-only pacing at different AV-delays, while the ADAPTIVECRT ${ }^{\mathrm{TM}}$ estimates A-RV using measurements performed when CRT is turned off. Furthermore, the VCG and EGM-VCG methods are more robust than the ADAPTIVECRT ${ }^{\mathrm{TM}}$ algorithm since they are independent of the exact position of the RV lead and of LV latency. Therefore, the ADAPTIVECRT $^{\mathrm{TM}}$ algorithm could be improved by using the VCG or EGM-VCG to find the exact A-RV. The idea of using the VCG or EGM-VCG to find the exact A-RV and using it to individualize the ADAPTIVECRT ${ }^{\mathrm{TM}}$ algorithm is already part of a patent application in collaboration with Medtronic, Inc. To do so, there are two options. First, a single determination of A-RV, at time of implant or shortly after, could be performed using the regular ECG from which a VCG and subsequently the maximal QRS vector amplitude can be calculated. The exact difference in timing between A-RVsense, the delay between atrial activation and the moment of sensing of activation on the RV lead, and A-RV can be programmed in the device instead of the estimated difference relation used in the current ADAPTIVECRT $^{\mathrm{TM}}$ algorithm. This would only require adding the constant delay to the algorithm. A second option would be to extract the A-RV from the EGM-VCG. The algorithm needed to find A-RV can be embedded in the CRT device, making automatic and continuous optimization possible. Again, the difference between A-RVsense and A-RV can be determined every few days, and the ADAPTIVECRT ${ }^{\mathrm{TM}}$ algorithm can perform its usual continuous optimization with this timing difference embedded.

The methods proposed here can be used to objectively and easily tailor the ADAPTIVECRT $^{\mathrm{TM}}$ algorithm, possibly leading to a further increase in hemodynamic response by CRT. It does so without spending additional current, purely by optimizing fusion pacing, which benefits form the natural activation of the RV. Because of the high potential of the VCG or EGM-VCG to improve the ADAPTIVECRT ${ }^{\mathrm{TM}}$ algorithm, this idea was patented together with Medtronic, Inc.

\section{Conclusion}

The findings of this thesis provide valuable tools to improve patient selection for CRT and CRT device optimization, which have been derived from extensive basic and clinical research prior to and during this thesis. These tools can be easily embedded in already existing systems, either ECG machines or devices. Therefore, findings from the present study may well have significant practical implications. 


\section{References}

1. M Bots, I van Dis, C Koopman, I Vaartjes, and F Visseren. Hart- en vaatziekten in Nederland. (2013).

2. NM Hawkins, D Wang, JJV McMurray, MA Pfeffer, K Swedberg, CB Granger, S Yusuf, SJ Pocock, J Ostergren, EL Michelson, FG Dunn, and CHARM Investigators and Committees. Prevalence and prognostic impact of bundle branch block in patients with heart failure: evidence from the CHARM programme. Eur J Heart Fail (2007) 9:510-517.

3. M Bots, I van Dis, C Koopman, I Vaartjes, and F Visseren. Hart- en vaatziekten in Nederland. (2014).

4. WT Abraham, WG Fisher, AL Smith, DB Delurgio, AR Leon, E Loh, DZ Kocovic, M Packer, AL Clavell, DL Hayes, et al. Cardiac resynchronization in chronic heart failure. N Engl J Med (2002) 346:1845-1853.

5. M Brignole, A Auricchio, G Baron-Esquivias, P Bordachar, G Boriani, OA Breithardt, J Cleland, JC Deharo, V Delgado, PM Elliott, et al. 2013 ESC Guidelines on cardiac pacing and cardiac resynchronization therapy: the Task Force on cardiac pacing and resynchronization therapy of the European Society of Cardiology (ESC). Developed in collaboration with the European Heart Rhythm Association (EHRA). Eur Heart J (2013) 34:2281-2329.

6. CM Tracy, AE Epstein, D Darbar, JP Dimarco, SB Dunbar, NAM Estes 3rd, TB Ferguson Jr, SC Hammill, PE Karasik, MS Link, et al. 2012 ACCF/AHA/HRS Focused Update of the 2008 Guidelines for Device-Based Therapy of Cardiac Rhythm Abnormalities: a report of the American College of Cardiology Foundation/American Heart Association Task Force on Practice Guidelines. Heart Rhythm (2012) 9:1737-1753.

7. European Heart Rhythm Association, European Society of Cardiology, Heart Rhythm Society, Heart Failure Society of America, American Society of Echocardiography, American Heart Association, European Association of Echocardiography, Heart Failure Association, JC Daubert, L Saxon, et al. 2012 EHRA/HRS expert consensus statement on cardiac resynchronization therapy in heart failure: implant and follow-up recommendations and management. Heart Rhythm (2012) 9:1524-1576.

8. BM van Gelder, FA Bracke, A Meijer, and NH Pijls. The hemodynamic effect of intrinsic conduction during left ventricular pacing as compared to biventricular pacing. 
Journal of the American College of Cardiology (2005) 46:2305-2310.

9. G Boriani, W Kranig, E Donal, L Calo, M Casella, N Delarche, IF Lozano, G Ansalone, M Biffi, E Boulogne, C Leclercq, and B-LEFT HF study group. A randomized double-blind comparison of biventricular versus left ventricular stimulation for cardiac resynchronization therapy: the Biventricular versus Left Univentricular Pacing with ICD Back-up in Heart Failure Patients (B-LEFT HF) trial. Am Heart J (2010) 159:1052-1058.e1.

10. H Krum, B Lemke, D Birnie, KLF Lee, K Aonuma, RC Starling, M Gasparini, J Gorcsan, T Rogers, A Sambelashvili, A Kalmes, and D Martin. A novel algorithm for individualized cardiac resynchronization therapy: rationale and design of the adaptive cardiac resynchronization therapy trial. Am Heart J (2012) 163:747-752.e1. 



\section{Dankwoord}

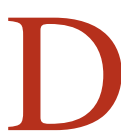

IT proefschrift is het resultaat van teamwork. Dit proefschrift zou niet tot stand zijn gekomen zonder de samenwerking met verschillende labs en zonder de steun van vrienden en familie. Daarom sluit ik dit werk af met een woord van dank.

Allereerst wil ik mijn promotor, prof. dr. Frits W. Prinzen bedanken, Beste Frits, in 2011 hebben wij voor het eerst kennisgemaakt. Als masterstudent aan de TU/e was ik op zoek naar een interessant afstudeerproject. Zoals altijd was je erg enthousiast over de verschillende projecten, waardoor ik ook enthousiast werd. Begin 2012 ben ik bij jou begonnen aan mijn afstudeerproject en dit was het begin van een goede en productieve samenwerking, die werd verlengd met een promotie. Ik kan me geen betere promotor voorstellen: je was altijd beschikbaar voor vragen, dacht mee over mogelijke oorzaken van onverwachte resultaten en door je grote netwerk heb ik tijdens mijn promotietraject mogen samenwerken met veel verschillende mensen uit verschillende landen. Daarnaast ben ik naar vele congressen geweest waar ik veel van heb geleerd en waardoor ik ook veel van de wereld heb kunnen zien. Heel erg bedankt voor alles.

Naast een goede promotor had ik ook het geluk van een goede co-promotor, dr. Kevin Vernooy. Beste Kevin, als arts keek jij vaak anders naar onderzoeksresultaten dan ik als ingenieur, wat de resultaten vaak een ander en nieuw perspectief gaf. Je hebt mij geïntroduceerd in de ziekenhuiswereld en me geleerd hoe om te gaan met de gang van zaken in het ziekenhuis: je kunt er nooit vanuit gaan dat alles goed geregeld is; zorg er altijd voor dat je alles zelf gecheckt hebt. Ik heb onder jouw begeleiding een klinische studie mogen uitvoeren waarvan ik heel veel geleerd heb. Mijn dank is heel erg groot voor alles wat jij mij hebt bijgeleerd.

Leden van de beoordelingscommissie, prof. dr. Uli Schotten (voorzitter), prof. dr. Angelo Auricchio, prof. dr. Harry J.G.M. Crijns, prof. dr. Tammo Delhaas, en dr. Mathias Meine, hartelijk bedankt voor de kritische beoordeling van mijn proefschrift.

Beste Masih en Twan, jullie waren voor mij altijd een goed aanspreekpunt voor al mijn vragen gerelateerd aan het reilen en zeilen in het ziekenhuis. Masih, heel erg bedankt voor al je hulp tijdens het opzetten van de Tailor-CRT studie. Jij hebt mij wegwijs gemaakt in het ziekenhuis en mij geleerd hoe alles rondom de studie geregeld moest worden. Daarnaast wil ik je bedanken voor alle gezelligheid, ook tijdens onze gezamenlijke congressen. Twan, nadat Masih is begonnen aan zijn opleiding cardiologie heb jij min of meer zijn taken over- 
genomen. Je was er altijd om mee te helpen waar nodig. Bedankt voor onze fijne en gezellige samenwerking.

Tijdens het laatste anderhalf jaar van mijn promotie heb ik de klinische studie Tailor-CRT uitgevoerd waardoor ik van tijd tot tijd ook op de vaatkamer te vinden was. Ik wil al het vaatkamerpersoneel en alle pacemakertechnici van harte bedanken voor alle geleverde bijdragen.

I would also like to thank dr. Jagmeet Singh and Eszter for our collaboration, our discussions and for sharing their database with us. This enabled me to perform research on a large patient population resulting in two nice articles.

Patrick en Thomas, jullie wil ik graag bedanken voor de hulp tijdens mijn TAVI project. Het heeft lang geduurd maar er is nu toch een mooi manuscript uitgekomen. Thomas, ik wil jou ook bedanken voor onze niet-werkgerelateerde gesprekken.

Ook iedereen van de afdeling Fysiologie wil ik bedanken voor de fijne samenwerking, de prettige werksfeer en alle gezelligheid. Caroline, Siamack, Chantal, Uyen en Joris: bedankt voor de leuke sfeer op onze kamer. Marc, Lars, Frans, Marion, Rick en Nienke: ik wil jullie ook bedanken voor jullie bijdragen.

Daarnaast wil ik graag de secretaresses van de vakgroep Fysiologie, Bianca en Vivian bedanken voor alle hulp gedurende de afgelopen jaren.

Verder wil ik ook een aantal mensen bedanken van de afdeling Biomedische Technologie. Lauren, Georgina, and Jeire thank you for the coffee breaks, lunch breaks, and during the summer for the ice cream breaks. I could always tell you all my complaints and you were always able to make me laugh. Lauren, thank you for being my paranymph. John, Niek en Marieke: bedankt voor de gezellige lunches en borrels.

Raf en Jeire en Peter en Sabine, bedankt voor de gezellige uitjes buiten het werk om. Peter en Sabine: Bart en ik zien er al naar uit om jullie te mogen ontvangen in Sydney.

Elly en Paul, Bart en ik kunnen altijd bij jullie terecht. Of het nou voor de gezelligheid is, voor het vermaken van kleren, of voor klusjes in het huis. Daarnaast ben ik jullie erg dankbaar voor de gezellige avonden toen Bart in Australië zat, dit was altijd een fijne afleiding voor mij.

Lieve papa en mama, bedankt voor jullie onvoorwaardelijke steun. Jullie hebben altijd achter mijn keuzes gestaan zolang ik maar dat deed wat ik leuk vond. Ook zorgden jullie voor de altijd welkome afleidingen. Jullie hebben mij geleerd om zoveel mogelijk te genieten van het leven en zoveel mogelijk van de wereld te zien. Zonder jullie steun, voornamelijk in de maanden dat Bart niet thuis was, was het me nooit gelukt om dit boekje tot een goed einde te brengen.

Lieve Tim, Bart en Mirthe, wat ben ik blij dat jullie mijn broers en schoonzus zijn. Tim, jij kan altijd alles zo lekker relativeren, alles komt wel goed. Ik wou dat ik soms iets meer van jouw relaxheid had. Bart en Mirthe, wat heb ik genoten van alle gezellige avondjes toen 
jullie nog in de Zakstraat woonden. Nu wonen jullie wat verder weg, Tanzania of all places, maar toch zijn jullie nog altijd heel erg betrokken bij alles wat er hier in ons kikkerlandje gebeurt. Bart, fijn dat je mijn paranimf wilt zijn. Ook al wonen we straks allemaal ergens anders op de wereld, ik hoop dat onze broer-en-zus band altijd zo sterk mag blijven.

Allerliefste Bart, zonder jou was het me allemaal nooit gelukt. Ik kan altijd mijn hart bij jou luchten en je krijgt me op de een of andere manier altijd rustig. Ook kunnen we inhoudelijke discussies voeren en kan ik je altijd om hulp vragen waar nodig. Daarnaast zorg je ervoor dat ons leven nooit saai is, we reizen heel wat af en we gaan nu voor langere tijd naar het buitenland. Ik zie er naaruit om deze mooie ervaring samen met jou te beleven. 


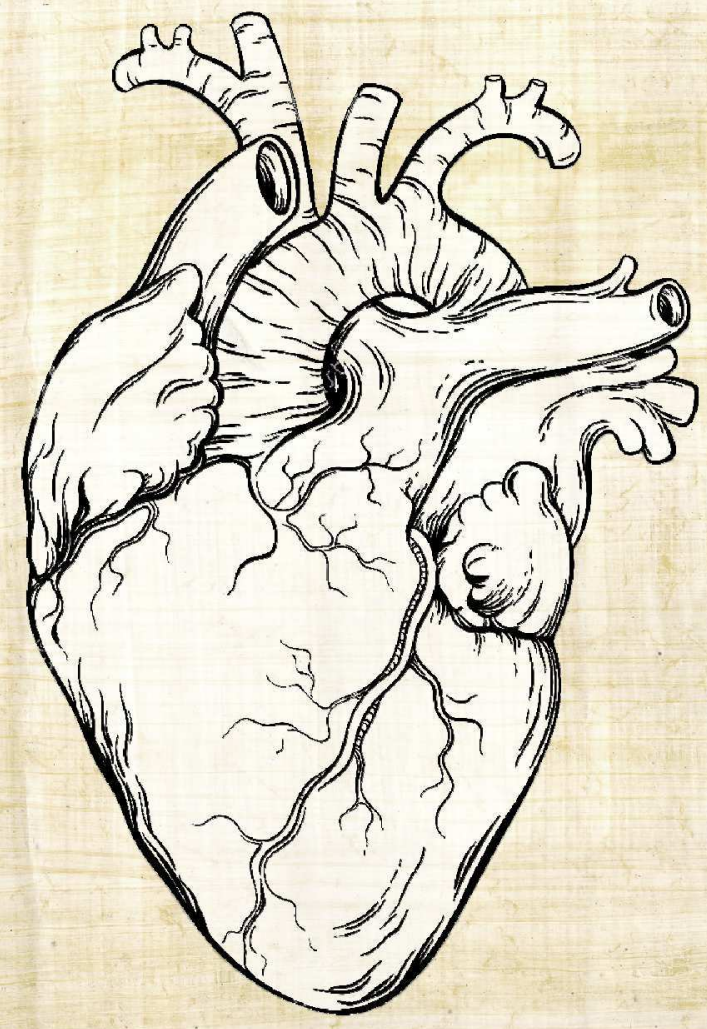




\section{About the author}




\section{Curriculum Vitae}

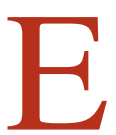

LIEN Engels was born on the 4th of August 1989 in Helmond, The Netherlands. From 2001 until 2007 she attended secondary education at the Theresialyceum in Tilburg where she obtained her high school diploma (atheneum).

In September 2007 she started her academic education at Eindhoven University of Technology were she obtained her Master of Science degree in Biomedical Engineering in January 2013. The Master's program included an internship at the Hôpital du Sacré-Coeur in Montreal, Canada (September 2011-December 2011) under the supervision of dr. ir. Vincent Jacquemet. She investigated the sensitivity of QT heart-rate correction methods for detecting drug-induced QTc changes. In her final Masters project, she developed an algorithm to automatically analyze 12-lead electrocardiograms and convert them to vectorcardiograms. She used both tools to study changes over time in left bundle branch block patients and to study different types of left bundle branch blocks. This project was performed under supervision of dr. ir. Nico H.L. Kuijpers and prof. dr. Frits W. Prinzen.

From March 2013 until July 2016, she worked as a PhD candidate at the department of Physiology (CARIM School for Cardiovascular Diseases, Maastricht University) under the supervision of dr. Kevin Vernooy and prof. dr. Frits W. Prinzen. During her PhD project, she aimed to investigate vectorcardiographic manners to improve the response rate of cardiac resynchronization therapy. Moreover, she was involved in supervising medical students during this period. In 2015 she received an award for best oral presentation at the annual MALT meeting and won the best poster prize at the local CARIM conference.

As of August 2016, she is working as a postdoctoral research fellow at the department of Physiology at Maastricht University.

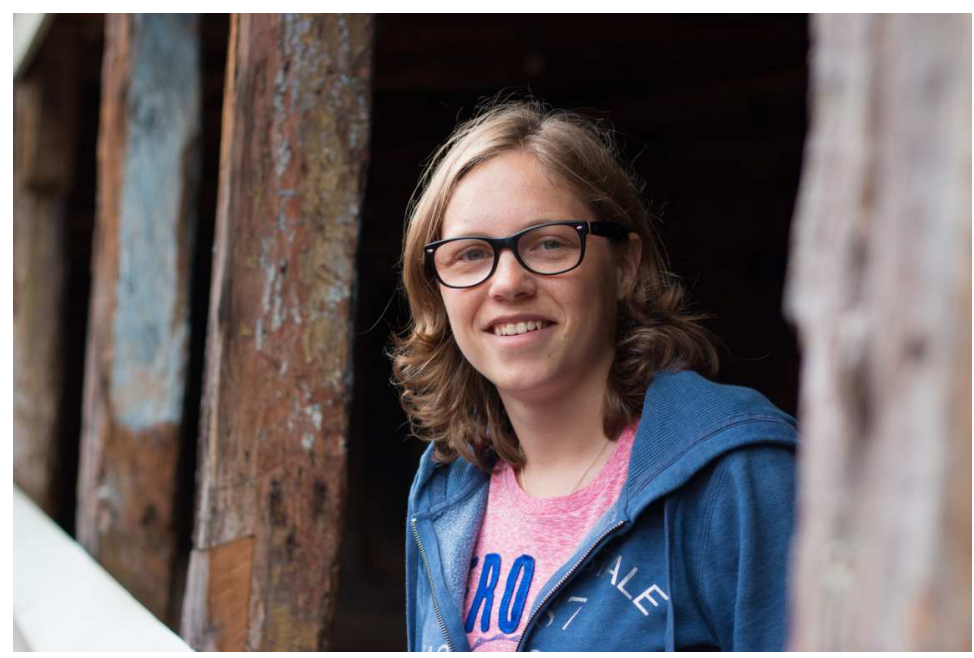




\section{List of publications}

UC Nguyên, M Mafi-Rad, JP Aben, MW Smulders, EB Engels, AMW van Stipdonk, JGLM Luermans, SCAM Bekkers, FW Prinzen, K Vernooy. A novel approach for left ventricular lead placement in cardiac resynchronization therapy: intra-procedural integration of coronary venous electro-anatomic mapping with delayed enhancement cardiac magnetic resonance imaging. Heart Rhythm (2016) [Epub ahead of print]

EB Engels*, M Mafi-Rad*, AMW van Stipdonk, K Vernooy, FW Prinzen. Why QRS duration should be replaced by better measures of electrical activation to improve patient selection for cardiac resynchronization therapy. J Cardiovasc Transl Res (2016) 9(4):257-65

*authors contributed equally

EM Végh*, EB Engels*, CJM van Deursen, B Merkely, K Vernooy, JP Singh, FW Prinzen. T-wave area as biomarker of clinical response to cardiac resynchronization therapy. Europace (2016) 18(7):1077-85

*authors contributed equally

M Mafi-Rad, GWM Wijntjens, EB Engels, Y Blaauw, JGLM Luermans, L Pison, HJGM Crijns, FW Prinzen, K Vernooy. Vectorcardiographic QRS area identifies delayed left ventricular lateral wall activation determined by electroanatomical mapping in candidates for cardiac resynchronization therapy. Heart Rhythm (2016) 13(1):217-25

EB Engels, S Alshehri, CJM van Deursen, L Wecke, L Bergfeldt, K Vernooy, FW Prinzen. The synthesized vectorcardiogram resembles the measured vectorcardiogram in patients with dyssynchronous heart failure. J Electrocardiol (2015) 48(4):586-92

EB Engels*, EM Végh*, CJM van Deursen, K Vernooy, JP Singh, FW Prinzen. T-wave area predicts response to cardiac resynchronization therapy in patients with left bundle branch block. J Cardiovasc Electrophysiol (2015) 26(2):176-83

*authors contributed equally

RC González, EB Engels, B Dubé, R Nadeau, A Vinet, AR LeBlanc, M Sturmer, G Becker, T Kus, V Jacquemet, Assessment of the sensitivity of detecting drug-induced QTc changes using subject-specific rate correction. J Electrocardiol (2012) 45(6):541-5 
